\title{
'Community': A Q study exploring perspectives in community governance settings in Taranaki, New Zealand
}

\author{
By \\ Te Aroha Louie Rauhuia Hohaia
}

\author{
A thesis \\ submitted to the Victoria University of Wellington \\ in fulfilment of the requirements for the degree of \\ Doctor of Philosophy
}

Victoria University of Wellington 

This thesis is dedicated to those who love where they live. 



\section{Abstract}

Attend any public meeting in Taranaki and, more often than not, one will hear the word 'community' used to bolster a policy proposal, or oppose it. But when that happens, what exactly is meant by 'community'? Taking advantage of her position as an embedded participant, the author of this thesis set out to understand what 'community' means to those who occupy roles of influence in decision-making settings in Taranaki, AotearoaNew Zealand. To the study's informants and participants, a deceptively simple question was put: 'what do you understand by 'community'?'

The set of techniques used to elicit responses to this question was William Stephenson's Q Methodology. Data collection began with 29 informant interviews from which 45 statements representative of what is understood by 'community' were extracted. Those statements were rank-ordered by 35 participants generating $47 \mathrm{Q}$ sorts (the mechanism by which each viewpoint was captured). Using PQMethod 2.35, a three-factor solution generated through principal components analysis and subjected to a varimax rotation was selected for further analysis.

The interpretation of the results substantiated three somewhat highly correlated, yet nuanced perspectives where 'community' is:

- 'Everyone and we're all in this together' (Factor 1),

- 'Well... it depends' given the multiplicity of interests (Factor 2), and

- 'It's everything' (Factor 3). 
The primacy of relationships and expectations to contribute to where one lives provide the basis for consensus. The nuance is in the scope and reach in terms of who counts, what matters and why it is important at a given point in time. The subsequent discussion noted there is still no agreement on a definition of 'community' and its malleability in meaning makes 'community' useful for furthering political interests. Its use in the community governance settings of this study reflects the pragmatism of everyday life. 'Community' is affirmed as a concept that frames policy discourse.

This study also identifies 'community' as a practice and as a way of governing that frames policy responses where the basis for 'community' is as:

- A preference for face-to-face interaction and usually over a cup of tea (Factor 1),

- A strategy of enabling that is realistic and pragmatic (Factor 2), and

- An account of the integrated connections to places, with people and to events across time and space (Factor 3).

The study opens up new ground as the collection, analysis and interpretation of firstperson, vested responses from those 'doing' 'community' in community governance settings is missing from the scholarly and practitioner literature. This study forms a bridge in an identified gap between those who theorise in the political philosophy of 'community' and those who advocate in the political practice of 'community'.

Furthermore, the three perspectives identified and discussed in this study also lead to a proposition that the phrase 'governing communities' would be a more apt and authentic alternative to 'community governance'. Such a development is positioned as the next step in the evolution of the theory surrounding local decision-making and local government in New Zealand and as a normative model for political practice. 


\section{Table of Contents}

$\begin{array}{ll}\text { Abstract } & \text { i }\end{array}$

Preface ix

Chapter 1: The research inquiry into 'community': the introduction 1

1.1 The inquiry line of this study 1

1.2 The research questions 3

1.3 The research setting $\quad 4$

$\begin{array}{ll}\text { 1.4 The thesis arrangements } & 10\end{array}$

Chapter 2: The scholarly context of 'community': the literature 13

2.1 'Community' in general 13

2.1.1 A controversial concept from the start 13

$\begin{array}{ll}\text { 2.1.2 With no agreement on a definition } & 14\end{array}$

2.1.3 But undoubtedly significant and profoundly important 16

$\begin{array}{ll}\text { 2.1.4 'Community' as the 'true site of politics' } & 17\end{array}$

2.2 'Community' conceptualised in 'community governance' 20

2.2.1 A working definition of 'community governance' 20

2.2.2 A note about 'communities of place' 23

2.2.3 An exposition of 'communities of interest' 26

2.2.4 A consideration of 'community' as policy and practice 30

2.3 'Community' in 'civic leadership' 34 
$\begin{array}{ll}3.1 \text { The research strategy } & 40\end{array}$

3.1.1 Q methodology examines subjectivity $\quad 40$

3.1.2 Subjectivity is behaviour $\quad 41$

3.1.3 Subjectivity is observable and measurable $\quad 42$

3.1.4 Subjectivity relies on concourse $\quad 44$

3.2 The methods used $\quad 44$

3.2.1 Stage 1: Choosing the topics 45

3.2.2 Stage 2: Sampling the sub-concourse $\quad 48$

3.2.3 Stage 3: Conducting the Q sort $\quad 58$

3.2.4 Stage 4: Doing the factor analysis and interpretation 63

$\begin{array}{ll}3.3 \text { Other considerations } & 72\end{array}$

$\begin{array}{ll}\text { 3.3.1 The inherent place-based-ness } & 72\end{array}$

3.3.2 The methodological struggles $\quad 74$

$\begin{array}{ll}\text { 3.3.3 The other studies } & 75\end{array}$

Chapter 4: The empirical data on 'community': the results $\begin{array}{ll}\text { and interpretation } & 77\end{array}$

4.1 The big picture view of the data $\quad 77$

$\begin{array}{ll}\text { 4.2 A platform of shared agreement } & 81\end{array}$

4.2.1 What matters most is relationships and respect 82

4.2.3 There is an expectation of contribution 90

4.2.4 It is inherently place-based $\quad 92$

4.2.5 Similarities but not necessarily the same 93

4.3 The Factor 1 perspective $\quad 95$

4.3.1 'Community' is everyone, of course! 95

4.3.2 As a practice, it's face to face and usually over a cup of tea 102 
4.3.3 But it's NOT for raiding 106

4.3.4 Factor 1-It's everyone and we're all in this together 108

$\begin{array}{ll}\text { 4.4 The Factor } 2 \text { perspective } & 108\end{array}$

4.4.1 'Community' is all about interests 109

4.4.2 As a practice, it is a strategy of enabling 116

4.4.3 But it's also about being realistic and practical 121

$\begin{array}{ll}\text { 4.4.4 Factor 2-Well, It Depends } & 127\end{array}$

$\begin{array}{ll}\text { 4.5 The Factor } 3 \text { perspective } & 127\end{array}$

4.5.1 In practice, it is an inextricable account of 'all things' 127

4.5.2 'Community' is place, place is 'community' 133

4.5.3 But it's also about personal responsibility and accountability 134

4.5.4 Factor 3-It's Everything 137

Chapter 5: The implications for 'community governance' in Taranaki: the discussion 139

5.1 'Community' is undeniably important 141

$\begin{array}{ll}5.2 \text { 'Community' as a way of governing } & 145\end{array}$

5.3 'Communities' rather than 'community' 148

5.4 'Governing communities’ reorients ‘community governance’ 151

Chapter 6: A future direction for 'community' in Taranaki: $\begin{array}{ll}\text { the conclusion } & 157\end{array}$

$\begin{array}{ll}\text { References } & 165\end{array}$

$\begin{array}{ll}\text { Appendices } & 177\end{array}$ 


\section{List of Tables}

Table 1: Research framework 4

$\begin{array}{ll}\text { Table 2: Topics } & 47\end{array}$

Table 3: Informant participation by topic and leadership domain 49

Table 4: Q sample $\quad 55$

Table 5: Q-sorter participation by topic and leadership domain 60

Table 6: Factor loadings $\quad 65$

Table 7: Factor matrix with an $\mathrm{X}$ indicating a defining sort with confounded Q sorts in bold text and reflagged Q sorts, $\begin{array}{ll}\text { Q04 and Q35 highlighted } & 67\end{array}$

Table 8: Number of defining Q sorts and percentages of explanatory $\begin{array}{ll}\text { variance for each factor } & 78\end{array}$

$\begin{array}{ll}\text { Table 9: Correlations between factors } & 79\end{array}$

Table 10: Spread of participant roles across each factor 80

Table 11: Consensus statements $\quad 81$

$\begin{array}{ll}\text { Table 12: Consensus statements re-sorted } & 83\end{array}$

Table 13: Q-sort values and z-scores by factor, sorted in descending order for Factor 1

Table 14: Q-sort values and z-scores by factor, sorted in descending order for Factor 2

Table 15: Q-sort values and z-scores by factor, sorted in descending order for Factor 2 truncated

Table 16: Q-sort values and z-scores by factor, sorted in descending order for Factor 3 


\section{List of Figures}

Figure 1: Research setting 6

Figure 2: Q-sort tableau 


\section{List of Appendices}

Appendix 1: Local Government Act 2002 Schedule $6 \quad 178$

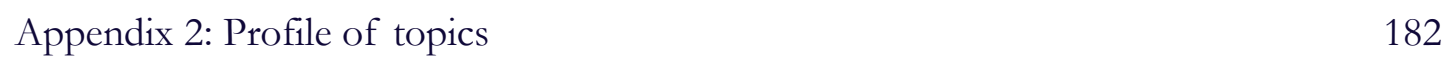

Appendix 3: Informant information letter, consent form and interview guide 185

$\begin{array}{ll}\text { Appendix 4: Statements } & 192\end{array}$

Appendix 5: Participant information letter, consent form and interview guide 199

Appendix 6: Q-sort results sheet 205

Appendix 7: Fixed output reports 206

Appendix 8: Factor matrix with an X indicating a defining sort 212

Appendix 9: Factor scores with corresponding ranks 213

$\begin{array}{ll}\text { Appendix 10: Correlations between factor scores } & 214\end{array}$

$\begin{array}{ll}\text { Appendix 11: Factor scores by Factor } & 215\end{array}$

Appendix 12: Descending array of differences 219

Appendix 13: Exact factor scores (B la SPSS) in Z-Score and T-Score units 223

Appendix 14: Factor Q-sort value for each statement 224

Appendix 15: Factor Q-sort values for statements sorted by consensus vs. disagreement (variance across factor z-scores) 225

Appendix 16: Factor characteristics 226

Appendix 17: Standard errors for differences in factor z-scores 227

$\begin{array}{ll}\text { Appendix 18: Distinguishing statements } & 228\end{array}$

Appendix 19: Consensus statements 232 


\section{Preface}

As you read this thesis, you will realise very quickly that as the researcher, I was-and still am—as much a part of the research setting as the study's informants and participants.

My genealogical roots are in Taranaki with direct affiliations to the iwi of Taranaki, Te Atiawa and Ngāruahine. For their reasons, my parents left Taranaki and my siblings and I were born and raised in the King Country and Waikato in the late 1960s. Since my return to Taranaki in 1999, I have taken an active interest in local affairs and been involved in a range of public benefit initiatives from school boards of trustees to improvements to local swimming pools. Nowadays, most of my time is given to high-level public and private sector governance and decision-making activities across the region.

Throughout the duration of this study, I held a number of governance roles with entities with high public expectations and accountabilities. The nature of those entities varied ranging from the operational emphasis of a marae committee to the strategic oversight of Taranaki's wellbeing as an elected member of a district health board. The net asset holdings were as small as $\$ 64,000$ for a social services provider operating in the family violence sector to the considerable consolidated asset base of a community trust. The impact of governance decisions has supported people having a voice through community access radio on one hand and re-establishing a constitutional presence through a post-settlement governance entity on the other. It is a diverse portfolio and one that draws on my hands-on local governance and community development work in Taranaki over the past fifteen years. 
For this study, my involvement in these settings provided a good general knowledge of the region's topical issues and a solid understanding of some highly localised ones. This knowledge and understanding is also strengthened by an established network of contacts and relationships with those who occupy roles of influence. Indeed, most are long-time colleagues, while a small number are close friends and whānau. This familiarity of issues and people facilitated the process identifying potential recruits and asking for their support as informants and participants. My residency in the field of study also provided flexibility when arranging and rearranging interviews. Furthermore, my involvement in regional and local decision-making helped me to tune into the political nuances of what informants and participants had to share and, where politically appropriate or personally sensitive, to tune out. The combination of each advantage-residency, an established network of contacts to access participants and prior knowledge to tap into contexts and information-made me, as a researcher, what Jessica Hutchings called "an embedded participant" (personal communication, February 9, 2012) with all the characteristics and dynamics of being an insider-researcher (also see Costley, Elliot \& Gibbs, 2010, p. 3).

I acknowledge there is privilege and advantage as an insider-researcher. I also know there are higher expectations to do a good job and to get it done.

Another point to note is that I have a governance philosophy that looks to making a difference to the local situation and everyday life. In my experience, this need to to 'give back' is an often articulated source of motivation for those who put or find themselves in roles of influence in decisions that affect them and those around them. As a consequence, my approach in the act of governing actively privileges the ordinariness of everyday life. Ask me why, and I will reply, "because that's where people live". More importantly, it is also where the future generations of my mokopuna and their mokopuna will live and they will have to deal with the benefits or the failures of the decisions made today. I believe that those recruited to the study—and many who were not—have a similar outlook.

Of course, what this all means is that the study has been carried out by a value-laden researcher with personal and professional interests in the findings of the study. Noted. And accepted. For me, it is impossible not to bring one's own opinions, beliefs and attitudes to a study set in the socio-political reality of day-to-day life and living. As Janet Barker (2008) has pointed out, there "are always at least two subjectivities present" (p. 918, emphasis added); one being the participant's and the other being the researcher's. To help offset the bias I knew I was bringing to this study, I depended on Q methodology to collect and 
analyse the data. The mitigation of bias was achieved to a certain degree and a close reading of Chapter 3 will identify the steps taken to impose a layer of professional disinterest to the process and provide academic rigour to the research topic.

Another bias to be noted is a personal inclination towards Q methodology. In my early readings of the $\mathrm{Q}$ literature, I recognised the opportunity that the Q sort gave for the quiet perspective to have a voice in a group of loud opinions. In this context, I had decided that Q methodology would be an appropriate framework to guide the study's data collection, analysis and interpretation. This pre-determination is an excellent illustration of the influence that a researcher's personal and professional situations and beliefs has on research design. A predisposition to support the quiet perspective voice to speak is also reflected in a current governance role that aims to give voice through community access radio. For some researchers, this melding of field bias and value-laden research may be untenable, but for others, like me, this is life. Deal with it. Embrace it. Work with it.

Which brings me to another point. The phenomenon of 'community' in study has not been held up as a research object to be observed from a distance, then generalised and theorised. Instead, it is a study of the lived experience, or more accurately, lived experiences. Rather than taking a public policy item, examining its outcomes, and assessing it for is relevance and other characteristics, I have opted for accepting that a certain policy matter exists and exploring how those who are effectively responsible for implementing that policy implement it. After all, we-this study's informants and participants and I-live and work where the consequences of public policy that affect our everyday lives and the lives of those around us. The public policy that frames, but does not constrain this study is the Local Government Act 2002 and its contribution to the enactment of 'community', and you will read examples of 'community' enacted in the opening paragraphs of Chapter 1. This positioning of the lived experience is deliberate making this study very much what Bill Ryan called "a good old-fashioned community study" (personal communication, 10 June 2010).

All of this-my self-identified interest and involvement in local and regional affairs, governance philosophy, attention to the impact of public policy on day-to-day life, and an awareness of what matters to me and those around me-and its influence in shaping the study amounts to what academics refer to as researcher positionality. You, the reader, are encouraged to keep my 'embedded-ness' as a participant in the field and as a researcher of the field in mind as you read this thesis. 
Before closing, I'd like to say thank you to my advisors, Bill Ryan and Claudia Scott along with Amanda Wolf, for their advice in getting through the PhD. Particular thanks to Parininihi ki Waitōtara Trust for their support as the inaugural Ted Tamati scholar in 2014 and to Mai ki Pōneke for their encouragement. A special acknowledgement needs to be made to my parents, Te Rangiurei and Louise Hohaia for their belief to education, and to my husband, Greg van Paassen for just hanging in there. There are many others, of course. You really can't do this stuff_-or any stuff for that matter- on your own.

He oti nō, tēnā rā koe. Ngā mihi ki te hunga kaiuru i tautoko i te rangahau nei, ā, ki te hunga kaiwhakaatu i whakawhiwhi i ō koutou kōrero. Ngā mihi hoki ki te hunga kaiwhakatau ō tēnā hāpori, ō tēnā hāpori ki Taranaki. Ko Taranaki te mounga. Ko Taranaki te turangawaewae. Ko Taranaki te whānau whānui. Ko Te Aroha Hohaia tōku ingoa.

With that, you, the reader, are acknowledged. As are the participants and informants who supported this research with their experiences and insights, and those who encouraged and cheered from the front-row seats. So too is everyone who is vested in and committed to where they live. My name is Te Aroha Hohaia. Taranaki is where I am from and Taranaki is where I live, work and play.

Ngā mihi. 


\section{Chapter 1: The research inquiry into 'community': the introduction}

\subsection{The inquiry line of this study}

In decision-making settings, the researcher has seen and heard first-hand calls on a conception of 'community' to support or oppose a policy proposal. Whether the objective has been to lobby for a seat at the decision-making table or respond to a change in geographic scope, those speaking on behalf invoke an idea of 'community' that is, apparently, easily recognised and well understood by all those within earshot. Even the reaction to the perceived threat of environmental degradation, or the assertion of a sense of place and belonging, the argument is oriented around the impact on or benefit to 'community'. The same has been observed of those involved with services offering support and advice on social issues like family violence, or projects to consolidate sports facilities, as well as planning the details of a family reunion.

When used in this way, what exactly is meant by 'community'?

Without a doubt, 'community' is a term of significance and a notion of profound importance in what it means to be human. It is also a term that has many and, sometimes contradictory, meanings creating and maintaining a multitude of understandings. It can mean something different to everyone. 
This thesis presupposes that an appreciation of what is understood by 'community' is also important to understanding the nature, content and effects of 'community governance'. It is not the adjectival role of the word 'community' that underlies this presupposition, but the deep significance of 'community' as an idea. While the word 'community' serves as a modifier in terms like 'community governance', its syntactic purpose has no materiality to those committed to a certain policy response. As a term that helps make sense of the world, the claim here is that each person who occupies a role of influence on matters of concern to them and to those around them has a viewpoint of 'community' that informs and shapes their practice and how they do 'community governance'.

Governance has been a topic of interest for millennia; ever "since humans first began to form groups and confronted issues regarding the distribution of power", wrote Mike Reid (2010, p. 1). It now has many forms reflective of the context in which it is used and applied and, consequently, there are many definitions. This study has adopted Reid's (2010) proposition of 'community governance' as "governance exercised by communities themselves... [through] policies and practices that empower citizens to make and influence decisions that affect them and their communities" (p. 81). It is important to note that with this definition, Reid regards governance as an activity that is located within 'communities' themselves.

In reference to those who occupy roles of influence, this study refers to them as 'civic leaders' in deference to Robin Hambleton's (2008, 2011, 2015) evolving model of 'civic leadership'. He visualised 'civic leadership' as comprising three domains: political, managerial and community leadership with each domain reflecting its source of legitimacy. Political leadership refers to "the work of those... elected... by the citizenry" (Hambleton, 2011, p. 3), managerial leadership to "the work of [those employed]... to plan and manage", and community leadership as "the work of the many civic-minded people who give their time and energy" to matters of concern and interest. These three distinctions provided the basis for recruiting research subjects for this study. They are also referred to as 'civic leaders' throughout the thesis for consistency and convenience, but it must be pointed out that the study's informants and participants would not apply that label to themselves.

What is understood by 'community' as a way of life and a way of living is well documented. However, what is missing in the literature is what 'civic leaders' mean by 'community' as they go about their work in 'community governance' settings. Yugyeong Eo 
and Soon Eun Kim (2016) noted the same lack of consideration in their Q study examining perceptions for "a desirable community" in an urban setting in Korea. As will be explained in the next chapter, Adrian Little (2002) has identified a gap between between those who theorise in the political philosophy of 'community' and those who advocate in the political practice of 'community'. Patricia Collins (2010) has criticised the way the term 'community' is overlooked and ignored in political philosophy. That there is a gap in the literature and the term 'community' is ignored is rather surprising for two reasons. Firstly, 'civic leaders' are expected to promote and facilitate community involvement and participation in local decisions. However, there is a tacit expectation that such work requires an understanding of 'community'. Secondly, communities expect to be involved and have opportunities to participate in decisions that affect them. Otherwise, it would be futile to make the effort to show up to speak to an annual plan submission.

This study is a bridge in Little's (2002) identified gap and a start to addressing the scholarly oversight of a term as important as 'community'.

\subsection{The research questions}

In no way does this study accept that 'civic leaders' arrive at their roles of influence as 'blank slates'. It is simply not conceivable. Instead, the presumption is that 'civic leaders' harbour their own perspectives and understandings of concepts like 'community'. Those views have been and continue to be shaped by their lived experiences and are informed by their own internal frames of reference. Therefore, the research objective in this study was to identify and understand those perspectives. The question put to those recruited to participate in the study was 'what do you understand by 'community'? or more specifically, 'for you in your role in a given 'community governance' context, what do you understand by 'community'?' Arising out of this simple question are two further queries which inform the analysis:

- What were the key components of the participants' perspectives of 'community'? and

- What were the points in common and points of difference amongst those perspectives?

Methodologically, these questions can be rephrased into one: what are the operant subjectivities of 'community' amongst 'civic leaders' in Taranaki? Operant subjectivity is a 
term specific to the research strategy, Q methodology, that was deployed for this study. The website for the International Society for the Scientific Study of Subjectivity identifies Q methodology as "both a technique and a methodology" that allows one to examine what people think and feel about a topic or question. Established by William Stephenson (1902-1989), Q methodology supports the study of human subjectivity or what Steven Brown (1980) described as a person's “own point of view” (p. 46).

An overview of the research objective and questions are presented in the Table 1.

Table 1: Research framework

\begin{tabular}{|c|c|c|c|}
\hline $\begin{array}{l}\text { Research } \\
\text { Objective }\end{array}$ & Research Questions & Participant Questions & Discussion Question \\
\hline $\begin{array}{l}\text { Identify the } \\
\text { operant } \\
\text { subjectivities of } \\
\text { 'community' or, } \\
\text { more simply, the } \\
\text { perspectives of } \\
\text { 'community' } \\
\text { amongst civic } \\
\text { leaders in } \\
\text { Taranaki }\end{array}$ & $\begin{array}{l}\text { What do civic leaders } \\
\text { understand by } \\
\text { 'community' as they } \\
\text { go about their work } \\
\text { in 'community } \\
\text { governance' settings? } \\
\text { What are the key } \\
\text { components to those } \\
\text { perspectives of } \\
\text { community? } \\
\text { What are the points in } \\
\text { common and points } \\
\text { of difference amongst } \\
\text { those perspectives? } \\
\text { What do civic leaders } \\
\text { understand by } \\
\text { 'community } \\
\text { governance'? }\end{array}$ & $\begin{array}{l}\text { For you in your role in } \\
\text { a given 'community } \\
\text { governance' context, } \\
\text { what do you } \\
\text { understand by } \\
\text { 'community'? } \\
\text { What is your } \\
\text { understanding of } \\
\text { 'community } \\
\text { governance'? }\end{array}$ & $\begin{array}{l}\text { What does all that } \\
\text { mean for 'community } \\
\text { governance' in } \\
\text { Taranaki? }\end{array}$ \\
\hline
\end{tabular}

\subsection{The research setting}

As depicted in Figure 1, the study is located in Taranaki, a region on the west coast of Te Ika a Māui, North Island, New Zealand. The landscape is dominated by Taranaki (also officially known as Mt. Egmont) which stands at 2,518 metres above sea level. Other distinct landforms include the hill country to the east, coastal terraces along both north and 
south Taranaki coasts and a 259 kilometre coastline (Taranaki Regional Council, 2010). The land area is 723,610 hectares, but its seaward boundary extends a further 12 nautical miles offshore. The region's topography is a major influence on the region's climate and contributor to soil fertility, and the physicality of the landscape is the main feature in the backdrop for a number of economic and lifestyle activities.

As at 5 March 2013, Taranaki was home to a usually resident population of 109,608 people occupying 43,215 private dwellings (Statistics New Zealand, 2015). Most of 2013 population, 74,184 people, (Statistics New Zealand, 2015) lived in the New Plymouth District, while 8,988 resided in the Stratford District and 26,577 in the South Taranaki District. The sum of the populations for the three districts does not match the regional figure because the regional population is matched to the boundaries of the Taranaki Regional Council. The difference in the population count will be in those parts of the Stratford District Council that are administered by Horizons Regional Council, and rounding adjustments (Statistics New Zealand, 2011).

This spatial distribution of people reflects the region's modern development that can be marked by the arrival of the first of six Plymouth Company ships, the 'William Bryan', to New Plymouth on 31 March 1841 (Rutherford \& Skinner, 1969, p. 235). Over a thousand settlers (Lambert, 2015) arrived to a land that was already peopled by a number of iwi with well-established social and political structures, and actively participated in trade (Taranaki Iwi Claims Settlement Act 2016, s. 8 \& 9; Rutherford \& Skinner, 1969, p. 69; Burke, 2014, p. 191).

With the Treaty of Waitangi signed in February of the previous year and British sovereignty proclaimed in May, colonial government sat with Governors William Hobson until his death in September 1842, Robert Fitzroy from 1843 to 1845 and then George Grey from 1845 until 1853 (Orange, 2004, p. 49). In an attempt to satisfy a growing desire for self-government, the British Parliament enacted a constitution in 1846, but Grey succeeded in having it suspended for five years. On 30 June 1852, with the passing of the 'Act to Grant a Representative Constitution to the Colony of New Zealand', New Plymouth was established as one of six provinces with its own legislature and a Superintendent (Friends of the Hocken Collections, 2000, p. 1). Provincial government was vested with "the power of making all laws for the government in the province with the exception of customs, high courts of law, currency, weights and measures, port duties, 



\section{Figure 1: Research setting}

(Image credits: Photographs: Author. Inset map: Taranaki District Health Board (2016) and is used with permission. Outline map: Schools@Look4 (2005-2017).) 
marriages, crown and native lands, criminal law, and inheritance" (Wells, 1878, p. 151), but the Governor retained "the power of vetoing all laws within three months".

Provincial government "vigorously asserted their powers" (McLintock, 1966) becoming "agents of development... responsible for surveys, land legislation, immigration, public works and harbours, education and hospitals... [and s]mall-scale local works were progressively delegated to boroughs and road boards". The outcome was a "consistent form of county and borough government" (Reid, 2010, 18). With the passing of the Municipal Corporations Act 1867, provincial administration was no longer needed and it was consequently abolished in 1876 (Wells, 1878, p. 290). The local government system that replaced it has grown and shrunk in the "constant political tug-of-war" (Dunne, 2016) of review and reforms. At one point, Taranaki had eight counties, 28 ridings, one river district, 26 road districts, and four town districts (Curnin, 2008). Currently, local government in Taranaki comprises the Taranaki Regional Council, and the South Taranaki, Stratford, and New Plymouth District Councils.

One particular feature of the context of 'community governance' arrangements in Taranaki is a coherent community outcomes framework that underpins regional and local planning across local government and, to a certain extent, central government (Burke, 2004). Introduced with the enactment of the Local Government Act 2002, the requirement to identify community outcomes was meant to "enhance co-ordination, address fragmentation and improve collaboration" (Reid, 2010, p. 53). Furthermore, it positioned councils as facilitator (McKinlay, 2014a). The output from a regional effort undertaken in Taranaki in 2003 and 2004 by local government with input from sectors around the mountain as well as central government agencies was a framework entitled Future Taranaki (Community Outcomes Project Team, 2004) and it identified six outcomes: Connected Taranaki, Prosperous Taranaki, Secure and Healthy Taranaki, Sustainable Taranaki, Together Taranaki and Vibrant Taranaki. The development of the individual outcomes was shaped by feedback received through public meetings, stakeholder meetings, focus group meetings, a telephone survey the distribution of a community flyer and a document review (p. 11-13).

Since then, the legislative requirements around community outcomes have changed. Amendments in 2010 resulted in the repeal of sections 91 and 92 (Local Government Act 2002 Amendment Act 2010, s. 13). The former outlined the process for identifying 
community outcomes, while the latter referred to the obligation to report against those outcomes. In 2012, community outcomes were redefined by further changes to the Act, stating that "a local authority aims to achieve in meeting the current and future needs of community for good-quality local infrastructure, local public services and performance of regulatory functions" (Local Government Act 2002 Amendment Act 2012, s. 5). In other words, instead of being what was widely regarded as owned by the community, community outcomes in the local government planning context were now to be identified and owned by council.

Even with these amendments to legislation, the foundation work undertaken as part of Future Taranaki continued to inform local government planning in Taranaki. The Taranaki Regional (2015) and South Taranaki District (2015) Councils' 2015-2025 Long-term Plans, for example, explicitly refer to the six outcomes of Future Taranaki. The New Plymouth District Council (2015) developed its strategic planning frameworks to take better account of their "residents' priorities... for the future of New Plymouth District" (p. 7), while the Stratford District Council (2015) "refine[d their] outcomes to better reflect what is important to Stratford" (p. 11). As facilitators, these four councils are critical players in the scheme of Reid's (2010) 'community governance', but as his definition infers, they are not always required to be a party.

In addition to the long-term planning mechanisms, all four councils are committed to "speak[ing] with one voice on matters of interest, concern or importance to Taranaki" (Taranaki Regional Council, New Plymouth District Council, Stratford District Council, and South Taranaki District Council, 2015, p. 3) and lay claim to have "unfailing done so". Over time, they have agreed a set of principles for collaboration and have reported they have over 50 shared services "organised without an overriding body such as a council controlled organisation" (p. 4) or a local authority shared services company (p. 5). Collaborative services include waste management, public transport, rural fire services, civil defence, regional tourism and economic development, as well as specialised staff and buying power in procuring services like insurance.

However, it is not just local government that takes a regional approach to strategy or implementation. The regional economic development agency, Venture Taranaki Trust (2015), is responsible for promulgating the benefits of a Taranaki lifestyle, and doing so with economic growth and development as their strategic priority. Population agencies such as the Ministry of Social Development and the Taranaki District Health Board deliver and 
fund services to benefit their target consumers. They, along with New Zealand Police, Corrections, and the Ministries of Justice and Education, are under political pressure to work together to address complex and difficult issues as articulated by the government's programme for Better Public Services (Better Public Services Advisory Group, 2011). Outside the domains of central and local government, the TSB Community Trust (2015) "champion[s] positive opportunities... and beneficial change" through philanthropy. The Bishop's Action Foundation (2016) aims "to achieve positive change for the common good" through a community development approach in their services. So, too, do many other entities from local sports clubs and service organisations to marae and halls to support and advocacy groups. All of these and other organisations are players in the activity of Reid's (2010) 'community governance' and the task of “empowering citizens to make and influence decisions that affect them and their communities" (p. 81).

Taranaki is the backdrop for this study and, in this thesis, is taken to refer to the area administered by the three district councils.

The geology, geography and history outlined in this section represent one set of factors for selecting Taranaki as a sub-national unit of analysis for this study. While its relative isolation to the rest of the country is acknowledged for its impact on the region's “economic performance and lifestyle benefits" (Venture Taranaki Trust, 2017, p. 27), it is also thought to foster a durable network of relationships amongst the region's residents. Edwards Hayes (1914) drew the same conclusion from his studies on the effects of geographic conditions upon social realties.

These reasons could apply equally well to other regions exhibiting similar characteristics. A contributing driver for choosing Taranaki is because the researcher lives and works there. As explained in the Preface, a familiarity of they key issues, access to information and an established network of contacts supported the process to identify potential recruits and ask for their support as informants and participants. Residency in the field of study that is Taranaki offered considerable flexibility when arranging or rearranging interviews. Furthermore, direct involvement in the regional and local decision-making settings allowed the researcher to tune into the political nuances of what informants and participants had to share and, where politically appropriate or personally sensitive, to tune out. The combination of each advantage-residency, access participants and prior knowledgeoffered all the advantages and dynamics of being an insider-researcher (Costley, Elliot \& Gibbs, 2010, p. 3). 


\subsection{The thesis arrangements}

This chapter, Chapter 1, introduces the study in terms of the observations that triggered this research, the presuppositions to the inquiry, the scholarly context in which this study is located and the research questions. It has also recognises that the study's contribution lies with gaining insights into the operant subjectivities of 'community' and then identifying what that means for 'community governance' in Taranaki. This chapter also provides a snapshot of the study's setting-Taranaki-with particular regard to its governance arrangements as a region.

The remainder of the thesis comprises a further five chapters.

Chapter 2 sets out the scholarly context for the study and does so across three sections. The first is an overview of what the literature has to say about 'community' in general terms with particular reference to its development. It notes a concern that there is a default abstraction of 'community' that puts its significance at the risk of being overlooked, and it is this concern that establishes the scholarly basis for asking what 'civic leaders' in Taranaki understand by 'community'.

The second section narrows the sociological field by looking at the concept of 'community' and its development in the context of Reid's (2010) 'community governance'. It reviews the use and development of two phrases that feature in local government settings: 'communities of place' and 'communities of interest'. Then, because local government is one of many actors in these contexts, and an influential one at that, this section also notes the use of the word 'community' in the Local Government Act 2002.

The third section brings the notion of 'civic leadership' into the study's scholarly context. It starts with the view that 'community governance' is a form of leadership, and an acknowledgement that those who occupy such roles of influence carry with them perspectives of 'community'. However, it also recognises that there is a lack of consideration for 'civic leader' understandings of baseline concepts like 'community'.

Chapter 3 is the methods chapter. The first of three sections outlines Q methodology, which is the research strategy deployed for this study, noting the originator's intentions and 
the theory behind it. It goes on to describe the techniques that characterise $\mathrm{Q}$ methodology, and closes with an account of the rationale for choosing Q methodology. The second, and longest, section details the research steps taken and then reports the results of the research process. It includes descriptions of the technical difficulties and dilemmas faced in the course of the data collection and analysis, and accounts for how those issues were addressed. The third section summarises the assumptions made, the learnings gained in the process and the study's limitations. Particular emphasis is placed on the interpretative nature of the study.

Chapter 4 presents the interpretation of the factor analysis. Whereas the results of the research process have been incorporated into Chapter 3, Chapter 4 sets out the results and interpretation of the factor analysis only, and it is presented in three sections. The first is an overview of the empirical results generated from 47 Q sorts by 35 participants, and the three-factor solution that was selected. The second and third sections detail the analysis and interpretation of the selected solution with the second section answering the question 'what are the points in common?', while the third section addresses the question 'what are the points of difference?'

Chapter 5 discusses five issues identified as arising from the factor analysis and interpretation. Each issue is described and illustrated with deliberations on what it means for 'community governance' in Taranaki. It is followed by Chapter 6, which brings the thesis to a conclusion. Because the backdrop to this study is Taranaki, the conclusion is specific to this region. Accordingly, the ramifications of the regional setting for the study are pointed out and noted. Consideration is given to the choice and deployment of $\mathrm{Q}$ methodology as a research strategy followed by an evaluation of what was learned in the process. Further opportunities for research are also identified.

It is important to note a number of attributes in the way this thesis is presented. One is in the treatment of the responses from informants and participants. They have been woven into the text throughout the thesis. But rather than labelling participant and informant contributions with pseudonyms, or a combination of role titles, gender and age, the unique identifiers assigned to them in the analysis have been retained. The procedure used to assign these identifiers is explained in Chapter 3, and the reason for doing this is to keep the focus on the opinions expressed rather than the demographics of the subjects.

Another characteristic is in differentiating between those recruited to this study as 
informants and participants. Those identified as informants were the sources for the statements that were later sorted by the participants. This distinction is purposeful. Not only is it intended to assist in the re-telling of their opinions and views, but it also acknowledges the nature of the contributions made to the study.

A third feature is that Māori words and concepts are an inextricable part of some participants' and informants' perspectives of 'community'. Where they occur, and their use is critical to the thesis of this study, there are explanations to support a cursory understanding of the Māori word or concept. The author's experience is that translation is problematic. As a consequence, there is no glossary.

The last characteristic is what may appear to be an overuse of single quotes-especially around the terms 'community', 'community governance' and 'civic leadership' or 'civic leaders'. This is a deliberate tactic used to identify when the term is the object under examination, and mark it as distinct to the matter being presented or discussed. 


\section{Chapter 2: The scholarly context of 'community': the literature}

\section{1 'Community' in general}

\subsubsection{A controversial concept from the start}

The Collins Dictionary of Sociology (Jary \& Jary, 1995) states that the concept of 'community' is "one of the most difficult and controversial in modern society... [and] ranks only with the notion of class in this respect" (p. 110). Unsurprisingly, a definition of 'community' has intrigued and eluded scholars for many years. In his work classifying ninety-four definitions, George Hillery $(1955,1982)$ identified four common components to 'community': people, common ties or connections, social interaction or interactions and area or place. Hillery concluded there is "no complete agreement as to the nature of community" (Hillery, 1955, p. 24). This study has found nothing to the contrary.

Hillery's work is the scholarly starting point for this study, but it must be noted that the sociological beginnings to the western concept of 'community' are attributed to Ferdinand Tönnies. In his book highlighting the importance of social connectedness, John Bruhn (2011) retraced the concept's development through three sets of influences back to Tönnies' 1887 proposal of "two contrasting kinds of social life" (p. 30): Gemeinschaft (village or community) and Gesellschaft (association or society). Gemeinschaft was an ideal "where members were bound together by common traditions and a common language, and 
villagers experienced a sense of "we-ness"; Gesellschaft was "a lifestyle of self-interest, competitiveness, and formal relationships". Bruhn explained that Tönnies favoured the former and was concerned that Gemeinschaft "would be lost" in the face of the changes brought on by the Industrial Revolution.

Bruhn's review went on to note that one of Tönnies contemporaries, Emile Durkheim, saw urbanisation as "a positive force" (p. 31) because it afforded choice and freedom while a second, George Simmel, "wondered how an individual could maintain a spirit of freedom and creativity in an urban environment" (p. 32). Tönnies, Durkheim and Simmel had formed their theories against the settings of the cities they knew, but a fourth contributor, Max Weber, denounced their dependency "on cities in only one part of the world at one time" (p. 32) and he developed his own ideal that he referred to as the "full urban community'. It was a sociological mix of ideas developed in response to the changing times that also established the city as an object of study, and made way for the urban and rural

life comparisons. But it was Tönnies' Gemeinschaft and Gesellschaft that helped make "a chaotic world... appear to have order and meaning" (Loomis, 2011, p. 263). It also instituted the dichotomy of 'community' and 'society'.

The second set of influences that Bruhn (2011) identified were those of the urban sociologists based in the United States of America (p. 33), and the attention paid to urban life prompted by the influx of immigrants and settlement of cities. In his assessment of the research undertaken between 1915 and 1950, Bruhn identified approaches oriented to human ecology and their emphasis on the relations between people. This body of research included studies of "real life conditions and behaviour" (p. 36). Other researchers looked at social structure in terms of class and power with the aim of identifying how those structures shaped day-to-day life. However, the reviewed studies on Bruhn's list do not appear to be attempts to provide a coherent definition of 'community' and, for the purposes of this literature review, nor were they expected to be. They are, as anticipated, the observations of researchers describing and trying to explain life within a social unit called 'community'.

\subsubsection{With no agreement on a definition}

The work of four researchers referred to in Bruhn's chapter were amongst the 94 definitions that Hillery $(1955,1982)$ analysed. The search process Hillery used started with known definitions and tracking back through references cited and doing the same again 
with those sources until no new definitions could be found. Not all of the definitions were included in the analysis because, in Hillery's assessment, "there was no clear formulation of a definition" (p. 17). He then put the definitions through "a process inspection and combination" (p. 17) that involved 'inspecting' each definition for the kinds of ideas it contained, and then identifying the 'combination' of ideas conveyed within each definition. The result was that the 94 definitions could be reduced to 22 combinations comprising 16 categories. Hillery's analysis and discussion on these results led him to identify four common components to 'community': people, common ties or connections, social interaction or interactions, and area or place; and, as already stated, there is no agreement on a definition.

Since Hillery's 1955 treatise, there has been an extraordinary amount of research. Michael Chisholm and Geoff Dench (2005) noted that researchers of the 1960s and early 1970s treated the idea of 'community' in two ways: one was as "an account of how people lived" (p. 11) and the other as "a model for living" (p. 11). The same two overarching themes can be seen in Bruhn's (2011) review of research into 'community' that was undertaken in those same decades (p. 39). 'Community' was seen as a way of life and a way of living, but evolving to accommodate notions of lifestyles and networks and expanding in scope from local to global (p. 40-41).

Competing definitions of 'community' followed (Smith, 2001) and by the mid-1970s, the concept of 'community' had attracted so much attention and become over-exposed to the point that Helen Fulcher (1991) citing William Harvey Cox (1976) wrote it had been "beaten into senselessness" (p. 6). The concept of 'community' had been rendered meaningless and irrelevant. Then in the late 1970s, interest in 'community' declined even further as priorities shifted to a focus on economic growth and centralised policymaking. By then, 'community' was an “obstacle to progress” (Chisholm \& Dench, 2005, p. 11) and, in some locations, was even described as "backward-looking, divisive and exclusive" (p. 12). An espoused way of life and living had fallen out of favour in the emerging globalised world pursuing economic gain and competitive advantage.

Interest in 'community' re-emerged in the 1980s. Most of this interest was attributed to "the feeling... that something valuable was lost" (Chisholm \& Dench, 2005, p. 12) and gone. Reflecting on that time, Gerard Delanty (2010) argued that people had been longing for the "cosy world of community, belonging and solidarity where one could feel at home" (p. 150). They yearned for an ideal of intimacy, commonality and self-determination 
and Delanty saw this yearning as an "antidote to the experience of homelessness and insecurity... [and to] a global crisis of belonging" (p. 158). But he also suggested that the search for 'community' has been "a quest for an irretrievable past which is irrecoverable" (p. 151): irrecoverable because times had changed and there was no going back; irretrievable because Delanty believed the 'community' people yearn for may not have existed anyway.

The sense of loss and the yearning for connectedness gave rise to movements and philosophies in the 1990s, namely the Communitarian Movement, and what Bruhn (2011) labelled as the Communities Movement (p. 45). Bruhn's examples of the latter are Healthy Communities, Sustainable Communities, Community Building, Civic Democracy, Liveable Communities, Safe Communities and Smart Growth. Their philosophies drew on a shared sense of 'community' in the pursuit of social justice where the emphasis was on the process (p. 45). Bruhn described communitarianism as "a progressive and reformative social movement aimed at promoting new social patterns in our society" (p. 44) associated with Amitai Etzioni (1993). Etzioni's lament was "the loss of traditional community" (p. 16) (much like Tönnies in 1887) and his remedy was "a return to 'we-ness' in our society, in our social institutions and in our social relationships" (Bruhn, 2011, p. 44). There was no indication in the reviewed literature that either the movement of communitarianism or the philosophies embraced by the various 'communities' ever considered what those in roles of influence understood to be 'community'. It seems to have been a given that 'community' simply 'was'.

\subsubsection{But undoubtedly significant and profoundly important}

For all the academic interest and social commitment to the idea of 'community', scholars are no closer to an agreed definition, nor is there a rush to settle on one. It is now well understood that 'community' is a social construct that serves as a representation of a reality and a knowledge through "an ongoing correspondence" (Berger \& Luckmann, 1996, p. 23) that continues until people "share a common sense about its reality" (p. 23). 'Community' is a term that helps make sense of the world.

Indeed, Collins (2010) has pointed out that as a core idea in society (like love and family), 'community' is part of "the cultural stock that forms the bedrock of social relations, that shapes social structures, and that makes those structures comprehensible" (p. 8). Collins has explained that there is no need for any agreement on the definition of a core idea, but 
what is required is an agreement that an idea is significant. The literature around the idea of 'community' confirms both: that there is no agreement on a definition of 'community', but there is agreement that it is significant. The reason why it is considered to be so significant is, as Peter Hamilton (1985) has stated, because "people manifestly believe in community" (p. 8).

Having the status of no agreed definition and profound significance is maintained by the symbolic nature of 'community', according to Anthony Cohen (1985). He has pointed out that its symbolism as the manifestation of belief "allows its adherents to attach their own meanings to it" (p. 15). Cohen argued that when people use the word 'community', they "share the symbol... [but they] do not necessarily share its meanings" (p. 15). Collins (2010) would agree, having also recognised that 'community' can have many and, sometimes, contradictory meanings creating and maintaining a multitude of understandings. The wide array of understandings are further supported and reinforced by an array of social practices. In other words, people make it what they will.

However, Cohen (1985) has also noted that its "variability of meaning" (p. 15) is what allows the notion of 'community' to be manipulated in ways for a person or a group to meet their political interests. It is not just a descriptive account of how people live, or a prescriptive model of how people should live. 'Community' is also "an expedient medium for the expression of very diverse interests and aspirations" (p. 108). This is an important quality because 'community' is now a ready resource to be invoked and called forth in order to "evoke and reinforce" (Edelman, 1985, p. 12) a certain response and ultimately achieve any number of outcomes. It is here that the concept of 'community' becomes a site of politics.

\subsection{4 'Community' as the 'true site of politics'}

For Collins (2010), the notion of 'community' is an 'important, albeit unrecognized, site of political contestation" (p. 9), and, she has further declared that 'community' is "the true site of politics". Her key assertion is that power relations are organised around core ideas and because 'community' is "refracted through the core idea of family" (p. 10), power arrangements inherent in 'community' are patriarchal, authoritative, and hierarchical (p. 10). Ruakere Hond (2013) also pointed out the associations with "highly charged tensions of power relations" (p. 20) especially in connection with nationalism. Hond labelled 'community' as "the word of choice" for those who want to draw on its "warmth of close 
interpersonal support”. However-citing Lois Bryson and Martin Mowbray (1981, p. 263) —Hond (2013) acknowledged 'community' has been "employed as a political 'spray-on additive" (p. 20) to imbue policy initiatives with an invitation to get involved and take ownership.

However, tactics such as these, or the hierarchical distributions of power, have rendered 'community' as “geographically specific, culturally homogenous, and inherently apolitical" (Collins, 2010, p. 9). Collins has pointed out that one consequence for public policy is that 'community' has become a marginalised, apolitical sphere that frames policy debates (p. 9). This is a view that persists even though observations of day-to-day life would confirm over and over that this abstraction of 'community' is far from the realities of lived experiences. Hillery (1982) thought the same in 1949 when he was "surprised to find out how little was being said with such an abundance of words... with nothing that could be 'pinned down' concerning what community 'was"' (p. 11). He questioned how that was possible when "everyone lived in communities".

This researcher has wondered the same.

Collins (2010) has criticised the default abstraction of 'community' as "geographically specific, culturally homogenous, and inherently apolitical” (p. 9) by pointing out that even avowedly non-political communities participate in power relations (p. 12). She has expressed concern that what is understood by 'community" "remain[s] neglected" (p. 10) in the political analysis, especially when trying to understand systems of power. It was a situation that Little (2002) had noted eight years earlier (p. 1). The scholarly neglect of this subject has continued into the twenty-first century because, in Collins's (2010) opinion, the idea of 'community' has been, and is, so pervasive in contemporary politics that it "remains hidden in plain sight" (p. 23). Collins's worry was that even though the many understandings of 'community' "catalyze dynamic social and political identities" (p. 12), the differences of those within represented 'communities' get overlooked, and the diversities get ironed out. For vivian Hutchinson (2012), it is more a case of 'community' being "so colonized by other interests that it is common not to even refer to it by its own name" (p. 2). He went on to point out that in "a peculiar reversal, we refer to this sector by what it's not: the not-for-profit sector, or the sector of non-government organisations". Little (2002) had similar concerns. He has noted the "rather random haphazard" (p. 3) deployment of 'community' held up by the assumption that it "exists and merely needs to be empowered" (p. 3). But, in his view, such insufficient thought is given to the 
practicalities of what is meant by 'community' that the obstacles are ignored stating that "the extent of the diversity and value pluralism is frequently neglected". For both Collins (2010) and Little (2002), the lived, ordinary life consequences are social inequalities and injustice.

This thesis does not pursue the line of critical inquiry taken by Collins (2010) or Little (2002), but it is mindful of their concerns for social justice. Instead, this thesis takes a step back. Little has pointed out that the notion of 'community' needs to be "detached from particular" (p. 2) political ideas in order to "understand the ways in which it can be used". In no way has Little suggested 'community' be treated as if it were devoid of its "political dimension", but rather that "any analysis... must deal with the normative implications of the concept" (p. 3). He has identified a gap between those who theorise in the political philosophy of 'community' and those who advocate in the political practice of 'community'. This literature review arrives at the conclusion.

The conceptual framework for this study accepts that there is no single definition of 'community', but nor does this study attempt to add another. Whatever it is that a theorist may hold 'community' to be, the abstract concept is relegated to the background. The scholarly framework also affirms that 'community' is a profoundly significant idea that is fundamental to understanding society and, on this point, there is no disagreement amongst the scholars. This study embraces Collins's (2010) and Little's (2002) critical thought layered with Cohen's (1985) and Edelman's (1985) interpretive approaches as the scholarly basis to explore the operant perspectives of 'community'.

With 'community' presumed to be operant in characteristic, this thesis takes the view that it can only be understood by the context in which it is enacted and observed. In this study, there are two contexts. The research setting is Taranaki for which a snapshot has already been provided. The other is the scholarly context of 'community governance' and the relevant literature is discussed in the next section. 


\section{2 'Community' conceptualised in 'community governance'}

\subsubsection{A working definition of 'community governance'}

In 'community governance', the elements of structure and process dominate the literature. The United Nations Development Programme (2004), which referred specifically to local governance, described it as a "set of institutions, mechanisms and processes". The focus on the structural elements is understandable given that institutions, mechanisms and processes are the direct means through which governments can deliver outcomes that benefit communities. But 'community governance' is more than that.

For Local Government New Zealand (2003a), local governance has "strong elements of citizen participation... to resolve questions of competing priorities" (p. 24). The UNDP's (2004) approach also emphasises "citizens and their groups" being able to "articulate their interests and needs, mediate their differences and exercise their rights and obligations at the local level". For the UNDP in particular and in New Zealand, local governance is primarily about citizen participation and community engagement that takes place 'at the local level'. What is meant by 'at the local level' is part of the ongoing policy debate, but this study holds to the view that it refers to local communities and that local governance is wholly centred on and around 'communities'. Therefore, just as Reid (2010) noted that the prefixes of 'local' and 'community' are interchangeable in local governance literature (p. 81) and opted for the term 'community governance', this study adopts the same view. Thus, 'community governance' is "governance exercised by communities themselves... [through] policies and practices that empower citizens to make and influence decisions that affect them and their communities" (Reid, 2010, p. 81).

Reid noted that the first mention of 'community governance' was John Stewart and Gerry Stoker's (1989) observation that political and institutional change was forcing local government in the United Kingdom to become what they called "community government" (Reid, 2010, p. 81). The vision was of territorial authorities working in partnership with local citizens to address issues of concern where the local government role shifted from being predominantly that of a provider to that of an enabler (p. 82). The term did not catch on with academics because it reportedly "failed to reflect the nature of the new relationships that were evolving and which extended beyond the traditional 
boundaries of 'governments"' (p. 82).

By 1994, John Stewart and David Clarke (1994) were using the phrase 'community governance' due to the need to recognise other actors created by public sector reforms in Britain in the 1980s and 1990s (Miller, Dickson \& Stoker, 2000, p. 12). One of the challenges that rose out of the reforms was the difficulty in achieving whole-ofgovernment outcomes, as the single-purpose focus of departments rendered them incapable of adapting to the demands of a place-based approach in an environment that was constantly changing while meeting national standards in performance. In Reid's (2010) opinion, that challenge identified the one advantage that local government had over central government which was that they were "the most knowledgeable agencies in their localities, better placed to make the connections between local service providers than any other single organisation" (pp. 83-84). This advantage, or "special position and role" as Stewart and Clarke (1994, p. 201) put it, was due to local authorities status as multi-purpose entities with the power to set and collect rates, as well as being controlled by elected representatives who exercised the decision-making power to determine priorities and allocate resources and "having the right and responsibility to speak out on issues of concern to its area" (p. 201). But the real plus was that local government is close to its citizens.

An important point needs to be noted here. The academic debate and discussion around 'community governance' is usually in the context of local government with territorial authorities playing a key, if not central, role. Recent research into the phenomenon of 'community governance' in Australia has led Peter McKinlay and his team (McKinlay, Pillora, Tan, \& von Tunzelmann, 2012) to see that there is a "growing distinction between the formal role of local government and the practice of governance" (p. 47). Local government is no longer the central player. One reason is that government-whether it be central or local — cannot do everything. Another reason can be attributed to McKinlay's (2014b) observation that the perceived "monopoly position" (p. 28) of local territorial authorities is driving citizens to seek out "ways in which they can take part in decisions that affect them". Consequently, McKinlay et al. (2012) have defined 'community governance' as "a collaborative approach to determining a community's preferred futures and developing and implementing the means of realising them" (p. 5). They have recognised that, in practice, "one or more of the different tiers of government, institutions of civil society, and private sector interests" may be involved.

McKinlay (2016) has pointed out that local government activity has tended to be an 
exercise of "seeking feedback" (p. 36) on council proposals. He described it as a typical approach that reflects the top-down nature of the public policy framework in which local government operates (p. 40). But McKinlay also noted two other variations. One is where a 'community' might "seek dialogue" with a council to implement an initiative, and the other is "dialogue within a council's community or communities themselves in order to arrive at a representative view on what it is the community wishes to see take place". McKinlay went on to emphasise that 'dialogue within communities' is not to be confused with "input from... individuals or groups with no specific mandate to speak on behalf of the community as a whole". But whatever the form, and however it is approached, McKinlay et al. (2012) concluded that it "is not whether clear and specific boundaries can be set around it, but whether it has utility in the sense of improving understanding of how decisions which affect a community's future are best taken and implemented” (p. 5). Such musings point to an observable shift in the look of 'community governance'.

Getting to grips with this shift will be critical because as McKinlay (2016) sees it, 'community governance' "will also increasingly be the essence of how successful communities function" (p. 40). More notably, it is an approach that puts 'community' at the centre of 'community governance' not institutions (McKinlay, 2014b). This study accepts that people, groups and entities can, and do, make and influence decisions that affect them and their communities without a council even knowing about it.

It is a bigger picture.

That said though, what is 'community' in a local government setting? It is as nebulous a term as it is elsewhere. In practice, 'community' in its day-to-day use, remains usefully undefined because the pragmatism of local government supports a fluid, dynamic and elastic understanding of 'community'. Stephanie Pillora and Peter McKinlay (2011) have acknowledged how "awkward" (p. 6) it can be for local government to "reflect the way in which people actually function" (p. 6). Instead, they argued that rather than seeking to "pin down precise definitions" (p. 6) for 'community', local government opts for a practical, common-sense approach by not defining 'community'. For Pillora and McKinlay, local government assumes "there is sufficient consensus on what is understood by community" (p. 6). It may well be the pragmatic option, but, as McKinlay et al. (2012) have pointed out, the lack of "any specific definition has probably helped rather than hindered" (p. 15) 'community governance' initiatives and the development of 'community governance' approaches. It has certainly allowed for 'community' to be re-conceptualised in 
two ways that are peculiar, but not limited, to the 'community governance' domain.

\subsubsection{A note about 'communities of place'}

One understanding of 'community' revolves around locality and place. Of course, people tend to gather in localities and, as Hillery $(1955,1982)$, has pointed out, place is one of three elements in 'community'. The socio-political structures in Taranaki, and no doubt in other parts of the country, have been and are tied to place. In the machinations of government, the meshblock is the smallest geographic unit used by Statistics New Zealand (2016) and it was "designed as an input geography... [to] ...optimise data collection and aggregation" (p. 4). As a classification, it assists with administering the count of people and dwellings at each Census, ensuring geographic boundaries can be identified (p. 4) as well "assigning" (p. 3) voters to their polling areas. In local government, Schedule 6 of the Local Government Act 2002 (also see Appendix 1) sets out the pre-conditions and requirements to constitute a 'community'.

In section 1 of Schedule 6, the emphasis is on containment within boundaries. A 'community' can be in any part of a district, but it must also "be wholly within 1 district" (subsection (1)), and, therefore, from a legislative perspective, a 'community' cannot span boundaries. Nor can two 'communities' occupy the same area: “a community may not be constituted for any part of district if a community is already constituted for that part of that district" (subsection (2)).

Section 2 of Schedule 6 outlines various administrative requirements. Boundaries must be easily identifiable (subsection (1)(a)), and match statistical meshblock areas (subsection (2)). They must also have a name (subsection (1)(b)). Section 2 also states when the first election may be held and that "the day after the day" (subsection (3)) on which election results are declared is the day the 'community' comes into existence. This legislative prescription of 'community' is very different from the sociological interpretation of 'community'. But it is also clear that Schedule 6 performs a strict legal function and that its application is explicitly for electoral, administrative and representation purposes. 'Community' in the public policy domain is primarily geographic.

In the discourse of 'community governance', 'place' has become more prominent. Josephine Barraket (2004), for example, has noted that state and local governments in Australia, spurred on by a "renaissance" (p. 233) and the persuasive appeal of 'community" 
in public policy discourses, have been "constructing local 'communities of place' as political spaces" (p. 233). She has further argued that its uptake is primarily due to increased recognition of the inequalities generated through spatial effects. But rather ironically, she has also identified that one of the challenges is the persistent view that there is a natural organisational form to 'community' (p. 237) and that 'communities' are "homogenous and distinct units with a common identity" (p. 236). This is the same conceptual difficulty that Collins (2010) identified. For Barraket (2004), the term 'communities of place' assumes there is "some kind of clear sense of 'place"' (p. 236) or that it is a clearly bounded locale, such as small rural town, urban-fringe and inner city (p. 236).

But Barraket also pointed out that insisting on a natural form, homogeneity, and a clear sense of place or bounded-ness exacerbates the inequalities in a 'community' or 'communities' through the lack of inclusiveness. People are left out. Barraket suggested that this happens whether or not diversity has been identified as important for the local initiative. Inequalities are ignored and diversities are aggregated.

Furthermore, she has explained that by refusing to recognise and acknowledge "the range of values and perspectives that exist at the local level" (p. 236) or "the diversity and power relations within communities" (p. 237), governance bodies struggle with developing mechanisms able to support a "local level of self-reliance" (p. 237). Ignoring the diversity of views and power relations will make place-based policy interventions "potentially ineffectual" (p. 237) and undermine their success. She did not state it outright, but Barraket may have wondered if 'communities of place' is really an appropriate phrase. If it were to be used in the way the public policy discourse intends, then those using it risk perpetuating the inequalities they are seeking to eliminate and aggregating the diversities that set their communities apart.

The emergence of the term 'community of place' and its plural has yet to be identified. It just seems to have appeared. In their research on the importance of 'community' to older people, Robin Means and Simon Evans (2012, p. 1301) acknowledged 'place' as a key component and there is little to disagree on that point. But they did not identify the term's point of origin, and nor did Andrew Hargreaves (2004) in his research on sustainable built environments. 'Communities of place' is in the title of the article written by Jan Flora (1998) where she presented a framework for examining whether social capital makes a difference for wellbeing in 'communities of place' (p. 481). But she gave no explanation of 
the term, or even a sign-post to its origins. Hargreaves (2004), Means and Evans (2012) as well as Barraket (2004) noted the popularity and uptake of place-oriented policy approaches, but it would seem that the term 'community of place' exists by usage.

Another example of 'place' in 'community governance settings' that needs acknowledging is 'place-shaping'. It was a proposition that rose out of Sir Michael Lyons's (2005, 2007) review of the role and function of local government in the United Kingdom. Lyons (2007) had described 'place-shaping' as "the creative use of powers and influence to promote the general well-being of a community and its citizens" (p. 3). He made no attempt to define 'community', but it does assume "a strong and successful community to be an attractive place to live and work, with effective public services and a good quality of life" (2005, p. 5). For Lyons, that put local government in a "unique" position to address those aspirations, and in a "modern role... for the improvement of public trust and satisfaction through closer engagement, honest debate and transparent decision-making" (2007, p. 35). With citizen wellbeing as the priority, he emphasised the relevance of 'place' and, in particular, the priorities for building and shaping local identity.

'Place-shaping' has been adopted with some enthusiasm by a number of UK institutions (Department of Communities and Local Government, 2007; Young Foundation, 2009), as well as various local authorities (such as Camden Council, 2011; Harrow Council, 2011; Herefordshire Council, 2010). In New Zealand, Auckland Council (2012) has adapted 'place-shaping' to refer to "planning to create attractive, prosperous and safe communities" (p. 109), and their plan seems to put the emphasis on the built environment and physical infrastructure. The same emphasis is apparent in Boffa Miskell Limited's (2016) 'place-shaping' focused review of a stocktake of spatial planning documents previously undertaken by the Greater Wellington Regional Council in 2013. The nearest consideration for Lyons's (2007) priorities for building and shaping local identity is Auckland's "community placemaking" (Trotman, 2015, p. 6). It refers to "communities engaging in shaping the look, function and feel of the places in which they live" and encompasses activities that "improve the look and feel of places and build a sense of community, local pride, identity and connection" (p. 6).

None of the 'place-shaping' sources identified in this section refer to 'community (or communities) of place' and Lyons $(2005,2007)$ made no mention of it in his review. Just to labour the point further, nor did any of the theorists referenced in the previous section even though the earliest publication found so far was published in 1998. Barraket's (2004) 
paper certainly affirms that 'communities of place' is a term that is in use, especially in Australia, and her discussion identifies it as a 'community building' strategy. 'Place-shaping' would fall into the same category.

\subsubsection{An exposition of 'communities of interest'}

A second differentiation of 'community' in 'community governance' used in New Zealand is 'community of interest'. According to Udo Averweg and Marcus Leaning (2011), the philosophical origins of 'community of interest' lie with Jean-Jacques Rousseau (1712-1778). Widely regarded as a major influence on modern political, sociological and educational thinking, Rousseau believed "that our best strategy lay in aligning ourselves with common interests" (p. 23).

Averweg and Leaning went on to explain that Robert MacIver (1882-1970) reiterated that “our interests are best served by being in a group" (p. 23). But MacIver (1917) extended Rousseau's idea by identifying interests as being discrete or common (p. 105). Focusing on common interests, he identified them as "the sources of community" (p. 105). In his opinion, "all like interests are potential common interests" (pp. 105-106), and when "that potentiality is realised community exists" (p. 106). MacIver identified three classifications of interests that reflected the associations they create. The first was 'community' where "members recognise as common a sufficiency of interests to allow the interactivities of common life" (p. 107). The second classification he called class being a set of interests where significant influence is observable from one part of society (p. 109). The third was associations and referred to single-purpose organisations that worked to assure the furtherance of specific interests. There is more to MacIver's examination of interests, but it is not relevant here. What does need to be noted is that it was a small part of his "attempt to set out the nature and fundamental laws of social life" in a book he entitled Community. (As an aside, McIver's (1917) work was one amongst those Hillery's $(1955,1982)$ analysed.)

How the leap was made from MacIver in 1917 to the term 'community of interest' adopted into British public policy after World War II as it relates to this study has not yet been found. When the Local Government Boundary Commission was established in 1945 (Gilbert, 1948, p. 184), their object was "all alterations in status of local government authorities, and of all alterations in the boundaries of local government areas" in order to provide for "individually and collectively effective and convenient units of local government administration". The then Minister of Health, who was also responsible for 
local government, had identified nine factors that the Commission was to take into account (pp. 184-185) and the first of these was 'community of interest'. What exactly was meant by 'community of interest' at that time needs further investigation, but reaching an agreed interpretation may not have had the chance to develop because the Commission was disbanded in 1949. It had put forward proposals for "far-reaching changes" (Minogue, 1977, p. 11) that required powers well beyond the Commission's legislatively prescribed terms of reference and the government of the day chose not to adopt the proposals.

In 1957, three government white papers led to the enactment of the Local Government Act 1958, which also saw the establishment of the Local Government Commissions for Wales and for England. The latter published a series of four reviews through which, according to George Jones (1963), "One can see how the Commission is interpreting the instructions it received from the Minister of Housing and Local Government” (p. 173). 'Community of interest' was once again a factor to be considered and it seems that this Commission was to take into account the same nine factors as its predecessor. Jones explained that 'community of interest' referred to "those special links more than mere proximity which connected one area to another" (p. 184). The Commission itself explained these special links in the 1961 reviews for West Midlands (p. 59) and East Midlands (p. 98) as:

\footnotetext{
...the journey-to-work pattern; the use of a town centre for shopping, entertainment and professional services; the provision of sewerage, water supply or other local government services by one authority for another; the building of council houses by one authority in another's area and voluntary migration from the town to privately built houses in the areas around: as well as a variety of arguments based on history, tradition and social habits (Jones, 1963, p. 184).
}

Note that 'community of interest' did not dominate the Commission's considerations and its influence varied from review area to review area. But the essential point here is that the term was established as relevant to local government settings.

In New Zealand, Local Government New Zealand (2003b) in its role as a policy advisor had noted that while 'community of interest' is not defined in the Local Government Act 2002, the phrase should be taken to refer to "the area to which one feels a sense of belonging and to which one looks for social, service and economic support" (p. 9). It is a proposition informed by Fulcher's (1991) work who had explored this concept in the context of local government and boundary changes. She described a 'community of 
interest' as "a group of people in the residential locality" (p. 7), which has one or more of three dimensions.

The first of these dimensions is the perceptual dimension that refers to the sense of belonging one feels to a defined area or locality in the same way people feel attached to place (Low, 1992; Low \& Altman, 1992) supporting the argument that it is the subjective experience that leads people to invest (or not invest) themselves in the places where they live. The second is the functional dimension which relates to the relationships between people living in an area (Fulcher, 1991, p. 7) and their ability to meet the social requirements for various physical and human services, such as distance to services, participation in local groups and patterns of movement (pp. 23-24).

The last dimension refers to the political ability to represent the interests of a 'community's' members as well as reconcile conflicts that may arise (p. 7). While it could be measured on variables, such as voter turnout or members' structural position (like their occupation and education) (pp. 29-31), its success also depends on the flow of information in newspapers and the debate and conversations through informal political networks ( $\mathrm{p}$. 32). All three dimensions in Fulcher's working definition describe various overarching qualities that characterise 'community'. Nothing in the dimensions of Fulcher's 'communities of interest' is at odds with anything that Tönnies (2011) or Hillery (1955, 1982) have argued, or anyone else for the matter. In practice, each dimension may carry a different weighting depending on the issue being investigated. So rather than "forcing the concept of community of interest to fit a formula" (p. 11), Fulcher's framework urges policy advisors to take proper account of a full range of measures.

An explanation of the definition of 'community' as it appears in Schedule 6 of the Local Government Act 2002 can be found earlier in this section. It is important to note that the Act carries two interpretations of 'community' and they are identified in section 5 . Subsection (1) prescribes 'community' as "a community constituted under Schedule 6". As already explained, Schedule 6 focuses on the pre-conditions and requirements to constitute a 'community', but specifically for electoral, administrative and representation purposes. But this interpretation is subject to subsection (2) which states:

The meaning given to the term community by subsection (1) does not apply in relation to-

(a) section 3; or

(b) the definition of the term long-term plan; or 
(c) any of the provisions of Part 2 and 6;

(d) any of the provisions of Schedule 10 and 11; or

(e) any other provisions of this Act in respect of which the context otherwise requires.

To provide further detail, section 3 sets out the purpose of the Act which is "to provide for the democratic and effective local government that recognises the diversity of New Zealand communities". Part 2 sets out the purpose of local government, and role and powers of local authorities, and Part 6 covers planning, decision-making and accountability. Schedule 10 refers to long-term plans, annual plans and annual reports, and Schedule 11 outlines matters relating to rates relief on Māori freehold land. Whereas the prescription of 'community' established by Schedule 6 is essentially boundary setting, elsewhere in the Act any interpretation of 'community' is tied to context. Most of the 339 uses of the word 'community' in the 27 May 2016 version of the Act are as an adjective. For example, there are 78 occurrences of 'community board(s)', 20 instances of 'community infrastructure' and two appearances of 'community magistrate'. But where it is used on its own, 'communities' is acknowledged as multi-faceted having social, economic, cultural and environmental aspects to it. The people within them are acknowledged as having views, interests and priorities as well as aspirations and futures, and the expectation placed on local authorities is that they must know what those are in order to inform their own decision-making processes. This acknowledgment and expectation infers that the 'community' of the Local Government Act 2002 that sits outside the requirements of Schedule 6 is akin to Fulcher's (1991) 'community of interest'.

So far it can be seen that the term 'community' in the 'community governance' domain is as flexible as the context requires. It is simple pragmatism to assume there is enough common ground in what is understood by 'community'. McKinlay et al. (2012) pointed out that the lack of a definition has supported the development of 'community governance' as a field and it certainly allowed for 'community' to be re-conceptualised as 'community of place' and 'community of interest'. Both, whether in their singular or plural forms, are useful labels for grouping people together according to where they live and their interests. Barraket (2004) highlighted the former is an explicit response to the inequalities of spatial effects and is more of a 'community building' strategy; like Lyons' $(2005,2007)$ 'placeshaping'. Fulcher (1991) emphasised the latter presumes locality, but it is intended to encourage policy advisors and practitioners to give proper consideration to the perceptual, functional and political dimensions of lived life. 


\subsubsection{A consideration of 'community' as policy and practice}

Turning away from the hands-on day-to-day pragmatism of local government to a theory of 'community' as policy and practice, Tony Blackshaw (2010) noted 'community' has become a matter of hermeneutics. In his narrative of the term's development, Blackshaw acknowledged interest in 'community' had broadened to the point where "by the end of the twentieth century, a group of disparate and unconcerned scholars had inaugurated what seemed to be a conceptualist revolution" (p. 5-6). The scholarly influences he identified began with Benedict Anderson's (1983) Imagined Communities, Cohen's (1985) The Symbolic Construction of Community and Phillip Wegner's (2002) Imaginary Communities. Blackshaw's (2010) summation of their work was that "all modern communities are hermeneutic communities" (p. 6). With hermeneutics defined as "the art of dialectical retrieval" (p. 7) and when applied to the modern context (and presumably that means the context of modern western societies) 'community' "will only be found again by trying to find new ways of meaning for it through interpretation" (p. 7).

In Blackshaw's opinion, the work of Anderson, Cohen and Wegner allowed for a wider, looser and more accommodating interpretations of 'community', but it also made way for “an extreme form of dialectics" (p. 7) where 'community' was both "real and imagined" and where "one is a strong refusal of the other". The "branding" (p. 8) of 'community' that followed created a paradox where "it was only when we were no longer sure of community's existence that it becomes absolutely necessary to believe in it" (p. 8). The "upshot" (p. 7) for Blackshaw was that 'community' is used in two ways:

- as "an orienting device" that sets the scene for action or frames how one should think about action

- as "an appropriating device" that determines the form and nature of services delivered, and the value and measure of what counts as important.

Depending on the context in which one operates and the beliefs one holds 'communities of interest' and 'communities of place' are in themselves appropriations and orientations of 'community'. As a phrase, 'communities of interest' was intended to help orient public policy professionals to consider what ought to be taken into account as proposed by Fulcher (1991). Barraket's (2004) remarks on 'communities of place' identify that the term was supposed to equip public policy makers to be more effective in their response to the inequalities generated through spatial effects. But for Barraket, 'communities of place' was 
simply an imposition that 'communities' have a natural form, are homogenous and have a clear sense of place and identity. As a consequence, the quirks that rise out of "the range of values and perspectives that exist at the local level" (p. 236) are aggregated out, or "the diversity and power relations within communities" (p. 237) are ignored. Whatever it is held to be, 'community' in 'communities of place' is an attempt to appropriate 'community' and the same could be said for 'communities of interest'. They are, for public policy purposes, useful imaginations of 'community'.

Blackshaw (2010) has used the term 'political community' to “describe the abstract, imagined (from without as well as within), ethical and self-determined totality of reciprocal interdependence, mutual commitment and solid solidarity that underlies the state" (p. 201). $\mathrm{He}$ also warned it should not be confused with 'community politics' which is "that decentralised ingredient of civil society whose impetus lies in the mutual commitment and social solidarity of men and women who revel in their reciprocal independence from the state". The former supports the state to fulfil its obligations while the latter "revels", to use Blackshaw's word, in its exceptionalism.

Blackshaw's argument drew on Zbigniew Pełczyński's (1984) view that "freedom reaches its fullest potential" (Blackshaw, 2010, p. 202) in the ideal of 'political community' because "citizens can interact with other citizens and the state through free public debate, the exercise of the right to vote, representative politics and direct democracy". In realising these social rights, Blackshaw explained, people experience and observe "respect, recognition and dignity" which in turn binds the ideal of 'political community' to the stuff of their everyday lives which in turn reinforces "mutual trust and the trust in the shared institutional network that endorses and validates collective solidarity" (p. 202 citing Bauman (2001) p. 141). Consequently, the state is affirmed and supported in its achievements.

Blackshaw (2010) reiterated his point by laying out that 'political community':

- starts with "the good of ethical community itself, the common good or the public interest, which full self-conscious and self-determined citizens promote for its own sake” (p. 202)

- moves on to those citizens "actuali[sing] their own deepest freedom and reali[sing] their nature not simply as individuals but as universal communal beings" and

- results in individuals, "while free to regard his or her happiness as a legitimate 
pursuit, should be willing to relinquish it if it interferes with the common good".

For Blackshaw, 'political community' is a contradiction of upholding individual freedom in one hand while achieving the common good or community wellbeing in the other. It seems impossible to do both because "one is a strong refusal of the other" (p. 7). Yet it is this impossible situation that has pushed 'political community' to the "centre of consciousness in politics" (p. 202) and Blackshaw has identified two reasons for this dichotomy. One is the increased attention and interest in human rights and the other is because the concept of 'community' has been appropriated for political ideology.

Blackshaw's explanation of the this latter point is that the 'Third Way' as an ideology binds together "increased public participation with more individual responsibility" (p. 204). With its communitarian morals, 'community' is an idea that "sells" (p. 204), and sells very well. Its appeal to those who favour free-market capitalism in that it is, "plain and simply... a family-friendly mechanism for mobilising neoliberal values" (p. 205). It offers a promise for grass-roots initiatives to be allocated resources address issues of deficit as a cost-efficient investment towards "self-actualised welfare" (p. 205). But the promise risks of oversimplifying matters resulting in 'community initiatives' being regarded as a "secondbest" option (p. 206) that is undervalued and "restore[s] social hierarchies" (p. 207). In short, the inequalities are upheld, the quirks are ironed out and as a result, "the so-called 'political community' often has nothing to do with community" (p. 207).

Instead, it is "a feel-good label employed to give creditability" (p. 208) to public policy initiatives. Hond (2013) had noted the same with 'community' as "the word of choice" (p. 20) for those who want to convey warmth and homeliness while Bryson and Mowbray (1981) pointed out its deployment as "political "spray-on additive" (p. 263) to invite involvement and a sense of ownership. For Blackshaw (2010), the state's appropriation of 'community' has set it with a "false face" (p. 207) that is welcomed for its "pullingtogetherness" (p. 208). His conclusion that "there is no longer any role for community in politics, other than its appropriation” (p. 208) is bleak. But Blackshaw has suggested it need not be. In his opinion, it is time to "muster a comparable critique" (p. 208) of neoliberalism because it has led to "human suffering, social disruption and the break-up of local communities" (p. 208).

Another scholar to note is Nikolas Rose (1999). In his chapter on 'community', he noted 
that the term had emerged rather unexpectedly in the latter decades of the twentieth century and was driving the discourse about a "'third way' of governing" (p. 167). This "third sector, third space", Rose had explained, challenged the presupposed authority of the state, the free and amoral exchange of the market and the liberty of the autonomous 'rights-bearing' individual subject. Instead of focusing on the power relations and resources available to the state and government, reforms looked to civic society and governance (p. 168) as a solution. For Rose, trust and collaboration were key to navigating complex political interactions and interpersonal relationships rather than economic rationality in a free market.

Rose labels this "third sector, third space" (p. 167) of trust and collaboration 'community'. It was not necessarily "a geographical space, a social space, a sociological space or a space of services" (p. 172) even though it could be. For Rose, 'community' was "a moral field binding persons into durable relations". It was "a third way of governing" (p. 167) and in Rose's summation, it would take good governance to span the paradox of 'community' as "an object and target for the exercise of political power whilst remaining, somehow, external to politics and a counterweight to it" (p. 168). Conceptually, 'community' as 'a way of governing' minimises it objectification by redirecting attention to the durability of relations. It also dissolves any sense of externality to politics and in doing so, affirms Collins's (2010) claim that 'community' is the 'true site' of politics.

The consequence for Rose (2010) was a reinvention of government (p. 173) to what he referred to as "government through community" (p. 176). This was not a situation where 'community' was a process of social control, but "an institution... a sector for government... whose vectors and forces can be mobilized, enrolled, deployed... [to] encourage and harness active practices of self-management and identity construction, of personal ethics and collective allegiances” (p. 176). 'Community' had become a willing and able partner and participant at the decision table.

The challenge for the 'third sector' that Rose (2010) identified is that the state sector was now off the hook. It no longer needed to provide the policy solutions to "all society's needs for order, security, health and productivity" (p. 174). It could draw on its "third sector' partner for assistance. According to Rose's diagnosis, 'community' was no longer the frame through which to grasp the difficult issues (p. 175), but was to be transformed into a profession where:

"Communities became zones to be investigated, mapped, 
classified, documented, interpreted, their vectors explained to enlightened professionals-to-be in countless college courses and to be taken into account in numberless encounters between professionals and their clients, whose individual conduct is now to be made intelligible in terms of the beliefs and values of 'their community'” (p.175).

Given this consideration of 'community' as policy and practice, one might think that with its professionalising a conception of the term, or even its practice would be not be difficult to articulate. But the scholarly literature reviewed so far makes no such offering. What is known is that there is no single definition of 'community'; there are many. Hillery's (1955, 1982) analysis identified three elements aside from people and Fulcher's (1991) framework identified three dimensions to consider in policy work.

There is no research that counters the belief that the concept is profoundly significant to people on a day-by-day basis and it widely recognised as crucial for understanding society. A point of scholarly interest for this study is Collins's (2010) proposition of 'community' as 'a true site of politics'. Collins's proposition requires further attention because it is the very place where the question 'what is 'community'?' is not being asked.

\section{3 'Community' in 'civic leadership'}

'Community governance' is a form of leadership and there is a range of terms to describe the phenomenon of enabling 'communities' to make decisions on matters that affect them. For example, Paul 't Hart and John Uhr (2008) have referred to "public leadership", Chris Collinge, John Gibney and Chris Mabey (2010) have written about "place-based leadership" and Lyons (2007) has promulgated "place-shaping". For Clarke and Stewart (1999), 'community leadership' and 'community governance' went hand in hand and Adrian Madden (2010) noted the same.

Robin Hambleton (2011) has opted for civic leadership and this study has deferred to the same for three reasons. The first reason is that the term 'civic leadership' conveys a sense of direct relevance to 'community governance' in contrast with the overly broad domain of public leadership or the narrower place-based leadership. Hambleton's approach attends to both in that 'civic leadership' is inherently public and ultimately place-based. In other words, it is public because 'civic leadership' is all leadership activity that serves a public purpose both inside and outside government (p. 3), and place-based because those 
"exercising decision-making power have a concern for the communities living in a particular 'place"' (p. 6). A second reason is Hambleton's direct contact with New Zealand local government arrangements as evidenced by his 2008 briefing paper that brought an international perspective to Auckland's eventual reorganisation. That work has no bearing on this study, but it does affirm his contribution to local government in New Zealand. A third reason for preferring Hambleton's 'civic leadership' over the other two is that his model is easy to understand and to explain.

Hambleton (2011) visualises 'civic leadership' as comprising three domains: political, managerial and community leadership. Each domain reflects its source of legitimacy (p. 16). To explain the Hambleton's approach more fully, political leaders refer to elected members, managerial leaders refer to those who hold roles as civil servants, and community leaders refers to everyone else that plays a lead role in their 'community' and civic society. Hambleton (2015) has recently expanded his model of civic leadership from three to five domains to include business leadership and trade union leadership, but the additional two domains are of no consequence to the inquiry of this thesis. The domains are not discrete and separate from one another, but overlap. Focusing on political and managerial leadership roles, Hambleton (2008) concluded that the separation between governance and management was not as clear-cut as assumed. It was not a simple matter of politicians deciding on policy and managers implementing it (p. 18). Instead, he recognised that on a day-to-day basis, there is an overlap in roles reflecting times when politicians and managers are not only joint leaders, but also, he argued, joint managers.

It is worth noting that 't Hart and Uhr (2008) also envisaged three "constituent (and admittedly overlapping) spheres of public governance" (p. 3): political leadership, administrative leadership, and civic or societal leadership. Both Hambleton's (2011) domains and 't Hart and Uhr's (2008) spheres are, largely, a match for the other and reflect the source of legitimacy to those occupying roles in each domain and sphere. Both also assert an interest in the response or, as 't Hart and Uhr highlighted, "leadership" (p. 3, emphasis retained). However, it was not the response from "the public institutions, organisations and routines" or the "skeleton of the body politic" that interested 't Hart \& Uhr. Instead, it was "the people living in and with them [the public institutions, organisations and routines] that provide the flesh and the spirit that bring [the body politic] to life". In no way, do they constrain the scope of people in leadership roles to those who occupy formally constituted positions. Hambleton (2011) would agree. Their combined views are an endorsement of this study's inclusion of those who do not necessarily occupy 
a formally constituted role, but certainly make a contribution to a given 'community governance' setting.

Returning to Hambleton's (2011) overlap in roles, he acknowledged that the dynamic between roles changes according to need and those needs are predominantly relational in nature. While verbs like facilitate, persuade and engage have featured in leadership, organisational and management literature for some time, the same action words and more also describe essential elements of the roles of 'civic leaders' and confirm that 'civic leadership' requires a high level of relational competency (Collinge \& Gibney, 2010). The citizen-oriented approach of 'community governance' demands both relational and cultural competencies from leaders (Kearns, 1995) requiring that elected members and officials must be competent and capable facilitators, mediators and convenors rather than restricting their thinking to service provision (Reid, 2010). The ability to relate to others is crucial.

The assertion here is that this ability is directly related to the conception of 'community' held by those in roles of influence. Yet, in terms of explaining its significance in 'civic leadership', there is almost nothing about 'civic leader' perspectives of 'community' in the literature. Hambleton (2011) has pointed out the literature on leadership "has given scant attention to how people feel" (p. 15) and that includes the notion of 'community'. The only inference that can be drawn is that 'community' is an adjective and a cross-reference to the source of leadership or the object of leadership. Even in recommendations for further research, there is barely a hint of a request for a better understanding of what civic leaders mean by 'community' when they use it to influence policy outcomes. The nearest find in the literature is Blackshaw's (2010) critique of the political appropriation of 'community', but his unit of analysis is the state and not the individuals who live and work in Collins's (2010) 'true site of politics'. Rose's (1999) diagnosis does the same. His point of view is as a third-party observing the impacts of the state on the 'community' partner. What no-one seems to have considered is what 'community' looks like from the viewpoint of those in it. Without any other indication of the lived experience, the fall-back assumption has to be that there is sufficient common ground on what is meant by 'community'.

Hambleton (2011) has also suggested that place-based action research on 'civic leadership' is needed to test for policy relevance and the challenges local communities face. While he recognised that governance comprises structure and process, Hambleton has urged that 'civic leadership' be “guided by 'instincts of appropriateness' and what is understood to be right and fair" (p. 16) by paying more attention to leadership processes rather than 
governance structures. For 't Hart and Uhr (2008), the attention ought to be on the "activities and interactions that people in position and power [and others] engage in" (p. 3) because public leadership is "an adaptive response to the non-routine, strategic challenges". For this study, any instinct or response about what is appropriate, right and fair are tied to what is understood by 'community'. After all, those who occupy roles that influence the response to the non-routine challenges must do so to protect, support or further whatever it is that is held to be the routine of everyday life; that is, the manifestations of 'community'.

The leadership literature describes the phenomenon of enabling communities to make decisions on matters that affect them, with emphasis on the ability to respond to challenges. Labelled variously as public leadership, place-based leadership, community leadership and civic leadership, it is Hambleton's (2011) domains of 'civic leadership' that forms the last layer to the scholarly framework that underpins this study. As will be explained in Chapter 3, which details the research approach that was applied to identifying civic leader perspectives of 'community', Hambleton's model supported the data collection and analysis by structuring the selection of the study's informants and participants. 
- 38 - 


\section{Chapter 3: The research approach to 'community': the methodology}

Chapter 3 is the methodology chapter of the thesis, and it is made up of three sections that describe the research process used to identify civic leader perspectives of 'community'. The first section is an outline of Q methodology, which is the research strategy deployed for this study. It takes note of the originator's intentions and elaborates on the theory behind it and closes with an explanation of why Q methodology was chosen to identify and examine what is understood by 'community'.

The second, and longest, section of chapter 3 is the technical detail of what took place across four stages of data collection and analysis, and those stages were: choosing the topics, sampling the sub-concourse, conducting the $Q$ sorts, and then doing and interpreting the factor analysis. This account also includes descriptions of the difficulties and dilemmas faced in the course of the data collection and analysis, and how those challenges were met.

The third section summarises the learnings from those dilemmas and what could be done differently if any aspect of the study were to be repeated in another location or for a specific setting. It also highlights the assumptions made in this study, and identifies the limitations. It ends with suggestions for further research from a methodological perspective. 


\subsection{The research strategy}

Q methodology was invented by William Stephenson (1902-1989), and one of the best explanations of Q methodology for someone who knows nothing about this methodological innovation is the five-minute video 'Rachel Baker introduces Q Methodology' (2013). In it, Baker explains Q methodology that allows one to examine what people think and feel about a topic or question, and how their viewpoint, or subjectivity on a matter at a given moment, can be captured with a $\mathrm{Q}$ sort. The methodological explanation as to how a Q sort does this follows in the paragraphs ahead.

There were at least two reasons Q methodology was chosen as the technique to elicit responses to the question 'what do you understand by 'community'?' The first was the pragmatic need to offset researcher bias. As noted in the Preface, Barker (2008) has pointed out, there "are always at least two subjectivities present" (p. 918, emphasis added); one being the participant's and the other being the researcher's. The researcher also acknowledged an impossibility not to bring one's own opinions, beliefs and attitudes to a study set in the socio-political reality of day-to-day life and living. As a resident and as much a participant in the research setting as study's informants and participants, there is considerable risk in researcher bias. Q methodology offered a way to manage that effectively.

The second reason was the researcher's personal inclination towards Q methodology. Early readings of the Q literature identified the opportunity that the $\mathrm{Q}$ sort gave for the quiet perspective to have a voice in a group of loud opinions. It was a finding that aligned with the researcher's values and the study provided an opportunity to learn about Q methodology within the parameters of academic discipline. The paragraphs that follow outline the theory that underpins Q methodology and, in particular, to understand what is meant by subjectivity and why it is important.

\subsubsection{Q methodology examines subjectivity}

For Stephenson (1981), subjectivity is the act of "viewing things exclusively through the medium of one's own mind" (p. 37), and there are two important elements in this working definition. The first is that subjectivity is a view in the sense of being an opinion, a perspective or an outlook. Subjectivity is also a first-person view; that is, it is one's own and no-one else's. As inferred, Bruce McKeown and Dan Thomas (2013) have emphasised that 
subjectivity is "anchored in self-reference" (p. 12).

Instances of subjectivity are easily identifiable when statements are prefaced with 'In my opinion' or 'It seems to me' or 'As far as I'm concerned'. When such qualifiers are deployed, a person is claiming ownership to the view expressed. She or he is also "saying something meaningful about personal experience" (p. 12). Not only is the comment 'mine', but it is also about 'my' experience and, most importantly, it is from 'my' perspective. It is a subjective view.

The contrast is an objective one. Simon Watts (2011) has explained that an objective view "tends to reiterate or share or cohere with whatever is typically 'observed by others" (p. 43). Stephenson (1986) himself noted the same and pointed out that in the objective domain "observations and measurements can be made by anyone (in principle) or even by machines" (p. 51). But, in the subjective domain "only the individual[s themselves] can observe and measure... [their] own subjectivity". If one were to post a selfie with a friend to a social media outlet and caption it with 'look who I caught up with at lunch today', it is in itself objective confirmation of those photographed being in a particular place at a certain time. But it does not convey the feelings felt, or the comments made while having lunch. It may be possible to guess from an observable combination of clues in the photograph what might have been felt or said, but even those guesses are speculations and opinions.

Stephenson's assertion is that only those 'who were there' can observe and measure their own subjectivity. In this study, the interest is in the understandings of 'community' held by those occupying 'civic leadership' roles; that is, the subjectivities of 'community' as observed and measured by 'civic leaders' in Taranaki.

\subsubsection{Subjectivity is behaviour}

The second element to subjectivity is that it is "pure behaviour" (Brown, 1980, p. 46). This is a difficult point to grasp. Subjectivity is "not inside us" (Watts, 2011, p. 39, emphasis added) like a character trait or a personality quirk. Instead, subjectivity is "an observable behaviour", and for Stephenson (1980), the observable behaviour is the act of "sharing knowledge between two or more persons, or with oneself self-reflectively" (p. 75). As emphasised above, Stephenson's interest was not in what a third party could observe but in the first person perspective. The published communiqués to social media of a person's 
experience, opinion, endorsement, support and approval are acts in sharing knowledge, and those acts are "a particular type of behaviour" (Watts, 2011, p. 38) that have two important features. The first is that they are "produced and emitted naturally, without need for special training or any other form of artificial induction" (p. 39) and, second, they are "defined by the relationship it established with, and the impact it makes upon, the immediate environment" (p. 39).

In other words, these acts of sharing knowledge seem to 'just happen' without any explicitly known reason as to why. They require no prompt, nor any inducement, and as Watts (2011) wrote, there is "no obvious or external cause" (p. 39). Furthermore, these acts can only be properly understood by the consequences that reinforce and sustain their ongoing occurrence in a particular setting. Outside this relationship between an act and its context, the behaviour has "no meaning" (p. 39). It has no relevance. But inside this relationship, the behaviour is "made meaningful" (Watts \& Stenner, 2012, p. 25) and "best understood relative to its impact" (p. 26) in and on the context in which it is enacted and observed. In these conditions, the 'item' of behaviour (as it is called in psychology circles) is deemed to be an operant.

The previous paragraph explains operant as a noun. However, Stephenson's preference was for "using operant as an adjective" (Watts, 2011, p. 39) and to talk about operant subjectivity. His intention was to disconnect subjectivity from its mentalist associations and redirect attention to the operant or behavioural features of subjectivity. Instead of subjectivity being regarded as "a mental entity" (p. 40) or treated as "a permanent or semipermanent disposition or mental orientation" (p. 40) like enthusiasm, a person's view exists only in the moment. They may express the same viewpoint again, in another point in time, but it still only exists in that moment. In different circumstances, opinions may change for any number of reasons, but, again, that operant subjectivity only exists at that point in time.

\subsubsection{Subjectivity is observable and measurable}

The challenge for a Q study is to "capture subjectivity in the very act of being an operant" (Watts, 2011, p. 39), and the technique that does that objectively is the Q sort. The Q sort is peculiar to Q methodology, and Stephenson is reported to have described Q sorting as "measurement—both as process and as result" (Wolf, 2009, p. 20). As "a data collection technique" (Baker, 2013), the Q sort is a process that centres around rankordering a set of statements in response to a "condition of instruction" (Brown (1991, p. 
155); Watts \& Stenner, 2005, p. 75; Wolf, 2009, p. 20), or "sorting instruction" as Webler et al. $(2009$, p. 21) preferred to call it. To assist the sorting process, the participant is also provided "with a scale and a suggested distribution" (Brown, 1993, p. 102). The participants are provided a sorting instruction and invited to work through the sorting process. As they do so, each Q sorter draws on their experiences, their beliefs and their opinions to consider each statement on its own merits, but also in relation every other statement. The result is a Q sort that Wolf (2009) described as a "rich and completely empirical... portrait" (p. 20) of a Q sorter's viewpoint. It is an observed and measured instance of subjectivity.

The Q-sort results are then correlated and subjected to factor analysis, and herein lies an innovation that is poorly understood. In his 1935 letter to Nature, Stephenson introduced the idea of inverted factor analysis. Being inverted means that the factor analysis identifies correlations between people, not around quantitatively measurable variables that characterise conventional studies (Brown et al., 2008, p. 727, Watts \& Stenner, 2007). It is important to note that there is no difference in the actual mathematics (S. Danielson, personal communication, March 18, 2017). What is different is that instead of a number of individuals being measured in an array of tests, the inverted factor analysis allows for a number of individuals to measure the tests (Brown, 1980, p. 9). The tests in Q methodology are the statements which the participants then evaluate, and therefore measure, the statements according to their own opinions, beliefs and attitudes. Another facet to this innovation is that the tests, or rather statements, require no pre-determination of measures or impositions of meaning. Responses to the "excess meaning" (Stephenson, 1981, p. 39) in each statement is precisely what is being sought from Q sorters.

With the results of a number of $\mathrm{Q}$ sorts, the factor analysis identifies correlations in the underlying beliefs amongst the subjectivities that have been captured and analyses for "similitudes among individuals" (Rozalia, 2008, p. 874). The factor analysis reconstructs the subjective view and reveals "a small handful" (Webler, Danielson, \& Tuler, 2009, p. 11) or clusters of perspectives and "brings out patterns of views" (Wolf, 2009). For this study, it means being able to identify the key components for an understanding of 'community' from amongst many understandings and to identify the points of difference and points in common amongst the study's participants. Furthermore, the techniques of the Q sort and factor analysis make it possible to observe, measure and examine subjectivity objectively. 


\subsubsection{Subjectivity relies on concourse}

The statements that individuals assess and test against their own internal frame of reference and according to their own opinions and beliefs are taken from a concourse. Brown (1980) described a concourse as "the very stuff of life, from the playful banter of lovers or chums to the heady discussions of philosophers and scientists to the private thoughts found in dreams and diaries... to collections of paintings, pieces of art, photographs, and even musical selections" (p. 95). A concourse is everyday talk and the theory of concourse recognises ordinary life as dependent on shared knowledge, and that knowledge is shared through "the ordinary conversation, commentary, and discourse of everyday life" (Brown, 1993, p. 94). As described earlier, it is the moment of sharing knowledge, whether it is with others or "with oneself self-reflectively" (Stephenson, 1980, p. 75), that is captured in the Q sort. These instances of communicability are a concourse, and it is "inherently contestable, infinite in principle, ubiquitous in character, and inescapably subjective... [and] it is also unpredictable, paradoxical, and erratic" (Brown et al., 2008, p. 729).

For $\mathrm{Q}$ researchers, the objective is to uncover and "reveal the inherent structure of a concourse - the vectors of thought that sustain it and which, in turn, are sustained by it" (Brown, 1993, p. 95). The starting point for uncovering the structural elements is to identify a sub-concourse. Where the concourse is the 'very stuff of life' might be all possible "facts, information, beliefs, opinions, and feelings" (Brown et al., 2008, p. 723), it is too unwieldy to work with. Instead, it is more appropriate and practical to choose statements from a sub-concourse that is representative of the everyday talk of the matter under examination. For this study, a sub-concourse was drawn from the "purely empirical" (Wolf, 2009, p. 18) talk of the study's informants. From their talk, a number of statements were extracted for the Q sort to be rank-ordered by the study's participants. The details of this data collection work are presented in the next section.

\subsection{The methods used}

In this study, methods refers to the steps taken and the techniques used to collect, analyse and interpret the data that forms the basis of this thesis. Most of the results produced by the analysis and the interpretation of that analysis are presented in the next chapter, but some aspects of the results also informed choices made in the research process. This section focuses specifically on what was done and where relevant, reports on aspects of the 
analysis that supported and informed the decisions made to further the data analysis and factor interpretation.

Data collection, analysis and interpretation spanned four stages and for each stage there was a single objective:

1. Choosing the topics that would support and focus the interactions with the informants and participants

2. Sampling a sub-concourse for statements representative of understandings of 'community'

3. Conducting the $\mathrm{Q}$ sorts and

4. Doing the factor analysis and interpretation.

A detailed explanation of each stage follows.

\subsubsection{Stage 1: Choosing the topics}

A range of topics were used to support the conversations and interviews with informants and participants throughout the study. One reason for choosing the term 'topics' rather than case studies or proxy issues has been simple pragmatism. In the ordinary day-to-day pressures of living life, people tend to talk about a topic rather than a proxy issue or a case study. That is not to say that the explanations underpinning those terms have been dismissed; not at all. But the key driver here has been to assure the study's relevance to its informants, as well as its participants. So it is with purpose that every interaction with the study's recruits has revolved around a topic much in the same was as Ruth Wodak and her colleagues (Wodak, De Cillia, Reisigl, \& Liebhart, 2009) did. Their work on the discursive construction of national identity saw the topic-oriented interview as "a very suitable tool" (p. 146) for exploring informant views, attitudes and levels of awareness of a topic. Wodak et al. had recognised that a topic is often framed as an "objectively existing problem" (p. 146) even though the topic has known and unknown layers of saved knowledge. What it means and has meant for this study is that informants and participants can talk, and have talked, about real-life situations that they are involved in with the knowledge, confidence and authority that their lived experience of that situation provides.

Identifying possible topics for this study needed to satisfy the first four of five criteria. 
First, it had to be an issue that affected citizens and groups who live and work in the Taranaki region; that is the area administered by the New Plymouth, Stratford and South Taranaki District Councils. Taranaki is the setting for this study. The second criterion was that the issue was topical in the minds of those involved or affected. Deciding whether it was topical or not depended on the evidence of discussion amongst those affected and to a certain degree depended on the researcher's knowledge and awareness of issues in the region.

An initial scan of potential topics included readings of published material especially in the regional newspaper, the Taranaki Daily News, and observations at various events such as annual general meetings as well as dinner and board table conversations with friends and colleagues. In most cases, concern played out in the regional and local media, on social media, and in discussion in public forums. But consideration also took account of the known discussion and debate at the neighbourhood level or amongst project members. The aim here was choose topics that mattered to people.

The third criterion for choosing a topic was that there had to be a discernible arrangement of governance. That meant being able to identify institutional structures, mechanisms and processes that supported debate and decision-making amongst those involved. Applying this criterion, and the one before it, aimed to make sure Reid's (2010) notion of 'community governance' could be observed; that is, governance exercised by communities through policies and practices that empower citizens to make and influence decisions that affect them and their communities (p. 81). 'Community governance' needed to be evident.

The fourth criterion was that potential informants and participants occupying roles in all three of Hambleton's (2011) leadership domains could be identified. Using Hambleton's model of civic leadership to moderate the selection of research recruits in this way helped reduce the likelihood of favouring one domain of recruits for the research over another and to minimise researcher bias. A fifth criterion was also considered in situations where there was a researcher-identified conflict of interest. Being what Jessica Hutchings (personal communication, February 9, 2012) called "an embedded participant" with the researcher living and working in the research field, conflicts of interest had to be properly managed in order to maintain professional and academic distance and reputation. A conflict of interest here is taken to refer to "duties or responsibilities to a public entity [that] could be affected by some other interest or duty" (Office of the Auditor-General, 2007, pp. 5 \& 9). While excluding topics where the researcher was directly involved, or 
where a third person observing might see it as a conflict of interest, was the planned intention, it proved impractical. Instead the embedded-ness in the researcher role was embraced and accepted as a feature of the study.

The second column of Table 2 below lists the topics that were chosen for this study. The Topic-ID in the left-hand column is a random, two-digit identifier assigned to each topic.

\section{Table 2: Topics}

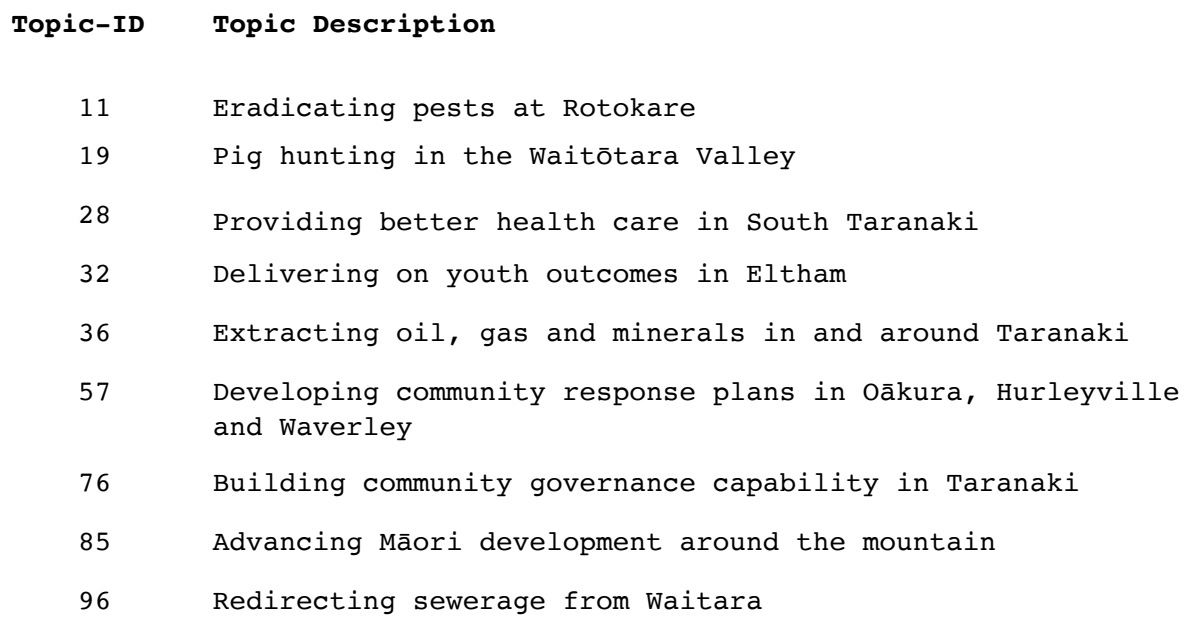

The main reason for profiling a selection of topics was to support the conversations with informants and participants. The topics also helped with selecting research participants, but the key objective was to provide a starting point from which informants could, would and did share their perspectives and experiences. They were able to speak with the knowledge and authority of their lived experiences. The same topics have also been (and will be) useful as platforms for presentations in academic settings and for feedback to, and from, informants and participants. But for the remainder of this thesis, there is no further reporting of results or discussion of implications on a topic-by-topic basis. For those interested, an expanded profile of each topic is available in Appendix 2.

The choice of topics also helped identify a concourse (Webler et al., 2001, p. 437), or more specifically a sub-concourse. While concourse is what Brown (1993) described as the knowledge shared through "the ordinary conversation, commentary, and discourse of everyday life" (p. 94), one starting point might to take a sample from every conceivable statement on what is understood by 'community'. But that is neither practical nor realistic for any Q study. Not every phrase is applicable or relevant to the 'community governance' 
settings in Taranaki or to the informants and participants recruited to the study. Indeed, it is possible that utterances peculiar to the study's recruits have no relevance for a counterpart in another region. Consequently, a concourse of every possible uttered understanding of 'community' is not the basis for this study but a sub-concourse that is peculiar to the study's setting.

Brown (1980) has emphasised the importance of naturalness in the language (p. 70) and, therefore, it also needed to be relevant. It was noted that the process of selecting topics may have resulted in missing out on certain 'community governance' issues or very particular perspectives of 'community'. There may have been statements more appropriate than the ones used, but such possibilities were noted and deemed unavoidable.

\subsubsection{Stage 2: Sampling the sub-concourse}

\subsection{2a The informants}

In this second stage of data collection and analysis, the task turned to identifying what 'civic leaders' in Taranaki understood by 'community' and sought out a sample of their talk using topic-oriented interviews. Potential informants were identified while profiling each topic, but the main criterion for recruitment was that they were active in the "community governance' aspects of one or more of the topics selected. To ensure a mix across each of Hambleton's (2011) civic leadership spheres, informants were further differentiated by leadership domain for a given context. Those who were known for their different views were prioritised over those with the similar views in the same setting. The aim here was to satisfy Watts and Stenner's (2012) advice to Q researchers to be strategic in their choices (p. 79) because it is "not the distribution of beliefs across the population" (Webler et al., 2009, p. 10) that is to be sought but "the breadth of opinion".

Actual recruitment involved approaching each potential informant with a personalised letter and information sheet (see Appendix 3.1) accompanied with the template consent form (Appendix 3.2). The request for their participation was direct and supported with a selection of dates and times to meet. All of this interaction was done largely by email. The final determinant for their involvement in the study was their availability.

In all, 29 informants shared their views through 27 interviews. Eleven occupied roles in the 
managerial domain, ten were elected to their roles and eight volunteered their time and energy to issues of pressing concern. On a topic-by-topic basis, and across leadership domains, informant participation was uneven. For example, with topic 11 (eradicating pests at Rotokare), one informant occupied a managerial role and a second was elected to his role. The breakdown of informant participation by topic and leadership domain is presented in the table below.

\section{Table 3: Informant participation by topic and leadership domain}

$\begin{array}{ccccc}\text { Topic-ID } & \text { Community } & \text { Managerial } & \text { Political } & \text { Total } \\ 11 & & 1 & 1 & 2 \\ 19 & 2 & 1 & 1 & 4 \\ 28 & & & & 0 \\ 32 & & 1 & 1 & 2 \\ 36 & 2 & 2 & & 4 \\ 57 & 1 & 1 & 2 & 4 \\ 76 & 1 & 1 & 3 & 5 \\ 85 & & 2 & 1 & 5 \\ 96 & 2 & 2 & 1 & 5 \\ & & & 10 & \mathbf{2 9}\end{array}$

There was no discernible pattern in the count of informants by topic and leadership domain. With large numbers, a pattern might emerge to identify the distribution of opinion, but that is a different study. This study is focused on the 'breadth' of opinion not on the 'distribution' of beliefs. It is provided here as a point of potential interest and nothing more.

\subsection{2b The informant interview}

The interview itself was what is typically described as a semi-structured interview with the assistance of an interview guide (see Appendix 3.3) to work through six sets of questions. One set of questions focused on the topic, like the background, the strategic issues and the desired outcomes. A second set focused on the interviewees' involvement and the circumstances, motivations and expectations surrounding their involvement. A third set of interview questions turned to what informants understand by 'community' and, because they were asked to participate in the study for a certain role, what they understood by 'community' in that role for a given topic. In this study, informants were asked how they know 'community' when they see it and what gives them confidence when others talk 
about 'community' that it is real and authentic. They needed little prompting to provide examples to illustrate. Informants were also asked to describe the ways in which they connect with the 'community' and what it was they did in practice.

Because the study sought out subjectivities that are interdependently created and maintained, the fourth set of questions asked informants to describe how others involved in the same 'community governance' issue might describe the other's understanding of 'community'. This proved a little more challenging because interviewees preferred to talk about their own views and were reluctant to be perceived to 'speak on behalf of someone else'. A small number ventured a guess as to what others might say and labelled it as such. There were also a few informants who had firm views on what they believed others understood to be 'community', and were quite forthcoming. One informant, for example, opined that a certain industry sector saw 'community' as 'a fictitious group'. It seemed that his concern was the way that particular industry made 'community' nameless and placeless. He retorted:

Name me the community. Show me the community they're talking
about. They don't say what their community is. If they said 'the
community of Kaponga, or the area around the maunga from x to
$z \ldots$, Yeah fine. Or 'Is there anything, you as a community need. Or
you as a group that will help improve things here.' That's a
different attitude. But I've not heard or seen anything. (19obF36C)

A fifth set of questions focused on 'community governance' and 'civic leadership', and the plan was to ask questions that identified what interviewees understood by these two concepts, what they looked like and what the key features were. Other planned follow-up questions included asking what had shaped informant expectations around 'community governance', what were the key responsibilities and challenges, and what were the links between their understanding of 'community' and their actions as a 'civic leader'. The full set of questions was never posed because only three of the 29 informants had a selfidentified working understanding of the term 'community governance'. Others suggested they might have heard of it, but may not have paid it any attention, and some admitted they had never heard of it at all. Many ventured a guess as to what it might mean and all of them were certainly interested to discover that they were already practising a form of 'community governance'. For example, after it had been explained to her, one informant remarked, "It's just a fancy word for doing stuff” (24vTu57C).

The end result was 27 interviews with 29 informants and they were transcribed and coded 
for content and intent. Each interview was numbered, each person was assigned a threecharacter alphanumeric identifier, and their role identified according to the relevant leadership domain. When combined with the topic reference, each informant (and later each participant) was then tagged with an eight-character unique identifier. The first two digits identify the interview, and the next three alpha-numeric characters identify the person. The fifth and sixth characters identify the topic, and the last letter tagged each person as occupying a role in the community leadership domain $(\mathrm{C})$, the managerial leadership sphere $(\mathrm{M})$ or the political domain $(\mathrm{P})$. As explained in the closing paragraphs of Chapter 1, these unique identifiers have been used throughout the thesis rather than marking participant and informant contributions with pseudonyms, or a combination of role titles, gender and age. The rationale is to maintain focus on the opinions expressed rather than draw attention to the characteristics of the subjects.

\subsection{2c The statement extraction process}

The unit of analysis for extracting a representative sample of the sub-concourse was the statement. In this study, the term 'statement' may refer to a part sentence, a whole sentence or more than one sentence and this treatment is consistent with Q methodology given the prominence to "the ordinary conversation, commentary, and discourse of everyday life" (Brown, 1991, p. 94). Statements from the substantive parts of the transcripts, however long or short, were then identified for their content and marked as referring to 'community', 'governance' or 'leadership', or if they were none of these, deemed to be either background, remarks or questions. Those statements flagged as 'community', 'governance' or 'leadership' were then assigned three more tags.

The first tag was an assessment for intent and it was done by applying John Dryzek and Jeffrey Berejikian's (1993) adaptation of Stephen Toulmin's (1958) claim types used in their Q study on Reconstructive Democracy (p. 51). Drysek and Berejikian (1993) had analysed their statements using a matrix structure across four categories (ontology, agency, motivations and natural) and by claim type (definitive, designative, evaluative and advocative). Only the claim types have been carried over into this study to help assess intent; that is, the way in which an informant's statement about 'community' characterised one of the following:

- Definitive and pointed out the meaning of 'community'

- Designative and concentrated on questions of fact about 'community' 
- Evaluative and emphasised the value or worth of 'community', and

- Advocative and promoted something about 'community' that should or should not be.

The second tag related to one of Hillery's (1955) elements of 'community'. That meant deciding whether the main idea underpinning the statement was a reference to geographical location, social interaction, common ties or people. The third tag involved deciding which of Fulcher's (1991) dimensions of 'community'-that is, the functional, social, perceptual or political dimension-were reflected in the statement. This process resulted in a statement being assigned one of 48 possible combinations. The systematic process of tagging and the resultant combinations helped with meeting Peter Schmolck's (2014a) recommendation for "breadth and heterogeneity" in the statements shortlisted for consideration. Where is was not clear which tag should be applied, the statement remained either partially or wholly untagged and, as a consequence, it was not considered at all. By the end of this initial elimination process, 427 statements were left for further consideration.

It must be emphasised that the purpose of this tagging process was to mitigate against researcher bias for certain statements over others and to ensure spread across Hillery's (1955) elements, Fulcher's (1991) dimensions and Dryzek and Berejikian's (1993) claim types. Not every combination in the $3 \times 3 \times 4$ matrix was assigned to a statement, and in the final Q sample, 20 of the 48 tag combinations were unassigned.

As each transcript was coded in the tagging process described in the previous paragraph, each statement was assessed for how it might be read and received by a potential Q-sort participant. Concise, strongly worded statements like 'Relationships', 'A fictitious group' and 'It's everyone' were retained because they were short and to the point and yet were expected to trigger useful conversations. And they did. Those that were extreme in their ambiguity in relation to all of the other statements were generally rejected as were statements that served as an illustration to an informant's understanding of 'community'. Expressions that were rare in their wording like 'So for me community is about whānau, it's about kōrero and it's about decision-making', 'It's really a risk mitigation strategy', 'To me, it's a whakapapa thing' and 'It's a community where I don't see any school sores' were kept for consideration and as can be seen in Table 4 further below, they made it to the final $Q$ set of statements. This step whittled down the number of statements for the Q sample to 158. The distribution of these 158 statements across the Hillery's (1955) elements and 
Fulcher's (1991) dimensions are available in Appendix 4.1.

The steps taken to arrive at the targeted 45 statements started with identifying the duplicates as Brown (2010) has advised. Of the initial list of 158 statements, 93 were eliminated because they were deemed to have been 'better said elsewhere'. For example, the first three statements immediately below were eliminated in favour of the fourth:

So you actually had to be friends with your neighbours, and you had to work in together if you wanted to get your hay in. $(13 z U J 38 P)$

Like it's good neighbours. Like I will say hello to everyone even people I might have arguments with...(17e9y19C)

There'd be somebody have a problem, and others would turn up to help. You know, nobody had to be asked to help when the chips were down for someone (142Ws11C)

Community is a hard thing to do because people come and go but you've got to get on with everybody even if you don't like them. (17dGC19C)

Another 20 were eliminated because the content was so open-ended that it often sent the informant into a spiral of self-reflection as they tried to explain themselves to the researcher and sometimes to themselves. For example, on the issue of social licence, one informant explained:

... the word community, it's such a great topic. You know. Like I said, to us it relates to us in... in this concept we keep hearing about is that "you guys need to earn your social licence to operate here". You know, we're trying to. We want to do that. How do you define that? (2028A36M)

The informant had acknowledged 'community' as "a great topic" and for their business, 'community' can be reframed as a "social licence". The informant also recognised that their 'social licence' has to be earned and, as was pointed out, "we're trying to" and "we want to". By then this line of thought has brought the informant back to the start with a closing question "how do you define that?" The 'that' in in this last question is "the word community" as framed by the concept of a 'social licence'. There were a number of conversations that had this spiralling pattern as informants tried to articulate their understanding of a term they used every day, but had spent little, if any, time considering its meaning or use. It was just as this informant said: 


\begin{abstract}
Well, I... to be quite honest, this is probably the most I've thought about communities, so it's just-it's all just (laughs) - my experience coming out. I mean I've never discussed communities in such detail, which is quite funny when you're [in the role named]. But... this is not something-you just sort of... They're there, aren't they? So you just sort of deal with them, but you don't analyse them in great detail. (13zUJ38P)
\end{abstract}

Note that reducing the list of 427 statements down to 45 was not as straightforward a process as the one outlined here. It took reading each statement again and again to identify the key theme and main point of a statement, given the topic to which it was referring and the tone with which it was said. The 48 possible tag combinations for content (that is, Hillery's (1955) elements and Fulcher's (1991) dimensions) and intent (that is, Dryzek and Berejikian's (1993) claim type) was a very useful guide and it served to mitigate for researcher bias and preference. Nonetheless, the objective here was to achieve Schmolck's (2014a) recommendation for "breadth and heterogeneity" and Brown's (2010) advice for a sample that is as "representative of the complexity of the verbal environment as possible".

With the probable $\mathrm{Q}$ set of 45 statements selected, the final step was editing. In Q methodology, there is no need, as Brown (1980) has urged, to "eliminate the kinds of ambiguities, conflicts, and inconsistencies that naturally occur in ordinary language" (p. 70). Indeed, Q-statements "should contain 'excess meaning", according to Webler et al. (2009, p. 10, emphasis added), but the statements should also be "short, 'stand-alone' sentences that are easy to read and understand" (p. 9). McKeown and Thomas (2013) have also advised removing "internal contradictions... [and] 'double-barrelled' meanings" (p. 41) so long as there is no "significant alter[ation] to phrasing and sentiment" (p. 41). Their aim is to minimise confusion and/or conflict to a Q sorter while allowing the participant full opportunity to bring their own beliefs and opinions to the statements, and as a consequence to the Q sort. However, Brown (2010) has offered a different course of action. His advice was to "keep it in the language of the audience we are dealing with it", and "with as little tampering and modification as possible" (Brown, 1980, p. 190). It is this 'keeping in the language' that has been applied in this study, and based on feedback remarking on the wording and grammar of some statements, Brown's advice may have been applied far more strictly than intended. The final set of statements, the Q sample, is presented in Table 4 below (and reproduced in Appendix 4.2 for easy reference later in the thesis). 


\section{Table 4: Q sample}

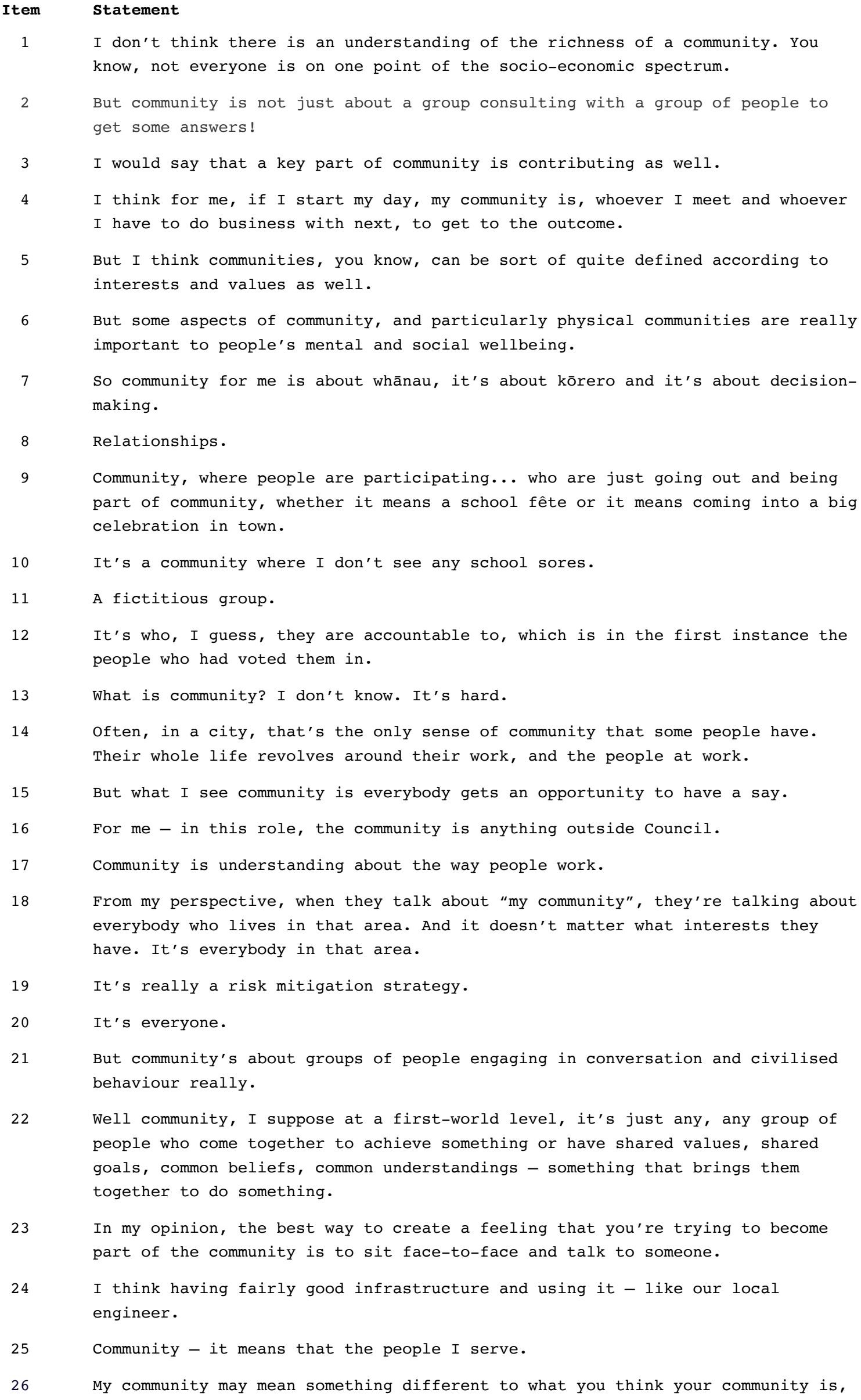
Their whole life revolves around their work, and the people at work. 
even though we're at the same table.

I don't think of community as a single thing. I think of it as very multilayered and in some cases temporal. It's a here-and-now, not an always. To me, community is a whakapapa thing. Community is a hard thing to do because people come and go but you've got to get on with everybody even if you don't like them. Community in my mind is immediately identified by the role that you or the hat that you are wearing at a particular point in time. He used to say, 'everybody has to take responsibility'. I mean he would walk down the road and pick up the bloody rubbish because anybody can do that. You don't have to leave it to someone else. It's not about you or me. It's about the community.

I think it's where the community has a full chance to react to things that they desire for their community and work within the community to achieve those things. So anyone, we'd be thinking, who could be impacted. In the past I would have just said 'it's just a group of people or a community thing like [a project]'. But it's far more than that. It's the meeting before the [project]. The whole way we interact. And [deciding] whether it's a good thing to do.

I don't think there's a community over the whole area; I think this place has a variety of small communities. Actively asking for that input and then delivering back results.

What I'm concerned about is that there's no transparency. There's no engagement with the community.

If you want to get your point of view across, it's no good us just going in and giving a submission, ourselves; we need a whole lot of people behind us, to say that's what they want.

So, I think it's about being committed to the place where you live, and saying, 'where I need to, I'll step up and I'll make a difference'. Knowing your neighbours and knowing you can rely on them, I suppose.

Community is just some sort of stuff that exists in some back paddock somewhere that's absolutely okay to go out and raid every now and then for its capital resources instead of actually seeing it as the central dynamic of what's going on.

And the community is and always has been the lowest level of local government. more important than anyone else, we're just all important.

Without a doubt... the best of our work is over a cup of tea and in [the] kitchen.

There are statements in this $Q$ sample that are not consistent with the advice in the previous paragraph and that could be construed as a methodological limitation. Each statement does certainly contain 'excess meaning' and, surprisingly, the single-word statements proved to be as demanding, if not more, as the double-barrelled items that 
McKeown and Thomas (2013) urged Q researchers to avoid. For example, in response to Item 8, 'Relationships', one Q sorter sought clarification, “So what's 'Relationships??” (Q04 31FqZ11P) and to Item 20, 'Everyone', a participant deemed it "too confusing” (Q32 53cGV19P) and "too vague". Yet for a third, both items were identified as "good strong statements" (Q36 60Jq332P).

One item that was identified as a double-barrelled item in the research process was Item 29, which stated, 'community is a hard thing to do because people come and go but you've got to get on with everybody even if you don't like them'. As will be presented in the interpretation of consensus results, this item is an example where participants agreed with one part but not the other. In effect, Q sorters had to face an internal contradiction and weigh up whether they agreed with only one part or both. The risk of contradiction was assessed as acceptable because the link between the informant's reason why 'community is a hard thing to do' and the claim itself (that is, 'community is a hard thing to do') reflected the circumstances in which the informant lived. That her lived experience might not resonate or be familiar to someone else is a given, but what was retained here was McKeown and Thomas's (2013) commitment to sentiment (p. 41) and the elasticity of meaning inherent in 'community'.

Forty-five statements made up the final Q sample and this number needs to be explained. There is no clear guidance in the how-to articles of $\mathrm{Q}$ methodology on the ideal number of statements or even the process by which that number should be determined. In this study, the size of the $\mathrm{Q}$ sample was driven by the practicalities of data collection with consideration for the research question being asked and the value of the post Q-sort interview.

In the design phase, first consideration was given to the target participants. The researcher's prior knowledge and insight identified that demands on their time was high, and it was important to provide them with certainty about what would be expected of them. Furthermore, as an embedded participant with a desire to foster and maintain long-term relationships, the researcher identified that 1.5 hours as an appropriate upper limit to ask of potential participants. It became crucial to ensure that both the Q sort and the post Q-sort interview could be completed in that time, and the number of statements in the Q sort would have a bearing on how that time would be used.

The Q-literature has identified that the Q sample could be as few as 20 and as many as 80 . 
Brown (1980) suggested Q samples would "normally contain 40 to 60 items" (p. 267) while Webler et al. (2009) advised a range between 20 and 60 and Watts and Stenner (2005) proposed "somewhere between 40 and 80" (p. 75). Dryzek and Berejikian (1993), who used a 4 x 4 matrix to analyse their initial compilation of statements, selected four statements from each cell at random, resulting in a Q sample of 64 statements (p. 51). Having noted that Webler et al. (2009) warned that any more than 60 is taxing (p. 17), anything close to 60 was soundly rejected with 50 statements deemed an acceptable upper limit.

A third practicality was the area a Q sort might take up and it had to be able to fit on an office desk or a large coffee table. It meant that the uniformly sized cards on which the statements were presented had to have enough space for the longest of the statements in a legible typeface and size and allow for a discrete statement identifier. There needed to be sufficient tactility to support the Q sorter to react to the statement and offer their viewpoint against a pre-defined distribution pattern. That pattern was based on the the default -5 to +5 scale which meant the tableau would have 11 columns. Although expected to be challenging with probable resistance, the plan was to ask them to place one statement in the -5 and +5 columns and two statements in the -4 and +4 columns. These four columns accounted for six statements. In order to be able to fit on a busy desk, the depth of tableau could be no more than eight cards including the header row. This limitation accounted for another seven statements for the 0 column taking the total number of statements assigned to columns to 13. That meant there needed to be enough statements to

fill columns $-3,-2$, and -1 along with columns $+1,+2$ and +3 in a pattern that matched the normal distribution curve. Layout tests resulted in accepting 45 as the target number of statements.

\subsubsection{Stage 3: Conducting the $\mathrm{Q}$ sort}

\subsection{3.a The participants}

The Q sort is one of the defining elements to Q methodology, and it is this technique by which a participant's viewpoint is captured. Recruiting participants for the Q sort was again the careful and non-random "purposive sampling" (Cuppen et al., 2010, p. 581) used for the informant interviews with the same added consideration for participants occupying roles across Hambleton's (2011) three leadership domains. Possible participants had been identified during the first and second stages of data collection and their selection was driven by their known diversity of views, where having "a different point of view is enough 
reason" (Cuppen et al., 2010, p. 581) to recruit a participant to the study. Of the 29 who participated in the topic-oriented interviews, nine of them were also recruited for the $\mathrm{Q}$ sort. Q methodology allows for participants involved in identifying the sub-concourse to be participants who rank-order the statements (Wolf, 2012).

Like the informant interview, recruiting participants for the Q sort involved approaching each potential informant with a personalised letter and information sheet (see Appendix 5.1) accompanied with the template consent form (Appendix 5.2). They were offered a selection of dates and times to meet and through an exchange of emails, dates and times were confirmed. The final determinant for their involvement in the study was their availability.

Thirty-five participants were successfully recruited to do the Q sort and each held one or more roles from across all three of Hambleton's $(2011,2015)$ leadership domains. These 35 Q sorters produced 47 Q sorts where 15 Q sorts were primarily from roles with a grassroots mandate (community leadership), 16 were employed (managerial leadership) and 16 were elected (political leadership) to a 'community governance' context.

Like the informants, Q sorter participation was uneven on a topic-by-topic basis. For example, with topic 19 (pig hunting in the Waitōtara Valley), one participant occupied a managerial role and two others were elected members. However, one of the $\mathrm{Q}$ sorters whose participation was tagged to topic 57 (developing community response plans) also drew on his involvement with issues related to topic 11 (eradicating pests at Rotokare). As a consequence, any cross-referencing from participants is not accounted for in the breakdown of Q sorter participation by topic and leadership domain as presented in Table 5 below. 
Table 5: Q-sorter participation by topic and leadership domain

$\begin{array}{ccccc}\text { Topic-ID } & \text { Community } & \text { Managerial } & \text { Political } & \text { Total } \\ 11 & 2 & 2 & 2 & 6 \\ 19 & & 1 & 2 & 3 \\ 28 & & & 1 & 1 \\ 32 & 6 & 5 & 2 & 13 \\ 36 & 1 & 1 & 2 & 4 \\ 57 & 2 & 2 & & 4 \\ 76 & 1 & 2 & 3 & 3 \\ 85 & 3 & 2 & 4 & 8 \\ 96 & & 1 & & 57\end{array}$

\subsection{3b The $Q$ sort itself}

Like the interviews, the Q sort began with obtaining consent using the form presented in Appendix 5.2 and making sure they understood what the research study was about. Permission was also sought and gained to record the audio for each Q sort interview. For those new to the study, the process started with questions about themselves, their background and the topic provided the basis for the conversation as set out in the interview guide presented in Appendix 5.3. These preliminaries were followed by the $\mathrm{Q}$ sort, and that involved asking participants to rank-order the statements with the following sorting instruction in mind:

For the context of [insert topic description] and for you role as [insert their confirmed role], what do you understand 'community' to be?

This task of rank-ordering was a two-step process.

After being handed the Q-deck of 45 statements on light card, and receiving the sorting instruction, the Q sorters were asked to read each statement and place them in three piles. One pile was for those statements with which they strongly agreed. The second was for those statements with which they strongly disagreed, and the third pile was for those statements about which they had some ambivalence. Once this first sort was completed, the $\mathrm{Q}$ sorters were then asked to rank-order each statement in relation to every other statement and place each card in the highly structured arrangement as depicted in Figure 2 below. 


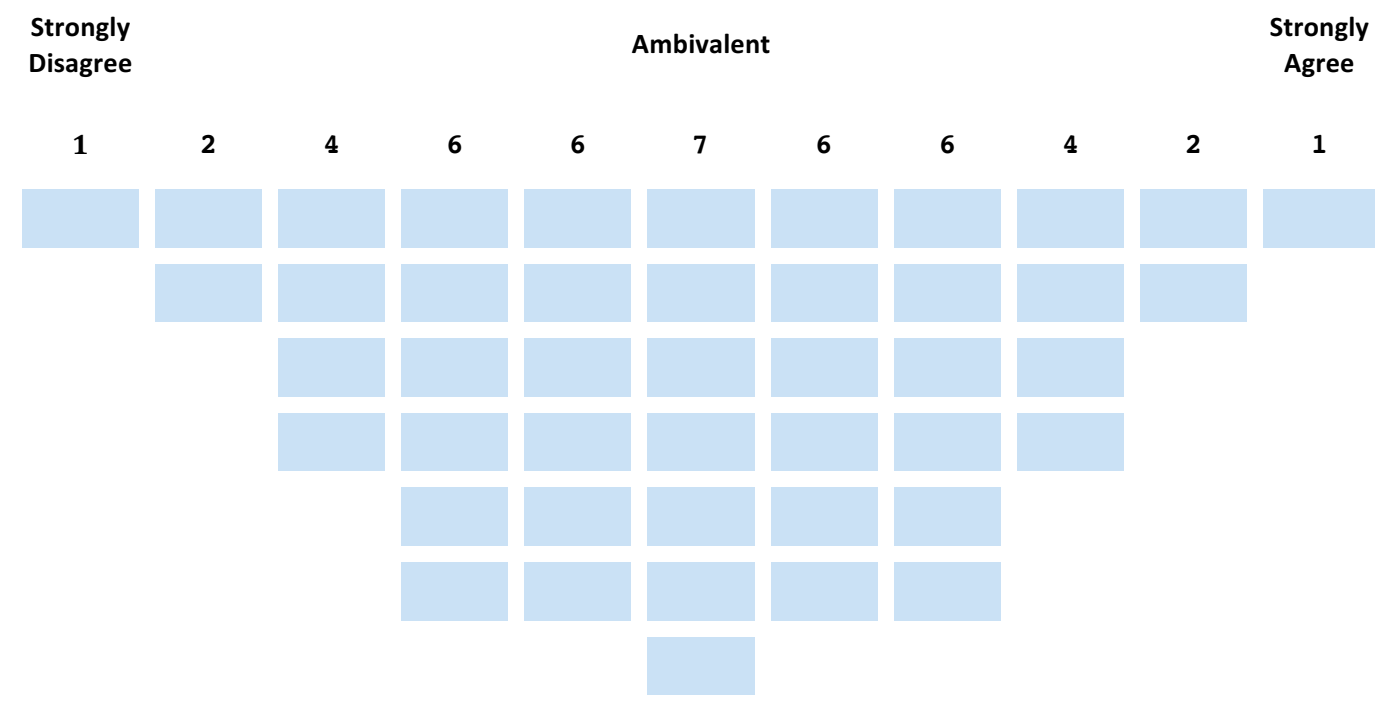

Figure 2: Q-sort tableau used in the field

Figure 2 shows a tableau that differs from a more typical ranking system that ranges from -5 to +5 . Instead, the researcher opted for a different approach comprising a row of headers cards with the numbers $1,2,4,6,6,7,6,6,4,2$ and 1 . The intention was to provide participants with very strong guidance in their rank-ordering and support them to rank-order and place the statements in a layout of a normal distribution curve that characterise a Q sort.

The stage of rank-ordering was explained in a way that both described and demonstrated what needed to be done on the part of the Q sorters. An example of what took place is as follows:

Now that you have put the statements into these three piles [gesture across the three piles], here is what I would like you to do next. There will be one statement in your pile of 'strongly disagrees' that really stands out as the one you most strongly disagree with. Put that one statement at this end of what's going to be a continuum in this column headed with this number one [place a 'I' card at one end of the table]. This is your strongly disagree end [place the 'strongly disagree' card to above the ' 1 ' card].

Then out of that same pile, pull out the two statements [place a ' 2 ', card on the table] that you strongly disagree with but not nearly as much as the one you have placed at this end strongly disagree.

Those two statements go in this column.

Do the same thing for this column but here you will have four 
statements [place a '4' card]. In this column, you will have six [place a '6' card], six here [place a '6' card], seven here [place the '7' card] and so on [place the '6', '6', 4', and '2' cards] until you have the one statement [place a ' 1 ' card] with which you most strongly agree at this end [place the 'strongly agree' card above the ' 1 '].

Your ambivalent statements will sit somewhere in the middle [place the 'ambivalent' card at the midpoint].

The Q sorter was then left to finish the exercise with a reaffirmation of the sorting instruction.

\subsection{3c The post Q-sort interview}

When the rank-ordering was completed, participants were asked for feedback on the process. Their responses are not covered in this thesis, but they do warrant attention in a future article that explores the transformative potential of the Q sort. Participants were invited to "elaborate on his or her point of view" (Brown, 1993, p. 106) and asked questions of clarification on the placement of certain statements. For example, what led them to place statements at the extreme ends of the continuum? What thoughts prompted the reshuffle after some observed action such as hesitation? What is the significance of this [participant-identified] cluster of statements and how do they fit together? In what way might certain statements be placed differently if the Q sorter were wearing a 'different hat'? If it was not volunteered, the participants were also asked the direct question "what do you understand by 'community'?" and what or who had shaped and influenced that understanding. At the end of the Q sort interview, the Q sorter was asked to read out the numbers for each statement with the researcher recording the data on to a results sheet (see Appendix 6).

Thirty-five participants completed $47 \mathrm{Q}$ sorts and, of these 35, one completed three consecutive Q sorts and ten completed two. In these multi-Q sort instances, the participant was asked to consider the sorting instruction again, but as it applied to a second (or third) role and/or context. On completion of the first $\mathrm{Q}$ sort and capturing the results, the researcher collected up the statements, shuffled them and then handed them back to the participant to repeat the $\mathrm{Q}$ sort process. This shuffling of statements occurred in all multiQ sort opportunities except for two. With Q sorts 01 and 30, and then again with Q sorts 02 and 31, this shuffling did not take place because the researcher missed that step. In both 
cases, the participants revised their already set-down layouts in response to the sorting instruction for different contexts, but roles that sat in the same leadership domain. Initially, the second Q sorts were rejected because of the missed step, but a later decision resulted in retaining both as valid viewpoints. In terms of the spread across leadership domains, 15 of the 47 Q sorts were set in contexts where the participant occupied a community leadership role, and there were 16 each for managerial and political leadership roles.

The durations for each of the Q sort interviews varied and ranged from 45 minutes to 90 depending on how long it took a participant to do the initial sort and then the rankordering. Later, the interview was transcribed and like the informant interview, it was coded for content and intent and used to inform and shape the interpretation of the results. The results from those Q sorts were keyed into the software application PQMethod version 2.35 to support the next step in factor analysis and interpretation.

Note that software required an eight-character 'case label' or Q sort unique identifier. It comprised the two-digit $Q$ sort interview number, the three-character alpha-numeric assigned to each participant, the relevant topic identifier and the role flag. For example, Q sorts $0628 \mathrm{aFZ19M}$ and 07 28aFZ57C identify the $\mathrm{Q}$ sorts generated from interview number 28 with participant aFZ. Q sort 06 is a response to topic 19 (pig hunting in the Waitōtara Valley) from a role in the managerial leadership domain, while Q sort 07 is a viewpoint on topic 57 (community emergency plans) from a role within the community leadership domain. However, as already mentioned, there were instances where a participant was recruited to the study for one topic, but in the course of the conversation may have remarked on others.

\subsubsection{Stage 4: Doing the factor analysis and interpretation}

The factor analysis was completed using PQMethod, which is described as "a statistical program tailored to the requirements of Q studies" (Schmolck, 2014c). One of its key features is the easy entry of Q sort data. Once that had been done, the high-level steps in this stage of work involved the following:

- Initiating the factor analysis

- Rotating for three factors

- $\quad$ Flagging and reflagging Q sorts 
- Performing a final Q-analysis and

- Undertaking the factor interpretation.

The next five sub-sections detail what took place in each step. They also include technical explanations of the options that were considered and, where necessary, an explanation of the challenges that those choices posed.

\subsubsection{Initiating the factor analysis}

PQMethod allows for two approaches to factor analysis: principal component analysis (PCA) or centroid analysis. Regardless of which approach is adopted, the aim is to search out "as much of the variability in the data as possible" (Ramlo, 2016, p. 74). With PCA, the underlying assumption is "that each item is invariant" (p. 74) and unchanging, and the analytical objective is "one best mathematical solution" (emphasis retained, p. 76). It is also the preferred method for those "that seek mathematical simple structure" (p. 76). While Brown (1980) has acknowledged PCA is "more accurate in a statistical sense" (p. 235), Brown and Robyn (2004) have recognised PCA as "more precise", and Ramlo (2016) has noted PCA “can provide better solutions statistically" (p. 75), their commitment is to Stephenson's well-known preference for centroid analysis. They hold to the philosophical basis that a researcher can bring the contextual realities of the inquiry into the research study (Brown \& Robyn, 2004, p. 104; Ramlo, 2016, p. 76), and through judgemental rotations, do so in an objective and systematic way. Q researchers are then able to look for the plausible from "an infinite number of possible solutions" (Ramlo, 2016, p. 76) "without violating any assumptions" (Brown, 1980, p. 56) and without having to commit to a single “"technically correct' solution” (McKeown \& Thomas, 1988, p. 75).

This quality of "indeterminacy" (Brown, 1980; Ramlo, 2016; Stephenson, 1953) in centroid analysis made for an attractive option for two reasons: one was to accommodate the elasticity inherent in the notion of 'community' and the other was to uphold the philosophical intent of Q methodology. Indeed a full analysis and interpretation of the data using centroid analysis with the option of 'Brown's centroid' for the default seven factors and manual rotation of three was pursued and presented. However it proved to be flawed and the data was re-analysed using PCA and the default of eight factors with varimax rotation for three. 


\subsection{4b Rotating for three factors}

Regardless of whether one uses central analysis or PCA, the next step in this stage of work was selecting which of the default seven or eight factors ought to be extracted. Watts and Stenner (2012) recognised that this step is "a difficult one" (p. 107) and urged that this decision is an informed one and "always... defendable" (p. 107). Not all seven factors will be part of a viable solution; it is possible, but it is not likely. The challenge lay with deciding which of the factors to extract and retain.

The widely accepted starting point amongst Q-methodologists is the significant factor loading, and it is calculated by multiplying the standard error by 2.58 . The standard error is the standard deviation in the distribution of the averages of many samples (Foltz, 2013), and in Q methodology, it is the square root of the number of items (Brown, 1980, pp. 222-223). As this study used 45 statements for the Q sort, the standard error was 1/ $\mathrm{SQR}(45)$ or 0.1491 . The 2.58 is a default value used to calculate and, therefore, identify the bounds within which one can have 99\% confidence in a matter. In this case, the matter is the degree of significance to which a factor loads against each Q sort. Therefore, for this study, multiplying the standard error of 0.1491 by 2.58 yielded a significant factor loading of 0.3846 .

The next table, Table 6, is the output from PQMethod and it identifies the factor loadings for each Q sort across eight factors. Those factor loadings greater than or equal to the significance factor loading of 0.3846 are identified in bold text.

\section{Table 6: Factor loadings using PCA for each $Q$ sort across the eight unrotated factors}

\begin{tabular}{|c|c|c|c|c|c|c|c|c|c|}
\hline \multicolumn{2}{|c|}{ SORTS \FACTORS } & 1 & 2 & 3 & 4 & 5 & 6 & 7 & 8 \\
\hline 01 & 34В3T57M & 0.6733 & 0.1630 & 0.1609 & 0.2798 & 0.1628 & 0.1384 & 0.1232 & -0.1708 \\
\hline 02 & 32MuE76M & 0.6448 & -0.1135 & -0.2101 & -0.1146 & -0.4307 & 0.1011 & 0.2454 & 0.4070 \\
\hline 3 & 31FqZ85C & 0.7202 & 0.2670 & -0.0676 & -0.0165 & -0.0665 & -0.3059 & -0.0279 & 0.0081 \\
\hline 04 & 31FqZ11P & -0.4542 & 0.3312 & -0.2223 & 0.2434 & -0.1073 & 0.2607 & -0.1733 & 0.2246 \\
\hline 5 & 29jBV36C & 0.4782 & 0.0647 & -0.0991 & 0.0002 & -0.1606 & -0.3410 & -0.0314 & 0.1650 \\
\hline 06 & 28aFZ19M & 0.7840 & -0.2085 & 0.1900 & -0.0295 & -0.0586 & 0.0670 & -0.0078 & -0.1204 \\
\hline 7 & $28 \mathrm{aFZ} 57 \mathrm{C}$ & 0.4850 & -0.4470 & 0.3103 & -0.0119 & -0.0872 & -0.0058 & 0.2574 & -0.0310 \\
\hline 8 & $38 W d g 76 \mathrm{M}$ & 0.7494 & 0.2693 & 0.2794 & 0.0567 & 0.0602 & 0.0333 & -0.0509 & 0.0944 \\
\hline 9 & $38 W d g 36 P$ & 0.5869 & 0.2323 & 0.0898 & 0.0348 & 0.1146 & 0.3250 & -0.2731 & 0.1677 \\
\hline 10 & $366 \mathrm{Bz} 11 \mathrm{M}$ & 0.6755 & -0.4861 & -0.2809 & -0.0089 & 0.0433 & -0.0801 & 0.0448 & 436 \\
\hline 1 & $37 \mathrm{ZGS} 11 \mathrm{C}$ & 0.7728 & -0.2730 & -0.2484 & -0.0619 & 0.0567 & 0.1122 & 0.1692 & -0.1175 \\
\hline 12 & $35 \mathrm{EMu} 32 \mathrm{C}$ & 0.6511 & -0.1257 & 0.1156 & 0.2483 & -0.1511 & -0.0092 & -0.2925 & 0.0532 \\
\hline 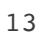 & $41 \mathrm{DWX} 96 \mathrm{P}$ & 0.6568 & -0.2372 & 0.2544 & 0.0470 & 0.2302 & 0.1863 & -0.1130 & -0.0261 \\
\hline 14 & 4 1DWX32C & 0.3877 & -0.2122 & 0.3282 & -0.2369 & 0.1278 & -0.2277 & 0.2144 & -0.0422 \\
\hline 15 & 390IQ96M & 0.7309 & 0.1970 & 0.0190 & 0.1050 & 0.0751 & 0.2234 & -0.2623 & 0.0048 \\
\hline
\end{tabular}




\begin{tabular}{|c|c|c|c|c|c|c|c|c|c|}
\hline 16 & $42 \mathrm{STm} 32 \mathrm{M}$ & 0.6300 & -0.4472 & -0.0857 & -0.1132 & 0.2259 & -0.0301 & 0.0600 & 0.0291 \\
\hline & 47 oyq $11 \mathrm{M}$ & 0.6100 & 0.0133 & 0.0734 & -0.2734 & 0.3030 & 0.0145 & -0.1512 & -0.2404 \\
\hline & $52 w 4 y 85 M$ & 0.5585 & 0.0046 & 0.5111 & -0.3971 & -0.2203 & 0.0725 & 0.1535 & -0.0661 \\
\hline & $33 \mathrm{STg} 11 \mathrm{P}$ & 0.7126 & -0.2703 & 0.1979 & 0.0356 & -0.1203 & -0.1637 & -0.0816 & 0.3054 \\
\hline & $43 \mathrm{uWH} 85 \mathrm{P}$ & 0.3852 & 0.4235 & -0.0632 & -0.4130 & -0.1412 & -0.2845 & 0.2756 & -0.0926 \\
\hline & 40 QNG11C & 0.6135 & 0.3722 & -0.0418 & 0.1356 & -0.1132 & 0.2489 & -0.1633 & -0.1009 \\
\hline & 30KjD85C & 0.8095 & 0.0298 & -0.0290 & 0.2943 & -0.0060 & -0.0124 & -0.0508 & -0.0396 \\
\hline & 30KjD56P & -0.0219 & 0.4302 & 0.0519 & 0.4891 & -0.3095 & -0.3539 & 0.2702 & -0.1432 \\
\hline & $55 \mathrm{Tt} \times 85 \mathrm{M}$ & 0.4175 & 0.4652 & -0.0234 & -0.4309 & -0.1161 & 0.2765 & 0.1023 & 0.0144 \\
\hline & 45PQ019P & 0.6614 & -0.1704 & -0.0065 & 0.0034 & -0.2323 & 0.0570 & 0.1626 & -0.2552 \\
\hline & 45PQo32M & 0.4436 & -0.1972 & -0.1744 & 0.4651 & 0.3330 & -0.2366 & 0.1781 & -0.0384 \\
\hline & $44 \mathrm{Ghb} 85 \mathrm{C}$ & 0.6572 & 0.3873 & -0.2251 & -0.0266 & 0.1237 & -0.0172 & 0.1253 & 0.1302 \\
\hline & $57 i 2 n 32 M$ & 0.6872 & 0.2335 & -0.3244 & -0.1471 & 0.0246 & -0.0458 & -0.2448 & 0.0793 \\
\hline & 59soV96P & 0.6598 & -0.2634 & -0.1946 & 0.2956 & -0.0367 & 0.0111 & -0.1998 & -0.1006 \\
\hline & 34в3т96м & 0.5608 & 0.2331 & -0.3140 & 0.3489 & 0.0287 & 0.2409 & 0.1850 & 0.0422 \\
\hline & 32MUE 32M & 0.6364 & -0.1459 & -0.2822 & -0.1667 & -0.4221 & 0.0480 & 0.1729 & 0.4147 \\
\hline & $53 \mathrm{CGV} 19 \mathrm{P}$ & 0.6028 & 0.0730 & -0.4115 & -0.0218 & 0.3217 & -0.0841 & 0.0444 & -0.0620 \\
\hline & $5015257 \mathrm{M}$ & 0.7365 & -0.0146 & -0.0415 & -0.2737 & 0.0919 & -0.1570 & -0.0967 & -0.0488 \\
\hline & 49Vsu96P & 0.6271 & -0.1759 & -0.0041 & -0.1245 & 0.1613 & -0.2068 & -0.3880 & 0.2133 \\
\hline & 49Vsu85P & -0.3691 & 0.1242 & 0.1885 & 0 . & 2 & -0.0146 & 0.3559 & 0.3928 \\
\hline & $43 \times \times 129 P$ & 0.1839 & 0.1857 & 0.6873 & 0.1615 & -0.2737 & -0.1326 & -0.1690 & 0.0772 \\
\hline & $43 \times \times 185 P$ & 0.5832 & 0.4337 & -0.1281 & -0.2993 & 0.0657 & -0.3194 & -0.0119 & -0.1470 \\
\hline & $43 \times \times 132 C$ & 0.3923 & 0.3410 & 0.4140 & 0.2701 & 0.2408 & -0.1033 & 0.1901 & 0.3194 \\
\hline & $60 \mathrm{Jg} 332 \mathrm{P}$ & 0.6702 & -0.1533 & 0.0225 & 0.3444 & -0.3927 & 0.0818 & 0.0991 & -0.2917 \\
\hline & $51 \mathrm{TvM} 32 \mathrm{C}$ & 0.6194 & 0.4338 & -0.0606 & -0.0435 & -0.1009 & 0.0122 & -0.1424 & -0.2461 \\
\hline & $56 t \operatorname{lp} 32 \mathrm{M}$ & 0.7300 & -0.1528 & 0.1236 & 0.1412 & 0.0023 & 0.1500 & 0.2329 & -0.0525 \\
\hline & $56 t \operatorname{lp} 32 \mathrm{C}$ & 0.5634 & 0.2632 & -0.1616 & 0.2703 & 0.2229 & -0.0794 & 0.3007 & -0.0605 \\
\hline & $46 \operatorname{Lm} 932 \mathrm{P}$ & 0.7389 & 0.0092 & -0.1792 & -0.0688 & -0.0426 & -0.2007 & -0.0777 & 0.1872 \\
\hline & $54 \mathrm{QQ} 736 \mathrm{M}$ & 0.7132 & 0.1009 & 0.3805 & 0.2476 & 0.0401 & -0.0725 & -0.1157 & 0.0770 \\
\hline & $61 \operatorname{Er} 332 C$ & 0.3582 & 0.2681 & 0.1918 & -0.3409 & 0.1759 & 0.4636 & 0.2604 & -0.0513 \\
\hline & 63МKT57C & 0.5950 & -0.2532 & -0.1021 & 0.0316 & -0.0149 & 0.4180 & 0.1293 & 0.1313 \\
\hline & $64 \mathrm{Gn} 576 \mathrm{C}$ & 0.7527 & -0.1228 & 0.1005 & -0.2359 & 0.1595 & -0.1050 & -0.1535 & 0.0219 \\
\hline & envalues & 17.5586 & 3.3284 & 2.5512 & 2.4543 & 1.9132 & 1.7608 & 1.6333 & 1.3661 \\
\hline & xpl.Var. & 37 & 7 & 5 & 5 & 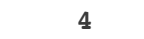 & 4 & 3 & 3 \\
\hline
\end{tabular}

As can be seen in Table 6, all but five Q sorts loaded to factor 1. Six Q sorts loaded to factor 2, three on factors 3 and 8, two on factors 4 and 6 , one on factor 5 and none to factor 7. Because "loadings express the extent to which each Q sort is associated with each factor" (Brown, 1991), the 42 of the 47 Q sorts loading to factor 1 indicate that there is only one observable viewpoint underpinning this solution.

Any contribution to understanding what is understood to 'community' from factors 5 and 7 can be ignored because Q-methodologists agree that accepting only one Q sort loading on to a factor is not sufficient reason to retain a factor for further consideration. While Brown (1980) has recommended accepting factors that have "at least two significant loadings" (p. 222), factors 4 and 6 can also be dismissed in favour of Webler, Danielson and Tuler's (2009) simplicity and clarity. With factors 1 and 2 as definite contributors-the former more so than the latter-some consideration may be warranted for factors 3 and 8 in order not to "lose important and interesting information" (p. 32) about what people 
might think about a particular topic.

But this wrangling over which factors to select for rotation was not required for the results that will be presented here because PCA simply asks how many factors are to be rotated (Schmolck (2014a). Three was the answer and that number was influenced by the number of factors extracted for the centroid based solution. A varimax rotation for four factors was tested given the factor selection described above identifying the unrotated factors of 1 , 2, 3 and 8 as possible contributors to a solution, but there was no observable gain in the crispness of the results. Consequently, the decision to work with three factors was upheld.

\subsection{4c Flagging and re-flagging $Q$ sorts}

While still in the varimax rotation sub-routine of the software, the now-rotated factors were subjected to auto-flagging. All but seven Q sorts were auto-flagged to one of the three factors. The unflagged seven-Q01, Q07, Q08, Q13, Q17, Q22 and Q32-were noted, in Q-terminology, as confounded; that is, they loaded to more than one factor. Schmolck (2014b) has explained that flagging is simply a task to "associate particular subjects with factors". He has also pointed out that one need not accept the flagging result produced by PQMethod and that it is possible to make changes.

For the analysis, two Q sorts were marked as unflagged after the auto flagging sub-routine because their negative factor loadings "introduce a negative factor weight [to the] calculations" (Watts \& Stenner, 2012, p. 133) and in effect, muddying the solution somewhat. These unflagged Q sorts are identified by the highlighted text in Table 7 below and the those auto-flagged as confounded are in bold text. The red $\mathrm{x}$ marks the defining $\mathrm{Q}$ sorts for each of the three factors.

Table 7: Factor matrix with an $\mathrm{x}$ indicating a defining sort with confounded $Q$ sorts in bold text and reflagged $Q$ sorts, $Q 04$ and $Q 35$ highlighted

$\begin{array}{llclr}\text { Q sort } & \text { Factor 1 } & \text { Factor 2 } & \text { Factor 3 } \\ 01 & \text { 34B3T57M } & 0.3126 & 0.4787 & 0.4230 \\ 02 & 32 \mathrm{MuE76M} & 0.5940 \mathrm{x} & 0.3360 & 0.0834 \\ 03 & 31 \mathrm{FqZ85C} & 0.3591 & 0.6417 \mathrm{X} & 0.2319 \\ 04 & 31 \mathrm{FqZ11P} & -0.4481 & 0.0478 & -0.4029 \\ 05 & 29 \mathrm{jBV} 36 \mathrm{C} & 0.3277 & 0.3515 \mathrm{X} & 0.1085 \\ 06 & 28 \mathrm{aFZ19M} & 0.6127 \mathrm{x} & 0.2467 & 0.5078 \\ 07 & \text { 28aFZ57C } & \mathbf{0 . 5 1 1 8} & \mathbf{- 0 . 1 4 1 2} & \mathbf{0 . 4 9 9 4} \\ 08 & \text { 38Wdg76M } & \mathbf{0 . 2 5 8 2} & \mathbf{0 . 5 7 7 2} & \mathbf{0 . 5 5 8 9}\end{array}$




\begin{tabular}{|c|c|c|c|c|}
\hline 09 & $38 W d g 36 P$ & 0.2333 & $0.4997 x$ & 0.3200 \\
\hline 0 & $366 \mathrm{Bz} 11 \mathrm{M}$ & $0.8736 x$ & 0.0808 & 0.0441 \\
\hline & $37 \mathrm{ZGS} 11 \mathrm{C}$ & $0.7967 x$ & 0.2952 & 0.1075 \\
\hline & 35EMu32C & $0.4937 x$ & 0.2520 & 0.3819 \\
\hline & 41DWX96P & 0.5197 & 0.1352 & 0.5139 \\
\hline & $41 \mathrm{DWX} 32 \mathrm{C}$ & 0.2905 & -0.0191 & $0.4672 \mathrm{x}$ \\
\hline & 390IQ96M & 0.3805 & $0.5727 x$ & 0.3173 \\
\hline & 42STm32M & $0.7500 x$ & 0.0378 & 0.2009 \\
\hline & 47 оуq $11 \mathrm{M}$ & 0.3924 & 0.3464 & 0.3219 \\
\hline 8 & $52 w 4 y 85 M$ & 0.2107 & 0.2048 & $0.6977 \mathrm{x}$ \\
\hline & $33 \mathrm{STg} 11 \mathrm{P}$ & $0.5988 x$ & 0.1553 & 0.4870 \\
\hline & $43 \mathrm{uWH} 85 \mathrm{P}$ & 0.0254 & $0.5683 x$ & 0.0904 \\
\hline & 40 QNG11C & 0.2097 & $0.6556 \mathrm{x}$ & 0.2072 \\
\hline & $30 \mathrm{KjD85C}$ & 0.5568 & 0.4996 & 0.3121 \\
\hline & 30KjD56P & -0.3029 & $0.3098 x$ & 0.0239 \\
\hline & $55 \mathrm{Ttx} 85 \mathrm{M}$ & 0.0081 & $0.6099 x$ & 0.1387 \\
\hline & 45PQ०19P & $0.5711 x$ & 0.2525 & 0.2770 \\
\hline & 45PQ०32M & $0.4936 x$ & 0.1457 & 0.0341 \\
\hline & $44 \mathrm{Ghb} 85 \mathrm{C}$ & 0.2940 & $0.7367 \mathrm{x}$ & 0.0587 \\
\hline & $57 i 2 \mathrm{n} 32 \mathrm{M}$ & 0.4457 & $0.6582 \mathrm{x}$ & -0.0138 \\
\hline & 59soV96P & $0.6932 x$ & 0.2243 & 0.1086 \\
\hline & $34 \mathrm{~B} 3 \mathrm{~T} 96 \mathrm{M}$ & 0.3539 & $0.5821 x$ & -0.0574 \\
\hline & $32 \mathrm{MUE} 32 \mathrm{M}$ & $0.6334 \mathrm{x}$ & 0.3232 & 0.0155 \\
\hline & $53 \mathrm{CGV} 19 \mathrm{P}$ & 0.5174 & 0.5052 & -0.1230 \\
\hline & $5015257 \mathrm{M}$ & $0.5379 x$ & 0.4258 & 0.2715 \\
\hline 4 & 49Vsu96P & $0.5497 x$ & 0.2277 & 0.2649 \\
\hline & 49Vsu85P & -0.4008 & -0.1626 & 0.0122 \\
\hline 36 & $43 \times x 129 P$ & -0.2252 & 0.0861 & $0.6946 \mathrm{x}$ \\
\hline & $43 \times \times 185 P$ & 0.1798 & $0.7066 \mathrm{x}$ & 0.1142 \\
\hline & $43 \times \times 132 C$ & -0.0826 & 0.3935 & $0.5290 x$ \\
\hline 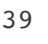 & $60 J g 332 \mathrm{P}$ & $0.5564 \mathrm{x}$ & 0.2639 & 0.3064 \\
\hline & $51 \mathrm{TvM} 32 \mathrm{C}$ & 0.1817 & $0.7115 x$ & 0.1906 \\
\hline & $56 t \operatorname{lp} 32 \mathrm{M}$ & $0.5630 x$ & 0.2747 & 0.4232 \\
\hline 42 & $56 t \operatorname{lp} 32 \mathrm{C}$ & 0.2844 & $0.5704 \mathrm{x}$ & 0.0811 \\
\hline & $46 \operatorname{Lm} 932 \mathrm{P}$ & $0.5722 \mathrm{x}$ & 0.4787 & 0.1469 \\
\hline 44 & $54 \mathrm{QQ} 736 \mathrm{M}$ & 0.3036 & 0.4008 & $0.6410 \mathrm{x}$ \\
\hline & $61 \operatorname{Er} 332 \mathrm{C}$ & 0.0159 & $0.3704 x$ & 0.3155 \\
\hline & 63МKT57C & $0.6096 x$ & 0.1724 & 0.1650 \\
\hline & $64 \mathrm{Gn} 576 \mathrm{C}$ & $0.5680 x$ & 0.3168 & 0.4108 \\
\hline & & 22 & 17 & 11 \\
\hline
\end{tabular}

\subsection{4d Performing the final Q-analysis}

As alluded to in the previous paragraph, the flagged Q sorts in the table above form the basis for the final and necessary step to complete the analysis of Q sorts collected (Schmolck, 2014a). With the press of a button, PQMethod generated an output of tables that provides structure to the factor interpretation. Some have been reproduced in this chapter already and the rest can be found in Appendices 7 to 19. 


\subsection{4e Undertaking the factor interpretation}

McKeown and Thomas (2013) have described factor interpretation as "the most challenging stage" (p. 33) in the Q methodology process, and there is no disagreement with this description. But the difficulty, as Watts and Stenner (2012) have pointed out, is that "there is material to be found... that tells us [the] what and $\boldsymbol{w} \boldsymbol{w} \boldsymbol{y}$... but there is very little that tells anyone how...” (pp. 147-148, emphasis added). Rather unhelpfully, Brown (1980) has pointed out that there "is no set strategy" (p. 247) to interpreting Q-results as it "depends... foremost on what the investigator is trying to accomplish". Philosophically, it is a nod to Stephenson's aversion to "the atomistic" (Watts \& Stenner, 2012, p. 149) approaches to data interpretation and his strong preference for upholding "the holistic nature" (p. 148) of factor analysis. Such flexibility may be welcome for those who have leanings toward the interpretive, but it offers little comfort for those who seek and need certainty. Q-theorists agree the "whole viewpoint" (p. 149) is the point of interest, but there is very little to support how to interpret for the 'whole viewpoint'.

Brown (1980) has suggested starting with statements characterising a factor (p. 24). McKeown and Thomas (2013) advised the same: once the significant factor loadings have been noted, "attending to the factor scores of Q sample items characterising the factor" ( $\mathrm{p}$. 26) would be a useful first step in the factor interpretation. Both Brown (1980) and McKeown and Thomas (2013) began with the distinguishing statements on a factor-byfactor basis. Simon Nash (2007) chose the same starting point in his study identifying the influence of subjective perspectives on planning and decision-making in a local government setting. He paid particular attention to those items identified as distinguishing statements, but his approach differed in that he began with comparisons across his three factors.

Webler et al. (2009) took another approach. They looked at the high- and low-ranking statements for each factor and then focused on the distinguishing statements, especially those that are "significantly different among the factors" (p. 33). They concentrated on certain groups of items within a factor and then distinguishing statements within a factor then across factors. Eefje Cuppen and her colleagues, Sylvia Breukers, Matthijs Hisschemöller and Emmy Bergsma, (2010) reported using the same process for their study on stakeholder dialogue on energy options from biomass in the Netherlands. They also started with the highest and lowest scores for each factor array and then looked at the distinguishing statements "between one factor and the other factors" (p. 582). It is an 
approach that Cuppen et al. also labelled as "typical" (p. 582). Watts and Stenner (2005) chose the same starting point as Weber et al. (2009) and Cuppen et al. (2010) that is, "at the two poles of a factor configuration" (Watts \& Stenner, 2005, p. 82), but then extended their focus to include "the supposedly 'neutral' area" of the factor array (p. 84). In their view, ignoring this zone is an invitation to "fail [in capturing] the subtleties of the viewpoint being expressed" (p. 84) and warned against focusing on "two few of the items in the array" (p. 84). Whether Watts and Stenner incorporate comparisons across factors is not apparent, but what these examples do illustrate is that a second starting point in factor interpretation is items sitting at the extreme ends of the continuum.

A development worth noting is Watts and Stenner's (2012) 'crib sheet'. They had recognised that "getting to grips with the whole item configuration is no easy task" ( $\mathrm{p}$. 149), and their response was "a simple system for delivering sound and holistic" (p. 150) factor interpretation. A detailed explanation can be found in their book but for now, it is enough to note that the output is a 'crib sheet' that lists the items ranked at +5 , those ranked higher in the factor array than in other factor arrays, those ranked lower in the factor array than in other factor arrays and items ranked at -5 . This 'crib sheet' is, in effect, a checklist to ensure each of the items is properly considered. Watts and Stenner make no claim to the 'crib sheet' being "perfect... [or] the only correct way to proceed" (p. 150) but feedback they have received has indicated it as "a very helpful way to start" (p. 150). Toni Sheed's (2014) use of the 'crib sheet' in her examination of Māori political agency is one such example.

Regardless of where one starts, it was well understood that factor interpretation is not a linear process. McKeown and Thomas's (1988) recollection noted the process as "cumulative... increas[ing] as one continuously engages" (p. 33) in the analysis. Watts and Stenner (2005) noted the recurring activity in "the production of a series of summarising accounts” (p. 82). Cuppen et al. (2010) acknowledged the factor interpretation of their Q study was "not straightforward" (p. 583) and highlighted that it was necessarily "iterative... [and an approach of] going back and forth" between their factor arrays and post Q-sort interview data. Nash (2007) reported repeatedly checking his factor interpretations for consistency against his interview material (p. 107). No one has suggested that factor interpretation is anything other than a circular engagement with the Q-results, and it was a situation that was borne out in this study, too.

All of these approaches were tried but none provided the foothold needed to gain 
sufficient traction towards a coherent narrative for each factor. Watts and Stenner's (2012) 'crib sheet', for example, and the way it systematised the interpretation process had strong appeal, and steps were made to maximise its use. However, early starts revealed that it was 'too atomistic' for the purposes of this study and did not lend itself to accommodating the intensity of feeling expressed by the participants in their post Q sort interviewsparticularly the rejection around Item 11. Looking at items at the extreme ends and especially the distinguishing statements provided glimpses into the features of each factor array, but not in a way that could adequately address a solution characterised by factor correlations so high as to potentially warrant correction (Brown, 2011).

The interpretation work then moved to each factor array and entailed looking first at the items at the 'Strongly Agree' end of the continuum with a particular focus on the distinguishing statements in that zone, while drawing in the contributions of the items in the immediate environs. Where evident, the interpretation work then incorporated contrasts in item placement and participant responses at the 'Strongly Disagree' end of the Q-sort tableau. It also involved comparisons with corresponding item ranks in other factor arrays. Where distinguishing items were not accounted for, the same process was applied at the 'Strongly Disagree' end of the continuum. At Watts and Stenner's (2005) urging, attention was also paid to those items in "the supposedly 'neutral' area" (p. 84) of the factor array. For this study, this zone was labelled as 'Ambivalent' although that did always mean that $\mathrm{Q}$ sorters felt ambivalent about an item. Interpreting this ambivalent zone depended in part on the placement of distinguishing items, the contribution of items surrounding them and, most especially, the responses from the participants.

A final note.

The process outlined in this chapter is presented as if it happened in a linear, straightdown-the-line fashion. That was not the case at all. What is documented here is the factor analysis that forms the basis for the factor reconstructions presented in the next chapter. Only those diversions relevant to the final analysis and factor interpretation have been included in this chapter. There were many excursions usually prompted by 'I wonder what would happen if...?'. If - perseverance had prevailed with the 'crib' sheet rather than being guided by participant responses. If - a certain Q sort was re-flagged as Factor 1 instead of confounded. If - centroid analysis with varimax rotations had been deployed, or principal components analysis with judgemental rotation. If - four factors or five factors or two had been extracted instead of three. It is also very possible that these side-trips have actually 
shaped the course of action actually taken. Those possibilities are noted.

\subsection{Other considerations}

To recap, this study has used Q methodology to identify the perspectives of 'community' amongst 'civic leaders' in Taranaki. With the Q sort and the way it looks for correlations as its defining features, and as a system of inquiry underpinned by communicability and a theory of concourse, Q methodology supports the study of subjectivity in an objective way. The actual work undertaken has resulted in 45 statements extracted from 27 interviews with 29 informants and then 47 Q sorts conducted with 35 participants. The sorting instruction put to the $\mathrm{Q}$ sorters was:

For the context of [insert topic description] and for your role as [insert their confirmed role], what do you understand 'community' to be?

There are aspects of this study that have had a significant impact on the results and their interpretation. The following paragraphs provide further elaboration of the limitations, opportunities and learnings that will have a bearing on how the results may be received, particularly as it relates to Q methodology.

\subsubsection{The inherent place-based-ness}

Being a place-based study is a key limitation. The research was situated in the Taranaki region, and consequently, the topics that were identified and selected to frame the conversations with the informants and participants were also place-centric. In turn, the informants and participants were themselves selected and recruited on the basis of their roles and involvement in the topic issues selected, and by virtue of these roles were known to have an observable and vested interest in their respective 'community governance' settings that were tied to place.

With hindsight, it may have been useful to have recruited those that Hambleton (2015) has referred to as "place-less actors" (p. 167); that is, those who have no direct investment in what Ted Relph (1976) has described as "experiencing, creating, and maintaining significant place" (p. 6), but may still have a significant influence on the decisions made in one or more of the topic contexts. Hambleton (2015) has been more direct in that the place-less 
actor is someone who is "not expected to care about the consequences of their decisions for particular places" (p. 167). Such potential participants were never considered as a possible source for the sub-concourse or for the Q sorts, in part because Relph's (2008) conception of 'placelessness' is made manifest in "uniformity, standardisation and disconnection from context" (p. 312). Just as Collins (2010) and Barraket (2004) had concerns about the homogenising effects of 'community' in policy discourses, there was no desire in this study to consider anything other than the lived and vested understanding of 'community', and that meant excluding those whose roles did not 'place' them in the 'community governance' topic. Their exclusion is noted.

Further to the study being place-based, so too was, and is, the researcher. Described as an “embedded participant” (J. Hutchings, personal communication, February 9, 2012), the researcher lives and works in Taranaki and is involved in 'community governance' initiatives. The researcher's position drew on all the characteristics and dynamics of being an insider-researcher (Costley, Elliot \& Gibbs, 2010, p. 3), like having access to participants, contexts and information, managing conflicts of interest, as well as having opportunity to make changes to real-time practice. It also lent itself to acknowledging other biases and beliefs upfront, such as preferring that local decisions ought to be made as close as possible to those affected, and accepting that people do not arrive to their roles as 'blank slates'.

Furthermore, most of the informants and participants were already known to the researcher with many of them deemed to be colleagues. Added to the mix was that the preexisting relationships meant that there was a risk of response bias. However, the risk was as applicable to the 17 cold-call recruitments as it was to long-time colleagues. On the occasions where it did occur, the mitigation tactic was to deal with it in the way that Andrea Fontana and James Frey (2005) advised; that is, by emphasising that it was the informant's or the participant's opinion that was being sought (p. 713) and not the researcher's approval.

That researcher bias was anticipated was one reason for choosing Q methodology because there "are always at least two subjectivities present" (Barker, 2008, p. 918, emphasis added); one being the participant's and the other being the researcher's. Q methodology puts distance between the researcher and participant through its quantitative elements. With the Q sort, researchers can "remain true" (p. 918) to their participants' views "without imposing [their own] subjectivity" (p. 918). Accuracy with data entry aside, the initial stages of the factor analysis require no input from the researcher. While judgemental 
rotations do require researcher judgement, interpretation of the selected solution "is very thoroughly constrained by the structure of the factor array... [making] it very difficult to wander" (Watts \& Stenner, 2012, p. 163) off track. The combination of these quantitative elements reduces the value-laden, embedded participant researcher to a constant that characterises any other mixed methods study.

There are two suggestions for addressing this 'place' issue. One is to do the study again but in another region, or even a different place setting like a neighbourhood, a suburb or a city. With Q methodology, the research would identify the commonalities and differences in their perspectives of 'community'. It would be interesting to use the $\mathrm{Q}$ sample of this study, but it makes more sense to extract a sub-concourse from the contexts in which the next set of informants and participants operate.

The second suggestion would be to recruit those who participate or contribute to decisions in Taranaki (or the neighbourhood, suburb or city of another research project), but have no vested interests or personal ties there. That is, undertake a $\mathrm{Q}$ study of the perspectives of 'community' held by the 'placeless' informant and participant. The narratives that will emerge from either of the suggested studies will on their own identify commonalities and differences, but they will also support a comparative analysis that may offer insights pertinent to a more general discussion of 'community'. Further value may arise by identifying what it would take to ensure place-based public policies and initiatives are successful.

\subsubsection{The methodological struggles}

There is a methodological struggle that sits outside this study that needs to be noted. Not because this study can do anything about them, but the perceptions of other researchers, whether they be Q-methodologists or not, will have a bearing on how this study is perceived and received. Q methodology has been around for 80 years (Ramlo, 2015), but it has struggled for general recognition and acceptance as a valid system of research methods (Brown, 1980, 1993; Brown et al., 2008; Capdevila \& Lazard, 2008; Stenner, 2008a, 2008b; Ramlo, 2015; Watts, 2011). There seem to be many reasons and Stenner's (2008a) traverse of the 'camps' identifies some. They are not identified or explained here because nothing of those debates is relevant to this thesis or its application (Brown, 1993, p. 132). That is not to say that the epistemological and ontological assumptions and the theoretical implications are not relevant. There is simply no room to accommodate their detail in this 
thesis.

What will be highlighted here is that Q methodology is reported to have been recently accepted as a mixed method (Ramlo, 2015). As this research has progressed, it became increasingly difficult to grasp why this acceptance took so long. The qualitative datagathering elements were the informant interviews and the post Q-sort interviews with the participants. This study also deployed the quantitative techniques of the Q sort and the factor analysis to capture and analyse the data. Factor analysis is widely regarded as a reliable statistical method to identify the structure of the relationships between factors (StatSoft, Inc, 2011). Factor interpretation was firmly structured by the results of factor analysis, but considerable judgement was needed to give proper and appropriate account of participant responses in order to produce a coherent narrative for each factor. Based on only the research process used in this study, there is no issue at hand; Q methodology is a research system that draws on a mix of quantitative and qualitative techniques to investigate subjectivity.

\subsubsection{The other studies}

The search for other studies into the perspectives of 'community' as understood by 'civic leaders' was fruitless. As the literature review revealed, there are many studies into the concept of 'community' and there is a growing body of work in the fields of 'community governance' and 'civic leadership', but nothing has been found as to what those occupying roles of influence in local decision-making understand by 'community'.

There are many Q-studies within the public policy domain but only a few for the New Zealand context. For example, Nash (2007) has looked into the influence of subjective perspectives on planning and decision-making in a local government setting. Robin Peace, Amanda Wolf, Simon Crack, Iris Hutchinson and Mathea Roorda (2004) investigated the views of Sickness and Invalids Benefit clients. Somewhat related to the notion of 'community' was a Q study by Anna Johnson and Sarah Weller (2007) that assessed the physical aspects of city liveability in Dunedin. Another is the work of Hanna van Dijk, Jane Cramm, Jon van Exel and Anna Nieboer (2014) who examined the "comparative importance of neighbourhood characteristics for ageing in place" (p. 1771). The point being made here is that this study is covering new scholarly ground using a research system that is only just beginning to overcome its reputation as being "neither a 'proper' quantitative nor qualitative approach”. 
There is one research project that it currently underway that aligns closely to this one than any other study. Eo and Kim (2016) presented their initial findings of a Q study investigating stakeholder perceptions of the "local community" in a particular urban setting in Korea at the 32nd Annual Conference for the Scientific Study of Subjectivity held in New Orleans, Louisiana in September 2016. Their preliminary findings identify "distinctive differences" in perspectives. Their presentation confirmed there are some conceptual similarities (and some technical differences) in that inquiry, but there may be future opportunities to share learnings. 


\section{Chapter 4: The empirical data on 'community': the results and interpretation}

This chapter is the factor interpretation and it is presented in five sections. The first is an overview of the three factor solution generated from 47 Q sorts by 35 participants as analysed using PQMethod 2.35. It also outlines the main characteristics of the selected solution. The second section is an analysis and interpretation of the points in common across all three factors. It describes a platform of shared agreement and identifies three baseline elements to an understanding of 'community'. In doing so, it provides context of meaning against which the nuances of each factor can be seen.

The third, fourth and fifth sections are the detailed interpretations for each factor. It describes the points of difference for each factor. Each of these sections closes with a brief account that will form the basis for the discussions in the next chapter.

\subsection{The big picture view of the data}

Once the results of each Q sorts were keyed into PQMethod version 2.35, the data was subjected to principal components analysis (PCA) with a varimax rotation of three factors. The output was a report of 22 results tables for the selected solution and those tables are presented in Appendices 7 to 19. 
Before moving to the factor interpretations, there are a number of factor characteristics to note.

The first is that the three factors extracted can be explained by 38 of the 47 Q sorts. As identified in the next table, there were 18, 15 and 5 defining Q sorts that loaded to Factors 1, 2 and 3 respectively. Seven of the remaining nine Q sorts were confounded, which means that they loaded to more than one factor, and these results have been largely ignored as they are not typically used to reconstruct the factor narratives (Watts \& Stenner, 2012, p. 143). Another two-Q04 and Q35-were manually unflagged for their negative loadings that had been auto-flagged to Factor 1. This unflagging removed their "negative factor weight" (Watts \& Stenner, 2012, p. 133) from the final analysis step in the software to ensure the solution was as "crisp" (A. Wolf, personal communication, February 27, 2018) as possible. As noted in the previous chapter, their negative factor loadings muddy the calculations somewhat.

\section{Table 8: Number of defining $Q$ sorts and percentages of explanatory variance for each factor}

$\begin{array}{lccc}\text { Factor } & \mathbf{1} & \mathbf{2} & \mathbf{3} \\ \text { Defining Q sorts } & 18 & 15 & 5 \\ \text { Explanatory variance } & 22 \% & 17 \% & 11 \%\end{array}$

The second characteristic is in the explanatory variances. Variance here refers to the extent to which one can "explain as much as we can about the relationships that hold between the many Q sorts" (Watts \& Stenner, 2012, p. 98) and, in doing so, identify "any sizeable portions of common and shared meaning" (p. 98). For this study then, the 18 defining Q sorts for Factor 1 share an understanding of 'community' that accounts for $22 \%$ of the variability from amongst all 47 Q sorts. The 15 of the 47 Q sorts that make up Factor 2 have a shared understanding of 'community' to the extent that it accounts for $17 \%$ of the variability in all of the viewpoints, while the five Q sorts loaded to Factor 3 account for $11 \%$. Together, the three factors provide an explanation for $50 \%$ of the variance across all 47 Q sorts.

The third feature that characterises the selected solution is that they are highly correlated. As Table 9 below shows, Factor 1 has a correlation of 0.6261 to Factor 2, and 0.4462 to Factor 3 while Factors 2 and 3 have a correlation of 0.4922 . 
Table 9: Correlations between factors

$\begin{array}{cccc}\text { Factors } & \mathbf{1} & \mathbf{2} & \mathbf{3} \\ 1 & 1.0000 & 0.6261 & 0.4462 \\ 2 & & 1.0000 & 0.4922 \\ 3 & & & 1.0000\end{array}$

In statistical inference, these correlations are unusually high and suggest that the three factors are aspects of the same underlying feature, or what Watts and Stenner (2012) described as "alternative manifestations of a single viewpoint" (p. 141). Their advice would be to reconsider a factor solution if a correlation between factors was more than the significant factor loading which for this study is 0.3846. As all three factor correlations exceed the significant factor loading, accepting Watts and Stenner's threshold would warrant a reconsidered solution. Stephen Wingreen's (2011) suggestion, on the other hand, would be to ask whether "one [factor] would suffice" if the factor correlations reached 0.80. As none of the factor correlations is greater than 0.80 , there was no scholarly need to adopt this course of action.

In a post to the Q-Method listserv, Brown (2011) pointed out that "correlations between factors should ideally be zero", but he has also acknowledged that "departures in either the positive or negative direction" are tolerable. Brown also wrote he "would normally start getting concerned" with factor correlations at $+/-0.30$, and then he went on to advise that he would become more concerned if the factor correlations were 2.5 times the standard error. With a standard error of 0.1491 , the threshold for this study would then be 0.3728 (being 0.1491 multiplied by 2.5). As all three factor correlations exceed this threshold, the selected solution can be tagged as concerning. Furthermore, in that same post, Brown (2011) deemed a correlation of 0.55 as "way too high and something would be done (if possible) to correct this". With one of the three factor correlations sitting beyond upper threshold of 0.55 , the selected solution presented here may not warrant 'corrective action', but there is a still a methodological risk of inadequacy and unreliability in the results.

However, there was a way forward.

Brown (2011) acknowledged that doing something may not be possible because "reality is messier than we would like". To illustrate, he cited a study where two factors were correlated at 0.49 , but there was sufficient differentiation between the factors to proceed. Wingreen (2011) wrote much the same and suggested looking to the nuances that might be found in the distinguishing statements or the post Q-sort interviews. This study certainly 
accepts that reality is 'messy'. Given the research topic is one where there is no agreement on a definition, but there is implicit agreement that the concept is significant and profoundly important, 'messy' is acceptable. With the fluid, dynamic nature and multiplicity of socially constructed notions of 'community', it would have been, and is, unrealistic to expect conveniently low factor correlations. Indeed, the high correlations affirm there is no agreed definition of 'community' as Hillery $(1955,1982)$ concluded, and adds weight to the reason why local government assumes there is sufficient consensus on what is understood by 'community' (Pillora \& McKinlay, 2011). Consequently, the selected solution was retained with an explicit acknowledgement of the commonalities in views and with particular attention paid to the nuances of what the study's participants understand by 'community'. That this study's factor analysis has identified three sides to the same conceptual coin is simply noted and accepted.

The picture thus far is one of three somewhat highly correlated factors that range from 0.4462 to 0.6261 . These correlations are not so high that they represent what Wingreen (2011) would deem to be a single viewpoint, but they are high enough to suggest that the three factors presented here are nuanced points of view of one widely understood conception of 'community'. These three factors account for $50 \%$ of the variability in shared meaning across all 47 Q sorts. Factor 1 is defined by 18 Q sorts while Factors 2 and 3 are defined by 15 and five $\mathrm{Q}$ sorts respectively.

Another point to note is that the influence of a Q-sorter's role is indeterminable. What the next table shows is there could be a line of inquiry for the Q-sorts generated by those occupying community leadership roles given they contributed least to defining Factor 1 and most to defining Factor 2. While there were moments when participants who completed more than one Q sort acknowledged that their views were re-oriented to the requirements of a role, the sample is too small to conclude that one perspective is characteristic of those who occupy a particular leadership domain.

Table 10: Spread of $Q$-sorter roles across each factor

$\begin{array}{lccc}\text { Leadership Domain } & \text { Factor } \mathbf{1} & \text { Factor 2 } & \text { Factor 3 } \\ \text { Community } & 4 & 7 & 2 \\ \text { Managerial } & 8 & 4 & 2 \\ \text { Political } & 6 & 4 & 1 \\ \text { Total } & 18 & 15 & 5\end{array}$


However, the purpose of this study was not to determine the influence of roles, but to identify participant perspectives, or rather their operant subjectivities of 'community'.

\subsection{A platform of shared agreement}

The starting point chosen to help understand the results is the commonalities amongst the viewpoints and subjectivities of the study's participants. What will be described here is the extent to which certain items across each of the three factors establishes a platform for shared agreement in what is understood to be 'community'.

Table 11 below lists the nine consensus statements as produced by PQ Method 2.35, and these are the items over which there is very little disagreement. The truncated statements are listed by item number in ascending order and identify each item's Q-sort value (Q-SV) and $z$-score (Z-SCR) across the three factors. Note that the software produces reports with truncated statements and that format has been retained in this thesis. Refer to Table 4 or Appendix 4.2 for the statements in their full form.

\section{Table 11: Consensus statements}

\begin{tabular}{|c|c|c|c|c|c|c|c|}
\hline \multirow[b]{2}{*}{ Item } & \multirow[b]{2}{*}{ Short Statement } & \multicolumn{2}{|c|}{ Factor 1} & \multicolumn{2}{|c|}{ Factor 2} & \multicolumn{2}{|c|}{ Factor 3} \\
\hline & & Q-Sv & Z-SCR & Q-SV z & $\mathbf{Z}-\mathbf{S C R}$ & Q-SV & Z-SCR \\
\hline $2 *$ & is not just about a group consulting wi 2 & & 0.43 & 1 & 0.35 & 0 & 0.15 \\
\hline 3 * & a key part is contributing as well & & 1.10 & 2 & 0.76 & 2 & 0.95 \\
\hline 8 & Relationships & & 1.68 & 4 & 1.32 & 3 & 1.43 \\
\hline $17 *$ & understanding about the way people wor 17 & & 10.41 & 2 & 0.50 & 1 & 0.15 \\
\hline 19 & a risk mitigation strategy & & $2-1.09$ & -2 & -0.68 & -2 & -0.80 \\
\hline $21 *$ & groups of people engaging in conversat 21 & & $1-0.25$ & 0 & 0.04 & 0 & -0.02 \\
\hline $23 *$ & sit[ting] face-to-face and talk[ing] $t 23$ & & 10.41 & 1 & 0.37 & 0 & 0.13 \\
\hline $29 *$ & you've got to get on with everybody ev 29 & & $1-0.47$ & -1 & -0.23 & -2 & -0.72 \\
\hline $40 *$ & being committed to the place where you 40 & & 30.94 & 3 & 1.06 & 3 & 1.15 \\
\hline
\end{tabular}

As footnoted in the table above, all of the items are non-significant at $p>0.01$ while those marked with a red asterisk $(*)$ are also non-significant at $p>0.05$. The technical explanation for probability value (also known as $p$-value) and the statistical consequences to it can be found elsewhere (Cox, 2006; Lane, 2013; Vickers, 2010), but for now it is enough to know that a $p$-value is an indicator of whether a result was due to chance or due to a true relationship or difference (Kalof \& Dan, 2008, p. 204). 
With non-significance at $p>0.01$ and $p>0.05$ as they apply here, these "two measures of consensus" (Wolf, 2014) allow one to have confidence in the communality of the statements and that the results are not a fluke. The difference between the two measures is that those items identified to be non-significant at $p>0.05$ "indicate an even greater degree of similarity" (Brown, 2014). In other words, there is comfort that all nine statements identified in the table above are items of consensus, and the seven marked with a red asterisk $\left(^{*}\right)$ are especially so.

It was stated earlier that these items are those over which there is little disagreement. The shared agreement is in the ranking of those statements, but those same rankings should be NOT be taken as a "guarantee that [a statement] has the same inter-factor meaning" (Brown, 2014). That said, the high correlations of 0.4462 between Factors 1 and 3, 0.4922 between Factors 2 and 3 and 0.6261 between Factor 1 and 2 do point to a communality in meaning that warrants further consideration. Hence the presentation of the consensus statements first.

The next four sections present an interpretation of themes that build an overall interpretation of the consensus statements derived from the $\mathrm{Q}$ analysis. These themes have been identified as a foundation for understanding the three nuanced perspectives of what is understood to be 'community' in Taranaki.

\subsubsection{What matters most is relationships}

The extent to which Q sorters agree 'Relationships' is central to their understanding of 'community' can be better seen by re-arranging the results table for consensus statements. Table 12 shows their re-sort in descending order of the sum of z-scores across the three factors. Item 8-'Relationships.' sits at the top of the table with Q-sort values of $+4,+4$ and +3 for Factors 1, 2 and 3 respectively. 
Table 12: Consensus statements re-sorted

\begin{tabular}{|c|c|c|c|c|c|c|c|c|}
\hline \multirow[b]{2}{*}{ Item } & \multirow[b]{2}{*}{ Short Statement } & \multicolumn{2}{|c|}{ Factor 1} & \multicolumn{2}{|c|}{ Factor 2} & \multicolumn{2}{|c|}{ Factor 3} & \multirow[b]{2}{*}{$\sum[\mathrm{z}-\mathrm{SCRS})$} \\
\hline & & Q-Sv & z-SCR & Q-Sv & Z-SCR & Q-Sv & z-SCR & \\
\hline 8 & Relationships. & 4 & 1.68 & 4 & 1.32 & 3 & 1.43 & 4.43 \\
\hline 3 * & * a key part is contributing as well 3 & 3 & 1.10 & 2 & 0.76 & 2 & 0.95 & 2.81 \\
\hline 40 * & * being committed to the place where 40 & 3 & 0.94 & 3 & 1.06 & 3 & 1.15 & 2.30 \\
\hline 17 * & * understanding about the way people 17 & 1 & 0.41 & 2 & 0.50 & 1 & 0.15 & 1.06 \\
\hline 2 * & * is not just about a group consulti 2 & 1 & 0.43 & 1 & 0.35 & 0 & 0.15 & 0.93 \\
\hline 23 * & * sit[ting] face-to-face and talk[in 23 & 1 & 0.41 & 1 & 0.37 & 0 & 0.13 & 0.91 \\
\hline 21 * & * groups of people engaging in conve 21 & $1-1$ & -0.25 & 0 & 0.04 & 0 & -0.02 & -0.23 \\
\hline 29 * & * you've got to get on with everybod 29 & $9-1$ & -0.47 & -1 & -0.23 & -2 & -0.72 & -1.42 \\
\hline 19 & a risk mitigation strategy & -2 & -1.09 & -2 & -0.68 & -2 & -0.80 & -2.57 \\
\hline
\end{tabular}

That Item 8 ranks so high across all three factors is not a surprise. When the source informant was asked the question 'what do you understand "community" to be?', there was no hesitation in his response: "Relationships" (236Bz11M). And he said it again: "Relationships." He then went on to explain how his work revolved entirely around his relationships with his governing body, with the volunteers he works with, and with the stakeholders who help make their initiative a success. Others said much the same. Some tied the success of projects they were involved in to 'Relationships'. One participant went so far as to identify it as the reason "why we're strong and... why we're achieving" (Q10 $366 \mathrm{Bz} 11 \mathrm{M})$ and two others referred specifically to the good working relationships with local authorities (Q12 35EMu32C, Q11 37ZGS11C) as contributors for project success.

When explaining what 'Relationships' looked like in practice, it was all about one's relational skills and ability to work with others. An elected member spoke about making sure "people can ring you or come and see you and ask you things; and vice versa" (Q19 33STg11P). For the rurally isolated, knowing your neighbours counted as "absolutely important and necessary... especially for health and safety reasons and for security reasons" (Q25 45PQo19P). For a policy advisor, her work is "always about building relationships of trust and it's always about listening" (Q18 52w4y85M) and one way to do that was by "not putting your own world view in as an overlay onto anything you do". While noting that "Relationships' require a lot of effort, the study's informants and participants also acknowledged, that they can be "challenging" (Q23 30KjD56P). There may, for example, need to be "a setting aside of personal values" especially when making 
decisions against the framework of the Resource Management Act 1993.

Added weight to the importance of Item 8's 'Relationships' is provided by Items 17, 2, 23 , 21, 29 and even 19. Item 17-'Community is understanding about the way people work' was seen as crucial to "finding a way to get people on board. Getting people involved. Making it possible for them to work. Providing an enabling environment" (Q37 43xx185P). There was a similar sentiment from a participant whose role in projects is to "help people and support people and bring people together and do... stuff” (Q08 38Wdg76M). But it is not just about facilitating action. It can also be the task of raising awareness to combat disinterest and mitigate the lack of engagement. The need to use the right language was inferred when an informant called for certain entities to stop "talk[ing] in a particular language" (103KjK96C) and making it difficult to understand what is being proposed or considered.

Another layer to this relationship-centric consensus of 'community' is the annoyance triggered by Item 2. It read as, 'But community is not just about consulting with a group of people to get some answers!'. The objection was to the one-way nature of consultation where the term 'community' framed the process to seek feedback on a policy proposal. The most vivid response was the disappointment felt by a political appointment to a working group. His annoyance was not with not consulting with communities but with how a named public service department "did more community consultation than you can imagine" (Q39 60Jg552P) and "got mountains of information"; and nothing came of it. "Nothing!".

Reflecting on Item 23, one manager identified 'face to face' as "crucial with [our] community [and] it's important in my role" (Q10 366Bz11M). He added that the trustees for the entity he works for had made a conscious decision to "ensuring we give [face to face as a mode of communicating] a high priority". Another participant in the same decision-making setting pointed out that while they do use email, his view was that "the bulk transfer of information is too impersonal [and] you don't get the results you're looking for" (Q11 37ZGS11C). In his experience, a phone call or a signed letter has "a far better impact than an email", but "dealing with people, looking them in the eye... gets us a lot further".

The importance assigned to face-to-face interaction is also conveyed in the Māori cultural concept of "kanohi ki te kanohi" (Q15 39OIQ96P) which translates to "face to 
face' (Moorfield, 2003a). For one elected member, kanohi ki te kanohi underpinned his interactions with people.

So far, what 'Relationships' look like in practice it is primarily face-to-face where there is meaningful engagement for those involved and there is a purposeful outcome. Face to face is the preferred mode of engagement whether it is to share information, gain support or seek feedback. The relational skills required are listening, and more listening along with using the right language and being able to set aside one's own beliefs. But reading between the lines, 'Relationships' also means being accessible, available and present.

\subsubsection{What matters even more is 'Relationships'}

The theme of 'Relationships' is also reiterated by Item 21—'But community's about groups of people engaging in conversation and civilised behaviour really'. It was tagged with Qsort values of $-1,0$ and 0 for Factors 1, 2 and 3.

There was a range of responses from participants, but with a surprising focus on the word 'civilised'. Responding from context where court action is an oft-mentioned event in the setting's history, one Q sorter laughed: “The community engaging in civilised behaviour? Really?" (Q22 30kjD85C). Another, who was speaking with the same setting in mind, was more forthright and explained how certain words cause her to "flip them" (Q03 31FqZ85C). She continued: "When I see 'civilised', what I really see is 'uncivilised":

Uncivilised behaviour. I think I'm commenting more about how we tried to define what a community is. That to be a community you need to be a group of civilised human beings... [and] be able to function. [But] sometimes I think, 'Who defines what civilised behaviour is?'Sometimes you need to be the mongrel to get anything done but that could be seen as 'Well that's uncivilised behaviour', 'That's aggressive', [or] 'That's everything what we don't like'. [Behaviour that is] so direct it almost comes across as being aggressive and challenging and threatening. (Q03 31FqZ85C)

If Item 21 were a conversation piece amongst the study's participants, another would have countered with the assertion that "every community needs to have some ground rules" (Q13 41DWX96P). No one would disagree. Ground rules may be helpful when engaging with one another, but what those rules look like and how they are agreed appears to be another matter. Engaging with one another in a 'civilised' manner may be preferred 
and certainly conducive to getting stuff done. But as one participant pointed out:

\section{It's not always civilised. And it doesn't have to be. Just because you're part of a community, doesn't mean it always have to be civilised. (Q25 45PQo19P)}

What exactly was actually meant by 'civilised' was not explored with these participants. Whatever 'civilised' is seems to be highly desirable, but it is not a pre-requisite to the way they practise 'community'. Observations of the study's participants are that most do conduct themselves in ways that reflect favourably in the local print media. But in no way would any of them avoid challenging others on important issues even if there are consequences. For example, two participants are known to have been formally censured by a representative body. A third seems to be quite comfortable with being off-side with his neighbours. A number of the informants are regarded as activists in their fields of interest and one of them spoke of a persecution - "a nastiness that happens" (01jBV36C) - to the point where his family would "get frightened" for his wellbeing. Two others have faced legal action as a consequence of their environmental activism.

What is indicated here is that 'civilised' is about the way one behaves with others, and this was a point emphasised by the source informant to Item 21. Her expectation was that those in roles of influence in decision-making settings ought "to behave as slightly civilised" (03xhv96C). She and her co-informant provided a number of examples that illustrated what they saw as a less-than-expected level of civility. The source went on to describe a situation where they were part of a delegation and:

\section{[They] sat us down like snotty children... behind them. They didn't open the meeting and say 'come and sit so that you can hear the conversation'. They didn't acknowledge us. They discussed the issue. They dismissed it. And that was it. Then they turned to us like 'well, get out' and they moved on [to the next agenda item]. $(03 \times h v 96 C)$}

Of another public forum, the informant described how their local representatives "don't get up to welcome us" (03xhv96C). She did name a councillor who "sometimes does" and then pointed out that "none of the others do". She, again, identified the lack of acknowledgement and a sense of "you can see them sitting there going 'Argh! Here they are again"'. Her expectations were likened to what happens in her home and work settings where "If someone goes to your house, you welcome them. People come in here and we're polite to them". Her expectations of the councillors were clearly stated as well: 
You know, they would have leapt to their feet every time we turn up in Council and go, 'on behalf of the Council, I'd like to personally welcome you here today' and 'it's great to see people from our area, representing our community' and saying we are key stakeholders. It would be really great because that's what they should do but they rarely do. $(03 x h v 96 C)$

For the source informant, 'civilised' means being respectful of, and towards, others whether it is greeting one another, or acknowledging the protestations to a policy proposal. One participant had a personal standard where he "will always turn up in a tie and a suit" (Q13 41DWX96P) as a sign of respect for those he represents. He went on to explain:

\begin{abstract}
Yep-I'm a councillor 24/7 and it's hard to distinguish when I'm out as [named me], you know, '[Named Me] the Nobody'. You can't write yourself off because you're having a good time with your mates or your family. You are still '[Named Me] the Councillor' and people see you as [that]. I think they appreciate the fact that you have a life and a family and you have to live. But they still expect a certain amount of decorum from you. Well that's my perception. (Q13 41DWX96P)
\end{abstract}

Nor was being civilised necessarily about "happy days" (Q18 52w4y85M) as one participant put it. She went on to clarify that "you can still have communities that fight amongst themselves but they still know they're communities. So it's not necessarily about happiness". But it does require respect for those views.

Another buttress to the primacy of 'Relationships' was the responses to Item 29. This statement read as 'Community is a hard thing to do because people come and go, but you've got to get on with everybody even if you don't like them', and the analysis tagged it with Q-sort values of -1, -1, and -2 for Factors 1, 2 and 3 respectively. These factor array rankings indicate a shared disagreement amongst the study's participants to the statement but their responses provided further nuance. On one hand, participants agreed wholeheartedly with the first half of the statement-'community is a hard thing to do because people come and go'. For example, one Q sorter exclaimed, “Oh I strongly agree with that!" (Q46 63MKT57C), and another declared, "Ain't that the truth!” (Q32 53cGV19P). Two others simply noted, "I wouldn't disagree" (Q06 28aFZ19M) and "I agree with that" (Q05 29jBV36C).

On the other hand, the response to the second half of the statement- 'but you've got to get on with everybody even if you don't like them'-was shared disagreement. For 
example, a participant who occupies a senior management role pointed out, “... you don't have to get on with everybody... [and] you don't have to agree with everybody" (Q24 $55 \mathrm{Ttx} 85 \mathrm{M})$. He went on to explain that in certain circumstances "you can decide 'I've had enough. I'm opting out. I'm going to form another community with this group over here."'

Another example came from an elected member who was considering his options because it was not a matter of whether he could work with others, but whether others could 'get on' with him. As he went on to explain, "You know this bloody [named event]? I'd like to support it in any way I can. The unfortunate thing is that [named person] may wish me to support it by not actually being part of it" (Q32 53cGV19P). It was a curious reflection of the situation.

Interestingly, while both responses illustrate shared disagreement-that is, they disagreed with having to 'get on' or 'agree' with everybody — the latter rank-ordered Item 29 at +4 and the former at +3 . Such rankings suggest the opposite - that is, they agreed one should 'get on' or 'agree' with everybody. However, the former participant's explanation was in his experience that 'community is a hard thing to do' (Q24 55Ttx85M). He went on to say that "nothing ever stays the same. A new element can come in to a community and completely change its entire dynamic [and] drive people away".

The latter participant identified the "contradiction" (Q32 53cGV19P) in supporting an event by not being part of its organisation, but what he was agreeing with was the first part of the statement; that is, 'community is a hard thing to do'. A third participant, who had assigned Item 29 with a Q-sort value of -2, spoke about his effort "to get to know [his colleagues] better" (Q17 47oyq11M) and then remarked, “I still don't like them”. He also recognised that 'community' is "hard because... it's multi-faceted and different people are different".

Two participants gave the impression that they do not find 'community' to be 'a hard thing to do' at all but, like the others, expressed disagreement with having to 'get on' with others. One was an environment commissioner who identified that the decision-making process prescribed through the Resource Management Act 1993 removes any need "to get on with everybody" (Q23 30KjD56P). In her assessment of the requirements of her role, "You just have to consider the effects [of the proposed initiative on the environment]". Having rankordered Item 29 at -4 , she went on to explain that the legislative process was one "where you can disagree and still live next door to each other". The other has been a long-time 
resident who is very involved where she lives, who also rank-ordered Item 29 at -2, and simply pointed out, "YYou] don't really need to get along with them all” (Q06 28aFZ19M).

There was one participant who agreed with both ideas in Item 29. After setting the statement down at +3 , an elected member responding to a topic where rural isolation characterises a certain decision-making setting identified a different approach was required. As she explained:

\begin{abstract}
You might not necessarily like your new neighbour very much but you have to get on with them. Because of the geographical isolation and because of the co-dependency-as far as the health and safety stuff and that-it's in your best interest to like your neighbour. To get on with them even if you don't like them. I mean if I don't like my neighbour here in [named town], it doesn't really matter. It matters hugely in an isolated community like that. (Q25 45PQo19P)
\end{abstract}

This last response is also consistent with the source informant's view. He and his family have lived in rural isolation most of their lives, and the latter spoke at length about how “you've gotta go out of your way to get on with your neighbour up here" (17e9y19C). He acknowledged "you'll upset your neighbours... without trying" but he advised "you just try and let things go as much as you can".

With all of this in mind, there are two angles to Item 29's interpretation as a consensus statement. The Q-sort values of $-1,-1$ and -2 indicate a shared disagreement amongst the study's participants and that disagreement has been presumed to apply to both parts of Item 29; that is, 'no, community is [not] a hard thing to do because people come and go', and 'no, we [don't $]$ have to get on with everyone'. But the responses from participants point to a plausible alternate reading which is, 'yes, community is a hard thing to do', and 'no, we don't have to get on with everyone'. There is certainly shared disagreement among the participants on the second part of Item 29 as it relates to having 'to get on' with everyone, but there are also differences of views as to whether 'community' is a 'hard thing to do' or not.

This last mentioned point of not having 'to get on' with everyone in Item 29 is also consistent with the responses to Item 21 where being part of a 'community' is not always 'civilised'. One does not need to 'get on' with everyone to be prepared to challenge others on important issues, but it ought to be done in a respectful manner. Being 'civilised' does not mean avoiding conflict but it does require 'engaging in conversation'. Nor does one 
need 'to get on with everybody' in order to get stuff done, but there is an expectation that the way participants and informants conduct themselves is respectful and engaging. It is an intricate and dynamic mix of behaviours and conduct that are not in themselves representative of a concept of 'community', but a practice of 'community'.

\subsubsection{There is an expectation of contribution}

The item that sets the tone for the second theme is Item 3 which says, 'I would say that a key part of community is contributing as well'. This explicit expectation of contribution became more apparent as the informant interviews progressed, and the Q-sort values of +3 , +2 and +2 for Factors 1, 2 and 3 respectively and responses support its lived significance to participants.

That Item 3 featured highly as a statistical result was not unexpected. Participants and informants alike spoke about contribution as the motivation and reason why they get involved in their respective decision-making settings in the way they do. For example, one participant identified contribution as a personal driver for his involvement in local body politics. He had described himself as someone who used to "get into a bit of mischief" (Q29 59soV96P), and now wants to "put back into society what I took out years ago".

Another spoke about the "responsibility to step up and do what you can, [and] use your talents" (Q08 38Wdg76M). For a third participant, it has been (and still is) about "being connected to where you live and saying, 'Well, I'll step up. I'll make a difference"' (Q02 $32 \mathrm{MuE} 76 \mathrm{M}$ ), and a fourth, who has businesses located in two different regions, believes that having a business in a local community requires giving back to the same (Q12 35EMu32C). Yet another is so involved with where he lives that he described with serious light-heartedness how he can locate the important goings-on in his life within a single digit kilometre radius of his home (Q14 41DWX32C).

But there is an added dimension to this view and it is conveyed in the circularity that the last participant made explicit. He said, "I strongly believe you need to contribute... you can't just sit back and take the handouts that a community is offering. You've got to be a part of that. You've got to make the cycle complete" (Q13 41DWX96P). Another said the same and spoke about reciprocity: 'You know, you can't sort of [be] the individual who takes all the time. You're going to run out of [goodwill and] people [will] get sick of you 
basically. You've got to give stuff back, too" (Q24 55Ttx85M).

An informant spoke about how his involvement in certain roles was because "somebody actually asked" (22xWb56P) and he did so "out of a sense of feeling that [he] could contribute something positive and also out of a feeling knowing that [he] would get satisfaction from being involved that way". As alluded to here, the expectations around contribution are also a mechanism to assess, which is better explained by an informant who said:

A club that uses [named sport] as a way of involving people takes active responsibility for making sure that the grounds add value to the wider community, that the profits they generate go towards their own improvement and other things, strikes me as being slightly more a member of the community than a club that just exists for its own purpose [and] only looks outside to draw in resource without giving much back. (18D7K19P)

It is an assessment filter that this informant also applies to her own governance work where she "would question the value... that [she] can contribute in those roles" that she occupies. As one participant explained, "At the end of the day, you've all got to make a contribution... you've got to get involved" (Q38 60Jg332P), no matter how "small" (Q02 $32 \mathrm{MuE} 76 \mathrm{M})$. Not only are these comments pointers to the depth of feelings informants and participants have for where they live, but they are also affirmations that 'a key part of community is contributing as well' as stated in Item 3.

But supporting people to contribute can also be problematic. A Q sorter, whose work revolved around advocacy, recognised contribution is not always important "because some can't" (Q21 40QNG11C). His view was an acknowledgement that not everyone has the means or resource base from which one can make a meaningful contribution to an initiative. As "hugely important" (Q03 31Fqz85M) and highly valued as contribution and participation was for another Q sorter, she identified that there was a challenge in "finding ways in which that participation can happen". She said the same in response to Item 45 , which declares 'The best of our work is over a cup of tea and in [the] kitchen', and for her, "the key is how do we create all those different types of cups of teas, by which people can participate". Both Q sorters recognised capacity and capability to contribute or participate is not a resource that is available to every individual.

Recognising this differentiation in capacity and capability suggested that one's contribution 
has a direct bearing on the levels of participation from others. For example, a participant described how their group had found email broadcasts to members "too impersonal" (Q11 37ZGS11C). He explained how a highly personalised approach to communicate through "a phone call or even just a letter", especially the latter because a "signed and posted letter [has] a far better impact than an email." His commitment to being "face to face, dealing with people, looking them in the eye" because it "gets us a lot further" is a personable approach that works for this group so much so that it is one of their defining characteristics.

As a cluster of consensus statements they also point to 'community' as a practice-a modus operandi-and 'community' as a standard of conduct expected of themselves and of others.

In summary, the second consensus theme is one that revolves around Item 3 and an expectation of contribution. As covered in the next section, there is the implicitness of place as a feature of an understanding of 'community' that is observable in the commitment and contribution one is willing to make to where one lives. This cluster of consensus statements is also the first hint of 'community' as a practice-a modus operandi - and, as a consequence, as a standard of conduct expected of themselves and of others.

\subsubsection{It is all about the place}

The Q-sort values of $+3,+2$ and +2 for Item 3 in Factors 1, 2 and 3 respectively indicate a shared agreement that place is an important component to 'community' as understood by the study's participants.

In the just-described consensus theme of contribution, there is the implicitness of place. 'Place' is as elastic in its connotations because, as Relph (1976) has explained, it draws on various sources of meaning (p. 30). Just like 'community'. Here, in this study, participants rarely made specific reference to the places where they lived, but it has to be noted that the research as a whole is inherently placed-based. As explained in the design section of the methods chapter, the governance settings inferred in the sorting instruction have an element of geographic specificity to them and, consequently, all of the participants occupy roles that are tied to place. Place was a given. 
Yet, even for this characteristic in the research, the descriptions from informants and responses from participants affirmed that stepping up and making a difference is an outworking of "being connected to where you live" (Q31 32MUE32M). There was an example of the $\mathrm{Q}$ sorter whose life events and involvements sit within a single digit kilometre radius of his home (Q14 41DWX32C) and the participant who believes that having a business in a local community requires giving back to the same (Q12 35EMu32C). Given that the factor analysis identified Item 40-'So, I think it's about being committed to the place you live, and saying, 'where I need to, I'll step up and I'll make a difference'-as a point in common amongst the Q-sort participants marks it as a structuring component in the understandings of 'community'. Even though Item 40 has a Q-sort value of +3 across all three factors, there are subtle divergences in the nature of place-based-ness for each factor and these will be identified in later sections. Whatever the degree of those divergences, it does not change the claim being made here that place is an implicit and foundation component to all three perspectives of 'community'.

\subsubsection{Similarities but not necessarily the same}

So far, there are three themes that form the basis for shared agreement around what is understood by 'community'. The cornerstone of these is that 'Relationships' matter and deemed crucial to success whatever that might be. If one were to ask the study's participants and informants to describe what 'Relationships' looked like, they would refer to sitting 'face to face', listening, talking and listening some more. Well-developed relational skills and an attuned capability to work with others will make the difference in one's role as a decision-maker from using the right language and getting people on board with a policy proposal to being able to set aside one's own beliefs and being accessible and present to the concerns of others.

For the study's recruits, 'Relationships' is very much a two-way interaction that also carries with it obligations of reciprocity and consideration. It is certainly not an abstraction of convenience one where a consulting party is simply looking for answers from another. At the same time, participants and informants were under no delusion that 'community' can be hard. Their reactions to Item 21-'But community's about groups of people engaging in conversation and civilised behaviour really' are particularly illustrative of this awareness. In no way does being civilised equate to avoiding conflict and disagreement with others, but it does require a preparedness to engage in conversation. Nor does one need 'to get on with everybody' in order to get stuff done, but there is an expectation that participants and 
informants conduct themselves in a way that is engaging and respectful.

That 'Relationships' matter is hardly a surprise. Its importance is something that all of the participants and informants would endorse, but for different reasons. As will be seen in later sections, 'Relationships' from a Factor 1 perspective is one of mutual familiarity and trust that supports social interaction and builds social cohesion. The objective would be to ensure that a policy position or response is properly informed, which in turn would assure the represented view is clear and coherent as well as widely shared and understood.

A Factor 2 approach has similar objectives, but the commitment is all about getting stuff done. The social interaction is the means to an end. The pragmatism required is backed by a willingness to set aside one's own viewpoint or mediate multiple viewpoints to achieve a given outcome. It is a subtle difference.

For Factor 3, long-term, durable relationships are a priority outcome in, and of, themselves. The nature of 'Relationships' has a broader reach. On a conscious level, they extend beyond the demands of agreed action in Factor 2, or the functional needs of social interaction in Factor 1. For Factor 3, 'Relationships' are an integration of connections in the layers across time, between generations, and with the natural and spiritual environment.

The second theme to 'community' is in a very real expectation of contribution for both informants and participants. The weight of expectation was identified by the placement of Item 3-'I would say that a key part of community is contributing as well'-as the second top-ranking consensus statement in a list of nine. Its manifestation showed up in the way participants and informants spoke about their willingness to commit and invest themselves in their localities to matters that interest or concern them. Indeed, the responses from participants affirmed that contribution, in particular, is a strong expectation they have of themselves and, because of its circularity and the nature of reciprocity, something to be expected of others.

Inherent in all of this is that 'community' is place-based and that was reflected in the known commitments to where the study's recruits live, and lived, and their involvements in a range of highly localised initiatives. That 'community' is place-based is undeniable. But as will be seen later, the subtleties between the factors is particularly distinctive for Factor 3 . With Factor 2, place is somewhat more impersonally considered as a locality or the backdrop for a policy proposal much like a set of co-ordinates might help locate a lost 
tramper. With Factor 1, place is so much a part of the context for an issue as to trigger the deployment of place-protection strategies and tactics. For Factor 3 though, place cannot be held apart or separated out from any policy discussions; it is a foundational consideration for the a decision.

Thus far, the consensus elements of 'community' lies in primacy of relationships and the expectations to contributing to where one lives; and that 'community' is ultimately placebased. These three points of commonality as captured in Items 8, 3 and 40 establish a platform for shared agreement in what is understood in 'community'; at least, amongst this study's participants. But as has been alluded, each element of shared agreement does not necessarily translate to having the same meanings in each factor.

The interpretation of the consensus statements also provides a glimpse at 'community' as a manifestation of conduct that is not in itself representative of a conception of 'community', but of a practice of 'community'. It is the practice or enactment of 'community' that constitutes what the study's informants and participants understand by 'community'. That the conception is construed as practice is a matter for further discussion in Chapter 6, but it will become more apparent in the next three sections describing the nuanced perspectives of each factor. It will also become more clear that consensus themes of relationships, contribution, place and risk have slightly different emphases that distinguish each factor from the other.

\subsection{The Factor 1 perspective}

Eighteen of the 47 Q sorts loaded to Factor 1. A standard error of 0.166 for differences within the factor indicates that there is little variation amongst these $18 \mathrm{Q}$ sorts. Of these 18, six were $\mathrm{Q}$ sorts produced by participants with roles from the political leadership domain, another eight were in roles in the managerial leadership domain and four were by Q sorters occupying community leadership roles.

\subsection{1 'Community' is everyone, of course!}

Of course, it is. How obvious is that!

The top ranked statement in Factor 1 was Item 44, which reads as, 'But to me it's that 
everybody's somebody and everyone's important. No one's more important than anyone else, we're all just important'. With a Q-sort value of +5 that is markedly different from the +1 and 0 assigned to Item 44 in Factors 2 and 3 respectively, the result identifies that there is a depth of feeling attached to Item 44 evident in Factor 1 that is not observable in Factors 2 and 3. Indeed, it is Item 44 that really sets Factor 1 apart from Factor 2. This difference was also reflected in the post Q-sort interview responses where an intensity to this belief that was heard over and over again from participants. For example, one Q sorter elected to his role pointed out, “it doesn't matter if you're the Prime Minister or the street kid who sleeps in the park... they should all be treated the same" (Q19 33STg11P). Another elected member shared the same sentiment with "if it's a guy collecting rubbish and a lawyer, they're the same to me" (Q29 59soV96P). These two responses matched the views of the source informant $(27 \mathrm{xhn} 96 \mathrm{P})$ for this item. While he recognised that there were many groups differentiated by interests like sports, regions or ethnicities, he was adamant that “everybody's somebody and everyone's important. No one's more important than anyone else. We're just all important".

Not only was Item 44 the top-ranked statement but the factor analysis also identified it as a distinguishing statement. This item, along with all of the other distinguishing statements for Factor 1, have been highlighted in yellow in Table 13. Those distinguishing statements with a significance of $p<0.1$ have also been marked with an asterisk in red and this state also applies to Item 44. A significance of $p<0.1$ is statistical comfort in their reliability as sign-posts for reconstructing this Factor 1 narrative. With Item 44 tagged as both a distinguishing statement and a top-ranked one, it is the starting point for reconstructing the narrative for this factor.

Table 13: Q-sort values and z-scores by factor, sorted in descending order for Factor 1

\begin{tabular}{|c|c|c|c|c|c|c|c|c|}
\hline \multirow[b]{2}{*}{ Item } & \multirow[b]{2}{*}{ Short Statement } & \multirow[b]{2}{*}{ Item } & \multicolumn{2}{|c|}{ Factor 1} & \multicolumn{2}{|c|}{ Factor 2} & \multicolumn{2}{|c|}{ Factor 3} \\
\hline & & & Q-SV & Z-SCR & Q-SV & Z Z-SCR & Q-SV & Z-SCR \\
\hline 44 & everyone's important & 44 & 5 & $1.773 *$ & 1 & 0.381 & 0 & 0.003 \\
\hline 8 & Relationships. & 8 & 4 & 1.678 & 4 & 1.317 & 3 & 1.427 \\
\hline 20 & Everyone. & 20 & 4 & $1.439 *$ & -2 & -1.148 & -1 & -0.489 \\
\hline 3 & a key part is contributing as well & 3 & 3 & 1.101 & 2 & 0.764 & 2 & 0.951 \\
\hline 15 & everybody gets an opportunity to hav & 15 & 3 & $1.094 *$ & 1 & 0.330 & -1 & -0.242 \\
\hline 40 & being committed to the place & 40 & 3 & 0.941 & 3 & 1.059 & 3 & 1.153 \\
\hline 18 & everybody who lives in that area & 18 & 3 & $0.940 *$ & -2 & -0.365 & 5 & 1.890 \\
\hline 32 & not about you or me & 32 & 2 & 0.929 & -1 & -0.168 & 2 & 0.642 \\
\hline 33 & a full chance to react to things & 33 & 2 & 0.909 & 2 & 0.910 & 0 & -0.031 \\
\hline 7 & about whānau, about kōrero and about & 7 & 2 & $0.811 *$ & 4 & 1.611 & 4 & 1.796 \\
\hline 25 & the people I serve & 25 & 2 & $0.800 *$ & $-1-$ & -0.097 & -4 & -1.354 \\
\hline
\end{tabular}




\begin{tabular}{|c|c|c|c|c|c|c|c|c|}
\hline 45 & best work over a cup of tea & 45 & 2 & 0.633 & 0 & 0.090 & 1 & 0.349 \\
\hline 22 & come together to achieve something & 22 & 2 & 0.608 & 5 & 1.999 & 1 & 0.332 \\
\hline 9 & where people are participating & 9 & 1 & 0.524 & 0 & 0.166 & 2 & 1.021 \\
\hline 37 & asking for input and then deliverin & 37 & 1 & 0.477 * & -2 & -0.391 & -1 & -0.547 \\
\hline 2 & is not just about a group consultin & 2 & 1 & 0.427 & 1 & 0.345 & 0 & 0.147 \\
\hline 17 & understanding about the way people & 17 & 1 & 0.414 & 2 & 0.503 & 1 & 0.150 \\
\hline 23 & sit[ting] face-to-face and talk[ing] & 23 & 1 & 0.409 & 1 & 0.374 & 0 & 0.131 \\
\hline 6 & some aspects are really important $t$ & 6 & 1 & 0.404 & 1 & 0.464 & 2 & 1.144 \\
\hline 26 & may mean something different even $t$ & 26 & 0 & 0.389 & 3 & 1.140 & 1 & 0.311 \\
\hline 5 & can be sort of quite defined & 5 & 0 & 0.336 & 3 & 1.244 & 0 & 0.013 \\
\hline 41 & knowing your neighbours and knowing & 41 & 0 & 0.331 & -1 & -0.332 & 1 & 0.260 \\
\hline 34 & Anyone who could be impacted. & 34 & 0 & 0.327 & 0 & 0.004 & -2 & -0.900 \\
\hline 35 & the whole way we interact & 35 & 0 & 0.176 & 2 & 0.898 & -1 & -0.185 \\
\hline 4 & is whoever I meet and whoever I nee & 4 & 0 & 0.172 & -2 & -0.751 & -1 & -0.354 \\
\hline 1 & [no] understanding of the richness & 1 & 0 & 0.153 & 2 & 0.492 & 3 & 1.263 \\
\hline 31 & where everybody has to take respons & 31 & -1 & 0.097 & 0 & 0.248 & 2 & 0.761 \\
\hline 39 & a whole lot of people behind us & 39 & -1 & 0.041 & 0 & 0.281 & -3 & -1.138 \\
\hline 27 & very multi-layered, a here-and-now & 27 & -1 & $-0.203 *$ & 3 & 1.207 & 2 & 0.586 \\
\hline 21 & groups of people engaging in conver & 21 & -1 & -0.249 & 0 & 0.045 & 0 & -0.017 \\
\hline 29 & you've got to get on with everybody & 29 & -1 & -0.471 & -1 & -0.235 & -2 & -0.723 \\
\hline 28 & a whakapapa thing & 28 & -1 & $-0.536 *$ & 1 & 0.406 & 4 & 1.526 \\
\hline 12 & who they're accountable to & 12 & -2 & $-0.605 *$ & -1 & -0.057 & -5 & -2.292 \\
\hline 43 & lowest level of local government & 43 & -2 & $-0.743 *$ & -4 & -1.858 & -4 & -2.059 \\
\hline 36 & a variety of small communities & 36 & -2 & $-0.862 *$ & 2 & 0.806 & 1 & 0.522 \\
\hline 14 & their whole life revolves around th & 14 & -2 & -0.920 & -3 & -1.335 & -2 & -0.675 \\
\hline 24 & having fairly good infrastructure & 24 & -2 & -0.978 & -2 & -0.724 & 0 & -0.042 \\
\hline 19 & a risk mitigation strategy & 19 & -2 & -1.087 & -2 & -0.681 & -2 & -0.797 \\
\hline 10 & where I don't see any school sores & 10 & -3 & -1.182 & -3 & -1.506 & 3 & 1.416 \\
\hline 30 & immediately identified by the hat & 30 & -3 & -1.242 & 0 & 0.055 & -3 & -1.199 \\
\hline 38 & concerned there's no transparency & 38 & -3 & -1.374 & -1 & -0.144 & -3 & -1.340 \\
\hline 16 & anything outside Council & 16 & -3 & -1.449 & -4 & -1.943 & -2 & -1.091 \\
\hline 13 & I don't know. It's hard. & 13 & -4 & $-1.708 *$ & -3 & -1.203 & -1 & -0.263 \\
\hline 42 & some sort of stuff in the back padd & 42 & -4 & $-2.323 *$ & -3 & -1.439 & -2 & -0.729 \\
\hline 11 & a fictitious group & 11 & -5 & -2.403 & -5 & -2.763 & -3 & -1.326 \\
\hline
\end{tabular}

NOTE: Distinguishing statements are highlighted and have a $p<0.05$. Those marked with a red asterisk $(*)$ indicates significance at $p<0.01$.

This belief that 'everyone is important' is what sets Factor 1 apart, and the emphasis on 'everyone' is made more apparent by Item 20. As the second highest distinguishing statement, Item 20 sits in the 'Strongly Agree' zone for Factor 1 with a Q-sort value of +4 . Also, when compared to the -2 and -1 Q-sort values for Factors 2 and 3 respectively, the thematic salience of 'everyone' in this factor is further intensified. With one response to Item 20 as "the best pick... [as an] all-encompassing statement [that] embodies what community is for [him]; it is just everyone" (Q10 366Bz11M), the 'everyone' motif of Factor 3 is unmissable. The centrality of 'everyone' is reinforced by the references to 'everybody' in Items 15 and 18 with their Q-sort values of +3 and +3 respectively placing them near the 'Strongly Agree' end of the continuum. That a conception of 'community' is 
'everyone' is firmly established by the combined placements of Items 44 and 20 with added support from Items 15 and 18 at the 'Strongly Agree' end of the continuum.

The same theme is also apparent at the other extreme of the Q-sort tableau. Item 13, which stated, 'I don't know. It's hard', sat at the 'Strongly Disagree' end of the factor array with a Q-sort value of -4 and a $z$-score of -1.708 . This result indicates shared disagreement that 'community' is 'hard'; or rather, there is shared agreement that 'community' is not 'hard'. As one Q-sort participant occupying a managerial role claimed, "It's not hard. I do know what community is" (Q10 366Bz11M). Responding specifically to Item 13, he defined 'community' as “everybody I could possibly affect and have an impact on negatively or positively" and then he went on to convey comfort with the inexactness of 'everybody'. As he explained:

So while it's hard to define a boundary, and describe accurately or precisely the make-up of the community, I don't think it's hard to consider that a community is a group of people in an undefined way. $($ Q10 366Bz11M)

None of this is a surprise and it reads as straightforward. But as will be explained next, there are limits as to what constitutes 'everyone'.

First of all, the 'everyone' of Factor 1 is not limited to individual people. For participants whose Q sorts define this factor, 'everyone' included local authorities. Item 16, which suggested 'the community is anything outside Council' attracted a Q-sort value of -3. Its rank-order position on the left-hand side of the Q-sort tableau towards the 'Strongly Disagree' end of the continuum supports a view that local authorities are members of 'everyone'. One illustration of this membership was one participant's insistence that "council is part of the community" (Q11 37ZGS11C). Not only did he assert that councils "need to be an active part of the community", he also went on to testify that "they are". Another confirmed the same and referred to his good working relationship with the local authority when he said:

Whoever wrote that probably doesn't know council very well.

Maybe they live in an area where council is very enclosed and removed. (Q12, 35EMu32C)

Council was not the only entity to be included as 'everyone'. One informant pointed out how businesses "have a role and responsibility within all of those communities to be a part 
of those communities" (2028A36M). He spoke at length, and with pride, about how he and his employees "are all part of our community... liv[ing] here... raising their families here in Taranaki". Although he was describing what occurred in the lives of individual staff members and their families, the expectation for them to be active in local life is a company one. A participant, who owns and operates agricultural enterprises in two different regions, expressed a similar sentiment. In his view, a business in a local community ought to be giving back to the same (Q12 35EMu32C). The Factor 1 conception of 'community' is one that extends beyond individuals to include local entities, and especially local authorities.

Of course, organisations were acknowledged as a 'community' of their own. Responding specifically to Item 16 , an elected member said:

The council organisation is a community. Everybody within that building has the same aspirations-most of them. They're wanting to achieve the same outcome. And even if I take the elected representatives, just them alone, they're their own little community within the council community. We're all around the table as our same common values, common goals that we want to achieve. It might be an odd way to look at it, but when I look at the council organisation and the staff within it, actually when you look at that, they're actually a community of their own. So I don't agree that it's everything outside of council. Because I think council itself is its own little community. (Q25 45PQo19P)

But whether a member of a 'community' is a natural person, an informal group or a legal entity that is itself considered a 'community', it is a vested presence in place which is the primary determinant of one's membership to 'everyone'. The place-based-ness of 'community' across all three factors was identified in the consensus statements, but it is also apparent in the responses above. In this factor, the combined placement of Items 40 and 18 emphasises the prominence of place in a Factor 1 conception of 'community' even further. Responding specifically to Item 40, a participant whose Q sort defines Factor 1 recalled how she, as an elected member, had "gone in to bat for that place more times than [she could] remember" (Q25 45PQo19P). In part, it was due to her historical association with the area, but mostly because of the known consequences of extreme weather events for various residents, especially those living in rural isolation. With Item 18, which stated, 'From my perspective, when they talk about "my community", they're talking about everybody who lives in that area. And it doesn't matter what interests they have. It's everybody in that area', it was ranked as +3 for Factor 1 . Compared to the -2 ranking of Factor 2, the result serves to intensify the inherent importance of place. 
But what exactly constitutes the 'that area' of Item 18 varied from one Q sorter to another. To a certain degree individual notions of 'community' reflected the roles participants and informants occupied. For example, the source informant (21F5L19P) for Item 36-I don't think there's a community over the whole area; I think this place has a variety of small communities - was a long-time resident whose highly localised involvement in where she lived has been recognised with the award of a Queen's Service Medal. A local body elected member with strong personal ties to various places did not see 'community' as 'a single thing' but an experience of "lots of levels" (Q25 45PQo19P). She did not agree with Item 36 and while she certainly saw "[a named district] as a whole [as] a community", she also explained that:

\section{...I think that within that, each little area, like [named town] has its own strong sense of community within [named district]. And then so does [second named town] and so does [third named town] to a certain extent. And then you can break it down even further than that to little communities within those communities. $(Q 25$ 45PQo19P)}

It is a view that acknowledges the dynamism that there is in geographic scale and, with it, elements of identity and association to match. Another participant held a different view expressing "denial” (Q31 32MUE32M) about there not being a "community' "over the whole area". He agreed "small communities are there", but this Q sorter also identified "a definable "We are a Taranaki community"'. The first of two reasons he provided to help explain his position was a discernible attachment to place, and more especially to the "maunga [Taranaki/Mt. Egmont that] is there and all of us co-locate around it". The second was his awareness of a "Taranaki Inc." and although he described it as "a terribly corporate phrase", he recognised that it provided a "sense of all of us going somewhere together" and a sense of purpose. It is also worth noting that his managerial role has a regional focus. These two reactions differ in that one reflects a strongly local orientation and the other is a regional one and both can be attributed to the nature of the roles they occupy. Both illustrate the inherent dynamism of 'community' in terms of its geographic scale and coverage, but neither detracts from the place-based-ness of 'community'.

The mention of 'all of us going somewhere together' in the last paragraph points to another element of 'community is everyone' as a concept in that there is a sense of 'we're all in this together' and, whatever the outcome, it must be for the benefit of 'everyone'. Although he was responding specifically to Item 30-where 'community' 'is immediately identified by the role that you or the hat that you are wearing at a particular point in 
time'-a Q-sort participant went on to explain that even if one came to the role "wearing [a] particular hat on [a] particular [issue]" (Q19 33STg11P), one ought to "be interested in the community as a whole". He advised it is not enough to be focused on a single issue; cognisance of the wider concerns is critical, too. His belief is that local decision-making must have outcomes that benefit everyone.

Responses to Item 32- 'It's not about you or me. It's about the community'-added further weight to the inherent commitment to benefiting others as a collective. Across the eighteen Q sorts loading to Factor 1, Item 32 was rank-ordered at +2. For one Q sorter, Item 32 was "the most important [statement] of the lot" (Q46 63MKT57C) because he sees the "whole group" as central to his understanding of 'community'. For him, it is the whole that matters. For another participant, the emphasis "is not about what you and me want, [but about] what the community wants" (Q29 59S0V96P) and it is a viewpoint that is consistent with his commitment to represent his constituents. Yet another participant acknowledged that "for some [individuals] at some level, [community] is about them because they have an opinion" (Q31 32MUE32M). But in his experience as a manager, "you can only go so far in terms of sacrificing [their views] to the whole", and he recognised it was important to "understand where each person and small group is coming from". However, he insisted it was more important to "interpret all of those pieces and define [an outcome] for the community as a whole". This expressed desire to benefit 'everyone' is an explicit feature of Factor 1.

An example that reinforces an expectation that 'everyone' will benefit is a reaction to Item 2, which reads as, 'But community is not just about consulting with a group of people to get some answers!' A political appointment to a working group had left one participant disappointed. His annoyance was not with not consulting with communities but with how a named public service department "did more community consultation than you can imagine" (Q39 60Jg552P) and "got mountains of information"; and nothing came of it. There was no benefit to anyone from all of the activity he described. He felt the entity was "going around and round in circles, having meetings for the sake of having meetings and achieving absolutely nothing". He was so frustrated by those he described as bureaucratic "boffins... who weren't going to change the way they operate" that he resigned from the role.

Thus far, a Factor 1 conception of 'community' is one that includes 'everyone' and its enactment seeks to involve 'everyone'. But 'everyone' is not literally everyone; there are 
expectations. One criterion to membership is that it is primarily place-based and made firm by long-time associations or intergenerational connections to a locality. Even organisations with a vested interest in place are considered part of the 'community'. The extent to which one invests and contributes to what matters also counts. This expectation of contribution applies across all three factors, but in Factor 1 and there must be a demonstrable commitment to achieving outcomes that benefit those who live locally.

\subsubsection{As a practice, it's face to face and usually over a cup of tea}

As elsewhere, when informants and participants spoke about 'community', they often illustrated their understandings with examples of behaviour and conduct. Sometimes it was as a comment on the behaviour of others, but mostly it was examples of their own practice. For participants whose views align with Factor 1, the third highest ranked-ordered distinguishing statement was Item 15 with a Q-sort value of +3 . This statement refers to how 'everybody gets an opportunity to have a say'. Not only does it reiterate 'community' as a concept of 'everyone' in Factor 1 because of the subject of the statement is 'everybody', but it also provides a starting point for describing 'community' as a practice of face-to-face interactions that have purpose and usually feature a 'cup of tea'.

The avenue through which one gets to have a say varies from one situation to another. One Q sorter believed "everybody does get a chance to have a say" (Q46 63MKT57C) and identified voting in general and local body elections and making submissions "at annual plans" as opportunities to do so. Those opportunities may not be taken up, but they are there. Advice from participants often reiterated the elements of 'face to face' and a 'cup of tea' contained in Items 23 and 45. Item 23 states, 'In my opinion, the best way to create a feeling that you're trying to become part of the community is to sit face to face and talk to someone', and Item 45- 'Without a doubt... the best of our work is over a cup of tea and in [the] kitchen'. One Q sorter insisted it should be coffee (Q46 63MKT57C) or a beer (Q11 37ZGS11C) according to another, and a glass of water for a fourth participant (Q29 59soV96P). The specifics of the beverage are a moot point but what is conspicuous here is the way refreshments feature in their practice of 'community'. It is also an activity that can only be done face to face because it is difficult to imagine that one would dare to make or accept an invitation for tea (or coffee, beer or water) and then have it over the phone, or via email or by video-conferencing. Nor did anyone suggest it.

Reflecting on Item 23, one manager identified 'face to face' as 'crucial with [our] 
community [and] it's important in my role" (Q10 366Bz11M). He added that the trustees for the entity he works for had made a conscious decision to "ensuring we give [face to face as a mode of communicating] a high priority". Another participant in the same decision-making setting pointed out that while they do use email, his view was that "the bulk transfer of information is too impersonal [and] you don't get the results you're looking for" (Q11 37ZGS11C). In his experience, a phone call or a signed letter has "a far better impact than an email", but "dealing with people, looking them in the eye... gets us a lot further". Face to face is the preferred mode of engagement whether it is to share information, gain support or seek feedback.

However, whether the opportunities for feedback were through the statutory processes of annual plans or the informality of Item 45's 'cup of tea', supporting 'everybody to have a say' as per Item 15 was acknowledged as a challenge. For one Q sorter, it was a question of "how do we create this process so everybody can have a say?" (Q06 28aFZ19M) and her remark identified the difficulties with getting the process right. But then she went on to ask, "How do we even get to them to the table so they can have a bloody say?!", as she conveyed her acknowledgement that a right process was no guarantee for participation. Another Q sorter offered some advice and in doing so, pointed directly at civic leader attitude and capability:

\begin{abstract}
You've got to be prepared to see both sides of the arguments y'know? And not everybody is going to have the same views as yourself, or as your neighbour or anyone else. And everybody probably wants to see something a bit different and y'know? If you're prepared to sit down and listen to everybody and work out the best solution to the problems. (Q1933STg11P)
\end{abstract}

Further to this advice is the acknowledgement that 'working out the best solution' requires judgement. Participants expressed a readiness to be held to account by the 'everyone' in this factor, but they also recognised that there are diverse interests. Responding to Item 12 - 'It's who, I guess, they are accountable to, which is in the first instance the people who had voted them in'-an elected member noted that even though voters may "expect you to agree with everything they say, once you've heard all the facts, you might change your mind completely" (Q19 33STg11P).

A participant in a managerial role said much the same. One cannot be "constantly seeking what the masses want [because you have] a responsibility to be evaluating what you're hearing and making calls on where to go" (Q31 32MUE32M) and what to do. However, in 
the mind of a long-serving trustee, whether one is elected to a local authority or a local trust, one "can't ignore the wishes of the people that put [you] there" (Q11 37ZGS11C) either. It is a dilemma that characterises decision-making, but, as an elected member acknowledged, if "people don't like what you're doing, they'll vote you out anyway" (Q19 33STg11P). No matter what, there is judgement involved.

One mechanism that was identified as a means to making good decisions was a 'cup of tea'. One Q sorter's reaction to Item 45 was “a little giggle” (Q25 45PQo19P) because "Absolutely. That's definitely how it works. We'll have a cup of tea. We'll discuss something. And then let's make it happen". With the 'cup of tea' as a mediating mechanism, it was widely acknowledged amongst participants as central to their interactions with others, and for planning further action.

One Q sorter, who occupied a role as an elected member, was dismissive of "the cup of tea' because he saw it as a means for "sitting around jaw jabbering doing nothing" (Q29 59soV96P). For him, "We're there to have a meeting. Get to the point. Do the business. And then go. [Sitting around?] That's not me. Time is precious." In no way does he oppose the phenomenon of a 'cup of tea' whatever its form. What he was highlighting was that a 'cup of tea' in a 'community governance' setting ought to lead to action. The Q sorter who giggled would agree. Her example was a hall upgrade that was “... whole of community thing [where they] all got stuck in and did it" (Q25 45PQo19P). She went on to explain, "If they don't step up and do it, chances are nobody else is going to."

When they are purposeful, face-to-face interactions mediated by a 'cup of tea' are recognised as facilitators for action. But they also expedite accountability through providing opportunities 'to have a say' as conveyed in Item 15, but also through 'actively asking for that input and then delivering back results' as stated by Item 37. This commitment to accountability also lies in the commitment to 'Relationships' with a capital ' $R$ '. Item 8 - Relationships' - was identified as a consensus statement and for Factor 1, it is the mutual familiarity and trust that underlies interaction.

One participant attributed the success of their initiative to their commitment to 'Relationships': “that is why we're strong and that's why we're achieving” (Q10 366Bz11M). That two Q sorters mentioned the good working relationships they enjoy with local authorities (Q12 35EMu32C, Q11 37ZGS11C) affirms how a project's success hinges on 'Relationships' and it identifies how important it is to maintain them. It is through 
'Relationships' that 'everybody gets an opportunity to have a say' (Item 15), and it is the outworking of doing 'our best work over a cup of tea' (Item 45) on a 'face-to-face' (Item 23) basis with other members of a 'community'. One elected member described how "people can ring you or come and see you and ask you things; and vice versa" (Q19 33STg11P). 'Relationships' are an interaction in two directions that requires a commitment to "build trust in people and with people, ...treat everybody the same [no] matter what [their] status or anything else". He went on to warn "community's not going to thrive if everybody just ignores everybody".

To illustrate the importance of being able to ring your neighbours, a participant spoke about how rural isolation makes it "absolutely important and necessary... for health and safety reasons and for security reasons" (Q25 45PQo19P). She was responding to Item 41 which stated, 'knowing your neighbours and knowing you can rely on them', and she described how "if somebody has an accident or something terrible happens, chances are it's your neighbour that's going to be there to help you." She reiterated her point with a follow-up question: "Because outside help is, how many hours away?"

There is throughout this interpretation a thread of familiarity, and indeed 'family' is an apt metaphor for Factor 1. For one elected member, "letting everybody have their say... and getting people together" (Q19 33STg11P) can only happen when "working as a group and as a family, as a collective rather than [as] a group of independents". His view was triggered by Item 7 which stated, 'So community for me is about whānau, it's about kōrero and it's about decision-making'. For the Factor 1 conception of 'community', the term 'kōrero' is a stand-in reference for debate and discussion and 'whānau' equates to family.

So far 'community' as practice is one that revolves around 'Relationships' formed and maintained over a proverbial a 'cup of tea' in 'face-to-face' interactions that are purposeful, functional and action-oriented. At its most fundamental level, this practice can be summed up in Item 35, which stated:

In the past I would have just said 'it's just a group of people or a community thing like [a project]'. But it's far more than that. It's the meeting before the [project]. The whole way we interact. And [deciding] whether it's a good thing to do.

At its core is 'the whole way we interact'. With a Q-sort value of 0 , Item 35 is located in the 'Ambivalent' zone of the factor arrays but an interpretation of ambivalence or 
indifference does not apply here. Instead, 'the whole way we interact' is taken to be a fundamental given in one's conduct and behaviour towards others as it was by its source (03xhv96C). A Q sorter response of 'Yeup' (Q11 37ZGS11C) to Item 35 may seem overly simple, but when the factor array is considered as a whole, this single-word endorsement carries weight as a central tenet in Factor 1.

\subsubsection{But it's NOT for raiding}

One manifestation of 'community' that irritates participants, especially those with Q sorts loaded to Factor 1, is activity that is seen as raiding for resources. Item 42 states 'Community is just some sort of stuff that exists in some back paddock somewhere that's absolutely okay to go out and raid every now and then for its capital resources instead of actually seeing it as the central dynamic of what's going on'. This item had a Q-sort value of -4 and sat in the 'Strongly Disagree' zone of the factor array. The intensity of shared disagreement with Item 42 affirms the rejection of 'community' as a resource to be raided and pillaged for its capital resources. Capital resources here are not limited to the classical interpretations of capital, such as labour, but also includes the modern applications like networks and local knowledge.

Participants certainly recognised there are resources within communities that can and should be called upon. For example, in responses to emergencies or emergency planning where "it'd be okay" (Q06 28aFZ19M), but to suggest "[we're] some sort of stuff that exists in some back paddock... It's not right. It's completely wrong” (Q11 37ZGS11C). The indignation lay with the way the item conveyed "the community idea as a thing [and] as a way to get something" and in his opinion, “[i]t shouldn't be". He was not alone in his reaction. Another Q sorter declared Item 42 as her "least favourite" (Q25 45PQo19P) statement and labelled it "a lot of bollocks" and then in a second Q sort, she still saw it as "utter nonsense" (Q26 45PQo19P). Again, the objection was not with making good use of local resources that would provide direct local benefit, but with the prospect of being "used as a free resource" (Q31 32MUE32M). For a participant whose Q sort was confounded across both Factors 2 and 3, Item 42 "rankled" (Q22 30KjD56P). She explained further:

It has no sense of community whatsoever. To me, it's all about what I can get out of an arrangement or a proposal or a project or a discussion. And call on the uninformed masses when it suits me. To get the backing that I might potentially need and then put them back out to pasture when I feel like I've done with them. It's almost 
like dial-a-community, or [dial-a-]kaumatua, or dial-a-whānau, or dial-a-submission. That really annoys me because I've seen it in action. [Laughs.] Or the dial-a-busload of people to come up and have a hui. That annoys me! (Q22 30KjD56P)

The Q sorter's annoyance at being treated like a commodity is another feeling that characterises Factor 1. For some, the realisation that there is a view of 'community' as resource to be raided or a commodity to be called up is perplexing. For example, a participant whose Q sort loaded strongly to Factor 1 with a correlation of 0.7967 conveyed difficulty in being confronted with a different perspective. Responding to 'community' as a risk mitigation strategy as conveyed in Item 19, he said:

I don't really understand what that means... I know what risk mitigation means but I don't really know what they mean by that statement, whoever's made that statement (Q11 37ZGS11C).

The same Q sorter reacted in a similar way to Item 43 which was also a distinguishing statement for Factor 1. It states, 'And the community is and always has been the lowest level of local government' and was rank-ordered -2 with a $\mathrm{z}$-score of -0.743 . He asked, "A level of local government? Is there a level below it?” (Q11 37ZGS11C). After registering his disagreement, this participant went on to assert his view that 'community" "should be the highest level", but expressed puzzlement of the proposition.

Both the results and the responses from post-Q-sort interview to Item 11 adds weight to the Strongly Disagree end of the continuum. As a statement, Item 11 read as 'a fictitious group' and the analysis resulted in a Q-sort value of -5 and being tagged as a distinguishing statement. Participant reaction to the statement was often terse, and that participants were offended was seen and heard over and over again. A participant whose Q-sort helped define Factor 1 labelled it "derogatory" and denounced it as an "absolute lie" (Q46 63MKT57C). One informant looked the researcher in the eye and stated with great deliberation, "We're not fictitious and nothing that I do is fictitious" (Q11 37ZGS11C). Unsurprisingly, Item 11 also elicited an expletive (Q12 35EMu32C) and a request to know "what circumstance would cause them to write about that?" (Q16 42STm32M). To be sure, the offence was palpable.

Not all Q sorters dismissed Item 11 so readily.

One confessed to being "really intrigued" (Q10 366Bz11M) and went so far as to suggest 
the statement had been "slip[ped] in there... to inspire people". Although the statement had not been 'planted', his response pointed to his openness to consider an entirely different opinion from his own. The same applied to the $\mathrm{Q}$ sorter who was "a bit bemused" (Q02 32MuE76M) by Item 11 and recognised that there could be "quite a debate" around 'community' as a fictitious group. He saw it as an opportunity to talk about community and ask "what is it-really?"

The puzzlement, the annoyance, and disdain to 'community' being commodified was detectable. It is not for raiding. It is not a resource to be used and abused to further agendas that offer no benefit to those affected or for those who have no vested interest. And it is definitely not fictitious.

\subsubsection{Factor 1-It's everyone and we're all in this together}

To summarise, the 'community' of Factor 1 is a conception of 'everyone and everyone is important'. But there is a proviso. 'Everyone' here is not literally every possible person because there is an inherent place-based-ness to membership. There is an expectation that a person or an entity has a long-time association and/or an intergenerational connection to a locality. Their commitment to where they live is demonstrated by contributions to activities that benefit those who live locally. Although there is an acknowledgement that an entity can be a 'community' in itself, organisations with a vested interest in place are considered part of the 'community'.

In practice, 'community' is produced and re-produced through 'face-to-face' interactions that have purpose, and usually feature a 'cup of tea'. These mediated encounters expedite accountability with the active intent of sharing information and seeking feedback. Done well, those interactions inform decisions and actions, and they build trust and strengthen relationships. Done poorly without any accountability, they can leave people feeling rankled, or worse still, raided.

\subsection{The Factor 2 perspective}

Fifteen of the $47 \mathrm{Q}$ sorts loaded to Factor 2. It also had a standard error of 0.181 for differences within the factor indicating that there is little variation amongst these $15 \mathrm{Q}$ 
sorts. Of these 15, seven were Q sorts conducted by participants with roles from the community leadership domain, another four were for roles in the managerial leadership domain and the remaining four were by Q sorters occupying political leadership roles.

The proposition here is that this conception of 'community' is one that is 'Well... it depends'. 'It depends' first and foremost on interests, and 'it depends' on an innate acceptance that there is a range of interests. In practice, 'it also depends' on an ability to work with the diversity of viewpoints within a given range and on an attitude of collaboration that is exemplified by relational competence and a strategy of enabling participation.

\subsection{1 'Community' is all about interests}

Generating a Q-sort value of +5 , Item 22 was the top-ranked distinguishing statement for Factor 2. This item read as:

Well community, I suppose at a first-world level, it's just any, any group of people who come together to achieve something or have shared values, shared goals, common beliefs, common understandings - something that brings them together to do something.

The result for this item is the first highlighted line in the next table. Table 14 lists the Qsort values and $z$-scores by factor sorted in descending z-score for Factor 2, and the highlighted rows are those items identified as distinguishing statements. The table also shows that the Q-sort values for Item 22 in Factors 1 and 3 are +2 and +1 respectively and the marked difference in Q-sort values across the three factors emphasises the structuring definition Item 22 has on Factor 2. Furthermore, the factor analysis result for this item is tagged with a red asterisk $(*)$ indicating statistical significance at $p<0.01$. In other words, the chance that the result is a fluke is less than $1 \%$ and the result can therefore be regarded with some assurance. The same applies to all of the distinguishing statements marked with a red asterisk $(*)$. 
Table 14: Q-sort values and z-scores by factor, sorted in descending order for Factor 2

\begin{tabular}{|c|c|c|c|c|c|c|c|c|}
\hline \multirow[b]{2}{*}{ Item } & \multirow[b]{2}{*}{ Short Statement } & \multirow[b]{2}{*}{ Item } & \multicolumn{2}{|c|}{ Factor 1} & \multicolumn{2}{|c|}{ Factor 2} & \multicolumn{2}{|c|}{ Factor 3} \\
\hline & & & Q-Sv & $\mathrm{Z}-\mathrm{SCR}$ & Q-Sv & $\mathrm{Z}-\mathrm{SCR}$ & Q-Sv & V Z-SCR \\
\hline 22 & come together to achieve something & 22 & 2 & 0.608 & 5 & $1.999 *$ & 1 & 0.332 \\
\hline 7 & about whānau, about kōrero and about & 7 & 2 & 0.811 & 4 & 1.611 & 4 & 1.796 \\
\hline 8 & Relationships. & 8 & 4 & 1.678 & 4 & 1.317 & 3 & 1.427 \\
\hline 5 & can be sort of quite defined & 5 & 0 & 0.336 & 3 & $1.244 *$ & 0 & 0.013 \\
\hline 27 & very multi-layered, a here-and-now & 27 & -1 & -0.203 & 3 & 1.207 & 2 & 0.586 \\
\hline 26 & may mean something different even $t$ & 26 & 0 & 0.389 & 3 & $1.140 *$ & 1 & 0.311 \\
\hline 40 & being committed to the place & 40 & 3 & 0.941 & 3 & 1.059 & 3 & 1.153 \\
\hline 33 & a full chance to react to things & 33 & 2 & 0.909 & 2 & 0.910 & & -0.031 \\
\hline 35 & the whole way we interact & 35 & 0 & 0.176 & 2 & $0.898 *$ & -1 & -0.185 \\
\hline 36 & a variety of small communities & 36 & -2 & -0.862 & 2 & 0.806 & 1 & 0.522 \\
\hline 3 & a key part is contributing as well & 3 & 3 & 1.101 & 2 & 0.764 & 2 & 0.951 \\
\hline 17 & understanding about the way people & 17 & 1 & 0.414 & 2 & 0.503 & 1 & 0.150 \\
\hline 1 & [no] understanding of the richness & 1 & 0 & 0.153 & 2 & 0.492 & 3 & 1.263 \\
\hline 6 & some aspects are really important $t$ & 6 & 1 & 0.404 & 1 & 0.464 & 2 & 1.144 \\
\hline 28 & a whakapapa thing & 28 & -1 & -0.536 & 1 & $0.406 *$ & 4 & 1.526 \\
\hline 44 & everyone's important & 44 & 5 & 1.773 & 1 & 0.381 & 0 & 0.003 \\
\hline 23 & sit[ting] face-to-face and talk[ing] & 23 & 1 & 0.409 & 1 & 0.374 & 0 & 0.131 \\
\hline 2 & is not just about a group consultin & 2 & 1 & 0.427 & 1 & 0.345 & 0 & 0.147 \\
\hline 15 & everybody gets an opportunity to hav & 15 & 3 & 1.094 & 1 & 0.330 & -1 & -0.242 \\
\hline 39 & a whole lot of people behind us & 39 & -1 & 0.041 & 0 & 0.281 & -3 & -1.138 \\
\hline 31 & where everybody has to take respons & 31 & -1 & 0.097 & 0 & 0.248 & 2 & 0.761 \\
\hline 9 & where people are participating & 9 & 1 & 0.524 & 0 & 0.166 & 2 & 1.021 \\
\hline 45 & best work over a cup of tea & 45 & 2 & 0.633 & 0 & 0.090 & 1 & 0.349 \\
\hline 30 & immediately identified by the hat & 30 & -3 & -1.242 & 0 & $0.055 *$ & -3 & -1.199 \\
\hline 21 & groups of people engaging in conver & 21 & -1 & -0.249 & 0 & 0.045 & & -0.017 \\
\hline 34 & Anyone who could be impacted. & 34 & 0 & 0.327 & 0 & 0.004 & -2 & -0.900 \\
\hline 12 & who they're accountable to & 12 & -2 & -0.605 & -1 & $-0.057 *$ & -5 & -2.292 \\
\hline 25 & the people I serve & 25 & 2 & 0.800 & -1 & $-0.097 *$ & & -1.354 \\
\hline 38 & concerned there's no transparency & 38 & -3 & -1.374 & -1 & $-0.144 *$ & -3 & -1.340 \\
\hline 32 & not about you or me & 32 & 2 & 0.929 & -1 & $-0.168 *$ & 2 & 0.642 \\
\hline 29 & you've got to get on with everybody & 29 & -1 & -0.471 & -1 & -0.235 & -2 & -0.723 \\
\hline 41 & knowing your neighbours and knowing & 41 & 0 & 0.331 & -1 & -0.332 & 1 & 0.260 \\
\hline 18 & everybody who lives in that area & 18 & 3 & 0.940 & -2 & $-0.365 *$ & 5 & 1.890 \\
\hline 37 & asking for input and then deliverin & 37 & 1 & 0.477 & -2 & -0.391 & -1 & -0.547 \\
\hline 19 & a risk mitigation strategy & 19 & -2 & -1.087 & -2 & -0.681 & -2 & -0.797 \\
\hline 24 & having fairly good infrastructure & 24 & -2 & -0.978 & -2 & -0.724 & & -0.042 \\
\hline 4 & is whoever I meet and whoever I nee & 4 & 0 & 0.172 & -2 & -0.751 & -1 & -0.354 \\
\hline 20 & Everyone. & 20 & 4 & 1.439 & -2 & $-1.148 *$ & -1 & -0.489 \\
\hline 13 & I don't know. It's hard. & 13 & -4 & -1.708 & -3 & $-1.203 *$ & -1 & -0.263 \\
\hline 14 & their whole life revolves around th & 14 & -2 & -0.920 & -3 & -1.335 & -2 & -0.675 \\
\hline 42 & some sort of stuff in the back padd & 42 & -4 & -2.323 & -3 & $-1.439 *$ & -2 & -0.729 \\
\hline 10 & where I don't see any school sores & 10 & -3 & -1.182 & -3 & -1.506 & 3 & 1.416 \\
\hline 43 & lowest level of local government & 43 & -2 & -0.743 & -4 & -1.858 & -4 & -2.059 \\
\hline 16 & anything outside Council & 16 & -3 & -1.449 & -4 & $-1.943 *$ & -2 & -1.091 \\
\hline 11 & a fictitious group & 11 & -5 & -2.403 & -5 & -2.763 & -3 & -1.326 \\
\hline
\end{tabular}

NOTE: Distinguishing statements are highlighted and have a $p<0.05$. Those marked with a red asterisk $\left({ }^{*}\right)$ indicates significance at $p<0.01$. 
Item 22 proved to be the most satisfying statement about 'community' for those participants whose Q sorts defined Factor 2. For one Q sorter, the 'shared values, shared goals, common beliefs, common understandings' that 'bring... [people] together' were identified as "fundamental" (Q27 44Ghb85C) to her own understanding of 'community'. The form of those values, goals, beliefs and understandings differed from one participant to another and for this first participant, it was "the spiritual beliefs" of her elders that had been handed down from one generation to the next.

For a second Q sorter, it was the contemporaneously "similar backgrounds" (Q20 $48 \mathrm{uWH} 85 \mathrm{P}$ ) of those he "chooses to spend time with", while a third was more specific and identified the school where "the kids were enrolled" (Q37 43xx185P,) as a point in common that she shared with others. For a fourth Q sorter, 'community' is "marked by the fact that it centres around people coming together for a purpose" (Q28 57i2N32M) and it was the 'doing something' that a fifth participant "really like[d]" (Q01 34B3T57M). It was the combination of shared interests and action that appealed to these Q sorters. A shared sense of "purpose" (Q27 44Ghb85C) was noted as important especially when one needs to "find a way to get [others] on board". But it was also identified as a pre-requisite for any change by a sixth Q sorter, who asked, "How can you be motivated or change if you don't have a common goal or shared values or shared beliefs?" (Q40 51TvM32C). Whether they are referred to as values, goals, beliefs or understandings, what is acknowledged here is the pre-requisite for a set of shared interests, or clearly articulated purpose.

That 'interests' are a major component of a Factor 2 conception of 'community' is reiterated by Item 5, which states, 'But I think communities, you know, can be sort of quite defined according to interests and values as well'. Of the three factors, Item 5 ranked highest in Factor 2 with a Q-sort value of +3 compared to the zeroes of Factors 1 and 3. Interests are still important across all three factors as identified in the consensus statements, but with Factor 2, interests and values are an explicitly acknowledged component. As one participant remarked rather pointedly, "Our interests and values define us. Separates us. Makes us go into our different groups" (Q40 51TvM32C), and the study's informants and participants provided numerous instances to illustrate. Examples ranged from industries like farming (Q25 45PQ019P), movements such as Parihaka (Q27 44Ghb85C), events like the Annual Pig Hunt (17e9y19C) or civil defence emergencies (Q01 34B3T57M), as well as the various projects participants were involved in and the places where they lived. 
With the focus on interests, the Factor 2 perspective of 'community' also accepts and expects interests and values to change over a period of time. Item 27-'I don't think of community as a single thing. I think of it as very multi-layered and in some cases temporal. It's a here-and-now, not an always'-was a distinguishing statement rank-ordered at +3 in the factor array. The 'temporal' and 'not an always' of 'community' is what one Q sorter acknowledged when he stated that "[communities] change over time" (Q24 55Ttx85M) and another noted "communities of interest can... collapse and disappear over time" (Q28 $57 \mathrm{i} 2 \mathrm{~N} 32 \mathrm{M}$ ) and they can "re-form around different things". The source informant noted the same in that there is "a broader community you're a part of that may have no form at any point in time but... you will mobilise united when something arises" (26FG3M85M).

Referring to a specific place that has been held up as an exemplar for 'community', a third Q sorter spoke about how “it was very fractured [and] you couldn't call [it] a community when I first come home" (Q27 44Ghb85C) and how that had changed. A fourth participant said "communities can be all sorts of things" (Q01 34B3T57M) and a fifth noted much the same when she emphasised that 'community' is "diverse... it is multilayered... it's not a single thing" (Q37 43xx185P). These responses also explain the difference between Item 27's Q-sort value of +3 for Factor 2 and the +1 and -1 for Factors 1 and 3 respectively. The numbers show that the statement resonated more strongly with Factor 2 participants than it did with those whose Q sorts define Factors 1 and 3. The results and the responses identify a Factor 2 viewpoint that is more accepting of the range of interests that might characterise any given situation.

Further insight to an innate acceptance of a multiplicity of views is provided by Item 1. For one participant, the statement 'I don't think there is an understanding of the richness of a community. You know, not everyone is on one point of the socio-economic spectrum' led her to focus on the second sentence of that statement. For her, "there is a day-to-day reality that not everyone is on the same point of socio-economic spectrum. I know that people live across the [socio-economic] spectrum" (Q37 43xx185P). Her concern was that the spread and depth of lived realities and diversity of experiences were too easily overlooked or dismissed. It may have been the same underlying concern for a Q sorter who doubted that certain decision-makers "really understood the impact of a decision that they made at that time" (Q30 34B3T96M) on people's lives. Their concerns are further illustrations of an awareness of lived realities other than their own.

A response to Item 30 reiterated the acceptance Q sorters have for the multiplicity of 
interests conveyed through Item 27. But rather than an awareness of other views, Item 30 identifies a flexibility to hold different views of 'community' that vary according to the context. That it "depends on the circumstances... and the things you're grappling with" (Q28 57i2N32M) is a sentiment with which few would disagree. A distinguishing statement, Item 30, reads as, 'Community in my mind is immediately identified by the role that you or the hat that you are wearing at a particular point in time'. The corresponding values were -3 for both Factors 1 and 3 and were indicative of the disagreement shared about Item 30 in those factors. However, for Factor 2, its Q-sort value was 0 and this is a result that sets it firmly in the 'Ambivalent' zone. Treating results in this area as a fulcrum around which a viewpoint might revolve, this zone in Factor 2 is looked on as 'business as usual', which is a tag that one of the Q sorters described in the 'Ambivalent' zone. She had said:

Those [items] that are in the ambivalent section... are just business as usual. Things like having cups of tea, face to face, actively asking for input, reporting back, contributing, knowing your neighbours. $(Q 37,43 \times x 185 P)$

Returning her attention back to Item 30, the participant went on to highlight that 'the hat' or context determines which viewpoint of 'community' is the relevant one. She said:

And even as in statement 30 , where community is immediately defined by the role or hat you're wearing at a particular time. Because it does. One day, it might be the immediate whannau. The next day it might be the wider whänau. It can even be the whänau $\bar{a}$-iwi, whānau $\bar{a}$-hapū and whānau $\bar{a}$-kaupapa. $(Q 37,43 x x 185 P)$

In this excerpt, 'whānau' here refers variously and severally to the family unit of immediate relations and to the extended family (Durie, 1997; Moorfield, 2003d). It has also been used to identify further decision-making groupings that might apply on an iwi and hapū or tribal basis as well as on a kaupapa or issues basis. While all but the last grouping infers a genealogical link amongst members, 'whānau ā-kaupapa' highlights a more contemporary grouping around a meaningful issue or a purposeful set of interests. The participant's opinion also acknowledges that every setting may require a different point of view because the interests of each setting demand a different viewpoint. There is still the foundation belief that 'community' is important to physical and social wellbeing and there are expectations of contribution and conduct. But Factor 2 is explicitly interests-focused, and it is also important to be able to identify and make clear distinctions between the different points of view that come with those interests. 
With Factor 1, 'community' is 'everyone'; but not so with Factor 2. Item 20-'It's everyone'-generated a Q-sort value of +4 in Factor 1 while, in Factor 2, the Q-sort value is -2. As well as being tagged a distinguishing statement, it is a result that affirms 'everyone' is not the salient feature that it is in Factor 1 and that view can be seen in the responses from two participants whose Q sorts define Factor 2. One identified 'community' as being “about a specific set of people" (Q20, 48uWH85P). To emphasise that point, he noted:

Sure there's diversity. But there's a similar set of core values or there's a similar set of going the same broad direction so by definition, [it] can't be everybody. 'Cause if it's everybody then you don't have a community... 'cause that's just people and that's just everyone. You may as well just talk about humanity and humanity is unfortunately not a community 'cause we're not the Borg-the Borg would be everyone. (Q20, 48uWH85P)

Had they been in the same Q sort interview, the other would have agreed. He said:

I don't think it's necessarily everyone. Because then it's a global community. I'm not part of [a named group]. Never want to be. I'm not part of [another named group]. Never want to be. So I don't think it is everyone (Q24 55Ttx85M).

Both reactions also highlight that 'everyone' is not a word that would be used in their understanding of 'community' because it is too broad a term. In part, this is because it is impossible to be a member of 'everyone' and that 'everyone' is “actually nobody" (Q20, $48 \mathrm{uWH} 85 \mathrm{P}$ ) because as a third participant pointed out, there is "nothing to distinguish them” (Q28 57i2N32M). For these three, one cannot have 'community' as 'everyone'. For the second of the three participants, even the local authority unit of 'district' is not sufficient. In response to Item 18- 'From my perspective, when they talk about "my community", they're talking about everybody who lives in that area. And it doesn't matter what interests they have. It's everybody in that area'-he explained:

I don't think that's it either. I don't think community is a bunch of ratepayers. I think me paying rates to [a named local authority]... makes me a ratepayer... [and] makes me part of the district ratepaying group of people, but that's not community. That's a structure we've set up to organise ourselves so that we can create infrastructure and live together. But that doesn't necessarily mean community in my view (Q20 48uWH85P).

His view also extends to events. When accounting for Item 9- 'Community, where people are participating... who are just going out and being part of community, whether it means a 
school fête or it means coming into a big celebration in town'- he reflected:

So me going to an event that somebody else has put on doesn't make me part of that community. It means I'm a user of services or somebody who is going to take advantage of an opportunity. It doesn't mean that I'm part of that community. It's like going to the movies. You know-community is where people are participating so I'm going to the movies? What! So am I part of the movie watching community? Not in my opinion. (Q20 48uWH85P)

Even societal units did not escape his commentary. Responding to Item 28, which states, 'To me, community is a whakapapa thing', he pointed out that "iwi are just relational constructs. Networks of big giant families" (Q20 48uWH85P). In his view, a network "doesn't necessarily make it a community because community is based on actual living relationships". He also acknowledged "social networks have enabled people to keep in touch", but the reality is that "some people keep in touch [and] some people don't".

For these last two participants, it is not the societal structures or bureaucracies that are the components to a conception of 'community'. Nor does participation in an event necessarily equate to 'community'. For these two, 'community' is an intimate space of hightrust interaction, but it is not so intimate as to invoke the metaphor of 'family' as one might with Factor 1. The former participant used the word 'whānau' to represent his understanding of 'community' and, for him, it is "where we choose to spend our everyday lives” (Q20 48uWH85P). His use of 'whānau' is consistent with Hond's (2013) view that "the word.. carries cultural integrity, in contrast with what has been considered the overused, missed and abused notion of "community"' (p. 41).

Although referring specifically to Item 7-'So community for me is about whānau, it's about kōrero and it's about decision-making' - he described how 'community' is "about whānau but in a more expansive sense" (Q24 55Ttx85M). By 'expansive', he said that meant "extending whānau with whanaungatanga [or familial links] to people who add value to your life". 'Whanaungatanga' here is consistent with Moorfield's (2003e) definition of

a relationship through shared experiences and working together which provides people with a sense of belonging. It develops as a result of kinship rights and obligations, which also serve to strengthen each member of the kin group. It also extends to others to whom one develops a close familial, friendship or reciprocal relationship. 
It also lines up closely with the former participant's choice in where he spends his everyday life. For the latter, 'community' is "such an abused word" (Q24 55Ttx85M) and in his opinion, "interest groups within communities would be a better way of looking at [community]". Again, the emphasis on interests is a key point of difference for Factor 2.

There are two more contributors to an understanding of 'community' as a multiplicity of interests. The first is the Q-sort result for Item 26-'My community may mean something different to what you think your community is, even though we're at the same table'. It was assigned a $Q$-sort value of +3 . When considered against the the 0 and +1 tagged to Factors 1 and 3 respectively, the Factor 2 perspective is more accommodating of different viewpoints.

The second contributor is the relative absence of the place-based-ness that characterises both Factor 1, and, as will be seen in the next section, Factor 3. By comparison, 'place' is less explicit in Factor 2 as indicated by Item 18's Q-sort value of -2 , whereas it is +3 for Factor 1 and +5 for Factor 3. Item 18-'From my perspective, when they talk about "my community", they're talking about everybody who lives in that area. And it doesn't matter what interests they have. It's everybody in that area'. This result also affirms the rejection of an 'area' as determinant of 'community' just as a participant (Q20 48uWH85P) dismissed the local government geographical unit of 'district' from his understanding of 'community'.

The same sentiment is reiterated by the result for Item 36, which stated, 'I don't think there's a community over the whole area; I think this place has a variety of small communities'. This statement drew a Q-sort value of +2 for this factor and is deemed an indicator of shared agreement amongst the Factor 2 defining $Q$ sorts. When compared to the Q-sort value of -2 for Factor 1, which is considered an indication of shared disagreement in that factor, a Factor 2 conception of 'community' is not the large-scale units that a Factor 1 conception would promote. Instead, a Factor 2 viewpoint of 'community' is one that is more human in its scale and revolves around a multiplicity of shared interests.

\subsubsection{As a practice, it is a strategy of enabling}

The second theme to the Factor 2 perspective also stems from the highest distinguishing statement, Item 22, and more specifically, it is the 'do something' part of the statement. 
That Item 22 contains two different ideas is noted. In the previous section, the emphasis was on having common or shared beliefs, understandings, and values. In this section, the focus is on achieving something. While the Q-literature suggests uncoupling ideas in order to support Q sorters to rank order without any ambiguity, in this study there is no evidence that Q sorters could not cope with double-barrelled statements. Item 22 is one example of that. One Q sorter saw the two parts as inseparable: "how can you be motivated or change if you don't have a common goal or shared values or shared beliefs?” (Q40 51TvM32C) she asked. Another made specific note of how other statements were "missing one or more of the elements" (Q28 57i2n32M) of what he understood to be 'community'.

Returning to the second theme for Factor 2, according to a participant, "there is nothing like a community achieving something" (Q21 40QNG11C). In his experience, there is a "feeling of great beneficence to everybody that comes from it. And people who are really down on luck or genetic talents... can find great wonderment and achievement out in the community".

But the 'achieving' depends entirely on conduct and the way those in roles of influence behave. This assertion is based on a number of responses to these Factor $2 \mathrm{Q}$ sorts. One was from a participant who placed Item 22 at +5 in his own Q sort and did so on the basis that the statement "seemed to capture what [he] thought" (Q28 57i2n32M) of 'community'. But the same item also prompted him to label 'community' as “a human construct" that guides "how we relate to each other". Another Q sorter whose Q-sort result for Item 22 was the same at +5 also identified 'shared goals' as “fundamental” (Q27 $44 \mathrm{Ghb} 85 \mathrm{C}$ ) to her conception of 'community', but she also spoke about how important it was "to find a way to get [people] on board or go around [them] as opposed to go[ing] over them".

A third Q sorter who had Item 22 rank-ordered at 0 explained that the effort to 'find a way' "doesn't necessarily mean that relationships have to be healthy all the time but at least if you know what your relationship is with the person you can work around it. Or through it. Or work over it or under it" (Q23 30KjD56P). She went on to elaborate further:

But obviously the more positive the relationship, the better the outcomes. But that's always going to be the case. Sometimes, it's just acknowledging the healthy ones and the most out of them that you can. And acknowledging the unhealthy ones and understanding how and when they may limit progress. If that makes sense. (Q23 30KjD56P) 
That last response was prompted by Item 8-'Relationships'-a consensus statement. While consensus statements identify shared agreement amongst all of the Q-sorters, there are nuanced differences for each factor. With Factor 1, there are elements of mutual familiarity and trust, and with Factor 3, there is a conscious awareness of being connected to all things. With Factor 2, 'Relationships' are recognised as "challenging... but critical" (Q23 30KjD56P) that require a degree of relational competency that may be perceived as technical and professional because legislative processes require "a setting aside of personal values". This recognition was a response set against the backdrop of the Resource Management Act 1993 and the processes that did not require having "to get on with everybody...[because] you can disagree and still live next door to each other". The Q sorter acknowledged that the Resource Management Act 1993 had shifted her to "thinking more around the individual participants in the process rather than the community perspective".

A distinguishing statement that supported the importance of relational competency to the study's participants was in relation to the 'whole way we interact' of Item 35-'In the past I would have just said 'it's just a group of people or a community thing like [a project]. But it's far more than that. It's the meeting before the [project]. The whole way we interact. And [deciding] whether it's a good thing to do'. Its factor result was a Q-sort value of +2 in this factor, which was the highest of the three factors. Item 35 in Factors 1 and 3 drew Q-sort values of 0 and -1 and are considered as fundamental givens and pivot points for both factors, but its position at +2 in Factor 2 has been interpreted as a willingness and an ability to set one's own viewpoint aside in order to foster good working 'Relationships'.

A further aspect of a Factor 2 practice of 'community' is that the decision-making process is deliberative and this claim has been informed by the results and responses to Items 7 and 33. The statement for Item 7 read as, 'So community for me is about whānau, it's about kōrero and it's about decision-making' and its Q-sort value was +4. Said one participant, "that's what ['community'] is for me-it's all about decision-making" (Q40 51TvM32C). For her, the decision-making process needs to be informed and the decisions themselves well understood by those making them. As a verb, 'kōrero' means "to tell, say, speak, read, talk, address" (Moorfield, 2003b) and as a noun, it is "speech, narrative, story news, account, discussion, conversation, discourse, statement, information". But in order to do that, people must first be supported to participate in those conversations and discussions.

The identified opportunity is reinforced by Item 33-'I think it's where the community has 
a full chance to react to things that they desire for their community and work within the community to achieve those things'. This statement generated a Q-sort value of +2 just as it did for Factor 1. Referring to a specific project, a participant pointed out the importance of asking questions like "Do our people really want this? Is this what they're telling us to do? Are they really sure? Do they give us the mandate to keep doing this mahi [or work]?” (Q23 30KjD56P). She went on to advise, "You've got to tell them more than once. Feeding back all the time. Holding wānanga. Asking for help for fundraising. And all of that'. Her approach to 'community' is to facilitate 'kōrero' and dialogue.

Where Factor 1 might have used the a 'cup of tea' of Item 45 as the mechanism to support discussion and build the relationship between those involved, a Factor 2 perspective would tend not to, as indicated by a Q-sort value of 0 . Indeed, one participant reacted to the statement with some scepticism because for her, it meant "deals to be done over a dinner table on a napkin" (Q01, 34B3T57M). Another found the statement to be "a bit of a contradiction... because for me, the key is how do we create all those different types of cups of teas, in which people can participate" (Q03 31FqZ85C). It is not necessarily the actual refreshment nor the relationship that matters, but whether the forum is an appropriate one to achieve an agreed objective. There is a design and an intent to the process that a participant recognised "can be a situational thing" (Q24 55Ttx85M). In his opinion, it includes the person facilitating the discussion:

Like just because you're the [named role] of the business or you're
the [named role] of the trust doesn't mean you're the right person
for that job all the time. There could be times when somebody else
is actually better to do something, you know. (Q24 55Ttx85M)

A fourth result is that informs the theme of enabling as a strategy is Item 16-'For me - in this role, the community is anything outside Council'. This statement generated a Q-sort value of -4 and when compared to the Q-sort values of -3 and -2 for Factors 1 and 3 , the result indicates that the shared disagreement is most strongly felt in Factor 2. One participant's objection was a firm "not for me" (Q40 51TvM32C). He went on to insist that "council has got to be a part of community". It was an objection that also aligns closely to a Factor 1 view but the Factor 1 relationship with a local authority is a more personal one, almost familial in nature.

With Factor 2, the relationships with councils are more technical and this was illustrated by a Q sorter who posited, "[what] a lot of people forget is that Council is merely the messenger for legislation and we have to enact a lot of the stuff" (Q23 30KjD56P). 
Another recalled that her working relationship had been initiated by the local council and she named projects as examples of how "we do lots of work together" (Q40 51TvM32C). A fourth participant referred to local government as "a system... that people have evolved to make decisions" (Q24 55Ttx85M) and a fifth said much the same and identified local government as "just a part of the infrastructure and if what you're doing works with council then good" (Q08 38Wdg76M). She also added, "If it doesn't, well just do your own thing". For Factor 1, local government is a partner, but for Factor 2, it is seen more as an enabler.

Participants did not, and may never, describe it this way, but the relationship with a local authority from a Factor 2 perspective is more transactional in nature. It is particularly illustrative in the strong disagreement with Item 43-'And the community is and always has been the lowest level of local government'. One participant questioned whether "that statement relates to the fact that the government doesn't look after its community or whether that means that... it's at the bottom of the heap" (Q08 38Wdg76M). Either way, she said, “it sounded negative so I didn't like it". Like many others, her opposition can be attributed to a view that 'community' is important and anything that suggests otherwise is to be rejected. Two elected members expressed opinions that assigned importance to 'community'. One saw 'community' as “the highest [and] it's what government should be about" (Q21 40QNG11C) and the other found the suggestion that 'community' "is the lowest level... [to be] a really derogatory answer" (Q15 39OIQ96P). The latter countered with the same assertion and that "it's the highest level [and] that's what local government is all about". In their respective fields, all three work on the basis that local government ought to be an enabler of local decision-making.

This practice of facilitating was couched as 'enabling' by a Q sorter commenting on Item 17. This item stated, 'Community is understanding about the way people work' and was rank-ordered at +2 in the factor array for Factor 2. The participant saw 'understanding the way people work' as “finding a way to get people on board. Getting people involved. Making it possible for them to work. Providing an enabling environment” (Q37 43xx185P). Although not specifically mentioned, an attitude of 'enabling' was apparent in the Q sorter who was challenged by "how do we create all those different types of cups of teas in which people can participate?” (Q03 31Fqz85M). A similar view was expressed by a participant who described her work as "capacity building" (Q08 38Wdg76M) with the aim to "help people and support people and bring people together and do... stuff in that community". Another went so far as to identify her role as a trustee as having "a strong servanthood 
stewardship element [not as] being controlled and directed ...but more like Robert Greenleaf" (Q37 43xx185P) where there is an ethic of service enacted through servant leadership. Another Q sorter saw 'community' as an act of leadership and described it as “a collaboration of goodwill [that] will basically make change... to make constructive positive change to reinforce support what's already happening in the community" (Q27 44Ghb85C). All these responses add up to 'community' as a practice of enabling.

But service, or rather 'serve', was not a word that any of the participants were comfortable with. One participant insisted, “I don't serve the community. I do what I do because I want to be out there and I'm lucky enough to be paid to do what I do. I also do volunteer work but it's not people I serve. It's people I help" (Q30 34B3T96M). Another said the same: "Personally, I don't see it as people that you serve" (Q08 38Wdg76M). Semantics aside, a Factor 2 understanding of 'community' is an enactment of influence for positive change and a commitment to enable others to get things done.

\subsubsection{But it's also about being realistic and practical}

Of the three factors, it is Factor 2 that carries the strongest shared disagreement with Item 11. The item was tagged with a Q-sort value of -5 in Factors 1 and 2 and -3 for Factor 3 with corresponding $z$-scores at $-2.403,-2.763$ and -1.326 . The difference in $z$-scores between Factors 1 and 2 is small at 0.360 and highlights the shared 'strong disagreement' around Item 11. But there is a nuanced distinction between Factors 1 and 2. The results just cited can be seen in the last line of Table 15, which is a truncated version of the Qsort value and z-scores by factor, sorted in descending order. This table re-lists the results for Item 22 and then for those items with Q-sort values ranging from -2 to -5 for Factor 2. It has been re-produced here for convenience.

Table 15: Q-sort values and z-scores by factor, sorted in descending order for Factor 2 truncated

\begin{tabular}{|c|c|c|c|c|c|c|c|}
\hline \multirow[b]{2}{*}{ Item } & \multirow[b]{2}{*}{ Short statement } & \multirow[b]{2}{*}{ Item } & \multicolumn{2}{|c|}{ Factor 1} & \multicolumn{2}{|c|}{ Factor 2} & Factor 3 \\
\hline & & & Q-SV & Z-SCR & Q-SV & Z-SCR & Q-SV Z-SCR \\
\hline 22 & come together to achieve something & 22 & 2 & 0.608 & 5 & $1.999 *$ & 10.332 \\
\hline ... & & & & & & & \\
\hline 12 & who they're accountable to & 12 & -2 & -0.605 & -1 & $-0.057 *$ & $-5-2.292$ \\
\hline 25 & the people I serve & 25 & 2 & 0.800 & $-1-$ & $-0.097 *$ & $-4-1.354$ \\
\hline 38 & concerned there's no transparency & 38 & -3 & -1.374 & $-1-$ & $-0.144 *$ & $-3-1.340$ \\
\hline 32 & not about you or me & 32 & 2 & 0.929 & -1 & $-0.168 *$ & 20.642 \\
\hline 29 & you've got to get on with everybody & 29 & -1 & -0.471 & -1 & -0.235 & $-2-0.723$ \\
\hline 41 & knowing your neighbours and knowing & 41 & 0 & 0.331 & -1 & -0.332 & 10.260 \\
\hline
\end{tabular}




\begin{tabular}{|c|c|c|c|c|c|c|c|}
\hline 18 & everybody who lives in that area & 18 & 3 & 0.940 & -2 & $-0.365 *$ & $5 \quad 1.890$ \\
\hline 37 & asking for input and then deliverin & 37 & 1 & 0.477 & -2 & -0.391 & $-1-0.547$ \\
\hline 19 & a risk mitigation strategy & 19 & -2 & -1.087 & -2 & -0.681 & $-2-0.797$ \\
\hline 24 & having fairly good infrastructure & 24 & -2 & -0.978 & -2 & -0.724 & $0-0.042$ \\
\hline 4 & is whoever I meet and whoever I nee & 4 & 0 & 0.172 & -2 & -0.751 & $-1-0.354$ \\
\hline 20 & Everyone. & 20 & 4 & 1.439 & -2 & $-1.148 *$ & $-1-0.489$ \\
\hline 13 & I don't know. It's hard. & 13 & -4 & -1.708 & -3 & $-1.203 *$ & $-1-0.263$ \\
\hline 14 & their whole life revolves around th & 14 & -2 & -0.920 & -3 & -1.335 & $-2-0.675$ \\
\hline 42 & some sort of stuff in the back padd & 42 & -4 & -2.323 & -3 & $-1.439 *$ & $-2-0.729$ \\
\hline 10 & where I don't see any school sores & 10 & -3 & -1.182 & -3 & -1.506 & 31.416 \\
\hline 43 & lowest level of local government & 43 & -2 & -0.743 & -4 & -1.858 & $-4-2.059$ \\
\hline 16 & anything outside Council & 16 & -3 & -1.449 & -4 & $-1.943 *$ & $-2-1.091$ \\
\hline 11 & a fictitious group & 11 & -5 & -2.403 & -5 & -2.763 & $-3-1.326$ \\
\hline
\end{tabular}

NOTE: Distinguishing statements are highlighted and have a $p<0.05$. Those marked with a red asterisk (*) indicates significance at $p<0.01$.

For the most part, the result and response to Item 11 continues to highlight the depth to which the participants themselves hold to the premise that 'community' is 'real'. As a Q sorter pointed out, "You can't make them up [as] there's too much involved" (Q27 44Ghb85C). But where the Factor 1 viewpoint tends to regard 'community' as an ongoing, stable constant in day-to-day life, the nuanced difference in Factor 2 is in an acceptance that 'community' can "collapse and disappear, and... re-form around different things" (Q28 57i2n32M). It was well illustrated by a Q sorter who referred to the rejuvenation of a context in which she was involved as the "history we've inherited" (Q27 44Ghb85C).

It was also as applicable to the participant who referred to those to whom she delivers a face-to-face service in building capability "as a community" (Q08 38Wdg76M), as well as those she connects with on Twitter. Both are very 'real' for her, and indeed, 'community' continues to be a very personalised notion across the Factor 2 conception. 'Community' is no less 'real' in terms of its importance or significance in people's lives, but there is, however, an element of functional pragmatism and realistic acceptance that its manifestation will rise and fall, expand and contract, and live and die as matters of importance change in priority. The Factor 2 viewpoint is considerably more open to and comfortable with diverse views and changing views.

That there is an underlying attitude of acceptance in lived realities and expressions of 'community' amongst Q sorts aligned to Factor 2 is also highlighted by a combination of results and remarks to three distinguishing statements that characterise Factor 2. They are Items 20, 16 and 42 and they are highlighted in Table 15. With Item 20, it has already been 
noted that 'It's everyone' is not the salient feature that it is for Factor 1. Instead, the Factor 2 conception is one where 'community' is "about a specific set of people" (Q20 48uWH85P), not the all-encompassing term that it is for Factor 1. For the participants whose Q sorts defined Factor 2, whatever it is that constitutes 'community' is determined by the extent of shared interests. It is as the tweeting participant had emphasised: it is possible to be a member of more than one 'community', and of many 'communities'. The results and responses to Item 16-'For me, in this role, the community is anything outside Council'-add further weight to the explicit recognition of multi-membership. This item drew the lowest of the Q-sort values across the three factors with -4 , which is a result that confirms strong disagreement with this statement in and amongst Factor 2 Q sorts. In this factor, a local authority is part of a 'community' and could be considered a 'community' of itself just as it is in Factor 1, but there is added acknowledgement that individual staff members are also part of their 'community' and 'communities'. One participant reiterated this point when she drew attention to her observation that "council staff are just everyday people who live in communities as well, who have to deal with issues... with mortgages, rates and insurance and whatever else they have to pay" (Q23 30KjD56P). Also noted earlier was her opinion, that "people forget... that council is merely the messenger for legislation" and "it's difficult... because they forget that amongst council, the council staff are just everyday people..." Another participant said much the same:

Statement 16 says for me in this role community is anything outside Council. Well I think Council is a part of this community. It's a hard idea to grasp but like it or not, people who work there live in the place more often than not. They're a part of community, they've got their kids enrolled in school. They buy their goods and services from local businesses. The individual employees are members of the community too. And Council by it's very nature is a key player and it is part of the community. (Q37 43xx185P)

This is not to say that the Factor 1 viewpoint cannot accommodate the idea that individual staff members are also members of a 'community' or 'communities'. What has been interpreted here is that the Factor 2 viewpoint is more explicitly aware of the dynamics of the settings and interactions in which, and with which, people live. As a consequence, this viewpoint is also comfortable with the realities of those circumstances and the diverse views that accompany them.

The last of the three items in this set supporting an interpretation that recognises the pragmatism in accommodating and acknowledging different points of view was Item 42 - Community is just some sort of stuff that exists in some back paddock somewhere 
that's absolutely okay to go out and raid every now and then for its capital resources instead of actually seeing it as the central dynamic of what's going on'. More specifically, it was the mixed reactions to Item 42 from two participants who had completed two Q sorts each that illustrated their openness to different ways of looking at something. In one Q sort that was ultimately flagged as confounded, a participant rank-ordered Item 42 as -5 , and her response was sharp: "Instantly disagree. Strongly disagree" (Q22 30KjD85C). She remarked on how the statement "rankled" because it carried "no sense of community whatsoever". She recalled instances of decision-makers who would "call on the uninformed masses when it suit[ed]... and then put them back out to pasture when... done with them". In this participant's second Q sort which loaded to Factor 2, Item 42 was rank-ordered at +3 . The participant herself identified the difference in placements and remarked how she "had a bit of a giggle" (Q23 30KjD56P). She was intrigued by her responses, but the $\mathrm{Q}$ sorter also acknowledged that it might be applicable in a civil defence emergency just as another participant had.

This second participant's first response to Item 42 was, “Oh, I don't like that one" (Q07 28aFZ57C), but after taking her time to re-read the statement, she reconsidered and remarked, "That's fair enough". Later, this participant explained that she had found the statement "tricky because a lot of this is in a community [response] plan". Her 'this' was an oblique reference to 'raiding', but without conceding to its use or remaking on its appropriateness. She did refer to examples of self-reliance in civil emergencies of the previous decade where "everyone has to come together to work" and she labelled those efforts as being "self-sufficient" as opposed to 'raiding'. The participant also linked this self-sufficiency to "people knowing each other [and] where the resources are".

So where the first Q sorter's placement of Item 42 was at -5 then at +3 for her second $Q$ sort, this second participant's rank-ordering barely changed with her first Q sort with Item 42 at -5 and her second at -4 . The first Q sorter's pair of results and her remarks illustrate an overt willingness to accept and acknowledge there is a different point of view. With the second Q sorter, there is some reservation, which is conveyed in the small change in placement for Item 42 and supported by her exchange of terms by referring to 'selfsufficiency' rather than 'raiding'. It may be a matter of semantics across all three factors, but for the Factor 2 viewpoint there is a demonstrable capability to accommodate different viewpoints even while personally disagreeing with a statement like Item 42.

A last pairing of items that adds further support for an interpretation of realistic 
pragmatism through Factor 2 are Items 19 and 38. Item 19, which reads as 'It's really a risk mitigation strategy', drew two reactions. One participant dismissed it as "a cynical way of looking at things" (Q21 40QNG11C), but went on to relate an observation naming a career bureaucrat whose default response to policy proposals was “yes-we've got to go and tell the community. We have to consult. We've got to let them have their say. And then we'll just do this". The participant disagreed with this "sort of attitude" and disapproved of any exercise intended to gain a ticked box for consultation. His objection was reflected in his placement of Item 19 at -3 in his Q-sort tableau. Another participant recognised that such a process might be construed as "sharing the load" (Q37 43xx185P) of decision-making by "inviting [communities] in... to be a part of a decision-making process or design or a policy design or its implementation". But she drew the line at any suggestion that as a risk mitigation strategy, 'community' is an acceptable "back stop" or a "fall back" (000505) position in the event of a project or policy failure. Her cynicism could be attributed to observations of policy initiatives where 'community' involvement was a "tokenistic" tick in the box. The dismay for these two participants (and others recruited to the study) was in the misalignment between what they saw and what they would like to see. While both preferred to see due attention paid to those who have interests in a matter and proper process to enable all forms of contribution to an issue, they were very well aware that it did not always work out that way.

Their concerns also tie in with Item 38- What I'm concerned about is that there's no transparency. There's no engagement with the community'. A third participant acknowledged that the statement represented the political reality in which she operates. The statement "made sense" (Q01 34B3T57M) to her; not only because she considered it "a political statement that's here all the time", but also because the response planning with which she was involved "should be all transparent, not to be hidden". For her, challenges to transparency are a political inevitability and are unavoidable. But more importantly, there ought to be an observable commitment to being transparent in one's dealings with those who are most affected. In that Q sort, she placed Item 38 at -3 , and in doing so affirmed her disagreement with the statement for that particular situation.

In a second $\mathrm{Q}$ sort completed by the same participant, she set Item 38 down at +4 . She openly acknowledged that her organisation "became that way" (Q30 34B3T96M); that is, 'lacking in transparency with no engagement with the community' is in part attributable to only the staff doing the engaging with little involvement from the decision-makers. The $\mathrm{Q}$ sorter went on to explain how "we learned from that" and it was "as a result of all the 
things that happened that we became transparent". She spoke of having learned "a bit more about the community and [being exposed to] the not so pleasant side of the active community". While she acknowledged "that you're putting your head out there to be chopped off sometimes", she rejected any possibility of cynicism creeping into her work and went on to note with a chuckle, 'I think they (the 'community') learned that the councillors do listen... but sometimes you have to really yell".

But there was also another take on Item 19. For a fourth Q sorter occupying a role in the managerial leadership domain, Item 19 conveyed the necessities and practicalities of survival, and he had much to say on the matter:

....at a basic human level, community-well grouping people together is a better survival strategy. Right? ...you as an individual human being stand a much better chance of survival and reproducing if you're in a community. If you're by yourself, you're kaput. Your chances of survival are that much lower. If you're in a community, you have access to more human capital, more manpower to actually create food, protect yourself-all of those sort of things. Find a mate. Reproduce. So that real basic animal level that's a risk mitigation strategy. Being part of the herd. That's what I meant by that. (Q24 55Ttx85M)

Like you know community exists in order to increase your chances of survival. If you're out on your own, and you get sick, you're buggered. Right? If you live in the wilderness yourself you've got to hunt for food. If you're part of a community where you agree, look we'll look after one another, you can spread the work. (Q24 $55 T t x 85 M)$

A fifth participant, also in a managerial leadership role by virtue of her employment, applied the statement to her situation. She saw Item 19 as exemplifying her work with young people where 'community' is a risk mitigating strategy. That is, the 'community' is the risk. In this participant's situation, youth were her 'community'. Not only was it necessary to ensure the safety of those she worked with, but also where they worked. She highlighted, "With my kids that's what we do. We look at the risks and plan around the risks" (Q40 51TvM32C). On the surface, these last two views seem very different from the previous three, but regardless of how each looked at Item 38, all of them point to a taking a pragmatic approach in their settings and being realistic about what that might look like. 


\subsubsection{Factor 2-Well, It Depends}

In summary, the Factor 2 'community' is explicitly interests driven, and if a participant aligned with this viewpoint were asked 'what does “community" mean to you?', the reply would likely be, 'well... it depends'. The 'Depends' is first and foremost on interest which, in turn, requires an innate awareness and acceptance of the range of interests involved. In practice, the 'Depends' of Factor 2 is the relational competence and capability to work with and accommodate diverse viewpoints and an attitude committed to enabling participation. Uppermost in the minds of those whose views are characteristically Factor 2 is the consideration for process where 'face-to-face' interaction is probably accompanied by a 'cup of tea' is business-as-usual, but the focus will be on getting the business done. Verbs like facilitating, connecting and brokering along with the phrase 'herding cats' would be apt, but in a way that is mindful of the dynamics of the settings and interactions in which, and with which, people live. It is a facilitated approach to decision-making. 'Community' is indeed a 'real' phenomenon, but the Factor 2 conception is also realistic and pragmatic about what that might look like in any given moment.

\subsection{The Factor 3 perspective}

Five of the $47 \mathrm{Q}$ sorts loaded to Factor 3. Two were undertaken by participants with roles from the managerial leadership domain, another two were from the perspective of community leadership roles and the last one was a Q sorter occupying political leadership roles.

\subsubsection{In practice, it is an inextricable account of 'all things'}

Commonalities aside, the Factor 3 conception of 'community' is very different from Factors 1 and 2. Its distinctiveness lies to a large extent with Item 28- 'To me, community is a whakapapa thing'. With a Q-sort value of +4 , this statement was the highest-ranked distinguishing statement and points to a theme where 'community' is, on a day-by-day basis, an inextricable account of 'all things'. The basis for this claim needs further explanation.

As useful as the factor analysis results is for setting down a pathway to interpret results, the interpretation for Factor 3 has been somewhat fraught because it draws on a Māori cultural 
concept that is foundational to understanding a Māori worldview. Like any concept outside a dominant discourse, incorporating the concept of Item 28's 'whakapapa' into the interpretation is all the more challenging because it does not have the same significance outside of whānau Māori settings. There is an awareness of 'whakapapa', but little in the way of widespread understanding. A cursory attempt to explain 'whakapapa' follows, but only to the extent that supports the interpretation of this study's selected solution, and its relevance to the scholarly context 'community governance'.

'Whakapapa' is a Māori cultural concept that Cleve Barlow (1991) has defined as "the genealogical descent of all living things" (p. 173). For some, the use of the term 'whakapapa' is applied strictly to the genealogies of people and the bloodlines from one generation to the next, and as Lynette Carter (2003) has identified, "in its simplest of definitions" (p. 7), 'whakapapa' is just that. But as she and Joseph Te Rito (2007) have warned, 'whakapapa' is "more than lists of names" (Carter, 2003, p. 7). Hond (2013) has described it as "a structure of integrated relationships" (p. 137) not only with people, but with all things. Just as it is an identifier of kinship and "relatedness" (Carter, 2003, p. 11) to the generations of the past, present and future, 'whakapapa' is also a reminder of the interconnectedness between humans, places and events in both the natural and spiritual worlds.

'Whakapapa' is also a "determinant of all mana" (p. 7) not only in terms of "kinship roles and responsibilities" on a day-to-day basis, but also one's "governance status" in certain affairs. 'Mana' here refers to power, authority or prestige (Barlow, 1991, p. 61; Moorfield, 2003c). This is an important point to note for this study because 'whakapapa' is a source of legitimacy. One's connections to people, to a place, to an issue, to a time are the basis by which some informants and participants occupy their roles. This is not as simple as it sounds, as there are checks and balances that operate in a framework of 'whakapapa'. What does need to be noted here is that although it may not be recognised, 'whakapapa' is a source of legitimacy of one's 'governance status'.

One instance that illustrates this claim was in the conversation with the source informant to Item 28. When asked the study question, 'what do you understand by 'community'?', she replied, “well, I guess for me, it's about... to me, it's a whakapapa thing” (103KjK96C). With this reply and the examples she used to illustrate her point, the informant identified her involvement was through her connections to place and to people. Through the history of environmental concerns and the future consequences of public policy, both she and another informant were motivated to environmental activism. 
Both expressed concerns about processes they deemed inadequate. The informant lamented that "a lot of people don't really have the ability to be aware of what's going on". The disinterest and lack of engagement worried her, but she also recognised that it did not help that certain entities "talk in a particular language", making it difficult to understand what is being proposed or considered. She and her colleague gave example after example illustrating their shock at the way those in managerial and political leadership roles treated them and their disappointment at the lack of substance and respect in their interactions and relationships. For them, it was absolutely crucial to understand the way people work as conveyed by Item 17_-Community is understanding about the way people work'. This view is consistent with Carter's (2003) summation of whakapapa as being "about relationships and the way we carry out relationships" (p. 12).

To return to Item 28 and the results of the factor analysis, the next table shows that this statement drew a Q-sort value of +4 . Given that it is also the top-ranked distinguishing statement with a statistical significance of $p<0.01$, Item 28 is the starting point and the foundation to understanding Factor 1. Note that the significance of $p<0.01$ provides added comfort that the result is not chance but one that is a genuine characteristic of the factor.

Table 16: Q-sort values and z-scores by factor, sorted in descending order for Factor 3

\begin{tabular}{|c|c|c|c|c|c|c|c|c|}
\hline \multirow[b]{2}{*}{ Item } & \multirow[b]{2}{*}{ Short Statement } & \multirow[b]{2}{*}{ Item } & \multicolumn{2}{|c|}{ Factor 1} & \multicolumn{2}{|c|}{ Factor 2} & \multicolumn{2}{|c|}{ Factor 3} \\
\hline & & & Q-Sv & Z-SCR & Q-SV & Z-SCR & Q-Sv & Z-SCR \\
\hline 18 & everybody who lives in that area & 18 & 3 & 0.940 & -2 & -0.365 & 5 & $1.890 *$ \\
\hline 7 & about whānau, about kōrero and about & 7 & 2 & 0.811 & 4 & 1.611 & 4 & 1.796 \\
\hline 28 & a whakapapa thing & 28 & -1 & -0.536 & 1 & 0.406 & 4 & $1.526 *$ \\
\hline 8 & Relationships. & 8 & 4 & 1.678 & 4 & 1.317 & 3 & 1.427 \\
\hline 10 & where I don't see any school sores & 10 & -3 & -1.182 & -3 & -1.506 & 3 & $1.416 *$ \\
\hline 1 & [no] understanding of the richness & 1 & 0 & 0.153 & 2 & 0.492 & 3 & $1.263 *$ \\
\hline 40 & being committed to the place & 40 & 3 & 0.941 & 3 & 1.059 & 3 & 1.153 \\
\hline 6 & some aspects are really important $t$ & 6 & 1 & 0.404 & 1 & 0.464 & 2 & 1.144 * \\
\hline 9 & where people are participating & 9 & 1 & 0.524 & 0 & 0.166 & 2 & 1.021 \\
\hline 3 & a key part is contributing as well & 3 & 3 & 1.101 & 2 & 0.764 & 2 & 0.951 \\
\hline 31 & where everybody has to take respons & 31 & -1 & 0.097 & 0 & 0.248 & 2 & 0.761 \\
\hline 32 & not about you or me & 32 & 2 & 0.929 & -1 & -0.168 & 2 & 0.642 \\
\hline 27 & very multi-layered, a here-and-now & 27 & -1 & -0.203 & 3 & 1.207 & 2 & 0.586 \\
\hline 36 & a variety of small communities & 36 & -2 & -0.862 & 2 & 0.806 & 1 & 0.522 \\
\hline 45 & best work over a cup of tea & 45 & 2 & 0.633 & 0 & 0.090 & 1 & 0.349 \\
\hline 22 & come together to achieve something & 22 & 2 & 0.608 & 5 & 1.999 & 1 & 0.332 \\
\hline 26 & may mean something different even $t$ & 26 & 0 & 0.389 & 3 & 1.140 & 1 & 0.311 \\
\hline 41 & knowing your neighbours and knowing & 41 & 0 & 0.331 & -1 & -0.332 & 1 & 0.260 \\
\hline 17 & understanding about the way people & 17 & 1 & 0.414 & 2 & 0.503 & 1 & 0.150 \\
\hline 2 & is not just about a group consultin & 2 & 1 & 0.427 & 1 & 0.345 & 0 & 0.147 \\
\hline
\end{tabular}




\begin{tabular}{|c|c|c|c|c|c|c|c|c|}
\hline 23 & sit[ting] face-to-face and talk[ing] & 23 & 1 & 0.409 & 1 & 0.374 & 0 & 0.131 \\
\hline 5 & can be sort of quite defined & 5 & 0 & 0.336 & 3 & 1.244 & 0 & 0.013 \\
\hline 44 & everyone's important & 44 & 5 & 1.773 & 1 & 0.381 & 0 & 0.003 \\
\hline 21 & groups of people engaging in conver & 21 & -1 & -0.249 & 0 & 0.045 & 0 & -0.017 \\
\hline 33 & a full chance to react to things & 33 & 2 & 0.909 & 2 & 0.910 & 0 & $-0.031 *$ \\
\hline 24 & having fairly good infrastructure & 24 & -2 & -0.978 & -2 & -0.724 & 0 & $-0.042 *$ \\
\hline 35 & the whole way we interact & 35 & 0 & 0.176 & 2 & 0.898 & -1 & -0.185 \\
\hline 15 & everybody gets an opportunity to hav & 15 & 3 & 1.094 & 1 & 0.330 & -1 & -0.242 \\
\hline 13 & I don't know. It's hard. & 13 & -4 & -1.708 & -3 & -1.203 & -1 & $-0.263 *$ \\
\hline 4 & is whoever I meet and whoever I nee & 4 & 0 & 0.172 & -2 & -0.751 & -1 & -0.354 \\
\hline 20 & Everyone. & 20 & 4 & 1.439 & -2 & -1.148 & -1 & $-0.489 *$ \\
\hline 37 & asking for input and then deliverin & 37 & 1 & 0.477 & -2 & -0.391 & -1 & -0.547 \\
\hline 14 & their whole life revolves around th & 14 & -2 & -0.920 & -3 & -1.335 & -2 & -0.675 \\
\hline 29 & you've got to get on with everybody & 29 & -1 & -0.471 & -1 & -0.235 & -2 & -0.723 \\
\hline 42 & some sort of stuff in the back padd & 42 & -4 & -2.323 & -3 & -1.439 & -2 & $-0.729 *$ \\
\hline 19 & a risk mitigation strategy & 19 & -2 & -1.087 & -2 & -0.681 & -2 & -0.797 \\
\hline 34 & Anyone who could be impacted. & 34 & 0 & 0.327 & 0 & 0.004 & -2 & $-0.900 *$ \\
\hline 16 & anything outside Council & 16 & -3 & -1.449 & -4 & -1.943 & -2 & -1.091 \\
\hline 39 & a whole lot of people behind us & 39 & -1 & 0.041 & 0 & 0.281 & -3 & $-1.138 *$ \\
\hline 30 & immediately identified by the hat & 30 & -3 & -1.242 & 0 & 0.055 & -3 & -1.199 \\
\hline 11 & a fictitious group & 11 & -5 & -2.403 & -5 & -2.763 & -3 & $-1.326 *$ \\
\hline 38 & concerned there's no transparency & 38 & -3 & -1.374 & -1 & -0.144 & -3 & $-1 \cdot 340$ \\
\hline 25 & the people I serve & 25 & 2 & 0.800 & -1 & -0.097 & -4 & $-1.354 *$ \\
\hline 43 & lowest level of local government & 43 & -2 & -0.743 & -4 & -1.858 & -4 & -2.059 \\
\hline 12 & who they're accountable to & 12 & -2 & -0.605 & -1 & -0.057 & -5 & -2.292 \\
\hline
\end{tabular}

NOTE: Distinguishing statements are highlighted and have a $p<0.05$. Those marked with a red asterisk $(*)$ indicates significance at $p<0.01$.

To help understand the significance of this distinguishing statement in Factor 3, consider the ranking of Item 28 across all three factors. As Table 16 shows, Item 28 ranked highest across the three factors: -1 for Factor 1, +1 for Factor 2, and +4 for Factor 3 . All of the participants had heard of the term 'whakapapa', but comfort levels amongst Q sorters varied.

Take the Q sort-value of -1 for Factor 1, for example. One participant conveyed reluctance because of his uncertainty of "the correct translation" (Q11 37ZGS11C). A second Q sorter acknowledged 'whakapapa' as "where you belong or where you live or who your family or where you [get involved]" (Q06 28aFZ57C), but she also pointed out that "it can be used to... shut people out as well". Another admitted not "really know[ing]" (Q19 33STg11P), but did venture, "It probably isn't what it should be [but] to me, ...it's the bringing together of things... [and] an involvement of everyone rather than the isolation". Even though a fourth participant was "not sure what whakapapa is" (Q46 63MKT57C), he stated he disagreed with the statement and set the item down at -2 . His reason for doing so was “because [that statement's] saying it's a Māori thing. And it's not. It's everybody”. These 
responses are examples of awareness of the cultural framework of 'whakapapa', but also discomfort, especially where is it perceived to contravene the 'Everyone' that characterises the Factor 1 conception of 'community'.

For those participants whose Q sorts defined Factor 2, individual understandings for Item 28 reflected a lived understanding. For example, a Q sorter pointed out that "that statement to me means forever" (Q03 31Fqz11P) and rank-ordered it at +2 in her own Q-sort that helped define Factor 2. She went on to explain that her own expectations were "regardless of what mood or what level of discomfort I might be experiencing at any time, well, too bad. I'm in and I'm committed". Her connectedness is long term and her connections are not for negotiation.

Two other participants with Q sorts loading to Factor 2 reiterated connectedness, but in different ways. One explained, "it definitely relates to connections" (Q40 TvM32C), but it is more about how "you look at relationships and how we work together, and how relate to each other along the way". The other was more forthright and rejected 'whakapapa' as the sole basis for 'community' and instead insisted 'community' is based on "actual living relationships" (Q24 55Ttx85M). For him, it is not enough to be simply related. What does count is one's contribution to an issue. After all, “it will never ever get better by being a spectator" (Q03 31Fqz11P). Like the participant in the previous paragraph, these two acknowledged their connections but both were focused on the value and contribution in those relationships.

From the Factor 3 defining Q sorts, Q18 was generated by a participant occupying a role in the managerial leadership domain whose work took her into settings where 'whakapapa' is understood and incorporated into everyday life. In her response to Item 28 she explained, "You see [whakapapa is] not really important to me because I still have my own cultural context. But [in my work], I really understand how important it is" (Q18 52w4y85M). To illustrate, she spoke about observing whānau Māori "com[ing] together and talk[ing] about whakapapa" and recognising that their "look[ing] back" informed their "going forward". Her observations are an example of how past events had a bearing on present-day relationships. But she went on to add how "[named groups] have such long memories [of] all the things that [have] happened" and amassed a "knowledge of who is trustworthy and who is not". Her addendum illustrates that 'whakapapa' as a form of knowledge is not just limited to events, but extends to an assessment of the characters involved. For the participants, it boils down to Items 8's 'Relationships'. 
The importance of relational connectedness in 'whakapapa' draws further emphasis with the consensus statement in Item 8 that is rank-ordered at +3 in this factor. This single word statement with a full stop- 'Relationships.'-drew an immediate and emphatic response (236Bz11M) to the question 'what do you understand "community" to be?'. As an employee (and therefore in a role in the managerial leadership domain), the informant spoke about how his work revolved entirely around his relationships with his governing body, with the volunteers he works with, and with the stakeholders who help make their initiative a success.

It is a response to 'Relationships' that all of the participants and informants of this study would endorse, but for different reasons. With its Q-sort value of +4 in Factor 1, the objective would be to assure the represented view is widely shared and understood, while Factor 2 approaches are committed to getting stuff done. But for Factor 3, long-term, durable relationships are a priority outcome in, and of, themselves. In other words, it is more important to have a right relationship with others than it is to be right about an issue. Against the overarching theme of 'whakapapa', the Q-sort value of +4 for Item 8 is a testament to that. It is also reiterated in participant responses.

What that looks like in practice for one policy advisor is that "it's always about building relationships of trust and it's always about listening" (Q18 52w4y85M). This is the same participant who recognised that 'whakapapa' was not really important to her, but it was for those she worked with. Her "complete realisation of cultural difference [that] is not just... superficial... [but deep and] all the way through" left her recognising that she "just couldn't use [her] own cultural context for anything". It meant building relationships were all the more important, and one way to do that was by "not putting your own world view in as an overlay onto anything you do".

Another item that adds further emphasis to the relational connectedness inherent in 'whakapapa' is Item 7-'So community for me is about whānau, it's about kōrero and it's about decision-making'. Whānau is widely understood to refer to one's extended family or family group and, for many, it is a "diffuse" (Durie, 1997, p. 1) unit of kinship based on a line of descent from a shared ancestor. Or as Hond (2013) has noted, 'whānau' has "become less associated with genealogical links and more aligned to areas of shared practice, common objectives or interests, and living or working in close geographical proximity" (p. 40). Both Durie's (1997) and Hond's (2013) explanations of whānau are reflected in the source informant's use of whānau. It is in the whānau setting where there is 
‘kōrero' and discussion sitting face to face, "kanohi ki te kanohi”" (16rT785P), and listening to the "grassroots point of view... and [their] lived realities". It is in the whānau setting where the decisions are made and where one is also held to account for those decisions.

For this participant, it is not the act of consulting that ought to be given precedence, but the process for problem-solving. It is a commitment to on-going dialogue that goes handin-hand with building 'relationships of trust' which are, in turn, manifestations of whakapapa. It is further support for the assertion that relationships are a priority outcome with effort and investment going into maintaining a right relationship, rather than being right. It all points to a holistic approach to 'community' as a practice.

\subsection{2 'Community' is place, place is 'community'}

The top ranking statement in Factor 3 was Item 18 and it has been dealt with second for reasons that will become clear. This statement read as:

From my perspective, when they talk about "my community", they're talking about everybody who lives in that area. And it doesn't matter what interests they have. It's everybody in that area.

For the study's participants, the part of the statement that captured their attention was the reference to area or place. The interpretation of the consensus statements results identified an implicitness of place and like 'community', it draws on various sources for meaning. However 'community' is understood, it is predominantly bound to place.

What the results also highlight is that there are subtle divergences in the nature of placebased-ness. For Factor 3, Item 18 was the highest ranked statement drawing a Q-sort value of +5 which is a quite a different rating to to the +3 and -2 for Factors 1 and 2 respectively. For Factor 1 where the emphasis is on 'Everyone', place is the setting or backdrop to the interaction and for Factor 2, where the attention is on interests, area is simply part of the context. Relatively speaking.

For Factor 3, on the other hand, place is what defines 'community'. A response that hints at this premise was from a Q-sorter whose Q sort helped define Factor 1. She spoke of how her father "had a strong association" (Q25 45PQ019P) with a named place and recalled his stories of living there. But the binding feature was its isolation which for health 
and safety reason, it was "absolutely and important and necessary that you know your neighbours". There was the example of the Q sorter whose life events and involvements sit within a single digit kilometre radius of his home (Q14 41DWX32C). Rather unhelpfully, there were no participant responses that can explicitly explain the high ranking of Item 18. But with a Q-sort ranking of +5 , it is significant.

It is pertinent here is to draw on the concept of 'whakapapa' as explained the previous section. Place is one of the many layers of Hond's (2013) structure of integrated relationships (p. 137) and 'community' is first and foremost place-based, although in different ways and for different reasons. For many of the informants and participants, issues centre on a named place or significant natural feature to such an extent that the place is the point of departure. It is not just a geographical reference for locational purposes. The place or the feature embodies and represents what it means to be and who one is. It is not just where one is from but what one is from. For the informants (03xhv96C, 03Kjk96C) whose concerns entered on the Waitara River, the river is who they are. For the one (10B3T57M) who spoke about her work with groups in Tikorangi, Ōākura, Inglewood, place was her identifier of them and their reported identifier of themselves. For others (05MuE76M, 2028A36M) was the mountain was the identity marker.

While it was not explicitly stated, what was perceived in the interviews with the informants and participants is a strong affiliation to place. The relevance of 'whakapapa' here is consistent with a line that embodies Whanganui iwi identity 'Ko au te awa, ko te awa ko au'. It is what Gabriel Marcel (as Relph (1976) cited Matore, 1966, p. 6) was said to have summarised as: "An individual is not distinct from his place; he is that place."

\subsubsection{But it's also about personal responsibility and accountability}

So with 'whakapapa' taken to be a constant reminder of the interconnectedness to, and between, all things and across generations, the Factor 3 conception of 'community' is that it is 'Everything'. Not just 'Everyone' as it is for Factor 1. Nor is there the pragmatic flexibility or political expediency of 'Depends' in Factor 2. 'Community' as a Factor 3 conception is 'Every' 'Thing', and with 'everything' comes personal responsibility and accountability, and this is made particularly apparent by Items 10 and 31 .

Item 10, which read as, 'It's a community where I don't see any school sores', drew a Qsort value of +3 . It was flagged as the third-highest distinguishing statement, and given the 
item's rank-orderings of -1 and -3 in Factors 1 and 2 respectively, it is easy to see why. Described as "a very interesting statement [that stuck] out as completely different to the rest" (Q47 44Gn576C), Item 10 triggered a range of responses.

For a participant whose Q sort was confounded across Factors 1 and 3, it was a measure of “doing something wrong” (Q17 47oyq11M). For another participant whose Q sort helped define Factor 1, Item 10 represented "the state of wellbeing of people who live in an area" (Q36 43xx128P). Although aligned to Factor 2, Item 10 was a challenge to a Q-sorter who saw it as "how we think [and] how we evaluate [ourselves]" (Q05 29jBV36C) and as "a sign... to worse things that are hidden away [where] maybe no school sores [are] visible but I see alcoholism and substance abuse". Another spoke of Item 10 as "a symptom a process that is broken... [and] of what's wrong" (Q34 49su96P) of an issue that is bigger than what can be seen on the surface.

A totally different response was that no 'school sores' was not necessarily evidence of 'community'. This participant explained that just because "you go to [a named school] where you won't see [school sores] there... that doesn't make them a community (Q24 55Txt85M). Later in the interview, he went on to explain that the statement "had more to say about socio-economics that it did about... people looking after one another". He pointed out "you could go to a rich community where that stuff doesn't exist, but those people could be as lonely as hell".

A very different reaction to Item 10 was its rejection. The first of five participants whose Q sorts loaded to Factor 1 exclaimed, “I don't see school sores. I've never seen them. [The statement is] irrelevant" (Q46 63MKT57C). He rank-ordered the statement as -1 in his own Q-sort. Another “wasn’t quite sure what it was saying” (Q39 60Jg332P) and positioned it in the -4 column of the Q-sort tableau. A third participant questioned the statement's relevance to the sorting instruction but did go on to acknowledge that "socioeconomic" (Q11 37ZGS11C) factors might be at play. Even so, he neither agreed nor disagreed with the statement and rank-ordered it as -2 . The was a similar response from a fourth Q sorter who acknowledged that his role does not require him to consider 'school sores'. He understood the point of view conveyed in Item 10 and recognised that 'school sores' "says to me there is help needed in my community"(Q10 366Bz11M), but it had no relevance to his role or to him personally.

A fifth participant saw Item 10 as "negative... very negative to me" (Q27 44Ghb85C) and 
deemed it to presume social deprivation. She rejected it as a "bench mark". A sixth participant identified it as "quite a narrow view" (Q28 57i2N32M) while a seventh labelled the statement as "stupid" (Q40 51TvM32C). Her reaction to Item 10 started with the statement but was soon extended to the author:

That actually should have really been the first at that end [with Item 11]. They should have been together. It's a community where I don't see any school sores. Where did they come from? Wrapped up in a bottle? A bubble? (Q40 51TvM32C)

What the responses to Item 10 add to the theme of personal responsibility and accountability is that there is an awareness amongst participants with a Factor 3 perspective of what might constitute success for a given understanding of 'community'. Although not every participant's preferred measure of success, 'school sores' may indicate something is broken, or be symptomatic of something wrong in a process. The measure may not necessarily be 'school sores' but the phrase 'school sores' could be representative of some other issue like alcoholism or substance abuse. However it is construed, the heightened sense of personal responsibility amongst the participants to do something about it was noticeable. It also illustrates an overt awareness of a system of inter-relationships and connections that characterise 'whakapapa'.

The second item that informs this them of personal responsibility is Item 31. As a distinguishing statement, it drew a Q-sort value of +2 . The statement read as, 'He used to say, 'everybody has to take responsibility'. I mean he would walk down the road and pick up the bloody rubbish because anybody can do that. You don't have to leave it to someone else.' The general sentiment is that there is no need to wait for "someone else to do" (Q18 $52 \mathrm{w} 4 \mathrm{y} 85 \mathrm{M})$ whatever it is that needs doing, "you can just do stuff yourself". The source informant intended the same, but it was the responsibility that went with it that mattered. She recalled:

He used to say, 'everybody has to take responsibility'. I mean he would walk down the road and pick up the bloody rubbish because anybody can do that. You don't have to leave it to someone else. He firmly believed that people had a responsibility to participate 'in the community' to make it better. So-yeah scary stuff really. (18D7K19P)

For one Q sorter, the "elements of personal responsibility" (Q36, 43xx128P) conveyed in Item 31 were also reflected in the commitment to place conveyed in Item 40 and Item 3's expectation of contribution. This participant had emphasised, "It is about being 
committed to the place where I live and saying, where I need to, 'I'll step up and make a difference"”.

Further support is provided in the result for Item 32-'It's not about you or me. It's about the community'. It drew a Q-sort value of +2 and indicates a degree of shared agreement amongst the seven $\mathrm{Q}$ sorts defining this factor. As the participants had pointed out, it was not about them as individuals, but about the 'community' in which they lived and worked. For one participant whose two Q sorts helped define Factor 3, the result for Item 32 is indicative of the selflessness that the study's recruits exhibited. The Q sorter explained, "As a councillor, it's not about me. All I'm there for is to represent everybody who put me on there" (Q14 41DWX96P).

Whether or not, this last participant was referring specifically to voters is not clear because in both his Q sorts, he rank-ordered Item 12-'It's who, I guess, they are accountable to, which is in the first instance the people who had voted them in'-as 0 and -2. For Factor 3, Item 12 was the lowest ranked distinguishing statement with a Q-sort value of -5 . The factor result is a strong indication of shared disagreement with Item 12 amongst the Q sorts defining this factor, but it is plausible that the disagreement is with the reference to voters. For another $\mathrm{Q}$ sorter, the role she occupied at that time was as a ministerial appointment and as she emphasised then, "no one voted me in" (Q36, 37xx128P). Her intimation was that as a ministerial appointment, and with the requirements of the role, accountability to voters was not a priority. It is the only response out of seven Q sorts that provides such an explicit explanation for Item 12, but when considered along side Item 32 and against the backdrop of Item 31, a Factor 3 conception of 'community' carries with it a critical awareness of personal and collective responsibility.

\subsubsection{Factor 3-It's Everything}

The underlying premise to Factor 3 is that it is grounded in 'whakapapa'. The Factor 3 understanding of 'community' is as 'a structure of integrated relationships' made possible by layers of connections. This perspective holds to an ingrained inter-connectedness to places, with people and to events across time and space. For this study, the Factor 3 'community' is one where 'It's Everything'. Relationships are long-term and enduring commitments created and maintained by building inter-generational trust through interaction and on-going dialogue. At their best, interactions are more deliberative with listening — and more listening-identified as a necessary relational skill. An added layer to a 
Factor 3 understanding and outworking of 'community' is the accompanying sense of personal accountability and responsibility that hold individuals to issues. The heightened sense of commitment is not inconsistent with the concept of 'whakapapa' when one also notes that it is a source of legitimacy for one's role in a decision-making setting. 


\section{Chapter 5: The implications for 'community governance' in Taranaki: the discussion}

The research objective of this study is to capture the operant subjectivities of 'community'; that is, the observable and measurable viewpoint of what is understood by 'community' amongst civic leaders in Taranaki. Using Q sorts as the key method for data collection, three viewpoints were extracted from a factor analysis of 47 Q sorts from 35 participants. The results and interpretation of the three-factor solution have been presented in Chapter 4. The elements making up those perspectives have been identified with particular attention to the points in common and the points of difference across and between those three factors. This chapter takes the interpretations of those results and considers three key implications for local decision-making as conceptualised in the term 'community governance'.

In this study, 'community governance' adopts Reid's (2010) definition where influence exercised by citizens through policies and practices empower them to make and shape decisions that affect them. In no way is 'community governance' seen as being solely about the elements of structure and process that tends to dominate the literature on the subject (United Nations Development Programme, 2004). Nor is it seen as the domain of local government, but rather as a sphere that involves "different tiers of government, institutions of civil society, and private sector interests" (McKinlay et al., 2012, p. 5). This study accepts 'community governance' involves many players operating through various structures and deploying a myriad of processes. However, the author's scholarly concern is 
with the views and opinions of those occupying roles of influence across Hambleton's (2011, 2015) leadership domains in those settings.

It is worth noting that 'community governance' was not a term that was widely recognised by the study's informants or participants. One informant did describe it as a "nice catchphrase" (26FG385M) with reference to a practice where a local representative body is told "these are the rules, [and] this is a little bit of money and you can play, but it doesn't really matter" because the next tier up is "taking care of the big stuff". The cynicism was noted. Another informant, after hearing an explanation of 'community governance', reflected that it was "just a fancy word for doing stuff" (24vTu57C) they were already doing and drew on numerous examples of people who "take responsibility for making sure things are done". While these two views illustrate reactions to the term that ranged from scepticism to appreciation, they are indicative of a knowledge of 'community governance' grounded in practice and experience. However, as Reid reflected, they "don't give a label to what they're doing" (personal communication, January 20, 2015).

At least, not yet.

It is against this scholarly backdrop that the discussion in this chapter addresses four points. First, there is an observable distinction between 'community' as a concept that frames policy discourse and 'community' as a practice that frames policy response. There is a discernible difference between the two. The implications for public policy are identified and discussed in this chapter.

The second key point looks at the lived and worked experience of 'community' as a way of governing. That realisation become more and more apparent as the research progressed. While the Factor 1 preference for face-to-face interaction over a 'cup of tea', and the facilitative approach of Factor 2 that prioritises processes in themselves may not seem extra-ordinary, the whakapapa-based practice conveyed in Factor 3 is. The discussion considers the ramifications for 'community governance'.

The third consideration in this chapter is a call to differentiate between 'communities' (plural) rather than 'community' (singular). While the use of 'community' has a role, the argument put forward here is that the plural would serve as a continual reminder of the diversities and the collective specificities of that which is held to be 
'community'. The discussion identifies benefits to this subtle adoption in policy practice.

The fourth discussion point examines whether the term 'community governance' is a fit and relevant descriptor for the decision-making that happens on a day-to-day basis. The proposition is that 'community' is a way of governing, which leads to an argument that the practice of 'community' described in this study signals a possible next phase in the evolution of 'community governance'.

\section{1 'Community' is undeniably important}

In general, 'community' is a term that helps make sense of the world. Its symbolism (Cohen, 1985) allows for multiple meanings which, in turn, supports a range of applications. Its deployment as a 'spray-on' (Bryson \& Mowbray, 1981) in the policy discourse may indeed secure the local buy-in necessary for implementing a policy initiative. Its use also inspires people to re-ignite the 'we-ness' (Bruhn, 2011) of their social relationships, and to rally them to a cause or shared purpose. This same elasticity makes 'community' as equally useful when seeking to influence proposals such as the examples set out in the very first paragraph of this thesis.

This study began with the same assumption; that is, 'community' helps make sense of the world, especially when it comes to responding effectively to local issues and concerns. Based on what the informants and participants in this research shared of their understandings and experiences of 'community', they, too, operate on a presumed shared understanding of what is meant by 'community' and they do so with apparent ease and comfort. It was particularly evident with one participant who acknowledged "small communities are there" (Q31 32MUE32M), but he also insisted there was "a definable... Taranaki community". In his explanation, he referred to the discernible attachment to place, and more especially to the mountain. He also pointed to the existence of a "Taranaki Inc.," and its function to provide direction and purpose. This participant, like all of the others, had no difficulty shifting across the range in the scale of 'community'. This is one example of the malleability of 'community' that scholars have noted.

There were, however, moments during the interviews that acknowledged 'community' was not a term where much, if any, thought had been given. One informant had noted how he had not thought about 'community' so much as he had in that research interview 
$(13 z \mathrm{Uj} 76 \mathrm{P})$. It was a self-identified revelation that seemed to surprise him. He was not alone. The study's recruits acknowledged bringing what they know and understand of 'community' to their respective decision-making settings. They recognised that what they know and understand about 'community' had been formed and developed through their own life-time of experiences and influences.

There were also instances where an understanding of 'community' seemed to be reshaped by existing influences of the situation. In a few instances, those views were re-oriented by the requirements of the role the study's participants occupied, but not to the extent where one could reach any conclusions. For example, that Factor 1 characterises those who occupy community leadership roles or Factor 2 is typical of those in managerial roles. As tempting as it is to make such a judgement, the results offer no such support as identified early in Chapter 4.

There was nothing in what the study's recruits shared that was at odds with what sociologists in general would present as a theory or experience of 'community'. People are, of course, central to the notion of 'community' as Hillery $(1955,1982)$ has established. In every attempt to explain 'community', informants and participants identified or referred to people. They also referred variously to a grouping of people in a locality who interact with each other in respect of a shared set of interests. Their understanding of 'community' features the same elements identified by Hillery; that is, area or place, social interaction or interactions and common ties or connections.

All three elements are especially observable in the results and subsequent interpretation of the consensus statements. The strength of shared agreement in Item 8's 'Relationships', along with the need for well-developed relational skills with a preference for face to face or kanohi ki te kanohi and a commitment for meaningful engagement speaks very much to Hillery's element of interaction. What that looks like for participants is being accessible, available and present, but, as was acknowledged over and over again, it does not necessarily mean having 'to get on with everybody' as stated in Item 29.

Item 8's 'Relationships' is also an articulation to Hillery's element of common ties or connections. Unsurprisingly, it is through 'Relationships' that connections are established and maintained. Arising from the common ties and characterise the inter-connections between people is the self-imposed or self-adopted expectation of contribution. This expecation was identified as the reason why participants and informants get involved in 
their respective decision-making settings in the way they do. Just like the participant who described himself as someone who used to "get into a bit of mischief" (Q29 59soV96P), and now wants to "put back into society what I took out years ago". Whatever the reason for his and others' involvement and contribution to a local cause or initiatives, they could all identify a common tie. For many, it was an intergenerational family presence and more often than not, it was a tie to place.

The study's recruits were chosen because of their involvements across various highly localised initiatives. Therefore the research as a whole is inherently place-based. Yet, even for this structuring characteristic of the study, the descriptions from informants and the responses from participants affirmed that stepping up and making a difference is an manifestation of "being connected to where you live" (Q31 32MUE32M) as conveyed by Item 40. Their input was an affirmation of Relph's (1976) place and Hillery's $(1955,1982)$ element of locality.

Similarly, informants and participants did not express any views contrary to what is prescribed or described as 'community' in the public policy domain. As noted as part of the literature review, 'community' has two interpretations in the Local Government Act 2002. Schedule 6 prescribes that 'community' can be in any part of a district, but it must also "be wholly within 1 district" (subsection (1)). Legislatively, a 'community' cannot span boundaries, nor can two 'communities' occupy the same area: "a community may not be constituted for any part of district if a community is already constituted for that part of that district" (subsection (2)). This strict legal interpretation for electoral, administrative and representation purposes was barely noted by the study's recruits except to acknowledge the district in which participants or informants lived. The other interpretation is that 'community' is whatever the context requires it to be. The former serves the machinery of government while the latter is consistent with Stoker's (2007) advice not to define 'community', and instead assume "there is sufficient consensus on what is understood by community" (Pillora \& McKinlay, 2011, p. 6).

The sufficiency in consensus in 'community' is also conveyed by the some-what high correlations that range from 0.4462 between Factor 1 and 3 to 0.6261 between Factors 2 and 3. The variation in viewpoints is wider between Factors 1 and 3 than it is between Factors 2 and 3. Another way to put it is that the viewpoints of Factors 2 and 3 are more alike than they are between Factors 1 and 3. However, given that factor correlations should be below the significant factor loading (Watts \& Stenner, 2012, p. 141) which for this study 
is 0.3846 , there is a question as to why the variation between a pair of factors matter. For Brown (2011), the factor correlations of this study would be tagged as concerning but only if one were to ignore the context in which the study was located. Brown has acknowledged that reality is not neat and tidy and this study accepts the same. Reality is messy.

All that aside, the somewhat high correlations add support to Pillora and McKinlay's (2011) assumption that there is sufficient consensus on what is understood by 'community' (p. 6). All three factors are founded on expectations of contribution and reciprocity where there is a 'giving back' and a 'taking part' in what is going on. Whatever the form one's contribution might take, there is shared agreement that one's contribution should give rise to interactions that are meaningful and engaging. Being available, accessible and present helps without any requirement to secure agreement on every issue or having 'to get on with everyone'. However, 'community' is conceived, its enactment is one where the participants and informants of this study value rightness in their relationships with others, and as such, they conduct themselves accordingly.

But what those same correlations also draw attention to is the nuance between perspectives and without a doubt, they are subtle. It is easy to see how the distinctions between the three factors can be overlooked when considering a policy project. It is not until one is onthe-ground and deep in the implementation that something about an initiative is perceived as off or out-of-whack.

One possible explanation as to why is that when informants and participants reflected more deeply on the term, they spoke about 'community' in terms of what they do, and the way they conduct themselves. In other words, they did not describe 'community' as an abstract concept or a thought that sits outside and separate to their lived experiences and realities. Instead, they view 'community' as an activity and a practice of their everyday work and lives. The view that 'community' equates to 'doing' was apparent early in the informant interviews, and was restated over and over again in participant responses. It was also confirmed in the factor analysis results.

Many examples of 'doing' have already been presented in Chapter 4. However, one example that has not already been cited was given by an informant who insisted, "You've got to be on the ground" (27xhn96P) to hear from those who are or could be affected and to see the impact of the decisions that may be, or were being, made. This informant expressed disappointment in elected members of the local authority who made no effort to 
visit where he lived. In his opinion, the elected members' actions-whether they were intended or not-conveyed disinterest and a disconnect on their part. His perceived lack of their role modelling reinforced a view that "you always make people welcome to come along and talk to you and that's number one" (002810). His enactment and practice of 'community' involves seeing and hearing matters of concern for himself. This example, along with all of the others cited throughout this thesis, identifies 'community' as a practice, or an enactment and it is one that frames his response to policy initiatives.

There are, therefore, two uses of 'community' at play. The first is as a concept that frames the talk around a policy issue. Admittedly, it does provide considerable administrative convenience as observed by one participant and it is useful for getting people on board. But it is not the same as the second use of 'community', which is as a practice that frames the way those who are affected respond to a policy proposal. People do not live in the abstract, theoretical version of 'community', but in their individual lived experiences and manifestations of 'community'. While each experience is unique from one person to the next, this study has identified three nuanced perspectives to which policy designers and advisors are oblivious, or deliberately overlook. The challenge for public policy work is how to acknowledge and give proper account to the subtleties as Barraket (2004) and Collins (2010) have urged. A solution is proposed later in this chapter.

In this section, 'community' as a practice is quite distinct from 'community' as a concept. The latter is a frame for policy discourse while the former is a frame for policy response. This is a distinction that has yet to be explicitly identified in both the academic or practitioner domains of 'community governance'.

\section{2 'Community' as a way of governing}

With 'community' now identified as a practice that frames policy response, it could be argued that as a mode of conduct and practice, it is addressed by Hillery's $(1955,1982)$ notion of interaction. That would be appropriate if one were looking for a broad category, but this study has identified discernible nuances that reorients the notion of 'community'. The reorientation is not a dismissal of 'community' as a conception that helps make sense of the world or its theoretical roots. Applying Blackshaw's (2010) argument, there is no need to refuse one in favour of the other (p. 7). What is proposed here is that it is also a practice and an enactment. 'Community' is not just being, but also doing. It is a practice 
that frames policy response.

Consider the nuanced features of a Factor 1 approach to doing 'community'. Interactions are especially personal probably involving a 'cup of tea'. These encounters are purposeful, supporting information-sharing and expediting accountability. Done well, these interactions inform decisions and actions, as well as building trust and strengthening relationships. Done poorly, people are left feeling 'raided'. With a Factor 2 practice of 'community', the primary consideration is the range of interests with emphasis on processes that enable, facilitate and support participation. A phrase identified as an apt descriptor for those whose practice is characteristic of Factor 2 was 'herding cats', but there is a mindfulness of the dynamics that go with lived lives of those who participate in the decisions affecting them. The underlying strategic activity to a Factor 2 practice of 'community' is in enabling participation. The face-to-face interaction of the Factor 1 approach to establishing feedback loops that support decision-making and the strategy of enabling that characterises Factor 2 are particularly illustrative of Reid's (2010) 'community governance'.

The Factor 3 approach to 'community' is one based on the Māori cultural framework, 'whakapapa', and it is one that provides for an expansive account of 'community' and 'community governance' issues across time, people, places and events. As both a concept and practice, 'community' is 'Everything'. The verifiable connections that one has to these elements as well as issues may even determine and establish the mandate by which a person may lobby for endorsement or rally for support. On its own, a claimed connection is not in itself sufficient as a track record of personal responsibility and accountability.

Of particular interest and significance in this study is that it empirically identifies 'whakapapa' as a basis for 'community' and 'community governance'. It is unlikely that it would have been possible to identify 'whakapapa' as an underlying structure to the talk around 'community' in the context of 'community governance' in New Zealand without Q methodology. Q methodology allows the researcher to uncover structural relationships by first analysing the correlations between the statements of each Q sort, and then between each of the $\mathrm{Q}$ sorts. This is a powerful feature. Without the principles of statistical inference underpinning factor analysis, it would have been very difficult to see or to justify the significance of a framework like 'whakapapa' that sits outside the conventional and the expected. 'Whakapapa' is a different way of thinking as highlighted by a participant who identified her own lack of understanding as a "complete realisation of cultural difference" (Q18 52w4y85M). Q methodology's ability to accommodate the alternate 
views, the different perspectives and the latent ideas is what makes its use attractive in policy analysis. 'Whakapapa' might not otherwise have been objectively identified as a point of difference or interest.

In itself, 'whakapapa' is its own topic (Barlow, 1991; Carter, 2003; Te Rito, 2007), but for the purposes of this discussion, it serves to re-orient a way of thinking about 'community' as "a structure of integrated relationships" (Hond, 2013, p. 137) that are enduring and long-lasting. The relationships that characterise 'whakapapa' extend beyond people to all things including places and events along with their respective histories and futures. For one participant, it has meant acknowledging that there are people who know what took place where and when, as well as who was involved (Q18 52w4y85M). It also requires being able to recall those events, places and people so that one may know how to decide how to go forward. It also means knowing who can be trusted and who ought not be. This elaboration of whakapapa, relationships and interaction also points to Rose's (1999) diagnosis of 'community' as "a moral field binding persons into durable relations" (p. 168). 'Community' is really about relationships and for this study's informants and participants, it always has been. It is just what they do.

With 'community' being more about practice rather than an abstract conception, the way people conduct themselves frames their policy responses. Whether that response is lobbying for a seat at the decision-making table, opposing a boundary change or reacting to a threat of environmental degradation, the way people behave and the extent to which their operant subjectivities are manifest sets the tone and forms the basis for meaningful engagement. Face-to-face interactions that have purpose and usually includes a 'cup of tea' characterise a Factor 1 practice of 'community'. For Factor 2, it is the ability to facilitate a workable outcome, while for Factor 3, it is the exercise of personal responsibility and accountability to the 'whakapapa' of an issue.

An alternate interpretation of the results presented in the previous chapter would be to claim 'community' means something different to each person. There are the common elements that Hillery $(1955,1982)$ identified (that is, people, interaction, area and ties), but the elasticity in its meaning make it tempting to accept this dynamism as a characteristic of local decision-making. However, to make such a concession in a thesis philosophising on public policy would be an endorsement of the very behaviour that Collins (2010) warned against. Because 'community' can be whatever the public policy context requires it to be, Collins's concern is that it has become a marginalised, apolitical sphere that frames policy 
debates. As a result, 'community' may be well be 'a unit of administrative convenience' especially when added as an adjective to identify boundaries or focus, or deployed as a 'spray-on additive' (Hond, 2013) to instil warmth. The term 'community' frames policy discourse.

For Blackshaw (2010), the state's appropriation of 'community' has set it with a "false face" (p. 207) that is often made compelling by its "pulling-togetherness" (p. 208). Interestingly, a Q-sorter used the phrase "false mask" (Q04, 31FqZ85C) as reflection of her conviction that a decision-making forum she involved in was "not doing as good of a job as it should be [in] being local representatives and part of the local community". She surmised that if that Board were disestablished, there would be no detriment whatsoever. Blackshaw (2010) went on to conclude there was nothing more for 'community' in politics "other than its appropriation" (p. 208). While that sounds bleak, Blackshaw has suggested it need not be and could be addressed by "muster[ing] a comparable critique" (p. 208) of neoliberalism. All that this thesis can contribute to Blackshaw's call for critique is to highlight that the lived and worked experiences of 'community' such as the many presented in this thesis is a starting point. It is here in the ordinariness of 'community' as a practice that Blackshaw's (2010) critique lies and it goes unobserved. It is overlooked because 'community' is an activity and a practice in the everyday work and lives of the study's recruits. It also happens to be that the study's recruits' enactment of 'community' is as a response to policy issues. It is a way of governing.

This study confirms that 'community' is as pervasive in contemporary politics as Collins (2010) has concluded "remaining hidden in plain sight" (p. 23). This study has also uncovered that while there is a concept of 'community' that frames policy discourse, there is also a practice of 'community' or a way of governing that frames policy response. The challenge is in distinguishing between the two given that there are ways in which to talk about 'community'; and ways in which 'community' is enacted. It is the latter that forms the basis on which this study's recruits operate.

\section{3 'Communities' rather than 'community'}

There is an interesting paradox in this study's findings. On one hand, the high factor correlations (0.6261 between Factors 1 and 2, 0.4462 between Factors 1 and 3, and 0.4922 between Factors 2 and 3) suggest that the three factors are aspects of the same underlying 
feature, or what Watts and Stenner (2012) referred to as "alternative manifestations of a single viewpoint" (p. 141). It reveals a possibility that this study's factor analysis simply identified three sides to the same conceptual coin.

On the other hand, the notion of 'community' is problematic with a multiplicity of meanings that can vary with each participant's (and by extension, each informant's) orientation to the idea (Cohen, 1985). It is a given that there is no agreed definition of 'community' in the general sociological sense of the word, and nor was one sought for this study. However, as Collins (2010) pointed out there is no need for agreement on the definition. Instead, all that is required is agreement that the idea of 'community' is significant. The findings of this study affirmed the same in a number of ways. For example, the profound significance of 'community' was especially evident in the strongly shared offence taken to Item 11-'a fictitious group'.

However, despite this paradox, there is one aspect of 'community' that was not obvious in the quantitative results, but was discernible in the qualitative aspects of the findings. In this study, the ease with which informants and participants alike moved across a range of interests, geographies and interactions all while referring to 'community' was particularly notable. As empiricists in their own right, the informants and participants shared observations and experiences that identified 'communities'. Interestingly, they never operated in only one space that they labelled as 'community'. There were overlaps and subsets of all sorts of combinations, as well as discrete groupings, but the study's recruits almost always spoke of more than one 'community'. This observation triggers whether consideration ought to be given to referring to 'communities' in the plural instead of 'community' in the singular, and the extent to which that should happen.

Whether more precision really is needed is debatable. The term, 'community', is already known for its malleability (Cohen, 1985). It is a characteristic that is not likely to change. 'Community' is also recognised as a "word of choice" (Hond, 2013, p. 20) in public policy initiatives when support and endorsement is needed to further political agendas. The term's ability to hold many and "often contradictory meanings" (Collins, 2010, p. 11) make it possible for people to use the same term as someone else without diminishing another person's understanding of 'community'. Local government, which is a key player in "enabl[ing] democratic local decision-making and action by, and on behalf of, communities" (Local Government Act, 2002, s. 10(1)(a)), is reported to be accepting of the presumed consensus of 'community' (Pillora \& McKinlay, 2011). It is undeniably useful to 
leave the word 'community' undefined.

However, Collins's (2010) and Barraket's (2004) apprehensions must be taken into account. Both have expressed concern about how the use of 'community' represents a marginalised sphere that frames policy debates and 'a unit of administrative convenience' (Q36 43xx128P) as one participant put it. For Collins (2010), 'community' is reduced to being "geographically specific, culturally homogenous, and inherently apolitical" (p. 9) that fails to recognise and acknowledge "the range of values and perspectives that exist at the local level" (Barraket, 2004, p. 236). Barraket has argued that ignoring the diversity of views and power relations will make place-based policy interventions "potentially ineffectual" (p. 237) and undermine any possibility of success. Indeed, the word 'community' in its singular form inadvertently forces users to think of 'community' as an aggregate of people and of interests even though that may not be the intention. The consequences to 'community' being used without any thought to what is being said are that diversities are aggregated out, differences are smoothed over and inequalities are ignored. As a result, 'community' as a term that embraces the myriad of conceptual nuances identified in this study is hidden, overlooked and unconsidered, and left without an analysis of its richness.

Reflection and critical thought are needed to help lift the concept and practice of 'community' to a level of critical consciousness. In the very least, those in roles of influence in local decision-making settings are urged to ask themselves 'what is community for me in this role?'. It is a question that is not asked as directly as it ought to be. That it was taken for granted was affirmed by an informant who recognised the research interview was "probably the most [he had] thought" (13zUj76P) about 'community'. He was not the only one to express this sentiment. That being so, policy advisors and designers could ask themselves the same question even if only to identify their own assumptions.

Another potential consideration is to use 'communities' in its plural form rather than 'community' in its singular. So instead of referring to the 'Taranaki community' to represent anything other than people living in the region known as Taranaki, it is more useful to speak of 'Taranaki communities'. Unless the term 'community' has a very specific purpose, 'communities' ought to be used, especially where there is a lack of specificity about whom or to what it relates. It is a small effort to replace the ' $y$ ' with an 'ies', but if applied mindfully, it serves as a reminder to users-speakers and listeners, writers and readers, supporters and opposers_of the diversities that characterise the very 'communities' they claim to represent. It is an explicit acknowledgement that there are 
many 'communities' whether one is talking about one of the multiple versions of 'everyone' identified for Factor 1, or interests of Factor 2 or layers of 'whakapapa' that underpin Factor 3. These three understandings, and as a consequence, their practices of 'community' are themselves nuanced, which adds further support for promulgating the plural 'communities' over the singular 'community'.

The use of the plural is also an explicit reminder that there are diversities, differences and even disparities within 'community'. In other words, users will be reminded of the very characteristics that make whatever they hold 'community' to be distinctive and significant, and in doing so, support them to give proper regard to those diversities, differences and disparities.

The singular form, 'community', certainly offers considerable administrative convenience and a degree of political expedience, but it is not an accurate reflection of the experiences of this study's informants and participants. The alternative to using the word in its plural instead of its singular form is to stop using the word 'community' altogether. However, that is neither a realistic nor a viable option.

Using the term 'communities' will go some way to addressing Collins's (2010) and Barraket's (2004) concerns about the way the concept of 'community' tends to be diminished. Furthermore, it also has an important role in reorienting 'community governance' as a practice. This proposition is discussed in the next section.

\section{4 'Governing communities' reorients 'community governance'}

As with all concepts, 'community governance' has evolved with use and continuing scrutiny. Reid's (2010) timeline of the concept's development identified Stewart and Stoker's (1989) “community government” (Reid, 2010, p. 81) as a starting point. This term referred to local authorities working with their citizens to address issues of concern with an expanded role as an enabler rather than just as a service provider or a regulator. However, the phrase failed to attract academic attention because it did not "reflect the nature of the new relationships that were evolving and... extended beyond the traditional boundaries of 'governments"' (p. 82). By 1994, Stewart and Clarke used the phrase 'community governance' in response to the public sector reforms in Britain in the 1980s and 1990s 
(Miller, Dickson \& Stoker, 2000, p. 12). One of the challenges that rose out of those reforms was the difficulty in achieving whole-of-government outcomes. The singlepurpose focus of departments rendered them incapable of adapting to the demands of a place-based approach in an environment that was constantly changing, while at the same time having to meet national standards in performance.

In Reid's (2010) opinion, that challenge threw the spotlight on the one advantage that local government had over central government; that is, local authorities were recognised as "the most knowledgeable agencies in their localities, better placed to make the connections between local service providers than any other single organisation" (p. 83-84). This advantage, or "special position and role" (Stewart \& Clarke, 1994, p. 201), can be attributed to local authorities being multi-purpose entities with the power to set and collect rates, and which are controlled by elected representatives exercising the decision-making power to determine priorities and allocate resources. Furthermore, they have "the right and responsibility to speak out on issues of concern to its area" (p. 201). In other words, of all the entities in the public sector, local government is seen as close to its citizens while central government is not.

McKinlay's et al. (2012) more recent research into 'community governance' in Australia has led them to identify a "growing distinction between the formal role of local government and the practice of governance" (p. 47). Local government may not necessarily be the central actor. It might be in one situation, but not in another. McKinlay and his colleagues have defined 'community governance' as "a collaborative approach to determining a community's preferred futures and developing and implementing the means of realising them" (p. 5). However, in practice, it might involve any number of other players from "the different tiers of government, institutions of civil society, and private sector interests". Reid (2010) would not disagree, but his definition explicitly assigns agency to 'communities'. For Reid, 'community governance' is "governance exercised by communities themselves... [through] policies and practices that empower citizens to make and influence decisions that affect them and their communities" (p. 81, emphasis added). In a later paper, McKinlay (2014a) expressed a similar view, positioning 'communities' at the centre of 'community governance'.

As a concept, 'community governance' was not a term that was widely known amongst those elected to, or employed by, councils, and pertinent to this research, by this study's recruits, even though the term has been explicitly used in local government discourse in 
New Zealand since 2002. Only three of the 29 informants conveyed a self-identified working understanding of the term 'community governance'. Others suggested they might have heard of the term, but not adopted it, and some admitted they had never heard of it at all.

For one informant, it was seen as "a nice catchphrase" (26FG385M) that she associated with Auckland's local government arrangements. In her mind, 'community governance' looked and sounded like "these are the rules, this is a little bit of money and you [Local Boards] can play, but it doesn't really matter [because] we're [Council is] taking care of the big stuff". Other informants ventured a guess as to what it might mean, breaking the term down to its component parts: 'community' and 'governance'. Almost all of the study's recruits were certainly interested to learn that they were already practising some aspect of 'community governance'. For example, after it had been explained to her, one informant remarked, "It's just a fancy word for doing stuff" (24vTu57C). The reactions from informants and participants illustrate the existence of a disconnect between day-to-day practice and academic theory. As a result, while 'community governance' might be a part of theory informing local government practice, it has no relevance to those who are on the ground, amongst the people and at the coal-face of 'community governance'.

There is, however, a way forward.

Reid (2010) has explained that 'community governance' also "signalled a shift in thinking from a focus on governing organisations to governing communities" (p. 86). He later confirmed that the phrase 'governing communities' was an impression he had formed while reviewing the literature relevant to his thesis (personal communication, January 20, 2015). Further reflection on this term identifies 'governing communities' as the next step in the evolution from Stewart and Stoker's (1989) 'community government' to what is currently known as 'community governance'.

One reason for this assertion is drawn from an informant whose extensive local government experience afforded a more in-depth conversation about the terminology. She pointed out that the term 'governing communities' sounded “a little bit more authentic" (26FG385M), but that it was also "a little bit harder and a little bit more complex". This informant noted that the realities of "communities' are "a little bit more multi-layered and multi-dimensional and a little bit more challenging", which, in turn, requires a commitment to "proactively engaging with them in a way that they 
[communities] engage back".

This call to be proactive in engagement is consistent with the practices of 'community' identified in the three factors of this study. With Factor 1, where it is important for 'everyone' to 'have a say', the practice will likely be 'we'll have a cup of tea, we'll discuss something, and then we'll make it happen'. Efforts will go into sharing information and getting feedback on a proposal, and reaching as wide an audience as possible. The Factor 2 approach is more targeted to those who have an interest in the matter. There will be opportunities to participate but considerable thought will go into providing 'different types of cups of tea' to engage with those who would not normally be involved. For Factor 3, the engagement is more deliberative in nature with acknowledgements to the history of events or the issue, the network of contributors and potential future consequences. The beliefs, or operant subjectivities, are manifested in the examples of 'doing' as noted earlier in this paragraph, or what Reid (personal communication, January 20, 2015) has referred to as "the business of governing communities".

However, this 'doing' could also be called 'community governance' work. For a researcher, an academic or a consulting practitioner listening to what the participants and informants do in their practice of 'community', it is 'community governance' work. But this is not a phrase that many of those involved with this study would use. Only a few could do so with observable confidence. One could speculate that as an adjective, perhaps as the 'spray-on additive' Hond (2013) noted, 'community' instils scepticism, while the term's association with the corporate sector and its managerialism gives rise to making 'governance' a profession. This is not to say that the study's recruits would take up 'governing communities', but because the phrase is oriented to the activities and tasks of 'governing' and to putting 'communities' at the centre of the concept, it is a 'more authentic' representation of what is already happening. Furthermore, if one informant thought the phrase was 'more authentic', then others might, too.

Thus, the term 'governing communities' has potential. Consequently, its viability needs further consideration especially if one accepts that governance is primarily "about how members of a society make decisions about their collective welfare" (Reid, 2010, p. 267). Determining its viability ought to start with salon-type conversations with those who do the work of 'governing communities' in order to identify their reactions to the idea along with any concerns or expectations. This suggestion assumes the research would continue in Taranaki. However, case studies of Southland, Thames-Coromandel, and Queenstown 
Lakes Districts (all in New Zealand) would be useful comparators. McKinlay (2014a) has identified these districts as placing "a strong emphasis on working with their communities whether or not they are formally constituted” (p. 9). Taking McKinlay's suggestions even further, jurisdictions known to be highly centralised in their decision-making should also be included in further research. As a series of case studies, they would all be useful additions to the growing body of knowledge and analysis of the local government sector in New Zealand.

An alternate pathway is to develop a conceptual framework of 'governing communities' as it applies to Taranaki. It would draw heavily on the worked experience of its contributors and acknowledge the social and political realities of day-to-day life, and provide the basis for further discussion and development.

Whatever path the research takes, the anticipated challenge will be in shifting the perceived 'centre of the universe' away from institutions to 'communities'. The study's informants and participants would welcome such a shift, but they would be wary lest the inertia of the machinery of government hampers efforts. McKinley (2014a) has identified a "need for a new theory" (p. 28) where 'communities' are "the node around which governance revolves" rather than the institutions of either central or local government. However, it will require a shift in thinking from traditional approaches where societies and 'communities' have organised themselves, usually through associations and institutions. One difficulty will be in being able to identify the 'communities' at the heart of a political theory without relegating them to the status of a stakeholder, a consumer or a resource.

The proposition here is that adopting the term 'governing communities' will reorient 'community governance', and trigger the "interpretive shift" (Collins, 2010, p. 10) necessary to put 'communities' at the "heart of politics itself". 


\section{Chapter 6: A future direction for 'community' in Taranaki: the conclusion}

This study set out to understand what 'community' means to those who occupy roles of influence in decision-making settings in Taranaki, Aotearoa-New Zealand. Taking advantage of her position as an embedded participant in the research setting, the researcher asked her informants and participants, 'for you in your role in a given 'community governance' context, what do you understand by 'community'? From this question, the objectives were to identity the key components to their perspectives of 'community' and identify the points in common and points of difference.

Data was collected and analysed using Q methodology. This methodological innovation in the study of subjectivity introduced by William Stephenson (1902-1989) in 1935 comprises a set of techniques that supports the examination of first-person perspectives on a topic. The outcome for this study was a three-factor solution generated by 35 participants completing $47 \mathrm{Q}$ sorts that were then analysed using PQMethod 2.35. These participants rank-ordered 45 statements extracted from 27 interviews with 29 informants.

Asking 'what is community' was a deceptively simple question, but just as many scholars have pointed out, it was not an easy question to answer. The informants and participants of this research alike found the question thought provoking. However, this study was not a search for the ever-elusive definition (Hiller, 1955, 1982). Instead, it affirmed 'community' as a term of significance and a notion of profound importance in making sense of the 
world as has been widely noted in the literature (Cohen, 1985; Little, 2002; Collins, 2010; Bruhn, 2011). This study provided numerous illustrations of how individuals' understanding of 'community' determines the way they organise ourselves and make decisions (Fulcher, 1991; Rose, 1999; Barraket, 2004; Blackshaw, 2010). It served to reiterate how overlooked the influence of what individuals understand by 'community' has in, and on their everyday lives (Barraket, 2004; Collins, 2010) and more particularly for this study, its manifestations as practice in the public policy domain of local governance.

Like Eo and Kim (2016), this research has found that there are "distinctively different" (p. 25) perspectives of 'community' amongst those who were involved in the study. Even though the factors were somewhat highly correlated, what has been identified in this study is that there are three nuanced perspectives or operant subjectivities of 'community' amongst the study's Q sorters. The Q literature confirmed that the correlations between the factors are not so high as to identify conclusively a single viewpoint of 'community' (Brown, 2011; Wingreen, 2011), but they are high enough to suggest that the three factors are nuanced points of view of one widely understood conception of 'community'. It is the nuance of each perspective that has been described and discussed in this thesis agains the backdrop of consensus.

The finding that each factor is characterised by certain practices of 'community' with its peculiar forms is a distinctive contribution to scholarly knowledge. Those whose views align with Factor 1 see 'community' as 'everyone_-and we're all in this together' with a proviso that 'everyone' here is not literally every possible person. The shared sentiment arising from this research is that individuals can achieve anything as long as they focus on what needs to be done, do it together, and look out for each other along the way. For those with a Factor 1 perspective, the emphasis is on people and their social wellbeing and 'community' as a practice prioritises face-to-face interaction. The extent to which one can participate in face-to-face interactions that have purpose, and usually feature a 'cup of tea', is a determinant of membership. As mediated encounters, these interactions expedite accountability and information-sharing. Implemented with consideration, those interactions inform decisions and actions, as well as building trust and strengthening relationships. Executed without any accountability, there is a risk that people are left feeling rankled, or worse still, raided.

With Factor 2, 'community' is less about 'everyone' and more explicitly about interests. If a participant aligned with this viewpoint were asked 'what does “community" mean to you?', 
the reply would likely be 'well... it depends'. 'It depends' first and foremost on interests, and 'it depends' on the process used to promote participation amongst those interested or affected by a policy proposal. For those who operate from a Factor 2 perspective there is an innate acceptance and capacity to work with diverse and multiple interests and views. Their practice of 'community' is facilitative in nature and is motivated by enabling others to participate. The focus is on getting the business done. Verbs like facilitating, connecting and brokering along with the phrase 'herding cats' would be apt, but in a way that is mindful of the dynamics of the settings and interactions in which, and with which, people live. Pragmatism and taking note of the lived realities prevail with Factor 2.

The Factor 3 perspective is the least straightforward of the three viewpoints. The prominent theme is that 'community' is an integrated account of 'all things'. It is not just 'Everyone' as it tends to be for Factor 1, nor is it a 'Depends' as it is for Factor 2. For Factor 3, 'community' is 'Every' 'Thing', and it is underpinned by the Māori cultural concept of 'whakapapa'. 'Whakapapa' is an explicit acknowledgement of an integrated structure of relational layers of, and between, all things, people, events and places along and across space and time. It also carries with it a heightened awareness of responsibility and accountability that holds individuals to issues. The awareness of being connected to all things in many ways and on multiple levels is pervasive. 'Whakapapa' is a source of legitimacy for one's role in a decision-making setting whereas those for Factors 1 and 2 are likely to be democratically appointed or elected through conventional avenues for reasons other than 'whakapapa'.

These three nuanced factors are grounded on a platform of consensus. A foundation belief to 'community' is that 'Relationships' matter and deemed crucial to the success of a policy initiative. Participants know full well that building relationships of mutual trust and respect can be hard and requires effort. In no way does being civilised equate to avoiding conflict and disagreement with others, but it does require a preparedness to engage in conversation. Nor does one need 'to get on with everybody' in order to get stuff done. There is, however, an expectation that participants and informants conduct themselves in ways that are engaging and respectful. A second consensus point is the strong expectation of contribution. Its manifestation showed up in the way participants and informants spoke about their willingness to commit and invest themselves in their localities to matters that interest or concern them. Indeed, the responses from participants affirmed that contribution, in particular, is a strong expectation they have of themselves and, because of its circularity and the nature of reciprocity, something to be expected of others. The third 
consensus point is that 'community' is inherently place-based.

These three consensus themes do not have the same meaning across all three factors. The subtleties for the place-based-ness of 'community', for example, reflect the emphases summarised above. Consistent with the pragmatism of Factor 2, place may be regarded as a locality or the backdrop for a policy proposal. With Factor 1, concern for place might trigger place-protection strategies and tactics whereas for Factor 3, place cannot be separated or held apart from any policy consideration.

It is surprising that such perspectives of 'community' have not been explored or investigated; or as Collins (2010) would say, overlooked and ignored. The "hidden in plain sight" (p. 23) first-person viewpoints identified in this study are a bridge to the gap Little (2002) identified between those who theorise in the political philosophy of 'community' and those who advocate in the political practice of 'community'. The informants and participants of this study are not the theorists, nor are they the advocates in political practice. As the ones doing the 'community governance', they are the empiricists of 'community' in 'community governance' settings'; and no one has noticed. What makes it all the more surprising is that the 'civic leaders' of this study are expected to promote and facilitate community involvement and participation in local decisions. Compounding the surprise is that the very communities affected by such decisions are expected and expect to be involved in opportunities to participate in the decision-making process.

The discussion in Chapter 5 acknowledges that 'community' is as pervasive in contemporary politics as Collins (2010) has claimed. It has also uncovered is that while there is a concept of 'community' that frames policy discourse, there is also a practice of 'community' or a way of governing that frames policy response. The challenge is in distinguishing between the two. In other words, there are ways to talk about 'community', and there are ways in which 'community' is enacted.

What does all this mean for 'community governance' in Taranaki? On a day-to-day basis, not much-life will go on as it has.

But for academia, the propositions of this study are to use the word 'communities' in its plural form more deliberately and, in doing so, reorient 'community governance' by describing what the study's participants and informants do as 'governing communities'. The key prompt for this suggestion is that when informants and participants talked about 
'community', they were referring to the way they conduct themselves and a way of governing when doing 'community governance' work. Although they might be employed by organisations, elected to positions or derive a mandate in another way, or involved in governing organisations, their work is actually about 'governing communities' as Reid (2010) has noted. McKinlay (2014a) inferred the same when he identified the need for local decision-making to revolve around 'communities' and not around institutions. The phrase is a viable, and certainly authentic, option because, based on what the informants and participants shared about their experiences, it reflects what really happens in Taranaki. Its potential also lies with the way it acknowledges that the work of 'governing communities' is distributed across many layers of decision-making. It is a proposal that needs to be developed and tested, especially if the next step in the evolution of local government to local governance and 'community governance' is indeed 'governing communities'.

There is one last point to be made and it relates to the applicability of 'civic leadership' and 'civic leaders' in the field, and very specifically, in Taranaki. In this study, those terms have been largely forsaken, mentioned only to maintain a link to the scholarly context in which this thesis is written. They are useful enough terms for academics and consultants, but they proved to be a point of disconnect for the study's participants and informants. For them, 'civic leadership' and 'civic leader' are terms that apply to other people in other contexts. The suspicion is that informants and participants feel that the labels fail to recognise those in leadership roles beyond the formal institutions and civics of local government. Consequently, they have been replaced by referring to the people and to the work of people who occupy roles of influence in local decision-making settings because it reflected their lived practice. A next step is to test this proposition with a view to identifying an alternate pair of descriptors to which they can relate.

With respect to deploying $\mathrm{Q}$ methodology to extract the three-factor solution for this study, its use has not been without its technical dilemmas or methodological struggles. It was a useful tool to help discover what is understood by 'community' with the further benefit of confirming what scholars have been writing about for some time. Delivering the Q sorts, keying in data and selecting the subroutines to implement the factor analysis were the most straightforward and simple of the data collection and analysis tasks. Sampling the sub-concourse through topic-oriented interviews and querying item placement in the post Q-sort interviews were collegial in nature and their analysis was well supported by a coding matrix that focused on content and intent. The process to extract statements representative of the sub-concourse identified through the topic-oriented interviews did require effort to 
ensure coverage. Interpreting the factor analysis was somewhat challenging in spite of the structuring effects of the selected solution. The only course of action that will support dealing with these steps more efficiently and more effectively is to do more Q-research. Another option is to choose a different analytical tool, but Q methodology is a robust and systematic process for studying subjectivity.

One issue worth highlighting is the need to be able to manage the sheer volume of data tables that offered so many different entry points to interpreting the factor analysis. Advice and guidance on the how-to of factor interpretation is available (Brown, 1991; Watts \& Stenner, 2012), although somewhat under-developed in the body of Q methodology literature. As a result, inexperience with the data made it difficult to find a viable starting point for the interpretation and analysis. In the end, as outlined in Chapter 4, factor interpretation began with the consensus statements primarily due to the somewhat high correlations of the factors in the selected solution.

That said, this study produced a rich mine of data that provides a firm platform for subsequent publication, or to inform further research. For example, one of the tables produced by PQMethod version 2.35 was a correlation of Q sorts. An early happenstance of conditional formatting of that table identified a heat-map that identified those $\mathrm{Q}$ sorts that stood out from the rest because they were either most unlike the others, or most like them. There has been no mention of a heat-map-like approach to the correlation of $\mathrm{Q}$ sorts in the literature, but it is possible that it offers an innovation to factor interpretation to assure validity.

A second matter that warrants closer examination is the post-Q sort question 'What did you think of the Q sort as a process?' A review of the transcripts affirms what has been alluded to elsewhere in the Q literature and that is that there is transformative potential in the Q sort. Some participants noted value in being exposed to other people's opinions and views and having to consider them against their own. Others appreciated its structure to allow them to think through their own beliefs, and ask questions of themselves. A third issue that is barely mentioned in this thesis is the response to Item 10, which states, 'It's a community where I don't see any school sores'. Much like Item 11, this statement attracted its own set of reactions that are worth examining in order to better understand the motivations for why people step up to issues and concerns where they live. Where Item 11 generated extreme Q-sort values amongst the participants, Item 10 did not. But the unexamined responses suggest there is something more to be discovered. 
There are two more suggestions for further research. Both are prompted by the placebased nature of the research. The region that is known as Taranaki was the backdrop to the study. It was chosen for its closely integrated political, social, cultural and economic governance networks. Setting the research in Taranaki and then using topic-oriented interviews explicitly established place as a parameter to the study.

One option is to repeat the study somewhere else, whether that be another region or an urban setting or even a neighbourhood. Such a task would broaden this study's applicability to other settings and introduce a degree of critical awareness of 'community' amongst those who participate. It would also provide an opportunity to highlight any commonalities and differences which exist in relation to this study, findings that could prove useful in ensuring place-based public policies and initiatives are successful.

A second possibility would be to recruit those who participate or contribute to decisions in Taranaki (or some other region, urban setting or neighbourhood), but have no vested interests or personal ties here (or there). In other words, a further $\mathrm{Q}$ study could be undertaken to examine the perspectives of 'community' amongst what have been referred to as the 'placeless' informant and participant. As is consistent with the principles of Qmethodology, there would need to be at least $12 \mathrm{Q}$ sorters in each suggested research project to support a viable solution for uncovering their perspectives of 'community'. Each undertaking would certainly identify where the similitudes and differences lie amongst the study's recruits. However, the real value will be in comparing the factor narratives of that study with this one, with the potential to identify what it would take to that ensure placebased public policies and initiatives are successful. The differences, as nuanced as they might be, could be the very barriers that hijack public policy projects.

There is one aspect of Q methodology that sets it apart from other research systems and strategies, and that is its ability to support an alternate view to be presented and thoughtfully considered. There are views and beliefs-even words-in this study that might never have become part of the analysis had the objective been to identify the majority view. Stephenson's (1986) recognition that the subjective domain where "only the individual[s themselves] can observe and measure... [their] own subjectivity" (p. 51) made way for identifying correlations around people, not around quantitatively measurable variables that characterise conventional studies (Brown et al., 2008, p. 727). This innovation, along with the combination of recruiting informants and participants with different views, extracting a $\mathrm{Q}$ sample representative of the sub-concourse and retaining 
the natural language of the statements made it possible for Māori cultural concepts to be presented for consideration. The rank-ordering process of the $\mathrm{Q}$ sort supported participants to think about and decide where in the scheme of their beliefs such concepts sit. The factor analysis structures interpretation and then, as has happened in this study, whakapapa was identified as an underlying theme to Factor 3. Of the many surprises identified in this study, the Factor 3 conception was the most unexpected. Therefore, given its ability to examine subjectivity objectively and give voice to the unheard view, it has been difficult to grasp why Q methodology is not more widely accepted and used. However, acceptance is reported to be growing, especially in the public policy domain where the many and varied perspectives and approaches to issues that affect peoples' lives and livelihood drives policy responses, but Q studies in New Zealand are few. There are even fewer studies looking at core ideas like 'community' in the public policy domain.

Where political theory has sought to "construct a normative model of community that can inform political practice" (Little, 2002, p. 3), this study has taken a different route. It asked those in roles of influence what they understand by 'community' and found 'community' as a normative model for political practice. There was nothing in the academic literature that asked what 'civic leaders' mean by 'community' as they go about their work in 'community governance' settings. The term 'community' has been largely overlooked and ignored in political philosophy (Collins, 2010). As noted in the opening paragraphs of this thesis, this was a surprise because those in roles of influence are expected to promote and facilitate community involvement and participation in local decisions and a prerequisite to such work is an understanding of 'community'. Another reason is that communities expect to be involved and have opportunities to participate in decisions that affect them. This study is the bridge in the gap identified by Little (2002); that is between between those who theorise in the political philosophy of 'community' and those who advocate in the political practice of 'community'.

None of the participants or informants would name what they do as normative practice, but they would recognise it as a way of governing. Even more likely is that as empiricists themselves, they would describe their operant subjectivities of 'community' as, 'It's what we do. Call it what you like. But it's just what we do'. 


\section{References}

Anderson, B. (1983). Imagined communities: reflections on the origin and spread of nationalism. New York, NY: Verso.

Ashton, L. (2010, September 15). The E-Town Breakfast Club. Retrieved 19 June 2017, from http:/ /www.anglicantaonga.org.nz/Features/Social-Justice/Etown

Auckland Council, Te Kaunihera o Tāmaki Makaurau. (2012). City Centre Masterplan 2012 (p. 112). Auckland, New Zealand: Auckland Council, Te Kaunihera o Tāmaki Makaurau.

Averweg, U. R., \& Leaning, M. A. (2011). Visions of community: Community informatics and the contested nature of a polysemic term for a progressive discipline. Information Technologies \& International Development, 7(2), 17-30.

Baker, R. (2013). Rachel Baker introduces Q Methodology. Glasgow, Scotland. Retrieved from http://www.youtube.com/watch?v=ZbZ2Kq-Fzxo

Barker, J. H. (2008). Q methodology: An alternative approach to research in nurse education. Nurse Education Today, 28(8), 917-925.

Barlow, C. (1991). Tikanga whakaaro: key concepts in Mäori culture. Auckland, New Zealand: Oxford University Press.

Barraket, J. (2004). Communities of place. Griffith REVIEW, 3, 233-238.

Bauman, Z. (2001). Community: seeking safety in an insecure world. Cambridge, United Kingdom: Wiley-Blackwell.

Berger, P. L., \& Luckmann, T. (1996). The social construction of reality. New York, NY:

Doubleday \& Company.

Better Public Services Advisory Group. (2011). Better Public Services Advisory Group report (p. 
76). Wellington, New Zealand: New Zealand Government.

Blackshaw, T. (2010). Key concepts in community studies. Thousand Oaks, CA: SAGE Publications Ltd.

Boffa Miskell Limited. (2016). Spatial planning: opportunities for options for metropolitan Wellington (p. 58). Wellington, New Zealand: Local Government Commission.

Brown, S. R. (1980). Political subjectivity: applications of Q methodology in political science. London, United Kingdom: Yale University Press.

Brown, S. (1991). Q methodology primer I. Retrieved 19 July 2009, from http:/_. facstaff.uww.edu/cottlec/QArchive/Primer1.html

Brown, S. R. (1993). A primer on Q methodology. Operant Subjectivity: the International Journal of $Q$ methodology, 16(3/4), 91-138.

Brown, S. (2010). The Q sample (Vol. 3). Retrieved from https://www.youtube.com/watch?v=7L7q-o6Xrus

Brown, S. (2011, December 2). Re: Correlation between factors - scores at or above .55. [Electronic mailing list message]. Retrieved from https:/_listserv.kent.edu/cgi-bin/_ wa.exe?A2 $=$ Q-METHOD; $\underline{4 \mathrm{c} 077 \mathrm{~d} 38.1112}$

Brown, S. (2014, December 2). Re: Consensus statement. [Electronic mailing list message]. Retrieved from https://listserv.kent.edu/cgi-bin/wa.exe?A2=ind1412\&L=Q= METHOD\&X $=166575 \mathrm{E} 0599 \mathrm{D} 600 \mathrm{E} 62$

Brown, S. R., Durning, D., \& Seldon, S. (2008). Q methodology. In G. Miller \& K. Yang (Eds.), Handbook of Research Methods in Public Administration (pp. 721-764). Boca Raton, FL: Taylor \& Francis.

Brown, S., \& Robyn, R. (2004). Reserving a key place for reality: Philosophical Foundations of Theoretical Rotation. Operant Subjectivity: The International Journal of $Q$ methodology, 28(3), 104-124.

Bruhn, J. G. (2011). Conceptions of community: past and present. In J. G. Bruhn (Ed.), The Sociology of Community Connections (pp. 29-46). Dordrecht, The Netherlands: Springer Netherlands.

Bryson, L., \& Mowbray, M. (1981). 'Community': the spray-on solution. Australian Journal of Social Issues, 16(4), 255-267.

Burke, K. (2004). Engaging with communities over outcomes: a review of innovative approaches to meeting the LGA 2002 challenge of identifying community outcomes (p. 50). Wellington, New Zealand: Local Government New Zealand.

Burke, R. (2014). Friendly relations between the two races were soon established'? Päkehà interactions with Māori in the planned settlements of Wellington, Nelson and New Plymouth, 1840-1860

(Doctor of Philosophy in Māori Studies). Victoria University of Wellington, Wellington, 
New Zealand.

Camden Council. (2011). Placeshaping. Retrieved 13 March 2011, from https:/// www.camden.gov.uk/ccm/navigation/environment/planning-and-built-environment/ our-plans-and-policies/placeshaping.

Capdevila, R., \& Lazard, L. (2008). 'Is it just me...?': Q methodology and representing the marginal. Operant Subjectivity: The International Journal of Q methodology, 32, 70-84.

Carter, L. J. (2003). Whakapapa and the State: some case studies in the impact of central government on traditionally organised Mãori groups (Doctor of Philosophy in Māori Studies). University of Auckland, Auckland, New Zealand.

Chisholm, M., \& Dench, G. (2005). Community identity: literature review and analysis for periodic electoral reviews (p. 46). London, United Kingdom: Electoral Commission.

Clarke, M., \& Stewart, J. (1999). Community governance, community leadership and the new local government (p. 4). York, United Kingdom: Joseph Rowntree Foundation.

Cohen, A. P. (1985). The symbolic construction of community. London, United Kingdom: Routledge.

Collinge, C., \& Gibney, J. (2010). Connecting place, policy and leadership. Policy Studies, $31(4), 379$.

Collinge, C., Gibney, J., \& Mabey, C. (2010). Leadership and place. Policy Studies, 31(4), 367378.

Collins, P. H. (2010). The new politics of community. American Sociological Review, 75(1), 7 30.

Community Outcomes Project Team. (2004). Future Taranaki: a report on community outcomes for Taranaki (p. 68). Stratford, New Zealand: Taranaki Regional Council.

Costley, C., Elliott, G., \& Gibbs, P. (2010). Key concepts for the insider-researcher. In Doing Work Based Research (pp. 1-7). London, United Kingdom: Sage.

Cox, D. R. (2006). Principles of statistical inference. New York, NY: Cambridge University Press.

Cox, W. H. (1976). Cities: the public dimension. Hammondsworth, United Kingdom: Penguin.

Cuppen, E., Breukers, S., Hisschemöller, M., \& Bergsma, E. (2010). Q Methodology to select participants for a stakeholder dialogue on energy options from biomass in the Netherlands. Ecological Economics, 69(3), 579-591.

Curnin, J. (2008). Index to the laws of New Zealand. Charleston, SC: BiblioBazaar.

Delanty, G. (2010). Community. New York, NY: Taylor \& Francis. 
Dryzek, J. S., \& Berejikian, J. (1993). Reconstructive democratic theory. American Political Science Review, 87(1), 48-60.

Dunne, P. (2016, April 4). The tension between central and local government carries on. Retrieved from http:/_/unitedfuture.org.nz/the-tension-between-central-and-localgovernment-carries-on/-

Durie, M. (1997). Whānau, whanaungatanga and health Māori development. In P. Te Whāiti \& M. B. McCarthy (Eds.), Mai i Rangitātea: Māori Wellbeing and Development (pp. 124). Auckland, New Zealand: Auckland University Press with Bridget Williams Books.

Edelman, M. J. (1985). The symbolic uses of politics. Chicago, IL: University of Illinois Press.

Eo, Y., \& Kim, S. E. (2016, September). Perceptions of local communities in the urban area. Presented at the 32nd Meeting of the International Society for the Scientific Study for Subjectivity, New Orleans, LA.

Etzioni, A. (1993). Spirit of community: the reinvention of American society. New York, NY: Simon \& Schuster.

Flora, J. L. (1998). Social capital and communities of place. Rural Sociology, 63(4), 481-506.

Foltz, B. (2013). Statistics 101: Standard Error of the Mean. Retrieved from https://www.youtube.com/watch?v $=$ bUu5HIHIrRw

Fontana, A., \& Frey, J. H. (2005). The interview: From neutral stance to political involvement. In N. K. Denzin \& Y. S. Lincoln (Eds.), The SAGE Handbook of Qualitative Research ( ${ }^{\text {rd }}$ ed., pp. 695-728). London, United Kingdom: Sage Publications.

Friends of the Hocken Collections. (2000, March). New Zealand's nine provinces (1853-76). Welcome to the Hocken, 31, 4.

Fulcher, H. (1991). The concept of community interest (Discussion Paper) (p. 52). South Australian Department of Local Government.

Gilbert, W. E. (1948). The boundaries of local government areas. The Geographical Journal, 111(4/6), 172-198.

Hambleton, R. (2008). Civic leadership for Auckland: an international perspective (Briefing Paper) (p. 38). Auckland, New Zealand: Royal Commission on Auckland Governance.

Hambleton, R. (2011). Place-based leadership in a global era. Commonwealth Journal of Local Governance, 0(8/9).

Hambleton, R. (2015). Power, place and the new civic leadership. Local Economy, 30(2), 167172.

Hamilton, P. (1985). Editor's Foreword. In The Symbolic Construction of Community. London, United Kingdom: Routledge. 
Hargreaves, A. (2004). Building communities of place: habitual movement around significant places. Journal of Housing and the Built Environment, 19(1), 49-65.

Harrow Council. (2011). Harrow Council, Organisation and Managers_Place Shaping. Retrieved 13 March 2011, from http:/_www.harrow.gov.uk/info/200026/_ council departments $/ 2172 /$ harrow council organisation and managers $/ 11$

Hayes, E. C. (1914). Effects of geographic conditions upon social realities. The American Journal of Sociology, 19(6), 813-824.

Herefordshire Council. (2010). Place shaping paper consultation (p. 25). Hereford, United Kingdom: Heresfordshire Council.

Hillery, G. (1955). Definitions of community: Areas of agreement. Rural Sociology, (20), 111-123.

Hillery, G. (1982). A research odyssey: developing and testing a community theory. Piscataway, New Jersey: Transaction Publishers.

Hond, R. (2013). Matua te reo, matua te tangata—Speaker community: visions, approaches, outcomes (Doctor of Philosophy in Public Health). Massey University, Palmerston North, New Zealand.

Hutchinson, vivian. (2012, February). Occupy our citizenship. Presented at the Changemakers Auckland Convention, Takapuna, Auckland.

International Society for the Scientific Study of Subjectivity. (n.d.). Welcome to qmethod.org. Retrieved 21 November 2015, from www.qmethod.org.

Jary, D., \& Jary, J. (1995). Community. Collins Dictionary of Sociology. London, United Kingdom: HarperCollins.

Johnson, A., \& Weller, S. (2007). What do New Zealanders want from their cities? Results from Dunedin. Presented at the 2nd International Conference on Sustainability Engineering and Science, Auckland, New Zealand.

Jones, G. (1963). The Local Government Commission and county borough extensions. Public Administration, 41(2), 173-187.

Kalof, L., \& Dan, A. (2008). Essentials of social research. London, United Kingdom: McGrawHill Education.

Kearns, A. (1995). Active citizenship and local governance: political and geographical dimensions. Political Geography, 14(2), 155-175.

Lambert, R. (2015, August 3). Taranaki region - Pākehā settlement. In Te Ara Encyclopedia of New Zealand. Retrieved from http://_www.teara.govt.nz/en/taranaki-region/page-7

Lane, D. M. (2013). Introduction to statistics: an interactive e-book (Version 1.4). Houston, TX: 
David Lane.

Little, A. (2002). The politics of community: theory and practice. Edinburgh, Scotland: Edinburgh University Press.

Local Government Act, New Zealand Statutes. (2002). Retrieved 20 January 2017, from http:/_/www.legislation.govt.nz

Local Government Act, New Zealand Statutes Schedule 6. (2002). Retrieved 20 January 2017, from http://www.legislation.govt.nz

Local Government New Zealand. (2003a). The KnowHow Guide to governance under the Local Government Act 2002 (Vol. 2). Wellington, New Zealand: Local Government New Zealand.

Local Government New Zealand. (2003b). The Local Government Act 2002: what does it mean for community boards? (p. 14). Wellington, New Zealand: Local Government New Zealand.

Loomis, C. P. (2011). Notes on Tönnies fundamental concepts. In C. P. Loomis (Ed.), Community and Society (pp. 263-284). Mineola, NY: Dover Publications.

Low, S. M. (1992). Symbolic ties that bind: Place attachment in the plaza. In I. Altman \& S. M. Low (Eds.), Place Attachment (Vol. 12, pp. 253-278). London, United Kingdom: Plenum Press.

Low, S. M., \& Altman, I. (1992). Place attachment: A conceptual inquiry. In I. Altman \& S. M. Low (Eds.), Place Attachment (Vol. 12, pp. 253-278). London, United Kingdom: Plenum Press.

Lyons, M. (2005). Lyons inquiry into local government: consultation paper and interim report (p. 146). London, United Kingdom: Lyons Inquiry.

Lyons, M. (2007). Lyons inquiry into local government (p. 44). London, United Kingdom: The Stationery Office.

MacIver, R. M. (1917). Community, a sociological study: being an attempt to set out the nature and fundamental laws of social life. London, United Kingdom: MacMillan \& Co.

Madden, A. (2010). Making sense of community leadership: a case study of local leadership, community empowerment and the enrichment of the public realm. In Sixty Years of Political Studies: Achievements and Futures. (pp. 551-617). Edinburgh, Scotland: Political Studies Association.

McLintock, A. H. (Ed.). (1966). Foundation of System. In An Encyclopaedia of New Zealand. Retrieved from http://_www.teara.govt.nz

McKeown, B., \& Thomas, D. (2013). Q methodology (Second). London, United Kingdom: SAGE.

McKinlay, P. (2014a). A good practice guide for enabling and supporting place-based and related 
community governance (p. 22). Tauranga, New Zealand: McKinlay Douglas Limited.

McKinlay, P. (2014b, November). Local democracy today and tomorrow: the emerging role of "nontraditional' entities of local governance. Presented at Local Democracy Workshop, Stockholm, Sweden.

McKinlay, P. (2016). Community governance. Policy Quarterly, 12(4), 36-41.

McKinlay, P., Pillora, S., Tan, S. F., \& von Tunzelmann, A. (2012). Evolution on community governance: building on what works (No. Vol I). Sydney, Australia: Australian Centre of Excellence for Local Government, University of Technology.

Means, R., \& Evans, S. (2012). Communities of place and communities of interest? An exploration of their changing role in later life. Ageing and Society, 32(8), 1300-1318.1

Miller, W. L., Dickson, M., \& Stoker, G. (2000). Models of local governance: political opinion and political theory in Britain. New York, NY: Palgrave.

Minogue, M. (1977). Local government in Britain (Vol. II). Cambridge, United Kingdom: Cambridge University Press.

Moorfield, J. (2003). Kanohi ki te kanohi. Te Aka Māori-English, English-Māori Dictionary (Online). Retrieved from http://_www.maoridictionary.co.nz

Moorfield, J. (2003a). Kōrero. Te Aka Māori-English, English-Māori Dictionary (Online). Retrieved from http:/_/www.maoridictionary.co.nz

Moorfield, J. (2003b). Mana. Te Aka Māori-English, English-Māori Dictionary (Online). Retrieved from http:/_www.maoridictionary.co.nz

Moorfield, J. (2003c). Whānau. Te Aka Māori-English, English-Māori Dictionary (Online). Retrieved from http://_www.maoridictionary.co.nz

Moorfield, J. (2003d). Whanaungatanga. Te Aka Māori-English, English-Māori Dictionary (Online). Retrieved from http://_www.maoridictionary.co.nz

Nash, S. J. (2007). Integrating citizens' agendas in New Zealand local government environmental planning and decision-making: an examination of two wastewater planning processes and implications for deliberative democracy (Doctor of Philosophy in Social Policy). Massey University, Palmerston North, New Zealand.

New Plymouth District Council. (2015). Long term plan 2015-2025. New Plymouth, New Zealand: New Plymouth District Council.

Office of the Auditor-General New Zealand. (60). Managing conflicts of interest: Guidance for public entities (Good Practice Guide) (p. 2007). Wellington, New Zealand: Office of the Auditor-General New Zealand. Retrieved from http:/_www.oag.govt.nz/2007/. conflicts-public-entities

Orange, C. (2004). An illustrated history of the Treaty of Waitangi. Wellington, New Zealand: 
Bridget William Books.

Peace, R., Wolf, A., Crack, S., Hutchinson, I., \& Roorda, M. (2004). Wellbeing, employment, independence: the views of Sickness and Invalids' Benefit clients (Working Paper No. 07/04) (p. 41). Wellington, New Zealand: Centre for Social Research and Evaluation: Te Pokapū Rangahau Arotaki Hapori.

Pełczyński, Z. (1984). Political community and individual freedom in Hegel's philosophy of the state. In Z. Pełczyński (Ed.), The State and Civil Society. Cambridge, United Kingdom: Cambridge University Press.

Pillora, S., \& McKinlay, P. (2011). Local government and community governance: A literature review (Working Paper No. 2) (p. 30). Australian Centre of Excellence for Local Government.

Ramlo, S. (2015). Mixed method lesson learned from 80 years of Q Methodology. Journal of Mixed Methods Research, 1-18.

Ramlo, S. (2016). Centroid and theoretical rotation: justification for their use in Q methodology research. Mid-Western Educational Researcher, 28(1), 73-92.

Reid, M. (2010). Strengthening local government and community governance in New Zealand (Doctor of Philosophy in Public Policy). Victoria University of Wellington, Wellington, New Zealand.

Relph, E. C. (1976). Place and placelessness. London, United Kingdom: Pion.

Relph, E. C. (2008). A pragmatic sense of place. In Making Sense of Place (pp. 311-324). Canberra, Australia: National Museum of Australia Press.

Rose, N. (1999). Community. In Powers of Freedom: Reframing Political Thought (pp. 167-196). Cambridge, United Kingdom: Cambridge University Press.

Rotokare Scenic Reserve Trust. (2013). About us. Retrieved 20 February 2014, from http:/_www.rotokare.org.nz/About-Us/_

Rozalia, G. M. (2008). Q factor analysis (Q methodology) as data analysis technique. The Annals of the University of Oradea. Economic Sciences, 4, 871-876.

Rutherford, J., \& Skinner, W. (Eds.). (1969). The establishment of the New Plymouth settlement in New Zealand (Second). New Plymouth, New Zealand: Thomas Avery \& Sons Ltd.

Schmolck, P. (2014a, March 6). PQMethod Manual. Retrieved 27 November 2016, from http://schmolck.userweb.mwn.de/_qmethod/_pqmanual.htm

Schmolck, P. (2014b, May 27). Re: Data suggesting one factor solution. [Electronic mailing list message]. Retrieved from https:/_listserv.kent.edu/cgi-bin/wa.exe?A2=Q: $\underline{\text { METHOD; }} ; \underline{\mathrm{f} 184 \mathrm{~b} 46.1405}$

Schmolck, P. (2014c, June 29). PQMethod (Version 2.35) [Mac OS X]. Retrieved from 
$\underline{\text { http}}: / /$ schmolck.userweb.mwn.de/qmethod/-

Schools@Look4. (2005-2017).Blank.outline map of New Zealand. Auckland, New Zealand: Look 4 NZ Limited. Retrieved from https:/_schools.look4.net.nz/_geography/_ country_information/outline maps/newzealand

Sheed, T. M. (2014). Mãori political agency: A Q-method study of Māori political attitudes in New Zealand (Masters of Arts in Political Science). University of Canterbury, Christchurch, New Zealand.

Smith, M. K. (2001). Community: a review of the theory. Retrieved 9 April 2011, from http:/__www.infed.org/community/_community.htm

South Taranaki District Council. (2015). 2015-2025 Long term plan (p. 294). Hawera, New Zealand: South Taranaki District Council.

Statistics New Zealand, Tātauranga Aotearoa. (2011). Standards. Wellington, New Zealand: New Zealand Government. Retrieved from http://www.stats.govt.nz/. browse for stats/Maps and geography/Geographic-areas/urban-rural-profile/_ $\underline{\text { standards.aspx }}$

Statistics New Zealand, Tātauranga Aotearoa. (2015, July 10). Taranaki region. 2013 Census Quickstats About a Place. Wellington, New Zealand: New Zealand Government. Retrieved from http://wwww.stats.govt.nz/Census/2013-census/profile-and-summary= reports/quickstats-about-a-place

Statistics New Zealand, Tātauranga Aotearoa. (2016). Statistical standard for meshblock (p. 15). Wellington, New Zealand: New Zealand Government. Retrieved from http:_/_ www.stats.govt.nz

StatSoft, Inc. (2011). Principal Components and Factor Analysis. In Electronic Statistics Textbook. Tulsa, OK: StatSoft. Retrieved from http:/_/www.statsoft.com/textbook/. principal-components-factor-analysis/_

Stenner, P. (2008a). Between method and ology. Operant Subjectivity: The International Journal of 2 methodology, 32, 1-5.

Stenner, P. (2008b). Q as a constructivist methodology. Operant Subjectivity: The International Journal of Q methodology, 32, 46-69.

Stephenson, W. (1935). Technique of factor analysis. Nature, 136, 297-297.

Stephenson, W. (1953). The study of behaviour: Q-technique and its methodology. Chicago, United States: University of Chicago Press.

Stephenson, W. (1980). Conscience and consciousness. Operant Subjectivity: The International Journal of Q methodology, 3(3), 74-78.

Stephenson, W. (1981). Principles for the study of subjectivity*. Operant Subjectivity: The International Journal of Q methodology, 4(2), 37-53. 
Stephenson, W. (1986). Protoconcursus: the concourse theory of communication (part one). Operant Subjectivity: The International Journal of Q methodology, 9(2), 37-58.

Stewart, J., \& Clarke, M. (1994). The local authority and the new community governance. Regional Studies, 28(2), 201-208.

Stewart, J., \& Stoker, G. (Eds.). (1989). The future of local government. London, United Kingdom: The MacMillan Press Limited.

Stoker, G. (2007). New localism, participation and networked community governance. Manchester, United Kingdom: University of Manchester.

Stratford District Council. (2015). Long term plan $2015-2025$ (p. 284). Stratford, New Zealand: Stratford District Council.

't Hart, P., \& Uhr, J. (Eds.). (2008). Public leadership: perspectives and practices. Canberra, Australia.

Taranaki District Health Board. (2016). Annual Report 2015-2016. New Plymouth, New Zealand: Taranaki District Health Board.

Taranaki Regional Council. (2010). Regional policy statement for Taranaki (p. 244) Stratford, New Zealand: Taranaki Regional Council.

Taranaki Regional Council. (2015). Long-term plan 2015/2025 (p. 170). Stratford, New Zealand: Taranaki Regional Council.

Taranaki Regional Council, New Plymouth District Council, Stratford District Council, \& South Taranaki District Council. (2015). Regional collaboration and shared council services in Taranaki (p. 37). Stratford, New Zealand: Taranaki Regional Council.

Taranaki Iwi Claims Settlement Act, New Zealand Statutes. (2016). Retrieved 20 January 2017, from http://www.legislation.govt.nz

Te Rito, J. S. (2007). Whakapapa: a framework for understanding identity. MAI Review. Retrieved 3 April 2009, from http://www.review.mai.ac.nz/index.php/MR/article/ viewFile $/ \underline{56 / \underline{55}}$

The Bishop's Action Foundation. (2016). Welcome. Retrieved 26 November 2016, from http:/_/www.bishopsactionfoundation.org.nz

The Wheelhouse. (2017). Our story. Retrieved 20 June 2017, from http:// www.wheelhouse.org.nz/about/our-story/

Tönnies, F. (2011). Community and society. (C. P. Loomis, Ed. \& Trans.). Mineola, NY: Dover Publications.

Toulmin, S. E. (1958). The uses of argument. Cambridge, United Kingdom: Cambridge University Press. 
Trotman, R. (2015). Communities shaping their places: a good practice resource - 2015 (p. 21). Auckland, New Zealand: Auckland Council, Te Kaunihera o Tāmaki Makaurau - Local Boards.

TSB Community Trust. (2015). Welcome to the TSB Community Trust. Retrieved 26 November 2016, from https:/_/tsbtrust.org.nz

United Nations Development Programme. (2004). Local governance. Retrieved 2 March 2011, from http://hrba.undp.sk/index.php/terms-and-concepts/understandingdecentralisation/local-governance

van Dijk, H. M., Cramm, J. M., van Exel, J., \& Nieboer, A. (2014). The ideal neighbourhood for ageing in place as perceived by frail and non-frail communitydwelling older people. Ageing and Society, 35(8), 1771-1795.

Venture Taranaki Trust. (2015). About us. Retrieved 19 June 2017, from http:/_/ www.energystream.co.nz/about-us

Venture Taranaki Trust. (2017). Tapuae roa: make way for Taranaki strategy (p. 60). New Plymouth, New Zealand: Venture Taranaki Trust.

Vickers, A. (2010). What is a p-value anyway?: 34 stories to belp you actually understand statistics. Boston, MA: Addison-Wesley.

Watts, S. (2011). Subjectivity as operant: A conceptual exploration and discussion. Operant Subjectivity: The International Journal of Q methodology, 35(1), 37-47.

Watts, S., \& Stenner, P. (2005). Doing Q methodology: theory, method and interpretation. Qualitative Research in Psychology, 2, 67-91.

Watts, S., \& Stenner, P. (2007). Q methodology: the inverted factor technique. Irish Journal of Psychology, 28(1-2), 63.75.

Watts, S., \& Stenner, P. (2012). Doing Q methodological research: theory, method \& interpretation. London, United Kingdom: Sage Publications Ltd.

Wells, B. (1878). The history of Taranaki: a standard work on the bistory of the province. New Plymouth, New Zealand: Edmondson \& Avery 'Taranaki News' Office.

Webler, T., Tuler, S., \& Krueger, R. (2001). What is a good public participation process? Five perspectives from the public. Environmental Management, 27(3), 435-450.

Webler, T., Danielson, S., \& Tuler, S. (2009). Using Q method to reveal social perspectives in environmental research. Greenfield, MA: Social and Environmental Research Institute. Retrieved from http:/_/www.seri-us.org/sites/default/files/Qprimer.pdf

Wegner, P. (2002). Imaginary communities. London, United Kingdom: University of California Press.

Wingreen, S. (2011, December 3). Re: Correlation between factors - scores at or above .55. 
[Electronic mailing list message]. Retrieved from https:/_listserv.kent.edu/cgi-bin/_ wa.exe?A2 $=$ Q-METHOD; 2 68416c9.1112

Wodak, R., De Cillia, R., Reisigl, M., \& Liebhart, K. (2009). The discursive construction of national identity (Second Revised). Edinburgh, Scotland: Edinburgh University Press.

Wolf, A. (2009). Subjectivity, the researcher, and the researched. Operant Subjectivity: The International Journal of Q methodology, 32(32), 6-28.

Wolf, A. (2012, August 11). Re: distributing q sorts to individuals outside the original contributors to the concourse? [Electronic mailing list message]. Retrieved from https:/_listserv.kent.edu/cgi-bin/wa.exe?A2=Q-METHOD; 4 f9a46c.1208

Wolf, A. (2014, March 24). The interview in Q. Retrieved from http:/_/www.esocsci.org.nz/. forums/topic/the-interview-in-g/-

Young Foundation. (2009). Place-shaping. Retrieved 21 August 2015, from http:/// www.futurecommunities.net 


\section{Appendices}




\section{Appendix 1: Local Government Act 2002 Schedule 6}

\begin{tabular}{lr} 
Local Government Act 2002 & Reprinted as at \\
Schedule 6 & 1 March 2016 \\
\hline
\end{tabular}

\section{Schedule 6}

\section{Constitution of communities}

ss $5(1), 8(2)(b), 49(1)$

1 Constitution of communities

(1) A community may be constituted in any part of a district in accordance with this schedule and must be wholly within 1 district.

(2) A community may not be constituted for any part of a district if a community is already constituted for that part of that district.

(3) A community may not be constituted for any part of a district that is within a local board area.

Schedule 6 clause 1(3): inserted, on 8 August 2014, by section 70 of the Local Government Act 2002 Amendment Act 2014 (2014 No 55).

2 Matters pertaining to constitution of communities

(1) An Order in Council or resolution constituting a community must-

(a) fix the boundaries of the community and describe them in a manner that makes them readily capable of identification; and

(b) assign a name to the community; and

(c) fix the date of the first election of members of the board of the community, which may not be a date within 12 months before the date of the next triennial general election of members of the territorial authority in which the community is situated.

(2) The boundaries of a community must coincide with the boundaries of the statistical meshblock areas determined by Statistics New Zealand and used for parliamentary electoral purposes.

(3) The community must come into existence on the day after the day on which the electoral officer declares the result of the first election of the members of the community board.

Compare: 1974 No 66 s 101ZH

3 Proposals to establish community

(1) Not less than $10 \%$ of the electors of a continuous area, having a population of 1500 persons or more and being within the district of a territorial authority, may propose that the area be constituted as a community.

(2) Not fewer than 100 electors of a continuous area having a population of fewer than 1500 persons and being within the district of a territorial authority, being electors present at a meeting called by public notice by any elector or electors and being the majority of the electors present at that meeting, may propose that the area be constituted as a community.

Compare: 1974 No 66 s 101ZI 
4 Requirements for proposal

(1) A proposal to constitute a community must be accompanied by a plan or other description sufficient to identify the area.

(2) Each signatory to the proposal must, against his or her signature, state his or her full name and the address in respect of which he or she possesses a qualification as an elector.

(3) The proposal, or a copy of it, must be delivered or sent by post to the chief executive at the principal office of the territorial authority affected by the proposal.

(4) The chief executive of the territorial authority must-

(a) check whether or not each signatory to the proposal possesses a qualification as an elector; and

(b) not later than 1 month after receiving the proposal, forward the proposal to the territorial authority, together with a certificate specifying the number of signatories to the proposal who are qualified as electors.

(5) In the absence of proof to the contrary, the certificate of the chief executive is final.

(6) The territorial authority must then consider the proposal and determine whether or not to constitute the community.

Compare: 1974 No 66 s 101ZJ

5 Proposal seeking constitution of communities

(1) A proposal seeking the constitution of a community by means of a resolution must be-

(a) submitted to the territorial authority; and

(b) considered by the territorial authority at its next meeting or subsequent meeting.

(2) If a territorial authority has considered a proposal, it must-

(a) resolve to give effect to the proposal and invite public submissions on it; or

(b) reject the proposal and give public notice of the rejection.

(3) If a territorial authority has resolved to give effect to a proposal and to invite public submissions on it, it must give public notice of the intended resolution, and a copy of the proposal and a copy of the plan showing the boundaries of the proposed community must be prepared and deposited in the principal office of the territorial authority and in any other place or places that it considers necessary.

(4) Each proposal and associated plan must be open for inspection by the public without fee for a period of 28 days following public notice of the proposal, and 
public notice must be given of the times and places where the proposal and plan are available.

(5) A person or group of persons may make a written submission on the proposal within that period of 28 days or any further period that the territorial authority may allow, and each submission must be considered by the territorial authority, which must resolve to-

(a) adopt the proposal; or

(b) reject the proposal.

Compare: 1974 No 66 s 101ZK

Schedule 6 clause 5(1)(b): amended, on 7 July 2004, by section 25 of the Local Government Act 2002 Amendment Act 2004 (2004 No 63).

6 Matters to be considered when constituting community

In deciding whether or not to constitute a community, the territorial authority or, if appropriate, the Commission must have regard to the criteria as set out in clause 19 of Schedule 3 that apply to draft proposals that the territorial authority or Commission considers appropriate in the circumstances.

Compare: 1974 No 66 s 101ZL

Schedule 6 clause 6: amended, on 5 December 2012, by section 37(1)(a) of the Local Government Act 2002 Amendment Act 2012 (2012 No 93).

Schedule 6 clause 6: amended, on 5 December 2012, by section 37(1)(b) of the Local Government Act 2002 Amendment Act 2012 (2012 No 93).

7 Appeal against refusal to constitute community

(1) If, following a proposal to constitute a community, a territorial authority resolves not to constitute a community, a signatory to the proposal may appeal tio the Commission.

(2) The Commission has all the powers of the territorial authority in respect of the constitution of the community, and may determine the functions of the community board for a period of up to 3 years.

(3) Nothing in subclause (2) prevents the territorial authority from conferring further responsibilities on the community board.

\section{Procedures relating to resolution to constitute community}

(1) An Order in Council or resolution giving effect to a proposal to constitute a community or communities must contain a description of each community concerned.

(2) A resolution constituting a community may not have effect unless-

(a) a description or plan of the community has been sent to the SurveyorGeneral of the land district within which the district is situated; and 
(b) the Surveyor-General, or some person appointed by the Surveyor-General, certifies that the description or plan is sufficient to render the boundaries of each ward capable of identification.

(3) If the description of a community to which subclause (2) applies is defective, but the Surveyor-General or person appointed by the Surveyor-General certifies that it may be amended and the defect overcome without making a change in what was evidently intended to be the area comprised in the description, the description may be so amended by resolution, and must have effect as if the provisions of subclause (2) had been complied with.

(4) The following provisions apply to each resolution constituting a community or communities:

(a) a copy must be sent by the territorial authority to-

(i) the Secretary; and

(ii) the Surveyor-General; and

(iii) the Government Statistician; and

(iv) the Commission; and

(v) the Remuneration Authority; and

(b) a copy must be kept at the principal office of the territorial authority, and must be available for inspection without fee by any person during normal office hours.

Compare: 1974 No 66 s 101ZN

9 Union, alteration, or abolition of communities

(1) A community may be abolished or united with another community, and the boundaries of a community may be altered, by-

(a) an Order in Council made under section 25:

(b) the territorial authority or Commission as part of a review of the territorial authority's representation arrangements.

(2) An Order in Council under this clause must fix the date on which the communities must be united or on which the boundaries are altered or on which the community or communities are abolished.

(3) On the union of 2 communities under this clause, the former communities must be deemed to be abolished and the members of the boards of the communities must go out of office.

(4) On the date on which a community is abolished under this clause, the community board is deemed to be dissolved.

Compare: 1974 No 66 s $101 z 0$

Schedule 6 clause 9(1)(a): amended, on 5 December 2012, by section 37(2) of the Local Government Act 2002 Amendment Act 2012 (2012 No 93). 


\title{
Appendix 2: Profile of topics
}

\author{
TOPIC-ID TOpic Description
}

Eradicating pests at Rotokare

The Rotokare Scenic Reserve Trust is proud to call itself a "community-led sanctuary project" and community-driven conservation initiative.

The reserve itself located 12 kilometres east of Eltham and comprises 230 hectares of forested hill country, wetlands and a 17.8 hectare natural lake.

Established in 2004, the Trust set out to raise $\$ 30,000$ for a pest-trapping project but soon realised a more comprehensive approach to biodiversity restoration was needed. The fundraising target was changed to $\$ 1.9$ million and by the end of 2008 , an 8.2 kilometre pest-proof fence made Rotokare the largest fenced natural wetland in New Zealand.

The Trust is governed by nine trustees, staffed by six employees and backed by a large number of volunteers and supporters. It delivers education programmes and has a number of biodiversity projects on the go.

www.rotokare.org.nz

Pig hunting in the Waitōtara Valley

At 67 kilometres, the Waitotara Valley Road is the longest no-exit road in the North Island and access is off state Highway 3 just south of the Waitotara township. Forty kilometres up the road is Ngāmatapouri where there is a full primary school (Years 1 to 8 ) and a hall.

Outside of the school-related activities, all other social events and local initiatives are organised by the Ngāmatapouri Community Club. It takes care of the hall, supports the school, and addresses issues such as the recurrence of poaching as well as river flooding.

Since the start of the century, the club has been responsible for a successful district fundraiser-the Annual Pig Hunt. Its purpose is to have fun with the kids, foster good relations amongst the locals and to maintain links to those who have left the area.

In 2011, the Taranaki District Health Board endorsed a project 'South Taranaki Alive with Opportunities for Better Health Care'. It was a whole of system review of services with the aim to 'deliver the same or better quality care, have the right services in the right place at the right time, and make the best use of all health sector resources'. The project was later governed by a steering group local representatives and chaired by the then Chair of the Taranaki District Health Board. This group was established after district-wide concerns were raised to a review of services and an unpopular proposal to cut services delivered out of the Hāwera Hospital. 
E-TOWN is an Eltham response to events of November 2006 when 'a gang of bored, drunken teens when on a letterbox-smashing spree'. That spree also left a man paralysed resulting in some teens being sentenced to long jail terms, and devastated families.

Working closely with locals, the then newly appointed Regional Dean for Central Taranaki, Peter Barleyman, established a youth space to 'weave a safety net' around vulnerable children.

Services centre on after school space and activities with visits from a Youth Health Nurse and Youth Transitions Services. E-TOWN also delivers a breakfast programme to local primary school children.

Operating as E-TOWN, the Eltham Youth Health and Development Trust is governed by six trustees and employs the E-TOWN Coordinator.

www.anglicantaonga.org.nz/Features/Social-Justice/Etown

Oil, gas and mineral extraction is a region that is often described as New Zealand's energy province is a topic that draws out very strong opinions.

On one hand, the oil and gas industry is a significant contributor to the region's economy reportedly accounting for 'almost a third of regional GDP'. On the other, concerns about the sustainability of fossil fuels, extraction methods and the risk of spills draws protest.

www.energystream.co.nz

Developing community emergency plans in Oākura, Hurleyville \& Waverley

Community emergency plans are an initiative promulgated by Civil Defence Emergency Management Taranaki but their development is led and owned by communities themselves. The initiative recognises that outside assistance is not always be available, but 'communities are often first responders'. The plans set out whatever is deemed necessary to a locality including the local hazardscape, local impact assessments in an event, and local resources that amy be available in the event of an emergency.

So far, plans have been developed for ōpunake, ōākura, Inglewood, and Waverley. Work in other localities has begun

www.cdemtaranaki.govt.nz/about-us/people-and-groups / community-emergency-plans / 
Governance is seen as an important element to an organisation's success and as a consequence, building that capability is an important priority for a number of organisations. Funders, for example, want to be assured that an applicant has capability to make the necessary decisions to achieve the prioritised outcomes.

Organisations who support the development of community governance capability do so with advice, training, research, and the already mentioned funding. Others also provide certain services such as information technology infrastructure and facilitation in strategic planning.

www. wheelhouse.org.nz

Māori development and advancement in Taranaki is a long story.

Beneath the topics that tend to make the news headlines (like Treaty settlements, pronunciation and reinstatement of place names, central and local government representation, social inequities and racial institutionalism) are decision-making structures, processes and priorities that have an intergenerational focus.

The base unit for socio-political action in Taranaki has changed over time and sat variously amongst whānau, marae, hapu, iwi. In the $21^{\text {st }}$ century, decision-making structures that are accountable to beneficiaries also include rūnānga and trusts.

Since the loss of kaimoana reefs in the 1980s, locals have been raising concerns about the compromised environmental and cultural integrity of the Waitara River and the coastline. For them, it was a consequence of industry and inadequate sewerage disposal.

To address this concern, planning for what was become the Wai Tataari \& Waitara to New Plymouth Sewer Pipeline began in 2002 .

It was a straightforward engineering infrastructure project but in 2009, district decision-makers were worried about the project's affordability and deferred the project by seven years. Locals rallied the Waitara community and marched, as a hilkoi of about 300 people on the New Plymouth District Council to express concern and disappointment.

The result was that the project was reprioritised and construction was well underway a year later, and was commissioned in October 2014. 


\section{Appendix 3: Informant information letter, consent form and interview guide}

Explanatory Note:

Both the informant and participant letters, consent forms and guides refer to 'conceptions' rather than 'perspectives' have been used throughout the thesis. During the design phase and early implementation stages, the phrase 'conceptions of community' was used to describe the research objectives, but as the study progressed, it because more and more obvious that 'perspectives of community' or 'understandings of community' were more appropriate. The reason for the gradual switch in terms began with informant and participant struggle with the word 'conception' and consequently, 'perspective' or 'understanding' were used. That in-field decision was reinforced by Stephenson's (1981) explanation that subjectivity is the act of "viewing things exclusively through the medium of one's own mind" (p. 37). The term conception seems more removed and third person in its nature, whereas perspective and understanding are more personal and first person. 


\subsection{Informant information letter}

\section{tE Whare Wánanga o te OPOKo o te IKa a MAUI

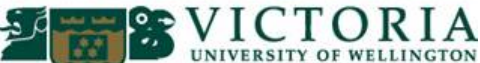

[Insert Date]

[Recipient]

[Title] - [Company]

[Address 1]

[Address 2]

Tēnā rā koe

Conceptions of Community Amongst Civic Leaders in Taranaki: Implications for Civic Leadership and Community Governance

My name is Te Aroha Hohaia and I am a PhD student in the School of Government, Victoria University of Wellington. I am undertaking a research study that asks civic leaders in Taranaki what they understand community to be. The aims of the study are:

- Identify and examine civic leader conceptions of community in the context of community governance and civic leadership and

- Inform an analysis of past, current and future policy settings surrounding community governance and civic leadership in local communities in New Zealand.

As I will be talking with people and asking for their views, the University requires that ethics approval be obtained for the research study and this approval was given on 19 August 2012.

I'd like to interview you about your understanding of community. In order to support the conversation, I'd also like to focus on your role as [insert role here] in [insert case study topic here].

I'm happy to meet with you at a time and place of your choice. The interview will follow a structured question guide and will be no more than 1.5 hours in length. If you agree, I'll also record the interview using a digital voice recorder to ensure the accuracy of your words. I will provide you with an electronic copy of the interview (voice recording, if one is made, and interview notes) and you will be able to review and amend the information you share.

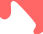

The information will become part of the background material and will inform the next stage in data collection. Opinions may be incorporated into the thesis but only in a non-attributable form where interviewees are not identified. No other person besides me or my advisors will see interview notes and be assured that all material collected will be treated as confidential.

If you feel the need to withdraw from this study, you may do so without question at any time before the final analysis of data or 31 August 2014 whichever is the later. 
I will call you next week to arrange an interview time.

In the meantime, if you have any questions or would like to receive further information about the project, you can contact me, or either of my supervisors. Our contact details are listed below.

Nā mātou noa nei,

Te Aroha Hohaia

PhD Candidate, School of Government, Victoria University of Wellington

062786598 or 0212604779

tearoha.hohaia@vuw.ac.nz

\section{Bill Ryan}

PhD Advisor, School of Government

Victoria University of Wellington

044635848

bill.ryan@vuw.ac.nz
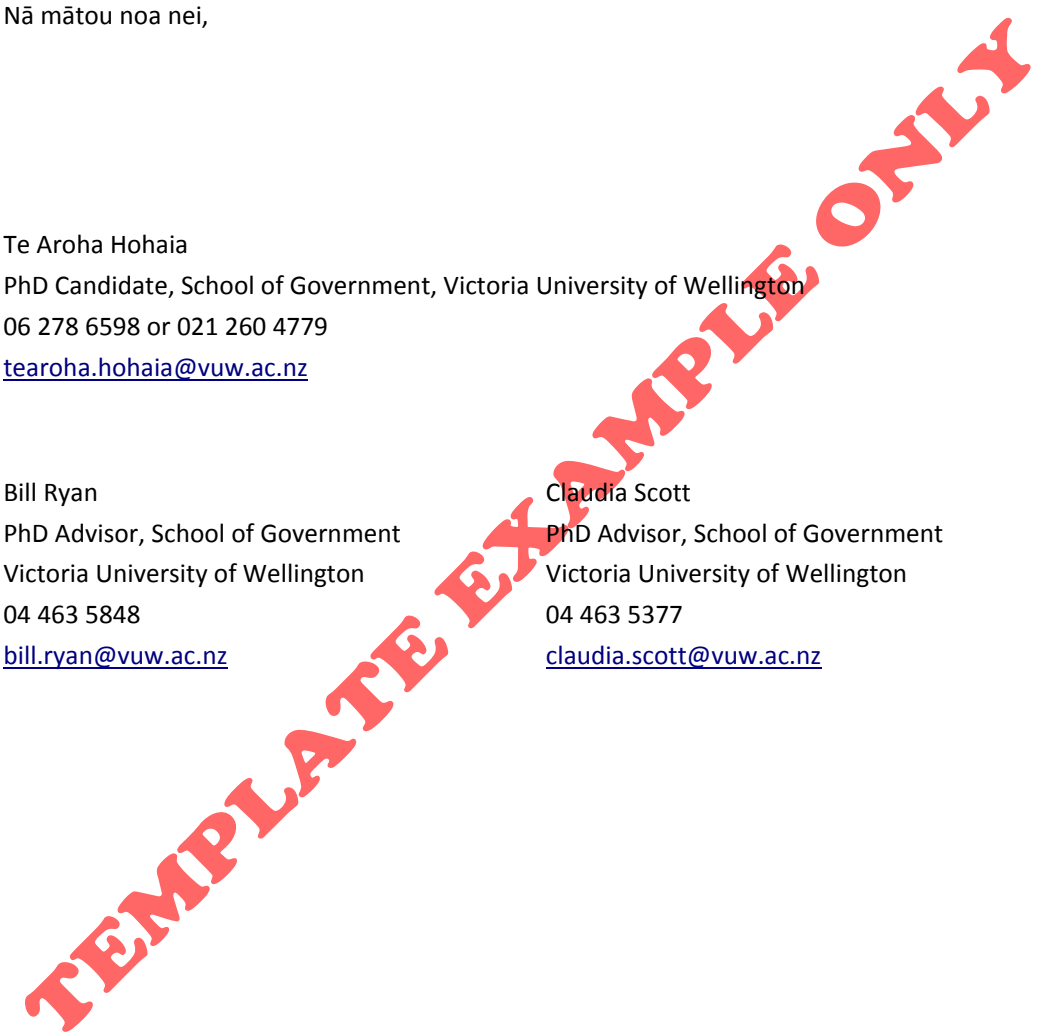

Claudia Scott

PhD Advisor, School of Government

Victoria University of Wellington

044635377

claudia.scott@vuw.ac.nz 


\subsection{Informant consent form}

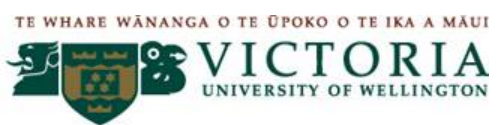

\section{CONSENT}

I understand what the research study Conceptions of Community Amongst Civic Leaders in Taranaki: Implications for Civic Leadership and Community Governance is about, what it's for and who's doing it. I also understand that

- I can pull out of this study at any time no matter what the reason

- If I do wish to withdraw from the study, I need to do so before 31 August 2014 and any data I have provided will be returned to me or destroyed as soon as practicable

- I may be invited to participate in the structured sort process scheduled later in the study

- I will be invited to a presentation of the preliminary findings with othe participants and will have an opportunity to participate in a facilitated discussion around those findings

- I may be approached at a later time to help clarify any surprises that may be identified in the analysis

- I will be provided with an electronic copy of the voice recording (if one is made) and the interview notes as soon as is practicable after its collection, and will be able to review and amend the information I have shared

- The information I provide will become part of the background material that will inform the next stage in data collection

- The information or opinions I provide may be presented at academic or professional conferences and if it is, the information or opinions will be reported only in an aggregated or non-attributable form

- All information I provide will be destroyed five years after the research has concluded and

- Any further use of the information I have provided will require my written consent.

I agree for a voice recording to be made of the interview

Name

Location

Date

Signature 


\subsection{Informant interview guide}

\section{Memo - Community: Conceptions \& Implications}

TO: SELF I SUBJECT: STAGE TWO INTERVIEW GUIDE I 24 SEPTEMBER 2012

\begin{tabular}{|c|c|}
\hline Set & Question \\
\hline \multirow[t]{2}{*}{0} & $\begin{array}{l}\text { Preparation: } \\
\text { - Know the case study well - what's going on, who's doing what where when and } \\
\text { why? } \\
\text { - Know the interviewees background well - where they're from, their background, } \\
\text { who they're connected to, what their education is, where they live, who their } \\
\text { family is, what their interests are, what other governance roles they have } \\
\text { - Have all equipment (voice recorder, iPad, pen and notepaper) ready }\end{array}$ \\
\hline & $\begin{array}{l}\text { Preliminaries: } \\
\square \text { Greet the informant } \\
\square \text { Ensure understanding of the research and obtain consent } \\
\square \text { Outline the process and answer any questions }\end{array}$ \\
\hline 1 & $\begin{array}{l}\text { Today, I'd like to talk to you about [case study] and your role as [leader role]. Let's } \\
\text { start with [case study]: } \\
\text { - What's the situation, as you understand it? } \\
\text { - What are the key issues for this [case study]? } \\
\text { - What would be the best outcome? Why is it important? } \\
\text { - What will it take to achieve that result? }\end{array}$ \\
\hline 2 & $\begin{array}{l}\text { As [leader role]: } \\
\text { - What's your involvement? With the group in general and with the [case study] in } \\
\text { - Warticular? } \\
\text { - What are the circumstances that have brought or led you to this involvement? } \\
\text { - What motivated you to get involved? } \\
\text { to [case study]? Your own? Of say, [other leader roles]? }\end{array}$ \\
\hline
\end{tabular}




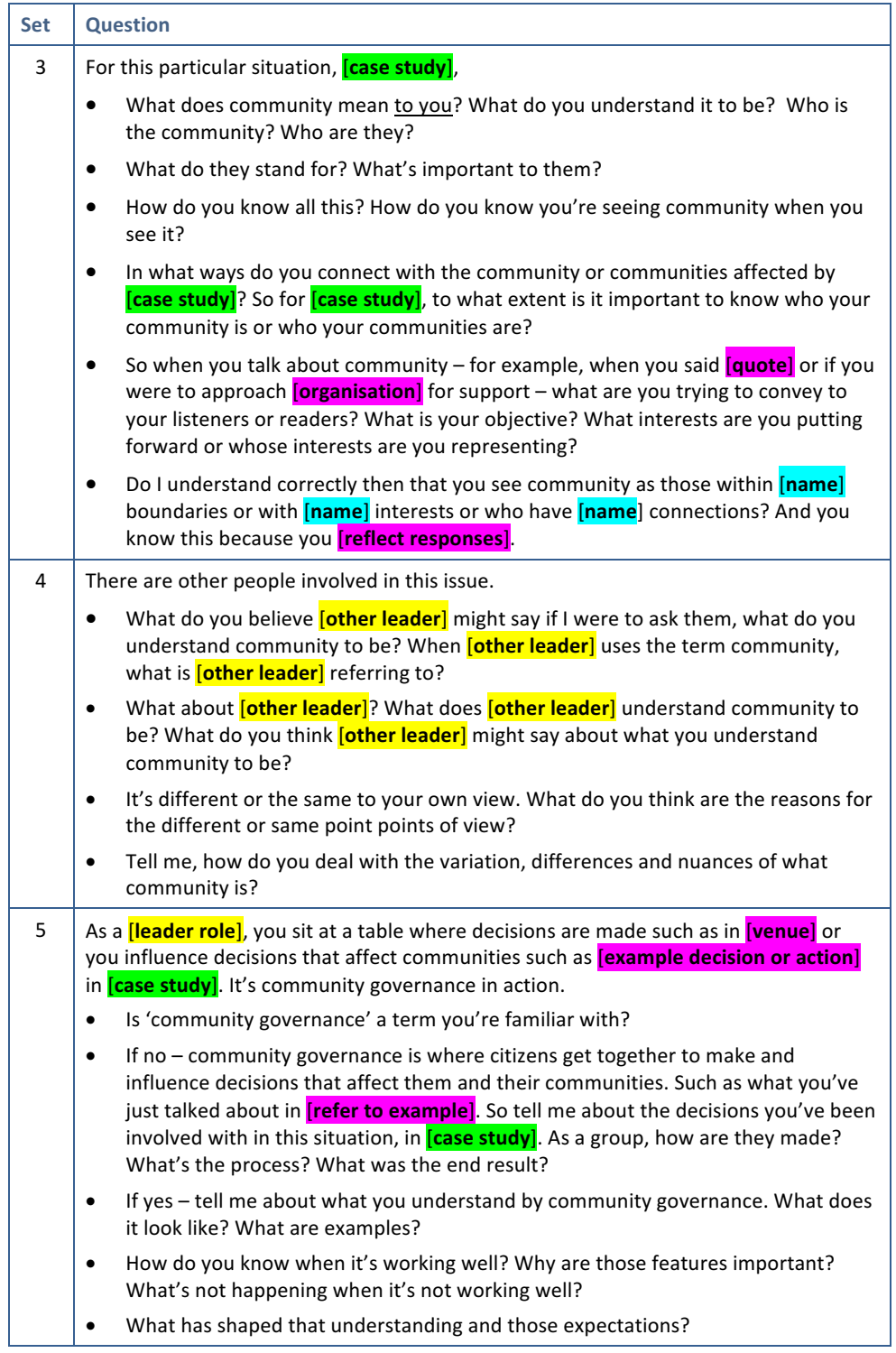




\begin{tabular}{|c|c|}
\hline Set & Question \\
\hline 6 & $\begin{array}{l}\text { In your role as a [leader role], you're a civic leader. } \\
\text { - What about the term civic leadership? What does that conjure up in your mind? } \\
\text { What do you know of it? What does it look like? } \\
\text { - What's your reaction to being called a civic leader? Tell me about what you see } \\
\text { are the key responsibilities for being a civic leader? What are the challenges to the } \\
\text { role? What would be an example? } \\
\text { - Just going back to what you were saying earlier, in what way does your } \\
\text { understanding of community shape the way you act as a [leader role]? Which } \\
\text { came first? }\end{array}$ \\
\hline 7 & $\begin{array}{l}\text { Finally, and this set of questions is for the general day to day living, what do you value } \\
\text { most about the community you live and work in? } \\
\text { - How long have you lived here in [name place or community]? } \\
\text { - How would you describe your feelings of attachment to [name place or } \\
\text { community]? }\end{array}$ \\
\hline 8 & $\begin{array}{l}\text { Closing } \\
\square \text { Explain the process and highlight the next step } \\
\square \text { Answer any questions the informant may have } \\
\square \text { Thank the informant }\end{array}$ \\
\hline
\end{tabular}

\section{CONTACT}

Te Aroha Hohaia

tearoha.hohaia@gmail.com or tearoha.hohaia@vuw.ac.nz

0212604779

PO Box 96, Hāwera 4640 
Appendix 4: Statements 


\subsection{Content $\&$ intent matrix}

Explanatory Note:

Each statement was assessed for intent; that is, the way in which an informant's statement about 'community' achieved one of the following:

- Definitive and pointed out the meaning of community (DEF)

- Designative and concentrated on questions of fact about community (DSG)

- Evaluative and emphasised the value or worth of community (EVA) and

- Advocative and promoted that something about community that should or should not be (ADV).

Each statement was also assessed twice for content:

- Hillery's (1955) elements of 'community' - geographical location (GEO), social interaction (INT), common ties (TIE) or people (PEO) and

- Fulcher's (1991) dimensions of 'community' - functional (FUN), social (SOC), perceptual (PER) or political (POL).

The next table shows which of the intent and content matrix categories that the 158 shortlisted statements were tagged. The right-hand column identifies the number of statements tagged to a category that were then elected for the final Q set.

$\begin{array}{ccc}\text { Matrix } & \text { Number } & \text { Number } \\ \text { Category } & \text { Shortlisted } & \text { Final } \\ & \text { Statements } & \text { Q set }\end{array}$

$\begin{array}{lll}\text { ADVGEOFUN } & 0 & \\ \text { ADVGEOPER } & 0 & 1 \\ \text { ADVGEOPOL } & 2 & 3 \\ \text { ADVINTFUN } & 8 & \\ \text { ADVINTPER } & 2 & 2 \\ \text { ADVINTPOL } & 5 & \\ \text { ADVPEOFUN } & 0 & 1 \\ \text { ADVPEOPER } & 1 & \\ \text { ADVPEOPOL } & 1 & \\ \text { ADVTIEFUN } & 0 & \\ \text { ADVTIEPER } & 2 & \\ \text { ADVTIEPOL } & 2 & \\ \text { DEFGEOFUN } & 5 & \\ \text { DEFGEOPER } & 2 & \end{array}$




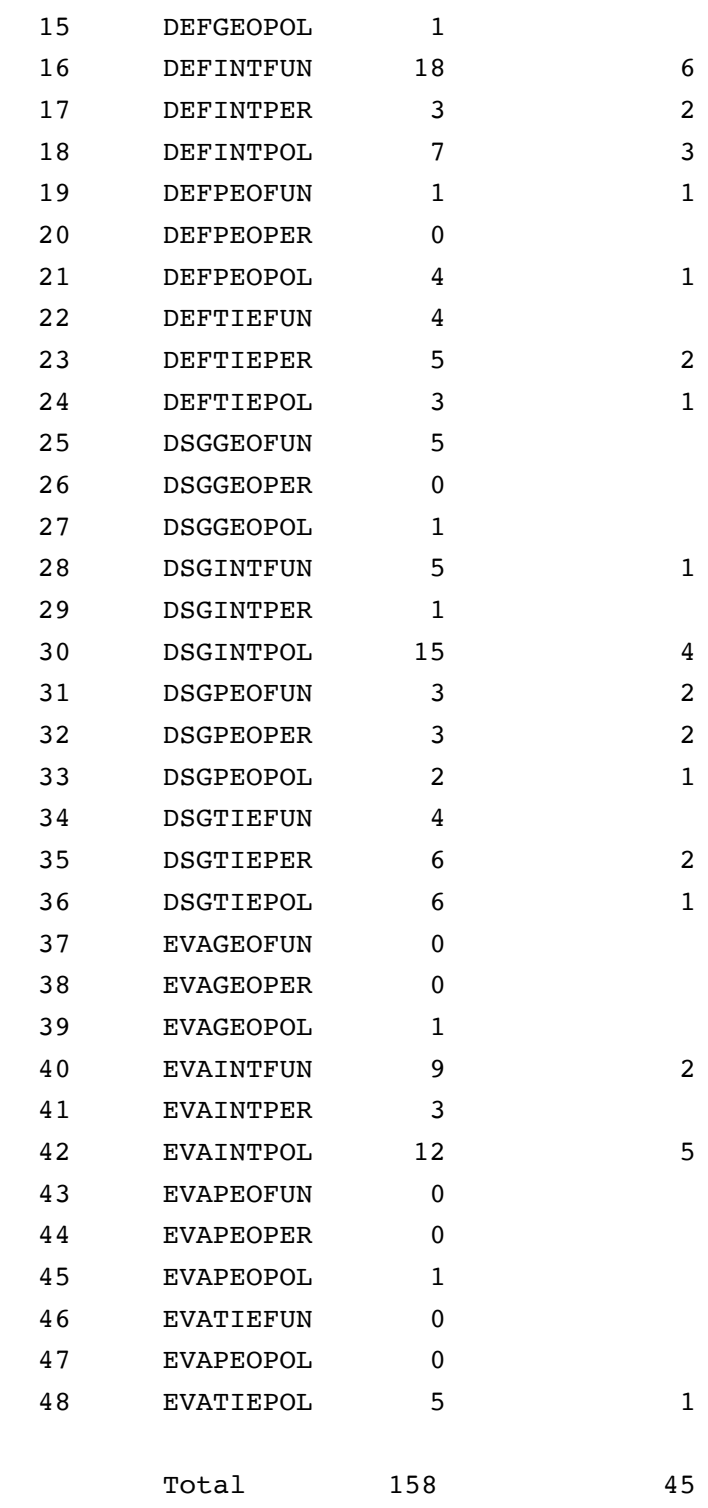




\subsection{Analysis of extracted statements}

1. I don't think there is an understanding of the richness of a community. You know, not everyone is on one point of the socioeconomic spectrum.

2. But community is not just about a group consulting with a group of people to get some answers!

3. I would say that a key part of community is contributing as well.

4. I think for me, if I start my day, my community is, whoever I meet and whoever I have to do business with next, to get to the outcome.

5. But I think communities, you know, can be sort of quite defined according to interests and values as well.

DEFTIEPER

6. But some aspects of community, and particularly physical communities are really important to people's mental and social well-being.

7. So community for me is about whānau, it's about kōrero and it's about decision-making.

EVAINTPOL

ADVINTFUN

DSGINTPOL

8. Relationships.

DEFINTFUN

9. Community, where people are participating... who are just going out and being part of community, whether it means a school fête or it means coming into a big celebration in town.

10. It's a community where I don't see any school sores.

DEFINTFUN

11. A fictitious group.

DSGTIEPER

12. It's who, I guess, they are accountable to, which is in the first instance the people who had voted them in.

DSGINTPOL

13. What is community? I don't know. It's hard.

DSGPEOFUN

14. Often, in a city, that's the only sense of community that some people have. Their whole life revolves around their work, and the people at work.

DEFTIEPER

15. But what I see community is everybody gets an opportunity to have a say. 
16. For me - in this role, the community is anything outside Council.

17. Community is understanding about the way people work.

DEFINTFUN

18. From my perspective, when they talk about "my community", they're talking about everybody who lives in that area. And it doesn't matter what interests they have. It's everybody in that area.

19. It's really a risk mitigation strategy.

EVAINTPOI

20. It's everyone.

DEFPEOFUN

21. But community's about groups of people engaging in conversation and civilised behaviour really.

DEFINTFUN

22. Well community, I suppose at a first-world level, it's just any, any group of people who come together to achieve something or have shared values, shared goals, common beliefs, common understandings - something that brings them together to do something.

23. In my opinion, the best way to create a feeling that you're trying to become part of the community is to sit face-to-face and talk to someone.

24. I think having fairly good infrastructure and using it - like our local engineer.

25. Community - it means that the people I serve.

DSGPEOPOI

26. My community may mean something different to what you think your community is, even though we're at the same table.

DSGTIEPOL

27. I don't think of community as a single thing. I think of it as very multi-layered and in some cases temporal. It's a here-andnow, not an always.

28. To me, community is a whakapapa thing.

DEFINTPER

29. Community is a hard thing to do because people come and go but you've got to get on with everybody even if you don't like them.

DSGINTFUN

30. Community in my mind is immediately identified by the role that you or the hat that you are wearing at a particular point in time.

31. He used to say, 'everybody has to take responsibility'. I mean he would walk down the road and pick up the bloody rubbish because anybody can do that. You don't have to leave it to someone else.

32. It's not about you or me. It's about the community.

ADVTIEPOL 
33. I think it's where the community has a full chance to react to things that they desire for their community and work within the community to achieve those things.

34. So anyone, we'd be thinking, who could be impacted.

DSGINTPOL

35. In the past I would have just said 'it's just a group of people or a community thing like [a project]'. But it's far more than that. It's the meeting before the [project]. The whole way we interact. And [deciding] whether it's a good thing to do.

36. I don't think there's a community over the whole area; I think this place has a variety of small communities.

DSGPEOFUN

37. Actively asking for that input and then delivering back results.

DSGINTPOL

38. What I'm concerned about is that there's no transparency. There's no engagement with the community.

EVAINTPOL

39. If you want to get your point of view across, it's no good us just going in and giving a submission, ourselves; we need a whole lot of people behind us, to say that's what they want.

ADVINTPOL

40. So, I think it's about being committed to the place where you

ADVGEOPOL live, and saying, 'where I need to, I'll step up and I'll make a difference'.

41. Knowing your neighbours and knowing you can rely on them, I suppose.

DEFINTFUN

42. Community is just some sort of stuff that exists in some back paddock somewhere that's absolutely okay to go out and raid every now and then for its capital resources instead of actually seeing it as the central dynamic of what's going on.

43. And the community is and always has been the lowest level of local government.

DEFPEOPOL

44. But to me it's that everybody's somebody and everyone's important. No one's more important than anyone else, we're just all important.

45. Without a doubt... the best of our work is over a cup of tea and in [the] kitchen.

EVATIEPOL

DSGPEOPER

EVAINTPOL

Explanatory Note:

All 45 statements are listed in their full form, and as presented to the Q-sort participants.

Do note that Tables 13 through to 16 and Appendices 9 to 19 inclusive present the statements in a shortened form. As the software PQMethod v. 2.35 produces reports that truncates statements, the statements were keyed into the software with a section of the text 
that would support recall in the analysis process. For example, the full version of item 9'Community, where people are participating... who are just going out and being part of community, whether it means a school fête or it means coming into a big celebration in town' - was shortened to "where people are participating". 
Appendix 5: Participant information letter, consent form and interview guide 


\subsection{Participant information letter}

\section{TE Whare WánANGa o te OPOKo O TE IKa a MAUt

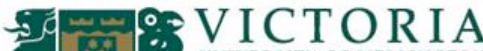 \\ (8.) UNIVERSITY OF WELLINGTON}

[Insert Date]

[Recipient]

[Title] - [Company]

[Address 1]

[Address 2]

Tēnā koe

Conceptions of Community Amongst Civic Leaders in Taranaki: Implications for C Leadership and Community Governance

My name is Te Aroha Hohaia and I am a PhD student in the School of Government, Victoria University of Wellington. I am undertaking a research study that asks Civic leaders in Taranaki what they understand community to be. The aims of the study are:

- Identify and examine civic leader conceptions of community in the context of community governance and civic leadership and

- Inform an analysis of past, current and future policy settings surrounding community governance and civic leadership in local communities in New Zealand.

As I will be talking with people and asking for their views, the University requires that ethics approval be obtained for the research study and this approval was given on 19 August 2012.

I am now well in to the data collection phase and during this time, I will be meeting with a selection of civic leaders in Taranaki - like you - to ask about what you understand by community especially as it relates to [insert case study topic here].

I'd like to meet with you at a time and place of your choice. Our time together will involve ranking a series of statements that I will provide you and a discussion afterwards. It should take no longer than an hour. If you agree, I'll also use a digital voice recorder to ensure the accuracy of your words.

The results and interview material will form the basis of the thesis. Opinions may be incorporated into the thesis but only in a non-attributable form that does not identify participants. No other person besides me or my advisors will see the interview notes and all material collected will be treated as confidential.

If you feel the need to withdraw from the study, you may do so without question at any time before the final analysis of data or 31 December 2014 whichever is the later. 
We will arrange a time to meet by email.

In the meantime, if you have any questions or would like to receive further information about the project, you can contact me, or either of my supervisors. Our contact details are listed below.

Nā mātou noa nei,

Te Aroha Hohaia

PhD Candidate, School of Government, Victoria University of Wellington

062786598 or 0212604779

tearoha.hohaia@vuw.ac.nz

\section{Bill Ryan}

PhD Advisor, School of Government

Victoria University of Wellington

044635848

bill.ryan@vuw.ac.nz

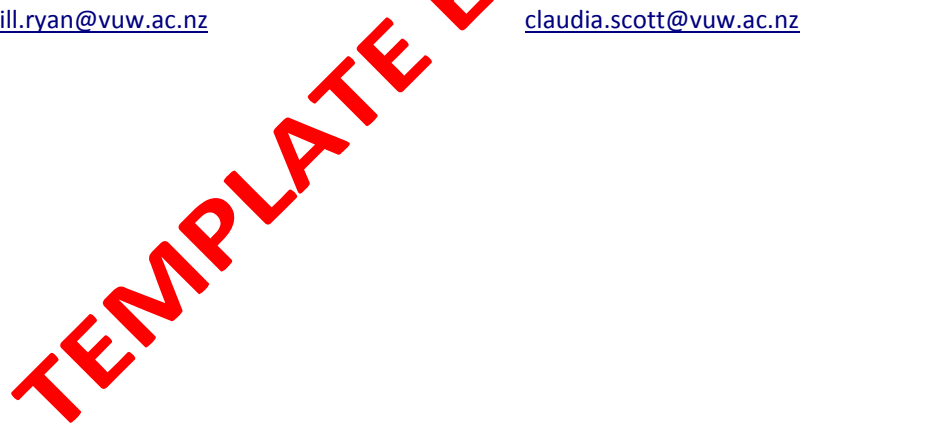

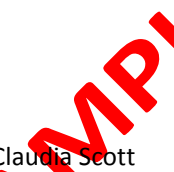

Pho Advisor, School of Government

1 vietoria University of Wellington

044635377

claudia.scott@vuw.ac.nz

COMMUNITY: CONCEPTIONS \& IMPLICATIONS - PARTICIPANT LETTER FOR Q-SORT INTERVIEW 


\title{
5.2 Participant consent form
}

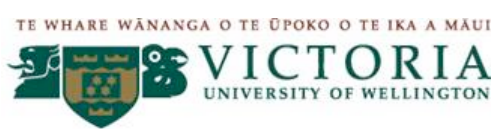

\author{
CONSENT
}

I understand what the research study Conceptions of Community Amongst Civic Leaders in Taranaki: Implications for Civic Leadership and Community Governance is about, what it's for and who's doing it. I also understand that

- I can pull out of this study at any time no matter what the reason

- If I do wish to withdraw from the study, I need to do so before 31 August 2014 and any data I have provided will be returned to me or destroyed as soon as practicable

- I will be invited to a presentation of the preliminary findings with other participants and will have an opportunity to participate in a facilitated discussion around those findings

- I may be approached at a later time to help clarify any surprises that may be identified in the analysis

- I will be provided with an electronic copy of the voice recording (if on is made) and the interview notes as soon as is practicable after its collection, and will be able to review and amend the information I have shared

- The information I provide will form the basis of the thesis

- The information or opinions I provide may be presented at academic or professional conferences and if it is, the information oropinions will be reported only in an aggregated or non-attributable form

- All information I provide will be destroyed five years after the research has concluded and

- Any further use of the information I provide will require my written consent.

I agree to take part in this stu
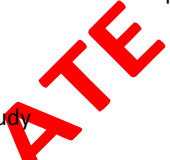

I agree for a voice recording tobe made of the interview before and after the card sort

I agree with non-attributable quotes being used in the thesis and associated publications

Name

Location

Date

Signature 


\subsection{Participant interview guide}

Explanatory Note:

The term 'case study' appears in the interview guide as an instruction to the researcher.

\section{Memo - Community: Conceptions \& Implications}

TO: SELF I SUBJECT: STAGE THREE INTERVIEW GUIDE I 01 AUGUST 2014

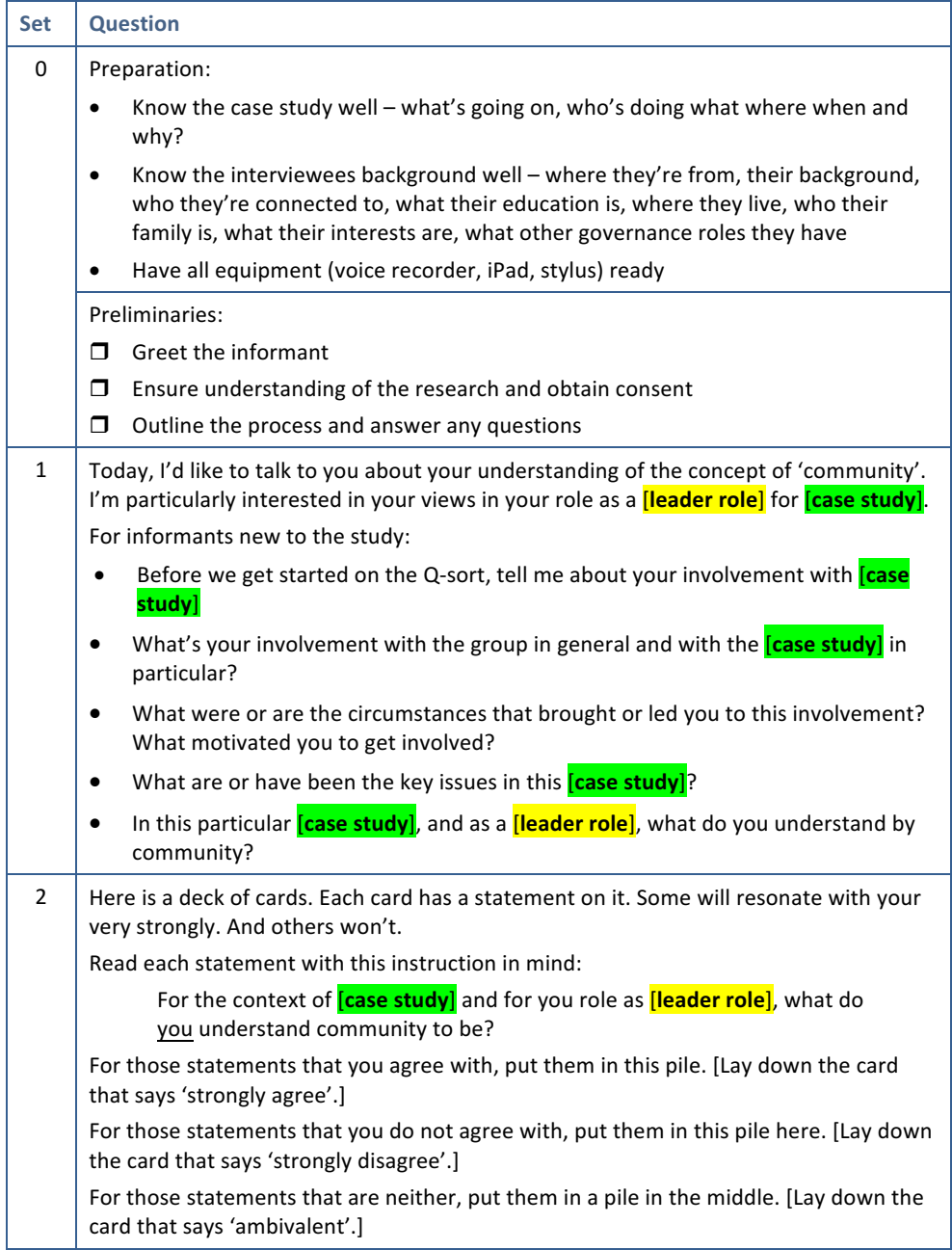




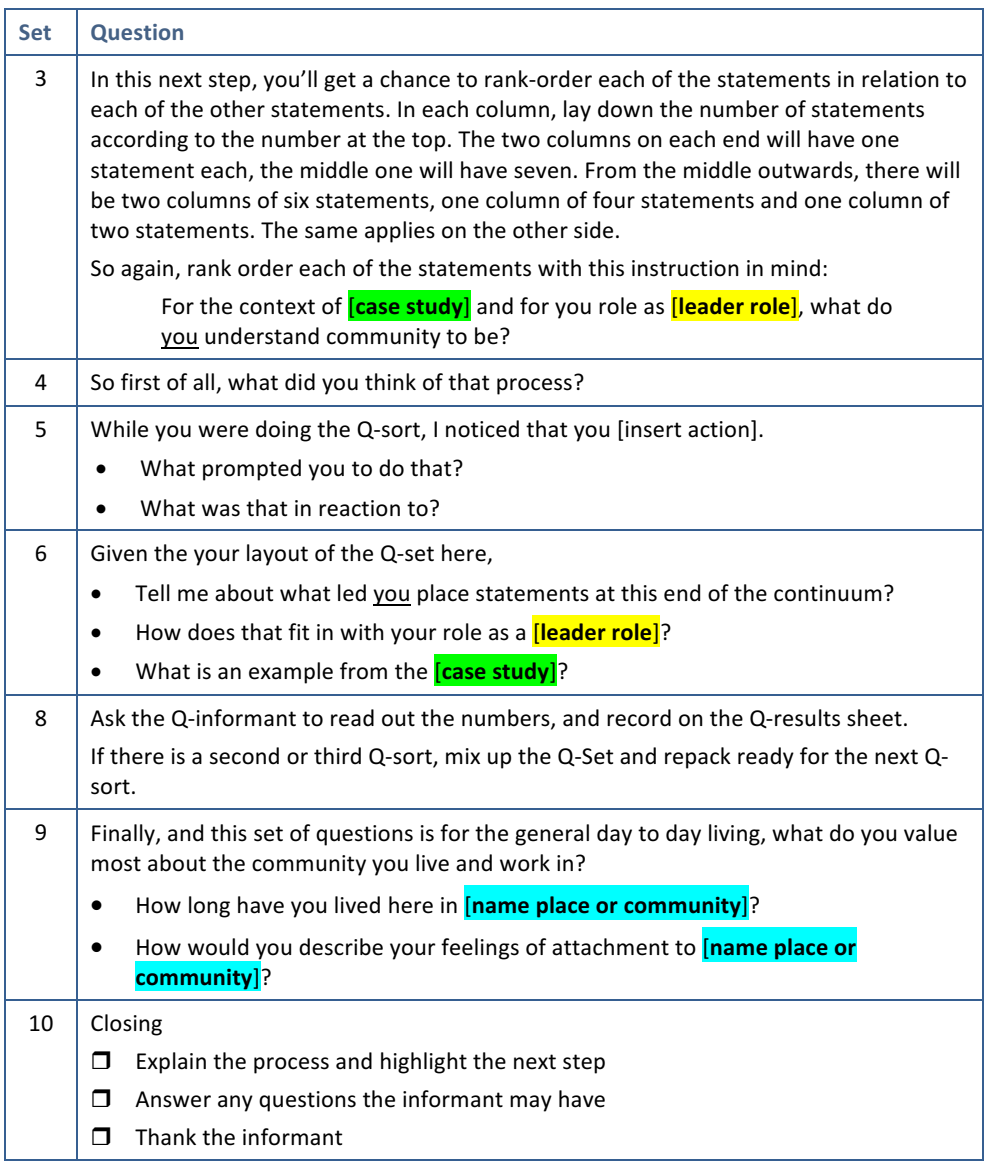

\section{CONTACT}

Te Aroha Hohaia

tearoha.hohaia@gmail.com or tearoha.hohaia@vuw.ac.nz

0212604779

PO Box 96, Hāwera 4640 


\section{Appendix 6: Q-sort results sheet}

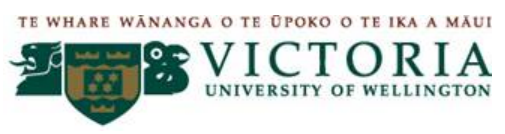

Q-SORT

Meta-Data:
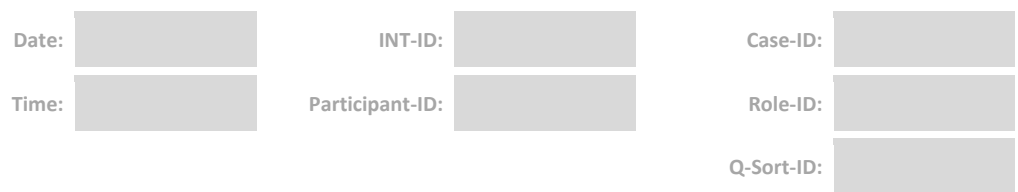

\section{Result:}

Strongly Disagree

Ambivalent

Strongly Agree
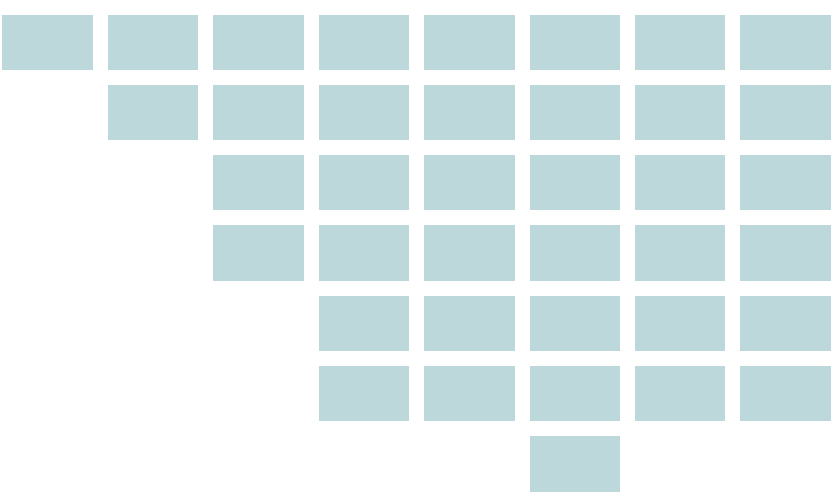

Notes: 


\section{Appendix 7: Fixed output reports}

Explanatory Note:

This appendix contains those tables produced by PQMethod that remain unchanged regardless of which factors are selected for extraction or rotated. 


\subsection{Unrotated factor matrix}

\begin{tabular}{|c|c|c|c|c|c|c|c|c|c|}
\hline \multicolumn{3}{|c|}{ SORTS \FACTORS 1} & \multirow{2}{*}{$\begin{array}{c}2 \\
.1630\end{array}$} & 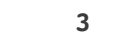 & 4 & 5 & 0 & 7 & 8 \\
\hline 1 & $34 \mathrm{~B} 3 \mathrm{~T} 57 \mathrm{M}$ & 0.6733 & & 0.1609 & 0.2798 & 0.1628 & .1384 & 0.1232 & -0.1708 \\
\hline 02 & $32 \mathrm{MuE} 76 \mathrm{M}$ & 0.6448 & -0.1135 & -0.2101 & -0.1146 & -0.4307 & 1011 & 0.2454 & 0.4070 \\
\hline 3 & $31 \mathrm{FqZ} 85 \mathrm{C}$ & 0.7202 & 0.2670 & -0.0676 & -0.0165 & -0.0665 & -0.3059 & -0.0279 & 0.0081 \\
\hline 4 & 31FqZ11P & -0.4542 & 0.3312 & -0.2223 & 0.2434 & -0.1073 & 0.2607 & -0 & 2246 \\
\hline 5 & $29 j B V 36 C$ & 0.4782 & 0.0647 & -0.0991 & 0.0002 & -0.1606 & -0.3410 & -0.0314 & 0.1650 \\
\hline 66 & $28 \mathrm{aFZ19M}$ & 0.7840 & -0.2085 & 0.1900 & -0.0295 & -0.0586 & 0.0670 & -0.0078 & 204 \\
\hline 7 & $28 \mathrm{aFZ57C}$ & 0.4850 & -0.4470 & 0.3103 & -0.0119 & -0.0872 & -0.0058 & 0.2574 & -0.0310 \\
\hline 8 & $38 \mathrm{Wdg} 76 \mathrm{M}$ & 0.7494 & 0.2693 & 0.2794 & 0.0567 & 0.0602 & 0.0333 & -0.0509 & 0.0944 \\
\hline 9 & $38 \mathrm{Wdg} 36 \mathrm{P}$ & 0.5869 & 0.2323 & 0.0898 & 0.0348 & 0.1146 & 0.3250 & -0.2731 & 0.1677 \\
\hline 10 & $366 \mathrm{Bz} 11 \mathrm{M}$ & 0.6755 & -0.4861 & -0.2809 & -0.0089 & 0.0433 & -0.0801 & 0.0448 & 36 \\
\hline 1 & $37 \mathrm{ZGS} 11 \mathrm{C}$ & 0.7728 & -0.2730 & -0.2484 & -0.0619 & 0.0567 & 0.1122 & 0.1692 & -0.1175 \\
\hline 2 & 35EMu32C & 0.6511 & -0.1257 & 0.1156 & 0.2483 & -0.1511 & -0.0092 & -0.2925 & 0.0532 \\
\hline 3 & 41DWX96P & 0.6568 & -0.2372 & 0.2544 & 0.0470 & 0.2302 & 0.1863 & -0.1130 & -0.0261 \\
\hline 4 & 41DWX32C & 0.3877 & -0.2122 & 0.3282 & -0.2369 & 0.1278 & -0.2277 & 0.2144 & -0.0422 \\
\hline 15 & 390IQ96M & 0.7309 & 0.1970 & 0.0190 & 0.1050 & 0.0751 & 0.2234 & -0.2623 & 0.0048 \\
\hline 6 & $42 \mathrm{STm} 32 \mathrm{M}$ & 0.6 & -0.4 & -0.0857 & -0.1 & 0.2259 & -0.0301 & 0.0600 & 0.0291 \\
\hline 17 & 47 oyq11M & 0.6100 & 0.0133 & 0.0734 & -0.2734 & 0.3030 & 0.0145 & -0.1512 & -0.2404 \\
\hline 8 & $52 w 4 y 85 M$ & 0.5585 & 0.0046 & 11 & -0.3971 & -0.2 & 0.0 & 0.1 & -0 \\
\hline 19 & $33 \mathrm{STg} 11 \mathrm{P}$ & 0.7126 & -0.2703 & 0.1979 & 0.0356 & -0.1203 & -0.1637 & -0.0 & 0.3054 \\
\hline 20 & 43 uWH85P & 0.3852 & 0.4235 & -0.0632 & -0.4130 & -0.1412 & -0.2845 & 0.2756 & -0.0926 \\
\hline 21 & $40 \mathrm{QNG} 11 \mathrm{C}$ & 0.6135 & 0.3722 & -0.0418 & 0.1356 & -0.1132 & 0.2489 & -0.1633 & -0.1009 \\
\hline 22 & $30 \mathrm{KjD} 85 \mathrm{C}$ & 0.8095 & 0.0298 & -0.0290 & 0.2943 & -0.0060 & -0.0124 & -0.0508 & -0.0396 \\
\hline 23 & 30KjD56P & -0.0219 & 0.4302 & 0.0519 & 0.4891 & -0.3095 & -0.3539 & 0.2702 & -0 \\
\hline 24 & $55 \mathrm{Ttx} 85 \mathrm{M}$ & 0.4175 & 0.4652 & -0.0234 & -0.4309 & -0.1161 & 0.2765 & 0.1023 & 144 \\
\hline 25 & 45PQ019P & 0.6614 & -0.1704 & -0.0065 & 0.0034 & -0.2323 & 70 & 0.1626 & -0 . \\
\hline 26 & $45 \mathrm{PQO} 32 \mathrm{M}$ & 0.4436 & -0.1972 & -0.1744 & 0.4651 & 0.3330 & -0.2366 & 0.1781 & -0.0384 \\
\hline 7 & $44 \mathrm{Ghb} 85 \mathrm{C}$ & 0.6572 & $0.3 \varepsilon$ & -0.2 & -0.0266 & 0.1237 & -0 & 0 . & 1302 \\
\hline 28 & $57 \mathrm{i} 2 \mathrm{n} 32 \mathrm{M}$ & 0.6872 & 0.2335 & -0.3244 & -0.1471 & 0.0246 & -0.0458 & -0.2448 & 0.0793 \\
\hline 9 & 59 sov96P & 0.6598 & -0.2634 & -0.1946 & 0.2956 & -0.0367 & 0.0111 & -0.1998 & -0.1006 \\
\hline 30 & 34В3т96М & 0.5608 & 0.2331 & -0.3140 & 0.3489 & 0.0287 & 0.2409 & 0.1850 & 0.0422 \\
\hline 31 & 32MUE32M & 0.6364 & -0.1459 & -0.2822 & -0.1667 & -0.4221 & 0.0480 & 0.1729 & 0.4147 \\
\hline 32 & $53 \mathrm{CGV} 19 \mathrm{P}$ & 0.6028 & 0.0730 & -0.4115 & -0.0218 & 0.3217 & -0.0841 & 0.0444 & -0.0620 \\
\hline 33 & $5015257 \mathrm{M}$ & 0.7365 & -0.0146 & -0.0415 & -0.2737 & 0.0919 & -0.1570 & -0.0967 & -0.0488 \\
\hline 34 & 49Vsu96P & 0.6271 & -0.1759 & -0.0041 & -0.1245 & 0.1613 & -0.2068 & -0.3880 & 0.2133 \\
\hline 35 & $49 \mathrm{Vsu} 85 \mathrm{P}$ & -0.3691 & 0.1242 & 0.1885 & 0.0927 & 0.5202 & -0.0146 & 0.3559 & 0.3928 \\
\hline 36 & $43 \times \times 129 P$ & 0.1839 & 0.1857 & 0.6873 & 0.1615 & -0.2737 & -0.1326 & -0.1690 & 0.0772 \\
\hline 37 & $43 \times \times 185 P$ & 0.5832 & 0.4337 & -0.1281 & -0.2993 & 0.0657 & -0.3194 & -0.0119 & -0.1470 \\
\hline 8 & $43 \times \times 132 \mathrm{C}$ & 0.3923 & 0.3410 & 0.4140 & 0.2701 & 0.2408 & -0.1033 & 0.1901 & 0.3194 \\
\hline 39 & $60 J g 332 P$ & 0.6702 & -0.1533 & 0.0225 & 0.3444 & -0.3927 & 0.0818 & 0.0991 & -0.2917 \\
\hline 0 & $51 \mathrm{TvM} 32 \mathrm{C}$ & 0.6194 & 0.4338 & -0.0606 & -0.0435 & -0.1009 & 0.0122 & -0.1424 & -0.2461 \\
\hline 41 & $56 t \operatorname{lp} 32 \mathrm{M}$ & 0.7300 & -0.1528 & 0.1236 & 0.1412 & 0.0023 & 0.1500 & 0.2329 & -0.0525 \\
\hline 2 & $56 t \operatorname{lp} 32 \mathrm{C}$ & 0.5634 & 0.2632 & -0.1616 & 0.2703 & 0.2229 & -0.0794 & 0.3007 & -0.0605 \\
\hline 43 & $46 \operatorname{Lm} 932 \mathrm{P}$ & 0.7389 & 0.0092 & -0.1792 & -0.0688 & -0.0426 & -0.2007 & -0.0777 & 0.1872 \\
\hline 44 & $54 \mathrm{QQ} 736 \mathrm{M}$ & 0.7132 & 0.1009 & 0.3805 & 0.2476 & 0.0401 & -0.0725 & -0.1157 & 0.0770 \\
\hline 45 & $61 \mathrm{Er} 332 \mathrm{C}$ & 0.3582 & 0.2681 & 0.1918 & -0.3409 & 0.1759 & 0.4636 & 0.2604 & -0.0513 \\
\hline 46 & 63МКT57C & 0.5950 & -0.2532 & -0.1021 & 0.0316 & -0.0149 & 0.4180 & 0.1293 & 0.1313 \\
\hline 47 & $64 \mathrm{Gn} 576 \mathrm{C}$ & 0.7527 & -0.1228 & 0.1005 & -0.2359 & 0.1595 & -0.1050 & -0.1535 & 0.0219 \\
\hline & & & 84 & 2 & 2 & 1.9 & 1.7608 & 1.6333 & 1 \\
\hline & & & & & & & & & \\
\hline
\end{tabular}




\subsection{Correlation matrix between sorts}

Explanatory Note:

The next table shows the correlation matrix between sorts ranging in value from 0 to 100 .

The correlations have been conditionally formatted across three grade points. As the correlations get closer to zero, the bluer the cell, and as the correlations get closer to 100, the more orange the cell. The diagonal of orange corresponds to a Q sort's correlation with itself, hence these cells are the brightest orange. 


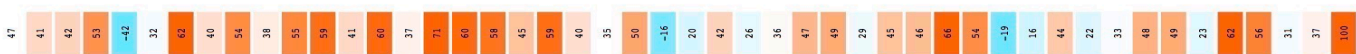

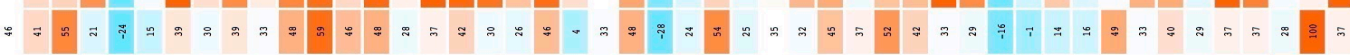

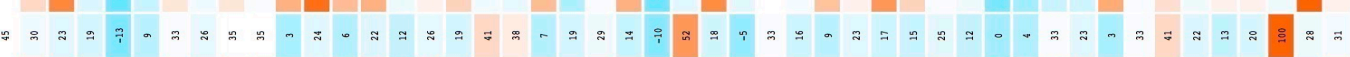

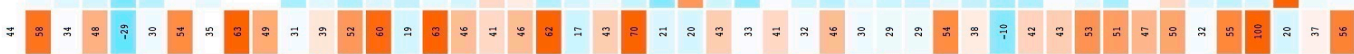

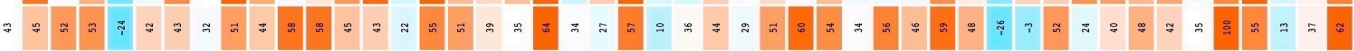
₹F:



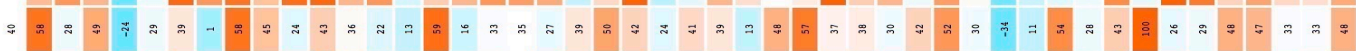

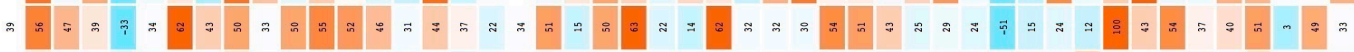



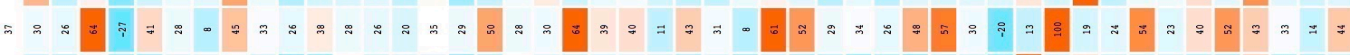

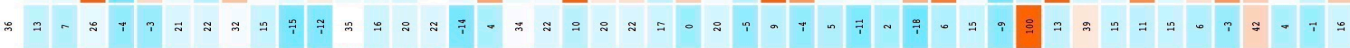

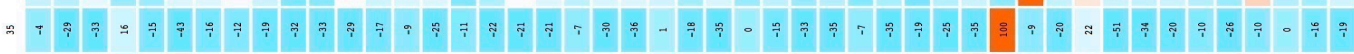

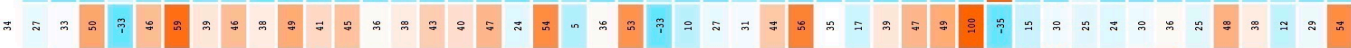

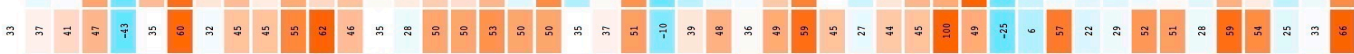
\#ะะ



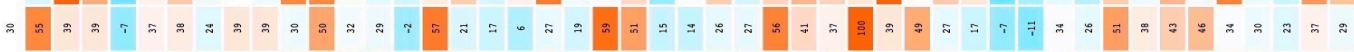

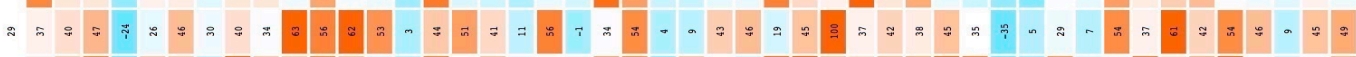

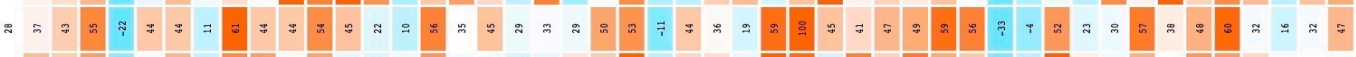

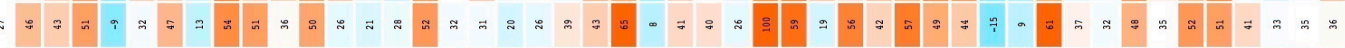

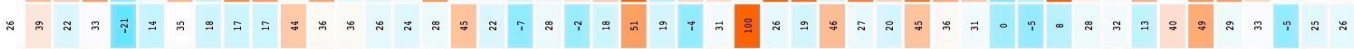

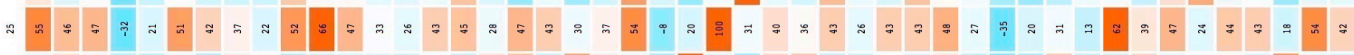

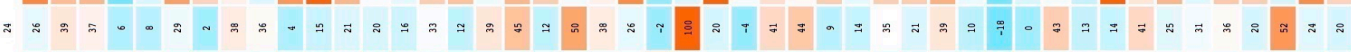

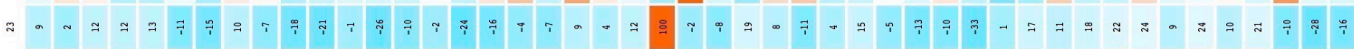

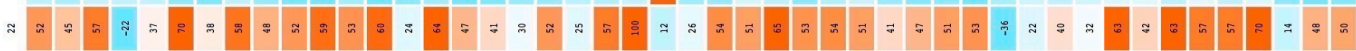

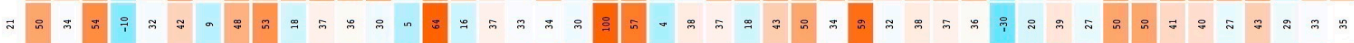

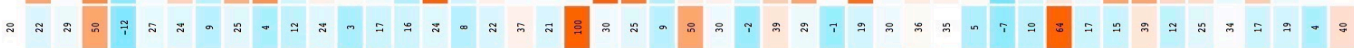

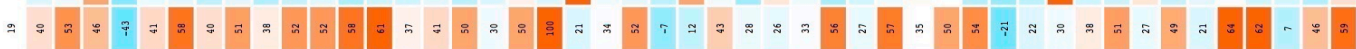

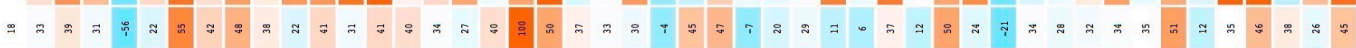

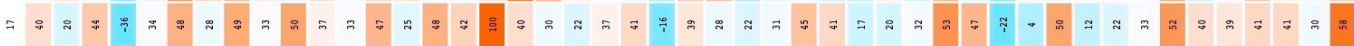

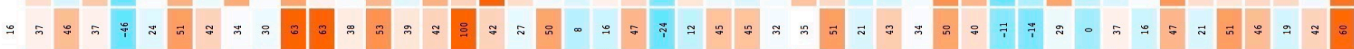

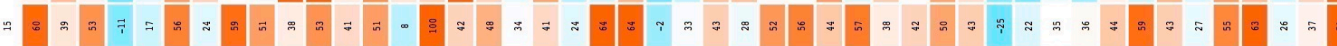

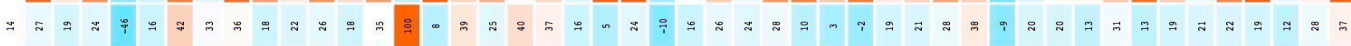

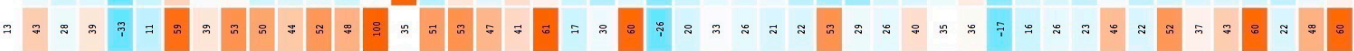

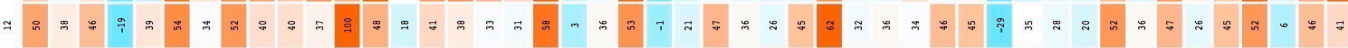

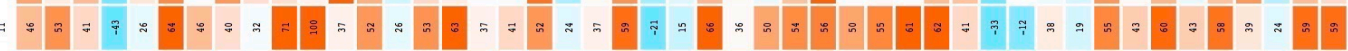

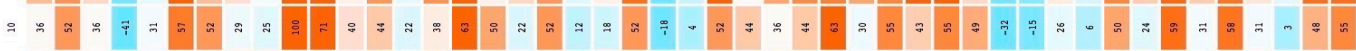
\&



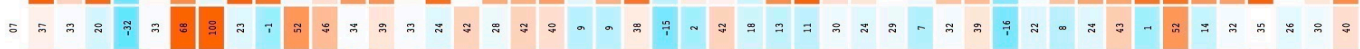

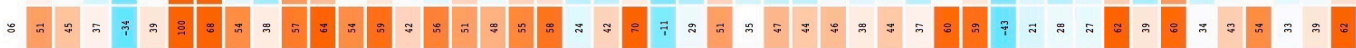

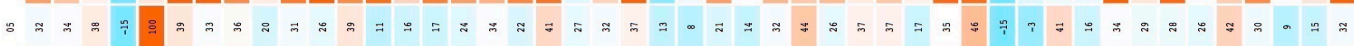

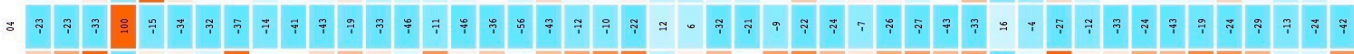

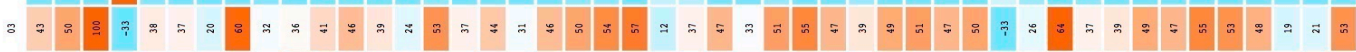

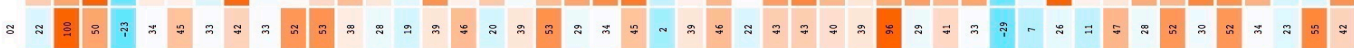

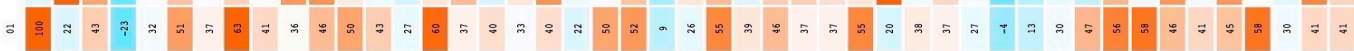




\subsection{Cumulative commonalities matrix}

\begin{tabular}{|c|c|c|c|c|c|c|c|c|c|}
\hline & & 1 & 2 & 3 & 4 & 5 & 6 & 7 & 8 \\
\hline $\mathrm{L}$ & 34В3T57M & 3 & 9 & 3 & 0 & 5 & 7 & 9 & $\perp$ \\
\hline 02 & 32MuE76M & 0.4158 & .4286 & 0.4728 & 0.4859 & 0.6714 & 0.6816 & 0.7418 & 0.9075 \\
\hline 03 & $31 \mathrm{FqZ} 85 \mathrm{C}$ & 0.5187 & .5899 & 0.5945 & .5948 & 0.5992 & 0.6928 & 0.6936 & 0.6936 \\
\hline 04 & 31FqZ11P & 0.2063 & .3160 & 0.3654 & 0.4246 & 0.4362 & 0.5041 & 0.5341 & 0.5846 \\
\hline 05 & 29 jBV36C & 0.2287 & 0.2329 & 0.2427 & 0.2427 & 0.2685 & 0.3847 & 0.3857 & 0.4129 \\
\hline 06 & 28aFZ19M & 0.6147 & .6582 & 0.6943 & 0.6951 & 0.6986 & 0.7030 & 0.7031 & 0.7176 \\
\hline 07 & $28 \mathrm{aFZ} 57 \mathrm{C}$ & 0.2352 & 0.4350 & 0.5313 & 0.5314 & 0.5391 & 0.5391 & 0.6053 & 0.6063 \\
\hline 08 & $38 \mathrm{Wdg} 76 \mathrm{M}$ & 0.5616 & 0.6341 & 0.7122 & 0.7154 & 0.7190 & 0.7201 & 0.7227 & 0.7316 \\
\hline 09 & $38 W d g 36 \mathrm{P}$ & 0.3 & .3984 & 0.4 & 0.4077 & 8 & 0.5264 & 10 & 0.6291 \\
\hline 10 & $366 \mathrm{Bz} 11 \mathrm{M}$ & 0.4563 & 0.6927 & 0.7716 & 0.7717 & 0.7735 & 0.7799 & 0 . & 0.7839 \\
\hline 11 & $37 \mathrm{ZGS} 11 \mathrm{C}$ & 0.5971 & .6717 & 0.7 & 0.7372 & 4 & 530 & & .7955 \\
\hline 12 & $35 \mathrm{EMu} 32 \mathrm{C}$ & 0.4239 & 0.4397 & 0.4531 & 0.5148 & 0.5376 & 0.5377 & 0.6232 & 0.6261 \\
\hline 13 & 41DWX96P & 0.4315 & 0.4877 & 0.5524 & 0.5547 & 0.6076 & 0.6424 & 0.6 & 0.6558 \\
\hline 14 & $41 \mathrm{DWX} 32 \mathrm{C}$ & 0.1503 & 0.1953 & 0.3030 & 0.3592 & 0.3755 & 0.4274 & 0.4733 & 0.4751 \\
\hline 15 & 390IQ96M & 0.5342 & 0.5730 & 0.5734 & 0.5844 & 0.5900 & 0.6399 & 0.7087 & 0.7087 \\
\hline 16 & $42 \mathrm{STm} 32 \mathrm{M}$ & 0.3970 & 0.5969 & 0.6042 & 0.6171 & 0.6681 & 0.6690 & 0.6726 & 0.6735 \\
\hline 17 & 4 7oyq11м & 0.3720 & 0.3722 & 0.3776 & 0.4523 & 0.5441 & 0.5443 & 0.5672 & 0.6250 \\
\hline 18 & $52 \mathrm{w} 4 \mathrm{y} 85 \mathrm{M}$ & 0.3119 & 0.3119 & 0.5732 & 0.7309 & 0.7794 & 0.7846 & 0.8082 & 0.8126 \\
\hline 19 & $33 \mathrm{STg} 11 \mathrm{P}$ & 0.5077 & 0.5808 & 0.6199 & 0.6212 & 0.6357 & 0.6625 & 0.6691 & 0.7624 \\
\hline 20 & 4 3uWH85P & 0.1484 & 0.3278 & 0.3318 & 0.5023 & 0.5222 & 0.6032 & 0.6791 & 0.6877 \\
\hline 21 & 40 QNG11C & 0.3764 & 0.5149 & 0.5167 & 0.5351 & 0.5479 & 0.6098 & 0.6365 & 0.6467 \\
\hline 22 & $30 \mathrm{KjD} 85 \mathrm{C}$ & 0.6553 & 0.6562 & 0.6571 & 0.7436 & 0.7437 & 0.7438 & 0 . & 0.7480 \\
\hline 23 & 30KjD56P & 0.0005 & 0.1856 & 0.1883 & 0.4275 & 0.5233 & 0.6485 & 0.7216 & 0.7421 \\
\hline 24 & $55 \mathrm{Tt} \times 85 \mathrm{M}$ & 0.1 & 0.3 & 0.3 & 0.5770 & 0.5905 & 0.6669 & 0.6774 & 0.6776 \\
\hline 25 & 45PQO19P & 0.4375 & 0.4665 & 0.4666 & 0.4666 & 0.5205 & 0.5238 & 0.5 & 0.6153 \\
\hline 26 & 45PQ०32M & 0.1968 & 0.2356 & 0.2661 & 0.4824 & 0.5933 & 0.6493 & 0.6810 & 0.6825 \\
\hline 7 & $44 \mathrm{Ghb} 85 \mathrm{C}$ & .4 & 0.5 & 0.6 & . & & 0 . & & 0 . \\
\hline 28 & $57 i 2 n 32 M$ & 0.4723 & 0.5268 & 0.6320 & 0.6536 & 0.6543 & 0.6564 & 0.7163 & 0.7226 \\
\hline 29 & 59 soV96P & .43 & 0.50 & 0.54 & .63 & 0 . & 0.6 & 0 . & 0. \\
\hline 30 & 34В3T96М & 0.3145 & 0.3688 & 0.4674 & 0.5892 & 0.5900 & 0.6480 & 0.6822 & 0.6840 \\
\hline 31 & 32MUE 32M & .40 & .42 & 0.50 & .53 & 0.71 & 0.7 & & 0.9160 \\
\hline 32 & $53 \mathrm{CGV} 19 \mathrm{P}$ & 0.3633 & 0.3687 & 0.5380 & 0.5385 & 0.6420 & 0.6490 & 0.6510 & 0.6549 \\
\hline 33 & $5015257 \mathrm{M}$ & 0.5424 & 0.5427 & 0.5444 & 0.6193 & 0.6277 & 0.6524 & 0.6617 & 0.6641 \\
\hline 34 & 49Vsu96P & 0.3932 & 0.4242 & 0.4242 & 0.4397 & 0.4657 & 0.5085 & 0.6591 & 0.7046 \\
\hline 35 & $49 \mathrm{Vsu} 85 \mathrm{P}$ & 0.1362 & 0.1517 & 0.1872 & 0.1958 & 0.4665 & 0.4667 & 0.5933 & 0.7476 \\
\hline 36 & $43 \times x 129 P$ & 0.0338 & 0.0683 & 0.5407 & 0.5667 & 0.6417 & 0.6592 & 0.6878 & 0.6937 \\
\hline 37 & $43 \times \times 185 P$ & 0.3402 & 0.5282 & 0.5446 & 0.6342 & 0.6385 & 0.7405 & 0.7407 & 0.7623 \\
\hline 38 & $43 \times \times 132 C$ & 0.1539 & 0.2701 & 0.4415 & 0.5145 & 0.5725 & 0.5831 & 0.6193 & 0.7213 \\
\hline 39 & $60 \mathrm{Jg} 332 \mathrm{P}$ & 0.4491 & 0.4726 & 0.4731 & 0.5918 & 0.7460 & 0.7527 & 0.7625 & 0.8476 \\
\hline 40 & $51 \mathrm{TvM} 32 \mathrm{C}$ & 0.3837 & 0.5718 & 0.5755 & 0.5774 & 0.5876 & 0.5877 & 0.6080 & 0.6686 \\
\hline 41 & $56 t l p 32 M$ & 0.5329 & 0.5563 & 0.5716 & 0.5915 & 0.5915 & 0.6140 & 0.6682 & 0.6710 \\
\hline 42 & $56 t \operatorname{lp} 32 \mathrm{C}$ & 0.3175 & .3867 & 0.4128 & 0.4859 & 0.5356 & 0.5419 & 0.6323 & 0.6359 \\
\hline 43 & $46 \operatorname{Lm} 932 \mathrm{P}$ & 0.5459 & 0.5460 & 0.5781 & 0.5829 & 0.5847 & 0.6250 & 0.6310 & 0.6661 \\
\hline 44 & $54 \mathrm{QQ736M}$ & 0.5087 & 0.5189 & 0.6637 & 0.7250 & 0.7266 & 0.7319 & 0.7453 & 0.7512 \\
\hline 45 & $61 \operatorname{Er} 332 \mathrm{C}$ & 0.1283 & 0.2002 & 0.2370 & 0.3532 & 0.3841 & 0.5991 & 0.6669 & 0.6695 \\
\hline 46 & 63МКT57C & 0.3540 & 0.4181 & 0.4285 & 0.4295 & 0.4297 & 0.6045 & 0.6212 & 0.6384 \\
\hline 47 & $64 \mathrm{Gn} 576 \mathrm{C}$ & 0.5665 & 0.5816 & 0.5917 & 0.6473 & 0.6728 & 0.6838 & 0.7073 & 0.7078 \\
\hline
\end{tabular}




\subsection{Free distribution results}

\begin{tabular}{|c|c|c|c|}
\hline SOR & TSS & MEAN & ST.DEV. \\
\hline 01 & 34В3T57M & 0.000 & 2.365 \\
\hline 02 & 32MuE76M & 0.000 & 2.365 \\
\hline 03 & $31 \mathrm{FqZ} 85 \mathrm{C}$ & 0.000 & 2.365 \\
\hline 04 & 31FqZ11P & 0.000 & 2.365 \\
\hline 05 & 29 jBV36C & 0.000 & 2.365 \\
\hline 06 & $28 \mathrm{aFZ19M}$ & 0.000 & 2.365 \\
\hline 07 & $28 \mathrm{aFz} 57 \mathrm{C}$ & 0.000 & 2.365 \\
\hline 08 & $38 \mathrm{Wdg} 76 \mathrm{M}$ & 0.000 & 2.365 \\
\hline 09 & $38 \mathrm{Wdg} 36 \mathrm{P}$ & 0.000 & 2.365 \\
\hline 10 & 366Bz11M & 0.000 & 2.365 \\
\hline 11 & $37 \mathrm{ZGS} 11 \mathrm{C}$ & 0.000 & 2.365 \\
\hline 12 & $35 \mathrm{EMu} 32 \mathrm{C}$ & 0.000 & 2.365 \\
\hline 13 & 41DWX96P & 0.000 & 2.365 \\
\hline 14 & $41 \mathrm{DW} \times 32 \mathrm{C}$ & 0.000 & 2.365 \\
\hline 15 & 390IQ96M & 0.000 & 2.365 \\
\hline 16 & $42 \mathrm{STm} 32 \mathrm{M}$ & 0.000 & 2.365 \\
\hline 17 & 47 oyq11м & 0.000 & 2.365 \\
\hline 18 & $52 \mathrm{w} 4 \mathrm{y} 85 \mathrm{M}$ & 0.000 & 2.365 \\
\hline 19 & $33 \mathrm{STg} 11 \mathrm{P}$ & 0.000 & 2.365 \\
\hline 20 & 48UWH85P & 0.000 & 2.365 \\
\hline 21 & $40 \mathrm{QNG} 11 \mathrm{C}$ & 0.000 & 2.365 \\
\hline 22 & 30KjD85C & 0.000 & 2.365 \\
\hline 23 & 30KjD56P & 0.000 & 2.365 \\
\hline 24 & $55 \mathrm{Ttx} 85 \mathrm{M}$ & 0.000 & 2.365 \\
\hline 25 & 45PQo19P & 0.000 & 2.365 \\
\hline 26 & 45PQO32M & 0.000 & 2.365 \\
\hline 27 & $44 \mathrm{Ghb} 85 \mathrm{C}$ & 0.000 & 2.365 \\
\hline 28 & $57 i 2 n 32 M$ & 0.000 & 2.365 \\
\hline 29 & 59soV96P & 0.000 & 2.365 \\
\hline 30 & 34В3T96M & 0.000 & 2.365 \\
\hline 31 & 32MUE32M & 0.000 & 2.365 \\
\hline 32 & $53 \mathrm{CGV} 19 \mathrm{P}$ & 1.978 & 3.187 \\
\hline 33 & $5015257 \mathrm{M}$ & 0.000 & 2.365 \\
\hline 34 & 49Vsu96P & 0.000 & 2.365 \\
\hline 35 & $49 \mathrm{Vsu} 85 \mathrm{P}$ & 0.000 & 2.365 \\
\hline 36 & $43 \times x 128 P$ & 0.000 & 2.365 \\
\hline 37 & $43 \times x 185 P$ & 0.000 & 2.365 \\
\hline 38 & $43 \times \times 132 C$ & 0.000 & 2.365 \\
\hline 39 & $60 \mathrm{Jg} 332 \mathrm{P}$ & 0.000 & 2.365 \\
\hline 40 & $51 \mathrm{TVM} 32 \mathrm{C}$ & 0.000 & 2.365 \\
\hline 41 & $56 \mathrm{tlp} 32 \mathrm{M}$ & 0.000 & 2.365 \\
\hline 42 & $56 \mathrm{tl} p 32 \mathrm{C}$ & 0.000 & 2.365 \\
\hline 43 & $46 \operatorname{Lm} 932 \mathrm{P}$ & 0.000 & 2.365 \\
\hline 44 & $54 \mathrm{QQ736M}$ & 0.000 & 2.365 \\
\hline 45 & $61 \mathrm{Er} 332 \mathrm{C}$ & 0.000 & 2.365 \\
\hline 46 & 63МKT57C & 0.000 & 2.365 \\
\hline 47 & $64 \mathrm{Gn} 576 \mathrm{C}$ & 0.156 & 2.354 \\
\hline
\end{tabular}




\section{Appendix 8: Factor matrix with an $\mathrm{X}$ indicating a defining sort}

\begin{tabular}{|c|c|c|c|c|}
\hline & & 1 & 2 & 3 \\
\hline 01 & 34B3T57M & 0.3126 & 0.4787 & 0.4230 \\
\hline 02 & 32MuE76M & $0.5940 \mathrm{x}$ & 0.3360 & 0.0834 \\
\hline 03 & $31 \mathrm{FqZ} 85 \mathrm{C}$ & 0.3591 & $0.6417 x$ & 0.2319 \\
\hline 04 & $31 \mathrm{FqZ} 11 \mathrm{P}$ & -0.4481 & 0.0478 & -0.4029 \\
\hline 05 & 29 jBV36C & 0.3277 & $0.3515 x$ & 0.1085 \\
\hline 06 & $28 \mathrm{aFZ19M}$ & $0.6127 x$ & 0.2467 & 0.5078 \\
\hline 07 & $28 \mathrm{aFZ} 57 \mathrm{C}$ & 0.5118 & -0.1412 & 0.4994 \\
\hline 08 & $38 W d g 76 \mathrm{M}$ & 0.2582 & 0.5772 & 0.5589 \\
\hline 09 & $38 W d g 36 \mathrm{P}$ & 0.2333 & $0.4997 x$ & 0.3200 \\
\hline 10 & $366 \mathrm{Bz} 11 \mathrm{M}$ & $0.8736 x$ & 0.0808 & 0.0441 \\
\hline 11 & $37 \mathrm{ZGS} 11 \mathrm{C}$ & $0.7967 x$ & 0.2952 & 0.1075 \\
\hline 12 & 35EMu $32 \mathrm{C}$ & $0.4937 x$ & 0.2520 & 0.3819 \\
\hline 13 & $41 \mathrm{DWX} 96 \mathrm{P}$ & 0.5197 & 0.1352 & 0.5139 \\
\hline 14 & $41 \mathrm{DWX} 32 \mathrm{C}$ & 0.2905 & -0.0191 & $0.4672 \mathrm{x}$ \\
\hline 15 & 390IQ96M & 0.3805 & $0.5727 x$ & 0.3173 \\
\hline 16 & $42 \mathrm{STm} 32 \mathrm{M}$ & $0.7500 x$ & 0.0378 & 0.2009 \\
\hline 17 & 47 oyq11M & 0.3924 & 0.3464 & 0.3219 \\
\hline 18 & $52 \mathrm{w} 4 \mathrm{y} 85 \mathrm{M}$ & 0.2107 & 0.2048 & $0.6977 x$ \\
\hline 19 & $33 \mathrm{STg} 11 \mathrm{P}$ & $0.5988 x$ & 0.1553 & 0.4870 \\
\hline 20 & $43 \mathrm{uWH} 85 \mathrm{P}$ & 0.0254 & $0.5683 x$ & 0.0904 \\
\hline 21 & $40 \mathrm{QNG} 11 \mathrm{C}$ & 0.2097 & $0.6556 \mathrm{x}$ & 0.2072 \\
\hline 22 & $30 \mathrm{KjD} 85 \mathrm{C}$ & 0.5568 & 0.4996 & 0.3121 \\
\hline 23 & 30KjD56P & -0.3029 & $0.3098 x$ & 0.0239 \\
\hline 24 & $55 \mathrm{Tt} \times 85 \mathrm{M}$ & 0.0081 & $0.6099 x$ & 0.1387 \\
\hline 25 & 45PQ०19P & $0.5711 x$ & 0.2525 & 0.2770 \\
\hline 26 & 45PQO32M & $0.4936 \mathrm{x}$ & 0.1457 & 0.0341 \\
\hline 27 & $44 \mathrm{Ghb} 85 \mathrm{C}$ & 0.2940 & $0.7367 x$ & 0.0587 \\
\hline 28 & $57 i 2 n 32 M$ & 0.4457 & $0.6582 x$ & -0.0138 \\
\hline 29 & $59 \mathrm{soV} 96 \mathrm{P}$ & $0.6932 x$ & 0.2243 & 0.1086 \\
\hline 30 & $34 \mathrm{~B} 3 \mathrm{~T} 96 \mathrm{M}$ & 0.3539 & $0.5821 x$ & -0.0574 \\
\hline 31 & 32MUE32M & $0.6334 x$ & 0.3232 & 0.0155 \\
\hline 32 & $53 \mathrm{CGV} 19 \mathrm{P}$ & 0.5174 & 0.5052 & -0.1230 \\
\hline 33 & $5015257 \mathrm{M}$ & $0.5379 x$ & 0.4258 & 0.2715 \\
\hline 34 & $49 \mathrm{Vsu} 96 \mathrm{P}$ & $0.5497 \mathrm{x}$ & 0.2277 & 0.2649 \\
\hline 35 & $49 \mathrm{Vsu} 85 \mathrm{P}$ & -0.4008 & -0.1626 & 0.0122 \\
\hline 36 & $43 \times \times 129 P$ & -0.2252 & 0.0861 & $0.6946 \mathrm{x}$ \\
\hline 37 & $43 \times \times 185 P$ & 0.1798 & $0.7066 \mathrm{x}$ & 0.1142 \\
\hline 38 & $43 \times \times 132 C$ & -0.0826 & 0.3935 & $0.5290 x$ \\
\hline 39 & $60 \mathrm{Jg} 332 \mathrm{P}$ & $0.5564 x$ & 0.2639 & 0.3064 \\
\hline 40 & $51 \mathrm{TVM} 32 \mathrm{C}$ & 0.1817 & $0.7115 x$ & 0.1906 \\
\hline 41 & $56 t l p 32 M$ & $0.5630 x$ & 0.2747 & 0.4232 \\
\hline 42 & $56 t l p 32 C$ & 0.2844 & $0.5704 \mathrm{x}$ & 0.0811 \\
\hline 43 & $46 \operatorname{Lm} 932 \mathrm{P}$ & $0.5722 \mathrm{x}$ & 0.4787 & 0.1469 \\
\hline 44 & $54 \mathrm{QQ736M}$ & 0.3036 & 0.4008 & $0.6410 \mathrm{x}$ \\
\hline 45 & $61 \mathrm{Er} 332 \mathrm{C}$ & 0.0159 & $0.3704 \mathrm{x}$ & 0.3155 \\
\hline 46 & 63МКТ57С & $0.6096 x$ & 0.1724 & 0.1650 \\
\hline 47 & $64 \mathrm{Gn} 576 \mathrm{C}$ & $0.5680 \mathrm{x}$ & 0.3168 & 0.4108 \\
\hline & 20 & 22 & 17 & 11 \\
\hline
\end{tabular}




\section{Appendix 9: Factor scores with corresponding ranks}

\section{Item Short Statement}

1 [no] understanding of the richness

2 is not just about a group consulti

3 a key part is contributing as well

4 is whoever I meet and whoever I ne

5 can be sort of defined according to

6 some aspects are really important

7 about whānau, about kōrero, about

8 Relationships

9 where people are participating

10 where I don't see any school sores

11 a fictitious group

12 who they're accountable to, the pe

13 I don't know. It's hard.

14 their whole life revolves around

15 everybody gets an opportunity to

16 anything outside Council

17 understanding about the way people

18 everybody who lives in that area

19 a risk mitigation strategy

20 Everyone

21 groups of people engaging in conve

22 people who come together to achieve

23 sit[ting] face-to-face and talk[ing]

24 having fairly good infrastructure

25 the people I serve

26 may mean something different even

27 very multi-layered, a here-and-now

28 a whakapapa thing

29 you've got to get on with everybody

30 immediately identified by the hat $y$

31 where everybody has to take respons

32 not about you and me, it's about th

33 a full chance to react to things

34 anyone who could be impacted

35 the whole way we interact

36 a variety of small communities

37 asking for input and then deliveri

38 concerned there's no transparency

39 a whole lot of people behind us

40 being committed to the place where

41 knowing your neighbours and knowing

42 some sort of stuff in the back paddock

43 the lowest level of local government

44 everyone's important

45 best work over a cup of tea
Item

Factor 1

0.1526

0.4316

1.104

0.1725

0.3421

0.4019

0.8110

1.682

$0.52 \quad 14$

$-1.1839$

$-2.40 \quad 45$

$-0.6033$

$-1.7143$

$-0.9236$

1.095

$-1.4542$

0.4117

0.947

$-1.0938$

1.443

$-0.2530$

0.6113

0.4118

$-0.9837$

$0.80 \quad 11$

0.3920

$-0.2029$

$-0.5431$

$-0.4732$

$-1.2440$

0.1027

0.938

0.919

0.3323

0.1824

$-0.86 \quad 35$

0.4815

$-1.37 \quad 41$
0.04

0.0428

0.946

0.3322

$-2.3244$

$-0.7434$

$1.77 \quad 1$

0.6312
Factor 2

0.4913

0.3518

$0.76 \quad 11$

$-0.7537$

$1.24 \quad 4$

$0.46 \quad 14$

1.612

1. 323

0.1722

$-1.5142$

$-2.7645$

$-0.0627$

$-1.2039$

$-1.3340$

0.3319

$-1.9444$

$0.50 \quad 12$

$-0.3633$

$-0.6835$

$-1.1538$

0.0425

2.001

$0.37 \quad 17$

$-0.7236$

$-0.1028$

1.146

1.215

0.4115

$-0.2331$

0.0624

0.2521

$-0.1730$

0.918

0.0026

0.909

$0.81 \quad 10$

$-0.3934$

$-0.1429$

$0.28 \quad 20$

1.067

$-0.33 \quad 32$

$-1.4441$

$-1.8643$

0.386

0.0923
Factor 3

1.266

0.1520

0.9510

$-0.3530$

0.0122

1.148

1.802

1.434

1.029

1.425

$-1.3341$

$-2.2945$

$-0.2629$

$-0.6733$

$-0.2428$

$-1.0938$

0.1519

1.891

$-0.8036$

$-0.4931$

$-0.0224$

0.3316

0.1321

$-0.0426$

$-1.3543$

0.3117

0.5913

1.533

$-0.7234$

$-1.2040$

0.7611

0.6412

$-0.0325$

$-0.90 \quad 37$

$-0.1827$

0.5214

$-0.5532$

$-1.3442$

$-1.1439$

1.157

0.2618

$-0.7335$

$-2.0644$

0.0023

0.3515 
Appendix 10: Correlations between factor scores

$\begin{array}{lccc}\text { Factors } & 1 & 2 & 3 \\ 1 & 1.0000 & 0.6261 & 0.4462 \\ 2 & 0.6261 & 1.0000 & 0.4922 \\ 3 & 0.4462 & 0.4922 & 1.0000\end{array}$




\section{Appendix 11: Factor scores by Factor}

Explanatory Note:

The line breaks in the next three tables are deliberate with the results in differences grouped according to the units value. For example, the differences that range between 2.000 and 2.999 are grouped together with a line break, as are those differences that fall into the range between 0.000 and 0.999 . There is no other reason for this grouping except to help make the table easier to read. 


\subsection{Factor scores for Factor 1}

\begin{tabular}{|c|c|c|}
\hline No. Statement & No. & Z-SCORES \\
\hline 44 everyone's important & 44 & 1.733 \\
\hline 8 Relationships & 8 & 1.678 \\
\hline 20 Everyone & 20 & 1.439 \\
\hline 3 a key part is contributing as well & 3 & 1.101 \\
\hline 15 everybody gets an opportunity to have a say & 15 & 1.094 \\
\hline 40 being committed to the place where you live & 40 & 0.941 \\
\hline 18 everybody who lives in that area & 18 & 0.940 \\
\hline 32 not about you and me, it's about the community & 32 & 0.929 \\
\hline 33 a full chance to react to things & 33 & 0.909 \\
\hline 7 about whānau, about kōrero, about decision-making & 7 & 0.811 \\
\hline 25 the people I serve & 25 & 0.800 \\
\hline 45 best work over a cup of tea & 45 & 0.633 \\
\hline 22 people who come together to achieve something & 22 & 0.608 \\
\hline 9 where people are participating & 9 & 0.524 \\
\hline 37 asking for input and then delivering back results & 37 & 0.477 \\
\hline 2 is not just about a group consulting with a group of people & 2 & 0.427 \\
\hline 17 understanding about the way people work & 17 & 0.414 \\
\hline 23 sit[ting] face-to-face and talk[ing] to someone & 23 & 0.409 \\
\hline 6 some aspects are really important to people's mental and soc & 6 & 0.404 \\
\hline 26 may mean something different even though we're at the same $t$ & 26 & 0.389 \\
\hline 5 can be sort of defined according to interests and values as & 5 & 0.336 \\
\hline 41 knowing your neighbours and knowing you can rely on them & 41 & 0.331 \\
\hline 34 anyone who could be impacted & 34 & 0.327 \\
\hline 35 the whole way we interact & 35 & 0.176 \\
\hline 4 is whoever I meet and whoever I need to do business with nex & 4 & 0.172 \\
\hline 1 [no] understanding of the richness of a community & 1 & 0.153 \\
\hline 31 where everybody has to take responsibility & 31 & 0.097 \\
\hline 39 a whole lot of people behind us & 39 & 0.041 \\
\hline 27 very multi-layered, a here-and-now not an always & 27 & -0.203 \\
\hline 21 groups of people engaging in conversation and civilised beha & 21 & -0.249 \\
\hline 29 you've got to get on with everybody even if you don't like $t$ & 29 & -0.471 \\
\hline 28 a whakapapa thing & 28 & -0.536 \\
\hline 12 who they're accountable to, the people who had voted them in & 12 & -0.605 \\
\hline 43 the lowest level of local government & 43 & -0.743 \\
\hline 36 a variety of small communities & 36 & -0.862 \\
\hline 14 their whole life revolves around their work & 14 & -0.920 \\
\hline 24 having fairly good infrastructure & 24 & -0.978 \\
\hline 10 where I don't see any school sores & 10 & -1.087 \\
\hline 19 a risk mitigation strategy & 19 & -1.182 \\
\hline 30 immediately identified by the hat you're wearing at a partic & 30 & -1.242 \\
\hline 38 concerned there's no transparency or engagement & 38 & -1.374 \\
\hline 16 anything outside Council & 16 & -1.449 \\
\hline 13 I don't know. It's hard. & 13 & -1.708 \\
\hline 42 some sort of stuff in the back pa & 42 & -2.323 \\
\hline 11 a fictitious group & 11 & -2.403 \\
\hline
\end{tabular}




\subsection{Factor scores for Factor 2}

No. Statement

22 people who come together to achieve something

7 about whānau, about kōrero, about decision-making

8 Relationships

5 can be sort of defined according to interests and values as $w$

27 very multi-layered, a here-and-now not an always 27

26 may mean something different even though we're at the same $t \quad 26$

40 being committed to the place where you live

33 a full chance to react to things

35 the whole way we interact

36 a variety of small communities

3 a key part is contributing as well

17 understanding about the way people work

1 [no] understanding of the richness of a community

6 some aspects are really important to people's mental and soc

28 a whakapapa thing

44 everyone's important

23 sit[ting] face-to-face and talk[ing] to someone

2 is not just about a group consulting with a group of people

15 everybody gets an opportunity to have a say

39 a whole lot of people behind us

31 where everybody has to take responsibility

9 where people are participating

45 best work over a cup of tea

30 immediately identified by the hat you're wearing at a partic

21 groups of people engaging in conversation and civilised beha

34 anyone who could be impacted

12 who they're accountable to, the people who had voted them in

25 the people I serve

38 concerned there's no transparency or engagement

32 not about you and me, it's about the community

29 you've got to get on with everybody even if you don't like $t$

41 knowing your neighbours and knowing you can rely on them

18 everybody who lives in that area

37 asking for input and then delivering back results

19 a risk mitigation strategy

24 having fairly good infrastructure

4 is whoever I meet and whoever I need to do business with nex

20 Everyone

13 I don't know. It's hard.

14 their whole life revolves around their work

42 some sort of stuff in the back paddock

10 where I don't see any school sores

43 the lowest level of local government

16 anything outside Council

11 a fictitious group
No.

z-SCORES

22

1.999

1.611

1.317

1.244

1.207

1.140

1.059

0.910

0.898

0.806

0.764

0.503

0.492

0.464

0.406

0.381

0.374

0.345

0.330

0.281

0.248

0.166

0.090

0.055

0.045

0.004

$-0.057$

$-0.097$

$-0.144$

$-0.168$

$-0.235$

$-0.332$

$-0.365$

$-0.391$

$-0.681$

$-0.724$

$-0.751$

$-1.148$

$-1.203$

$-1.335$

$-1.439$

$-1.506$

$-1.858$

$-1.943$

$-2.763$ 


\subsection{Factor scores for Factor 3}

\begin{tabular}{|c|c|c|}
\hline No. Statement & No. & Z-SCORES \\
\hline 18 everybody who lives in that area & 18 & 1.890 \\
\hline 7 about whānau, about kōrero, about decision-making & 7 & 1.796 \\
\hline 28 a whakapapa thing & 28 & 1.526 \\
\hline 8 Relationships & 8 & 1.427 \\
\hline 10 where I don't see any school sores & 10 & 1.416 \\
\hline 1 [no] understanding of the richness of a community & 1 & 1.263 \\
\hline 40 being committed to the place where you live & 40 & 1.153 \\
\hline 6 some aspects are really important to people's mental and soc & 6 & 1.144 \\
\hline 9 where people are participating & 9 & 1.021 \\
\hline 3 a key part is contributing as well & 3 & 0.951 \\
\hline 31 where everybody has to take responsibility & 31 & 0.761 \\
\hline 32 not about you and me, it's about the community & 32 & 0.642 \\
\hline 27 very multi-layered, a here-and-now not an always & 27 & 0.586 \\
\hline 36 a variety of small communities & 36 & 0.522 \\
\hline 45 best work over a cup of tea & 45 & 0.349 \\
\hline 22 people who come together to achieve something & 22 & 0.332 \\
\hline 26 may mean something different even though we're at the same $t$ & 26 & 0.311 \\
\hline 41 knowing your neighbours and knowing you can rely on them & 41 & 0.260 \\
\hline 17 understanding about the way people work & 17 & 0.150 \\
\hline 2 is not just about a group consulting with a group of people & 2 & 0.147 \\
\hline 23 sit[ting] face-to-face and talk[ing] to someone & 23 & 0.131 \\
\hline 5 can be sort of defined according to interests and values as & 5 & 0.013 \\
\hline 44 everyone's important & 44 & 0.003 \\
\hline 21 groups of people engaging in conversation and civilised beha & 21 & -0.017 \\
\hline 33 a full chance to react to things & 33 & -0.031 \\
\hline 24 having fairly good infrastructure & 24 & -0.042 \\
\hline 35 the whole way we interact & 35 & -0.185 \\
\hline 15 everybody gets an opportunity to have a say & 15 & -0.242 \\
\hline 13 I don't know. It's hard. & 13 & -0.263 \\
\hline 4 is whoever I meet and whoever I need to do business with nex & 4 & -0.354 \\
\hline 20 Everyone & 20 & -0.489 \\
\hline 37 asking for input and then delivering back results & 37 & -0.547 \\
\hline 14 their whole life revolves around their work & 14 & -0.675 \\
\hline 29 you've got to get on with everybody even if you don't like $t$ & 29 & -0.723 \\
\hline 42 some sort of stuff in the back paddock & 42 & -0.729 \\
\hline 19 a risk mitigation strategy & 19 & -0.797 \\
\hline 34 anyone who could be impacted & 34 & -0.900 \\
\hline 16 anything outside Council & 16 & -1.091 \\
\hline 39 a whole lot of people behind us & 39 & -1.138 \\
\hline 30 immediately identified by the hat you're wearing at a partic & 30 & -1.199 \\
\hline 11 a fictitious group & 11 & -1.326 \\
\hline 38 concerned there's no transparency or engagement & 38 & -1.340 \\
\hline 25 the people I serve & 25 & -1.354 \\
\hline 43 the lowest level of local government & 43 & -2.059 \\
\hline 12 who they're accountable to, the people who had voted them in & 12 & -2.292 \\
\hline
\end{tabular}




\section{Appendix 12: Descending array of differences}

Explanatory Note:

As with the previous appendix, the line breaks in the next three tables are deliberate with the results in differences grouped according to the units value. For example, those differences that range between -1.000 and -1.999 are grouped together with a line break as are those difference that fall into the range between 0.000 and 0.999 . There is no other reason for this grouping except to help make the table easier to read. 


\subsection{Descending array of differences between Factors 1 and 2}

\begin{tabular}{|c|c|c|c|c|}
\hline Item Short Statement & Item & Type 1 & Type 2 & Difference \\
\hline 20 Everyone & 20 & 1.439 & -1.148 & 2.587 \\
\hline 44 everyone's important & 44 & 1.773 & 0.381 & 1.392 \\
\hline 18 everybody who lives in that area & 18 & 0.940 & -0.365 & 1.304 \\
\hline 43 the lowest level of local government & 43 & -0.743 & -1.858 & 1.114 \\
\hline 32 not about you and me, it's about the & 32 & 0.929 & -0.168 & 1.097 \\
\hline 4 is whoever I meet and whoever I need & 4 & 0.172 & -0.751 & 0.923 \\
\hline 25 the people I serve & 25 & 0.800 & -0.097 & 0.897 \\
\hline 37 asking for input and then delivering & 37 & 0.477 & -0.391 & 0.868 \\
\hline 15 everybody gets an opportunity to have & 15 & 1.094 & 0.330 & 0.764 \\
\hline 41 knowing your neighbours and knowing $y$ & 41 & 0.331 & -0.332 & 0.662 \\
\hline 45 best work over a cup of tea & 45 & 0.633 & 0.090 & 0.543 \\
\hline 16 anything outside Council & 16 & -1.449 & -1.943 & 0.494 \\
\hline 14 their whole life revolves around the & 14 & -0.920 & -1.335 & 0.415 \\
\hline 8 Relationships & 8 & 1.678 & 1.317 & 0.361 \\
\hline 11 a fictitious group & 11 & -2.403 & -2.763 & 0.360 \\
\hline 9 where people are participating & 9 & 0.524 & 0.166 & 0.359 \\
\hline 3 a key part is contributing as well & 3 & 1.101 & 0.764 & 0.337 \\
\hline 10 where I don't see any school sores & 10 & -1.182 & -1.506 & 0.324 \\
\hline 34 anyone who could be impacted & 34 & 0.327 & 0.004 & 0.323 \\
\hline 2 is not just about a group consulting & 2 & 0.427 & 0.345 & 0.081 \\
\hline 23 sit[ting] face-to-face and talk[ing] & 23 & 0.409 & 0.374 & 0.036 \\
\hline 33 a full chance to react to things & 33 & 0.909 & 0.910 & -0.001 \\
\hline 6 some aspects are really important to & 6 & 0.404 & 0.464 & -0.060 \\
\hline 17 understanding about the way people $\mathrm{w}$ & 17 & 0.414 & 0.503 & -0.089 \\
\hline 40 being committed to the place where you & 40 & 0.941 & 1.059 & -0.117 \\
\hline 31 where everybody has to take responsib & 31 & 0.097 & 0.248 & -0.152 \\
\hline 29 you've got to get on with everybody e & 29 & -0.471 & -0.235 & -0.236 \\
\hline 39 a whole lot of people behind us & 39 & 0.041 & 0.281 & -0.240 \\
\hline 24 having fairly good infrastructure & 24 & -0.978 & -0.724 & -0.254 \\
\hline 21 groups of people engaging in convers & 21 & -0.249 & 0.045 & -0.294 \\
\hline 1 [no] understanding of the richness of & 1 & 0.153 & 0.492 & -0.339 \\
\hline 19 a risk mitigation strategy & 19 & -1.087 & -0.681 & -0.406 \\
\hline 13 I don't know. It's hard. & 13 & -1.708 & -1.203 & -0.505 \\
\hline 12 who they're accountable to, the peo & 12 & -0.605 & -0.057 & -0.548 \\
\hline 35 the whole way we interact & 35 & 0.176 & 0.898 & -0.721 \\
\hline 26 may mean something different even th & 26 & 0.389 & 1.140 & -0.751 \\
\hline 7 about whānau, about kōrero, about dec & 7 & 0.811 & 1.611 & -0.800 \\
\hline 42 some sort of stuff in the back paddock & 42 & -2.323 & -1.439 & -0.884 \\
\hline 5 can be sort of defined according to int & 5 & 0.336 & 1.244 & -0.908 \\
\hline 28 a whakapapa thing & 28 & -0.536 & 0.406 & -0.942 \\
\hline 38 concerned there's no transparency or & 38 & -1.374 & -0.144 & -1.229 \\
\hline 30 immediately identified by the hat you & 30 & -1.242 & 0.055 & -1.297 \\
\hline 22 people who come together to achieve & 22 & 0.608 & 1.999 & -1.390 \\
\hline 27 very multi-layered, a here-and-now & 27 & -0.203 & 1.207 & -1.410 \\
\hline 36 a variety of small communities & 36 & -0.862 & 0.806 & -1.668 \\
\hline
\end{tabular}




\subsection{Descending array of differences between Factors 1 and 3}

\begin{tabular}{|c|c|c|c|c|c|}
\hline Iten & m Short Statement & Item & Type 1 & Type 3 & Difference \\
\hline 25 & the people I serve & 25 & 0.800 & -1.354 & 2.154 \\
\hline 20 & Everyone & 20 & 1.439 & -0.489 & 1.928 \\
\hline 44 & everyone's important & 44 & 1.773 & 0.003 & 1.770 \\
\hline 12 & who they're accountable to, the peo & 12 & -0.605 & -2.292 & 1.687 \\
\hline 15 & everybody gets an opportunity to hav & 15 & 1.094 & -0.242 & 1.336 \\
\hline 43 & the lowest level of local government & 43 & -0.743 & -2.059 & 1.316 \\
\hline 34 & anyone who could be impacted & 34 & 0.327 & -0.900 & 1.227 \\
\hline 39 & a whole lot of people behind us & 39 & 0.041 & -1.138 & 1.179 \\
\hline 37 & asking for input and then delivering & 37 & 0.477 & -0.547 & 1.024 \\
\hline 33 & a full chance to react to things & 33 & 0.909 & -0.031 & 0.940 \\
\hline 4 & is whoever I meet and whoever I need & 4 & 0.172 & -0.354 & 0.526 \\
\hline 35 & the whole way we interact & 35 & 0.176 & -0.185 & 0.361 \\
\hline 5 & can be sort of defined according to & 5 & 0.336 & 0.013 & 0.324 \\
\hline 32 & not about you and me, it's about the & 32 & 0.929 & 0.642 & 0.287 \\
\hline 45 & best work over a cup of tea & 45 & 0.633 & 0.349 & 0.284 \\
\hline 2 & is not just about a group consulting & 2 & 0.427 & 0.147 & 0.279 \\
\hline 23 & sit[ting] face-to-face and talk[ing] & 23 & 0.409 & 0.131 & 0.278 \\
\hline 22 & people who come together to achieve & 22 & 0.608 & 0.332 & 0.276 \\
\hline 17 & understanding about the way people $\mathrm{w}$ & 17 & 0.414 & 0.150 & 0.264 \\
\hline 29 & you've got to get on with everybody & 29 & -0.471 & -0.723 & 0.253 \\
\hline 8 & Relationships & 8 & 1.678 & 1.427 & 0.250 \\
\hline 3 & a key part is contributing as well & 3 & 1.101 & 0.951 & 0.150 \\
\hline 26 & may mean something different even tho & 26 & 0.389 & 0.311 & 0.078 \\
\hline 41 & knowing your neighbours and knowing $y$ & 41 & 0.331 & 0.260 & 0.071 \\
\hline 38 & concerned there's no transparency or & 38 & -1.374 & -1.340 & -0.034 \\
\hline 30 & immediately identified by the hat you & 30 & -1.242 & -1.199 & -0.043 \\
\hline 40 & being committed to the place where you & 40 & 0.941 & 1.153 & -0.212 \\
\hline 21 & groups of people engaging in conversa & 21 & -0.249 & -0.017 & -0.232 \\
\hline 14 & their whole life revolves around thei & 14 & -0.920 & -0.675 & -0.245 \\
\hline 19 & a risk mitigation strategy & 19 & -1.087 & -0.797 & -0.290 \\
\hline 16 & anything outside Council & 16 & -1.449 & -1.091 & -0.358 \\
\hline 9 & where people are participating & 9 & 0.524 & 1.021 & -0.496 \\
\hline 31 & where everybody has to take responsib & 31 & 0.097 & 0.761 & -0.664 \\
\hline 6 & some aspects are really important to & 6 & 0.404 & 1.144 & -0.739 \\
\hline 27 & very multi-layered, a here-and-now not & 27 & -0.203 & 0.586 & -0.789 \\
\hline 24 & having fairly good infrastructure & 24 & -0.978 & -0.042 & -0.936 \\
\hline 18 & everybody who lives in that area & 18 & 0.940 & 1.890 & -0.951 \\
\hline 7 & about whanau, about korero, about de & 7 & 0.811 & 1.796 & -0.985 \\
\hline 11 & a fictitious group & 11 & -2.403 & -1.326 & -1.077 \\
\hline 1 & [no] understanding of the richness of & 1 & 0.153 & 1.263 & -1.110 \\
\hline 36 & a variety of small communities & 36 & -0.862 & 0.522 & -1.384 \\
\hline 13 & I don't know. It's hard. & 13 & -1.708 & -0.263 & -1.444 \\
\hline 42 & some sort of stuff in the back paddock & 42 & -2.323 & -0.729 & -1.595 \\
\hline 28 & a whakapapa thing & 28 & -0.536 & 1.526 & -2.062 \\
\hline 10 & where I don't see any school sores & 10 & -1.182 & 1.416 & -2.598 \\
\hline
\end{tabular}




\subsection{Descending array of differences between Factors 2 and 3}

\begin{tabular}{|c|c|c|c|c|}
\hline Item Short Statement & Item & Type 2 & Type 3 & Difference \\
\hline 12 who they're accountable to, the peo & 12 & -0.057 & -2.292 & 2.235 \\
\hline 22 people who come together to achieve & 22 & 1.999 & 0.332 & 1.667 \\
\hline 39 a whole lot of people behind us & 39 & 0.281 & -1.138 & 1.419 \\
\hline 25 the people I serve & 25 & -0.097 & -1.354 & 1.257 \\
\hline 30 immediately identified by the hat & 30 & 0.055 & -1.199 & 1.254 \\
\hline 5 can be sort of defined according to & 5 & 1.244 & 0.013 & 1.232 \\
\hline 38 concerned there's no transparency & 38 & -0.144 & -1.340 & 1.196 \\
\hline 35 the whole way we interact & 35 & 0.898 & -0.185 & 1.082 \\
\hline 33 a full chance to react to things & 33 & 0.910 & -0.031 & 0.941 \\
\hline 34 anyone who could be impacted & 34 & 0.004 & -0.900 & 0.904 \\
\hline 26 may mean something different even & 26 & 1.140 & 0.311 & 0.829 \\
\hline 27 very multi-layered, a here-and-now & 27 & 1.207 & 0.586 & 0.621 \\
\hline 15 everybody gets an opportunity to & 15 & 0.330 & -0.242 & 0.572 \\
\hline 29 you've got to get on with everybody & 29 & -0.235 & -0.723 & 0.489 \\
\hline 44 everyone's important & 44 & 0.381 & 0.003 & 0.378 \\
\hline 17 understanding about the way people & 17 & 0.503 & 0.150 & 0.353 \\
\hline 36 a variety of small communities & 36 & 0.806 & 0.522 & 0.283 \\
\hline 23 sit[ting] face-to-face and talk & 23 & 0.374 & 0.131 & 0.243 \\
\hline 43 the lowest level of local government & 43 & -1.858 & -2.059 & 0.201 \\
\hline 2 is not just about a group consulting & 2 & 0.345 & 0.147 & 0.198 \\
\hline 37 asking for input and then delivering & 37 & -0.391 & -0.547 & 0.156 \\
\hline 19 a risk mitigation strategy & 19 & -0.681 & -0.797 & 0.117 \\
\hline 21 groups of people engaging in convers & 21 & 0.045 & -0.017 & 0.062 \\
\hline 40 being committed to the place where & 40 & 1.059 & 1.153 & -0.094 \\
\hline 8 Relationships & 8 & 1.317 & 1.427 & -0.111 \\
\hline 7 about whānau, about kōrero, about & 7 & 1.611 & 1.796 & -0.185 \\
\hline 3 a key part is contributing as well & 3 & 0.764 & 0.951 & -0.187 \\
\hline 45 best work over a cup of tea & 45 & 0.090 & 0.349 & -0.258 \\
\hline 4 is whoever I meet and whoever I need & 4 & -0.751 & -0.354 & -0.397 \\
\hline 31 where everybody has to take responsi & 31 & 0.248 & 0.761 & -0.512 \\
\hline 41 knowing your neighbours and knowing & 41 & -0.332 & 0.260 & -0.591 \\
\hline 20 Everyone & 20 & -1.148 & -0.489 & -0.659 \\
\hline 14 their whole life revolves around their & 14 & -1.335 & -0.675 & -0.660 \\
\hline 6 some aspects are really important to & 6 & 0.464 & 1.144 & -0.680 \\
\hline 24 having fairly good infrastructure & 24 & -0.724 & -0.042 & -0.682 \\
\hline 42 some sort of stuff in the back padd & 42 & -1.439 & -0.729 & -0.711 \\
\hline 1 [no] understanding of the richness of & 1 & 0.492 & 1.263 & -0.771 \\
\hline 32 not about you and me, it's about the & 32 & -0.168 & 0.642 & -0.810 \\
\hline 16 anything outside Council & 16 & -1.943 & -1.091 & -0.852 \\
\hline 9 where people are participating & 9 & 0.166 & 1.021 & -0.855 \\
\hline 13 I don't know. It's hard. & 13 & -1.203 & -0.263 & -0.940 \\
\hline 28 a whakapapa thing & 28 & 0.406 & 1.526 & -1.120 \\
\hline 11 a fictitious group & 11 & -2.763 & -1.326 & -1.437 \\
\hline 18 everybody who lives in & 18 & -0.365 & 1.890 & -2.255 \\
\hline 10 where I don't see any school & 10 & -1.506 & 1.416 & -2.922 \\
\hline
\end{tabular}




\section{Appendix 13: Exact factor scores (ß la SPSS) in Z-Score and T- Score units}

\section{Item Short Statement}

1 [no] understanding of the richness

2 is not just about a group consulti

3 a key part is contributing as well

4 is whoever I meet and whoever I ne

5 can be sort of defined according $t$

6 some aspects are really important

7 about whānau, about kōrero, about

8 Relationships

9 where people are participating

10 where I don't see any school sores

11 a fictitious group

12 who they're accountable to, the pe

13 I don't know. It's hard.

14 their whole life revolves around

15 everybody gets an opportunity to ha

16 anything outside Council

17 understanding about the way people

18 everybody who lives in that area

19 a risk mitigation strategy

20 Everyone

21 groups of people engaging in conve

22 people who come together to achieve

23 sit[ting] face-to-face and talk[ing]

24 having fairly good infrastructure

25 the people I serve

26 may mean something different even

27 very multi-layered, a here-and-now

28 a whakapapa thing

29 you've got to get on with everybod

30 immediately identified by the hat

31 where everybody has to take respons

32 not about you and me, it's about the

33 a full chance to react to things

34 anyone who could be impacted

35 the whole way we interact

36 a variety of small communities

37 asking for input and then deliver

38 concerned there's no transparency

39 a whole lot of people behind us

40 being committed to the place where

41 knowing your neighbours and knowing

42 some sort of stuff in the back paddock

43 the lowest level of local government

44 everyone's important

45 best work over a cup of tea
Factor 1 Factor $2 \quad$ Factor 3

Item

Z-SCR T-SCR

Z-SCR T-SCR

Z-SCR T-SCR

\begin{tabular}{|c|c|c|c|c|c|}
\hline-0.22 & 48 & 0.45 & 54 & 1.50 & 65 \\
\hline 0.20 & 52 & 0.27 & 53 & -0.09 & 49 \\
\hline 0.76 & 58 & 0.42 & 54 & 0.94 & 59 \\
\hline 0.02 & 50 & -0.84 & 42 & 0.38 & 54 \\
\hline-0.14 & 49 & 1.67 & 67 & -0.79 & 42 \\
\hline-0.05 & 50 & 0.27 & 53 & 1.04 & 60 \\
\hline 0.14 & 51 & 1.33 & 63 & 1.23 & 62 \\
\hline 1.23 & 62 & 0.77 & 58 & 0.85 & 58 \\
\hline-0.01 & 50 & -0.10 & 49 & 1.09 & 61 \\
\hline-1.25 & 37 & -1.64 & 34 & 1.43 & 64 \\
\hline-1.81 & 32 & -2.19 & 28 & -0.62 & 44 \\
\hline 0.17 & 52 & 0.28 & 53 & -2.45 & 26 \\
\hline-1.56 & 34 & -0.90 & 41 & 0.26 & 53 \\
\hline-0.39 & 46 & -1.08 & 39 & -0.29 & 47 \\
\hline 1.60 & 66 & 0.01 & 50 & -0.76 & 42 \\
\hline-0.39 & 46 & -2.26 & 27 & -0.24 & 48 \\
\hline 0.43 & 54 & 0.43 & 54 & -0.71 & 43 \\
\hline 0.54 & 55 & -0.69 & 43 & 1.51 & 65 \\
\hline-1.24 & 38 & 0.25 & 53 & -0.71 & 43 \\
\hline 2.25 & 73 & -2.28 & 27 & 0.71 & 57 \\
\hline-0.32 & 47 & 0.35 & 53 & -0.28 & 47 \\
\hline 0.21 & 52 & 1.98 & 70 & -0.42 & 46 \\
\hline 0.38 & 54 & 0.20 & 52 & 0.15 & 51 \\
\hline-0.96 & 40 & -0.25 & 48 & -0.01 & 50 \\
\hline 1.24 & 62 & -0.34 & 47 & -1.42 & 36 \\
\hline 0.18 & 52 & 1.22 & 62 & -0.07 & 49 \\
\hline-0.78 & 42 & 1.53 & 65 & 0.33 & 53 \\
\hline-0.96 & 40 & 0.51 & 55 & 1.51 & 65 \\
\hline-0.20 & 48 & -0.16 & 48 & -0.77 & 42 \\
\hline-1.37 & 36 & 0.75 & 58 & -0.84 & 42 \\
\hline-0.21 & 48 & 0.11 & 51 & 1.37 & 64 \\
\hline 0.97 & 60 & -0.82 & 42 & 1.24 & 62 \\
\hline 0.96 & 60 & 0.85 & 59 & -0.35 & 47 \\
\hline 0.45 & 54 & -0.07 & 49 & -0.71 & 43 \\
\hline 0.07 & 51 & 0.93 & 59 & -0.36 & 46 \\
\hline-1.29 & 37 & 1.11 & 61 & 0.74 & 57 \\
\hline 1.07 & 61 & -0.63 & 44 & -1.02 & 40 \\
\hline-1.34 & 37 & 0.43 & 54 & -1.09 & 39 \\
\hline 0.31 & 53 & 0.51 & 55 & -1.60 & 34 \\
\hline 0.44 & 54 & 0.92 & 59 & 0.98 & 60 \\
\hline 0.52 & 55 & -0.90 & 41 & 0.70 & 57 \\
\hline-2.50 & 25 & -0.57 & 44 & -0.25 & 47 \\
\hline 0.20 & 52 & -1.29 & 37 & -2.34 & 27 \\
\hline 2.10 & 71 & -0.22 & 48 & -0.15 & 48 \\
\hline 0.55 & 55 & -0.33 & 47 & 0.40 & 54 \\
\hline
\end{tabular}




\section{Appendix 14: Factor Q-sort value for each statement}

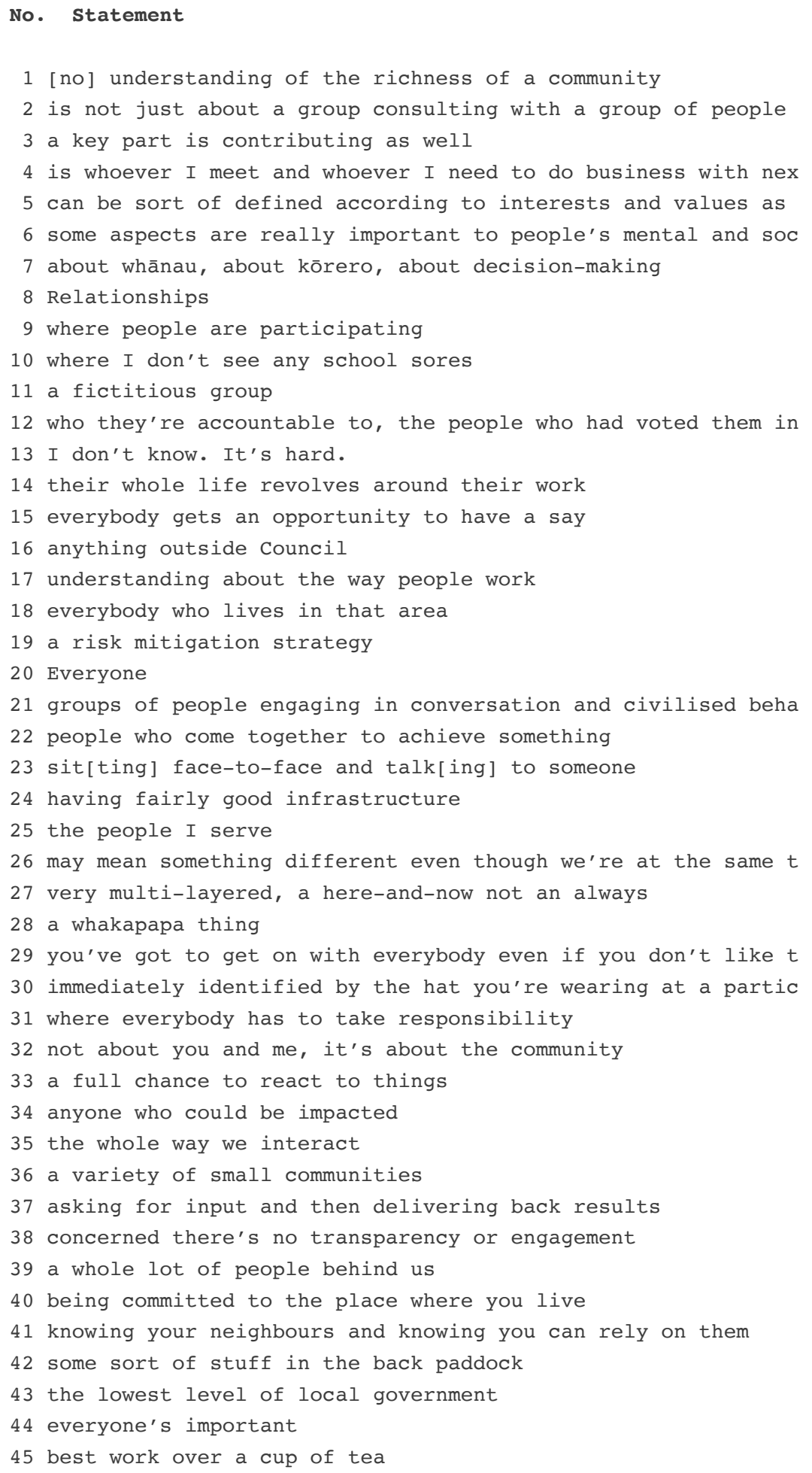




\section{Appendix 15: Factor Q-sort values for statements sorted by consensus vs. disagreement (variance across factor z-scores)}

No. Statement

40 being committed to the place where you live

2 is not just about a group consulting with a group of people 23 sit[ting] face-to-face and talk[ing] to someone

21 groups of people engaging in conversation and civilised beha

3 a key part is contributing as well

17 understanding about the way people work

8 Relationships

19 a risk mitigation strategy

29 you've got to get on with everybody even if you don't like $t$

45 best work over a cup of tea

14 their whole life revolves around their work

31 where everybody has to take responsibility

41 knowing your neighbours and knowing you can rely on them

6 some aspects are really important to people's mental and soc 16 anything outside Council

9 where people are participating

26 may mean something different even though we're at the same $t$

4 is whoever I meet and whoever I need to do business with nex

24 having fairly good infrastructure

7 about whānau, about kōrero, about decision-making

33 a full chance to react to things

35 the whole way we interact

37 asking for input and then delivering back results

1 [no] understanding of the richness of a community

32 not about you and me, it's about the community

34 anyone who could be impacted

5 can be sort of defined according to interests and values as

15 everybody gets an opportunity to have a say

38 concerned there's no transparency or engagement

27 very multi-layered, a here-and-now not an always

43 the lowest level of local government

13 I don't know. It's hard.

30 immediately identified by the hat you're wearing at a partic

11 a fictitious group

39 a whole lot of people behind us

42 some sort of stuff in the back paddock

36 a variety of small communities

22 people who come together to achieve something

44 everyone's important

28 a whakapapa thing

25 the people I serve

18 everybody who lives in that area

12 who they're accountable to, the people who had voted them in

20 Everyone

10 where I don't see any school sores

\begin{tabular}{|c|c|c|c|}
\hline No. & 1 & 2 & 3 \\
\hline 40 & 3 & 3 & 3 \\
\hline 2 & 1 & 1 & 0 \\
\hline 23 & 1 & 1 & 0 \\
\hline 21 & -1 & 0 & 0 \\
\hline 3 & 3 & 2 & 2 \\
\hline 17 & 1 & 2 & 1 \\
\hline 8 & 4 & 4 & 3 \\
\hline 19 & -2 & -2 & -2 \\
\hline 29 & -1 & -1 & -2 \\
\hline 45 & 2 & 0 & 1 \\
\hline 14 & -2 & -3 & -2 \\
\hline 31 & -1 & 0 & 2 \\
\hline 41 & 0 & -1 & 1 \\
\hline 6 & 1 & 1 & 2 \\
\hline 16 & -3 & -4 & -2 \\
\hline 9 & 1 & 0 & 2 \\
\hline 26 & 0 & 3 & 1 \\
\hline 4 & 0 & -2 & -1 \\
\hline 24 & -2 & -2 & 0 \\
\hline 7 & 2 & 4 & 4 \\
\hline 33 & 2 & 2 & 0 \\
\hline 35 & 0 & 2 & -1 \\
\hline 37 & 1 & -2 & -1 \\
\hline 1 & 0 & 2 & 3 \\
\hline 32 & 2 & -1 & 2 \\
\hline 34 & 0 & 0 & -2 \\
\hline 5 & 0 & 3 & 0 \\
\hline 15 & 3 & 1 & -1 \\
\hline 38 & -3 & -1 & -3 \\
\hline 27 & -1 & 3 & 2 \\
\hline 43 & -2 & -4 & -4 \\
\hline 13 & -4 & -3 & -1 \\
\hline 30 & -3 & 0 & -3 \\
\hline 11 & -5 & -5 & -3 \\
\hline 39 & -1 & 0 & -3 \\
\hline 42 & -4 & -3 & -2 \\
\hline 36 & -2 & 2 & 1 \\
\hline 22 & 2 & 5 & 1 \\
\hline 44 & 5 & 1 & 0 \\
\hline 28 & -1 & 1 & 4 \\
\hline 25 & 2 & -1 & -4 \\
\hline 18 & 3 & -2 & 5 \\
\hline 12 & -2 & -1 & -5 \\
\hline 20 & 4 & -2 & -1 \\
\hline 10 & -3 & -3 & 3 \\
\hline
\end{tabular}




\section{Appendix 16: Factor characteristics}

$\begin{array}{lccc}\text { Factors } & \mathbf{1} & \mathbf{2} & \mathbf{3} \\ & & & \\ \text { Number of Defining Variables } & 18 & 15 & 5 \\ \text { Average Reliability Coefficient } & 0.800 & 0.800 & 0.800 \\ \text { Composite Reliability } & 0.986 & 0.984 & 0.952 \\ \text { Standard Error of Factor Z-Scores } & 0.117 & 0.128 & 0.218\end{array}$


Appendix 17: Standard errors for differences in factor z-scores

$\begin{array}{cccc}\text { Factors } & \mathbf{1} & \mathbf{2} & \mathbf{3} \\ 1 & 0.166 & 0.173 & 0.248 \\ 2 & 0.173 & 0.181 & 0.253 \\ 3 & 0.248 & 0.253 & 0.309\end{array}$

NOTE: Diagonal entries are standard error within factors. 


\section{Appendix 18: Distinguishing statements}

Explanatory Note:

As elsewhere, the line breaks in the next three tables are deliberate. They have been inserted to group distinguishing statements by Q-sort value and make eating easier. 


\subsection{Distinguishing statements for Factor 2}

\begin{tabular}{|c|c|c|c|c|c|c|c|c|}
\hline Item & Short Statement & Item & Q-Sv & z-SCR & Q-Sv & z-SCR & Q-Sv & $\mathrm{Z}-\mathrm{SCR}$ \\
\hline 22 & people who come together to achieve & 22 & 2 & 0.61 & 5 & $2.00 *$ & 1 & 0.33 \\
\hline 5 & can be sort of defined according to & 5 & 0 & 0.34 & 3 & 1.24 * & 0 & 0.01 \\
\hline 27 & very multi-layered, a here-and-now & 27 & -1 & -0.20 & 3 & 1.21 & 2 & 0.59 \\
\hline 26 & may mean something different even $t$ & 26 & 0 & 0.39 & 3 & $1.14 *$ & 1 & 0.31 \\
\hline 35 & the whole way we interact & 35 & 0 & 0.18 & 2 & $0.90 *$ & -1 & -0.18 \\
\hline 28 & a whakapapa thing & 28 & -1 & -0.54 & 1 & $0.41 *$ & 4 & 1.53 \\
\hline 15 & everybody gets an opportunity to ha & 15 & 3 & 1.09 & 1 & 0.33 & -1 & -0.24 \\
\hline 9 & where people are participating & 9 & 1 & 0.52 & 0 & 0.17 & 2 & 1.02 \\
\hline 30 & immediately identified by the hat $y$ & 30 & -3 & -1.24 & 0 & $0.06 *$ & -3 & -1.20 \\
\hline 12 & who they're accountable to, the peo & 12 & -2 & -0.60 & -1 & $-0.06 *$ & -5 & -2.29 \\
\hline 25 & the people I serve & 25 & 2 & 0.80 & -1 & $-0.10 *$ & -4 & -1.35 \\
\hline 38 & concerned there's no transparency or & 38 & -3 & -1.37 & -1 & $-0.14 *$ & -3 & -1.34 \\
\hline 32 & not about you and me, it's about the & 32 & 2 & 0.93 & -1 & $-0.17 *$ & 2 & 0.64 \\
\hline 41 & knowing your neighbours and knowing & 41 & 0 & 0.33 & -1 & -0.33 & 1 & 0.26 \\
\hline 18 & everybody who lives in that area & 18 & 3 & 0.94 & -2 & $-0.36 *$ & 5 & 1.89 \\
\hline 20 & Everyone & 20 & 4 & 1.44 & -2 & $-1.15 *$ & -1 & -0.49 \\
\hline 13 & I don't know. It's hard. & 13 & -4 & -1.71 & -3 & $-1.20 *$ & -1 & -0.26 \\
\hline 14 & their whole life revolves around $t$ & 14 & -2 & -0.92 & -3 & -1.33 & -2 & -0.67 \\
\hline 42 & some sort of stuff in the back pad & 42 & -4 & -2.32 & -3 & $-1.44 *$ & -2 & -0.73 \\
\hline 16 & anything outside Council & 16 & -3 & -1.45 & -4 & -1.94 * & -2 & -1.09 \\
\hline 11 & a fictitious group & 11 & -5 & -2.40 & -5 & -2.76 & -3 & -1.33 \\
\hline
\end{tabular}




\subsection{Distinguishing statements for Factor 3}

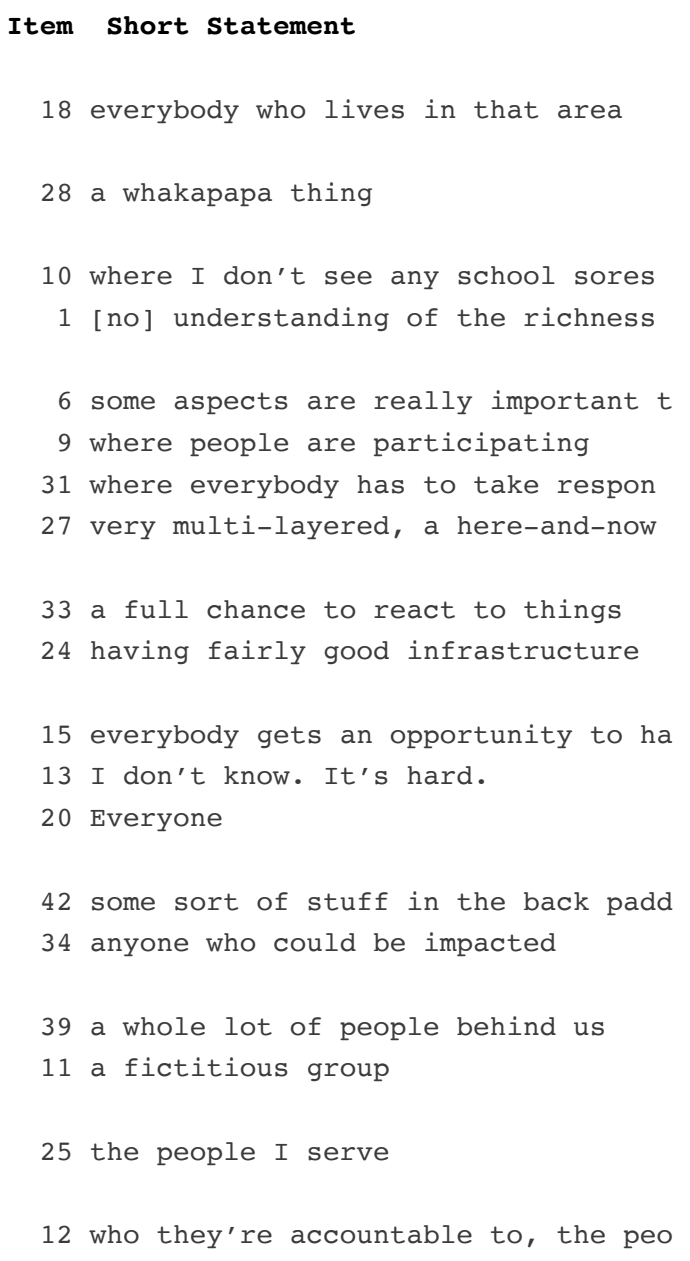




\section{Appendix 19: Consensus statements -- those that do not distinguish between ANY pair of factors.}

No. Statement

\section{Factor}

2 * is not just about a group consulting wi 2

3 * a key part is contributing as well 3

8 Relationships

17* understanding about the way people wor 17

19 a risk mitigation strategy

21 * groups of people engaging in conversat 21

23 * sit[ting] face-to-face and talk[ing] $t 23$

29* you've got to get on with everybody ev 29

40 * being committed to the place where you 40

\section{1}

$\mathbf{S C R}$

$\begin{array}{rrrrrr}1 & 0.43 & 1 & 0.35 & 0 & 0.15 \\ 3 & 1.10 & 2 & 0.76 & 2 & 0.95 \\ 4 & 1.68 & 4 & 1.32 & 3 & 1.43 \\ 1 & 0.41 & 2 & 0.50 & 1 & 0.15 \\ -2 & -1.09 & -2 & -0.68 & -2 & -0.80 \\ -1 & -0.25 & 0 & 0.04 & 0 & -0.02 \\ 1 & 0.41 & 1 & 0.37 & 0 & 0.13 \\ -1 & -0.47 & -1 & -0.23 & -2 & -0.72 \\ 3 & 0.94 & 3 & 1.06 & 3 & 1.15\end{array}$

NOTE: All of the items are non-significant at $p>0.01$ and those marked with asterisk (*) are also non-significant at $p>0.05$. 